\title{
MOLECULAR MARKERS FOR SELECTION OF RESISTANCE TO FACIAL ECZEMA
}

by

JABBAR KUHAIT

Submitted to Victoria University of Wellington for the Degree of Doctor of Philosophy

Victoria University of Wellington

July 2003 


\section{ABSTRACT}

The disease facial eczema is caused by the fungal metabolite sporidesmin which produces photosensitisation of animals whose liver and biliary tract have been damaged by the toxin. Sporidesmin is produced by the pasture fungus Pithomyces chartarum and affects ruminant animals that graze on contaminated pasture. Previous studies have shown that sporidesmin is metabolised in the liver and have suggested that the toxin is metabolically inactivated by enzymes in the glutathione S-transferase and cytochrome P-450 families. The activities of these enzymes were therefore measured in liver extracts from Romneys that had been selected for resistance or susceptibility to sporidesmin - induced liver damage.

Although there were no differences in cytochrome P-450 CO binding spectra or cytochrome c reductase between the selection lines, resistant Romneys had greater nitroanisole O-demethylase activity and this difference was apparently enhanced two days after dosing with sporidesmin. Dose-dependent differences occurred in the absence of major hepatocellular injury suggesting that they reflected changes in enzyme activity rather than changes in tissue mass Aminopyrine $\mathrm{N}$-demethylase did not vary significantly between the selection lines. Some differences in GSH-dependent metabolism were also observed. Undosed resistant Romneys showed greater GSH-dependent metabolism of sporidesmin in a spectrophotometric assay. It is possible that glutathione S-transferase Mu or Theta isoforms had greater activity in the resistant lines as differences were observed using p-nitrobenzyl chloride and 1,2 epoxy-3-p-nitrophenoxypropanol but not with 1-chloro-2,4-dinitrobenzene or 1,2-dichloro-4-nitrobenzene that are good 
substrates for these isoforms. 2-D PAGE was applied to the separation of whole homogenate and soluble proteins. Variations in expression of some proteins including GST Mu isoforms were found between the selection lines.

Roles of cytochrome P-450 and glutathione S-transferase in the hepatic detoxication of sporidesmin have previously been demonstrated. Results obtained in this study suggest that resistant Romneys may have greater cytochrome P-450 O-demethylase and glutathione S-transferase activities that could be responsible for increased metabolic inactivation of sporidesmin. These differences may in the future be of use in design of DNA probes to enhance detection and selection of facial eczema resistant livestock. 


\section{ACKNOWLEDGEMENTS}

I would like to express my deep appreciation to my supervisor Dr. T.W. Jordan for offering this opportunity to study toward the Ph.D. in Biochemistry. My appreciation is also extended for his professional advice, skill and assistance in planing the strategy of this project and his patience and support during the preparation of the manuscript of my thesis.

I would also like to thank the mycotoxin research group of Ruakura Agricultural Research Centre, Hamilton, New Zealand for providing the sheep liver samples which have made this project possible.

I would also like to extend my thanks to many others who contributed to the preparation of this thesis; Mrs. E. Hodgson from the VUW school of Mathematics and Computing Science for her skilled assistance in designing the programs for the statistical analysis; Mr. P. Watson and Mrs. L. Milicich for printing the photographs; my colleagues for helping me in some computer skills.

My special thanks are also extended to my friend Mrs. A. Fairclough for her support, encouragement and her skill in proof reading of my thesis.

I also wish to thank the office staff of the SBS for their assistance in photocopying my thesis.

I also wish to express my appreciation to my mother, my wife Amal, my brothers and sister for their support and inspiration during the whole course of this work. 


\section{TABLE OF CONTENTS}

Abstract $\quad$ i

Acknowledgements iii

Table of Contents iv

List of Tables xii

List of Figures $\quad$ xiv

List of Abbreviations xix

INTRODUCTION

1.1 Facial eczema. 1

1.2 Pathological effects of sporidesmin. 3

1.3 Sporidesmin toxicity in animals. 5

1.4 Mechanism of sporidesmin toxicity in sheep. 5

1.4.1 Mechanism of action of sporidesmin on hepatocytes 5 and bile duct cells.

1.5 Metabolism of sporidesmin in sheep. 9

$\begin{array}{ll}1.6 \text { Cytochrome P-450. } & 11\end{array}$

1.7 Species and strain differences in expression of 15 cytochrome P-450.

1.8 The role of cytochrome P-450 as a biomarker of susceptibility 16 and resistance to environmental toxicity.

$\begin{array}{ll}1.9 \text { GST enzymes. } & 18\end{array}$

$\begin{array}{ll}\text { 1.9.1 Functions of GST. } & 18\end{array}$

1.9.2 GSTs isoforms in eukaryotes. 20

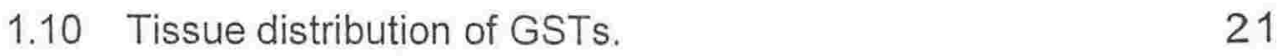


1.11 Properties of GSTs.

1.11.1 Molecular weight and subunit structure. 22

1.11 .2 Isoelectric points. 25

1.11.3 Catalytic activities. 25

1.12 General and specific substrates of GSTs. 26

1.13 Development and variation of GST isoenzymes. 28

$\begin{array}{ll}\text { 1.13.1 Developmental patterns. } & 28\end{array}$

1.13.2 Factors influencing GST class expression. 30

1.13.2.1 Hormonal influences. 30

1.13.2.2 Induction. $\quad 30$

1.13.2.3 Tissue selective expression of GST subunits. 32

1.13.2.4 Genetic variation in the expression of GST. 32

1.14 Drug metabolizing enzymes in sheep liver. 33

1.15 Aims of this study. 35

MATERIALS AND METHODS

2.1 Sources of materials. $\quad 36$

$\begin{array}{ll}2.1 .1 \text { Sources. } & 36\end{array}$

2.1.2 Materials and their sources. 36

2.2 Animals. 38

2.2.1 Selection of the R and S flocks. 38

$\begin{array}{ll}2.2 .2 \text { Animals used. } & 39\end{array}$

2.3 Preparation of liver microsomes. $\quad 40$

2.3.1 Partial purification of cytochrome P-450. 40

$\begin{array}{ll}2.4 \text { Electrophoresis. } & 41\end{array}$

$\begin{array}{ll}2.4 .1 & \text { IPG focusing. }\end{array}$ 
2.4.2 2-D SDS PAGE.

2.4.3 SDS molecular weight markers.

2.5 Sample preparation for MALDI-TOF. 45

2.5.1 Coomassie blue stained gel. 45

2.5.2 MALDI-TOF plate preparation. 46

2.5.3 Sample preparation with ZipTips ${ }^{\text {TM }}$. 47

2.5.4 MALDI-TOF Mass Spectrometry. $\quad 47$

2.5.5 Analysis of MALDI-TOF spectra. 48

2.6 Immunoblotting techniques (Western blotting). 49

2.6.1 Immunoprobing with HRP conjugated $\quad 49$ secondary antibody.

2.7 Computerised densitometry. 51

2.7.1 Gel scanning. $\quad 51$

2.7.2 Image display. 51

2.7.3 Drawing tools and integration. 51

2.7.4 Quantitative analysis of 2-D gel. 52

2.8 Protein assays. 52

2.9 Spectrophotometric determination of cytochrome 53 P-450 concentrations.

2.10 Spectrophotometric determination of NADPH 53 cytochrome $\mathrm{c}$ reductase activity in sheep hepatic microsomal fractions.

2.11 Enzyme assays for cytochrome P-450. 54

2.11.1 Assay for 4 - nitroanisol O-demethylase activity. 54

2.11.2 Assay for aminopyrine N - demethylase activity. 54 
2.12 HPLC assay for the metabolism of sporidesmin by cytochrome P-450.

2.13 GST assays.

56

2.13.1 Assay with synthetic substrates.

2.13.2 Spectrophotometric analysis of sporidesmin metabolism by liver cytosolic fraction.

2.14 GSH dependent metabolism of sporidesmin.

2.15 Histopathology.

2.16 Statistical analysis.

2.16.1 Test of resistant vs susceptible where the interaction was significant.

RESULTS

3.1 Liver histology in sheep experimentally dosed with sporidesmin

3.1.1 Undosed Romneys.

3.1.2 Dosed Romneys.

3.2 Metabolism of sporidesmin by liver microsomes.

3.3 Analysis of P-450 enzyme activities using model substrates. 73

3.3.1 The effect of enzyme, substrate concentration and time of 73 incubation on O-demethylase enzyme assay.

3.3.2 4-Nitroanisole O-demethylase. 75

3.3.3 The effect of enzyme, substrate concentration and time of 78 incubation on $\mathrm{N}$-demethylase enzyme assay.

3.3.4 Aminopyrine $\mathrm{N}$-demethylase.

3.4 Statistical analysis. 
3.4.1 O-demethylase.

3.4.1.1 Animals born 1994. 83

3.4.1.2 Animals born 1995. 83

3.4.1.3 Animals born 1997.

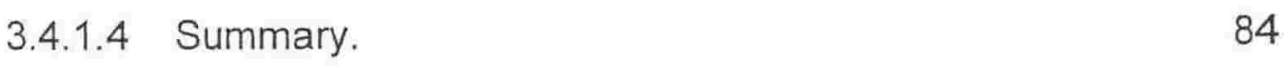

$\begin{array}{lll}\text { 3.4.2 N-demethylase. } & 91\end{array}$

3.4.2.1 Animals born 1994. 91

3.4.2.2 Animals born 1996.

3.4.2.3 Animals born 1997. 92

3.5 Repeat assays of O- and N-demethylase. 95

3.6 Analysis of cytochrome P-450. 99

3.6.1 Purification of cytochrome P-450. 99

3.6.1.1 Partial purification and analysis of cytochrome 101 P-450 from control sheep liver microsomes.

3.6.1.2 Partial purification and analysis of cytochrome 102 P-450 from undosed susceptible and resistant animals.

3.7 Analysis of microsomal cytochrome c reductase. 104

3.8 1-D gel electrophoresis of microsomal proteins. 104

3.9 Analysis of P-450 by Western blotting. 107

3.10 GSH dependent metabolism of sporidesmin. 109

3.10.1 Spectrophotometric analysis of the reaction of 109 sporidesmin with GSH.

3.10.2 Enzyme catalysed reaction between sporidesmin and $\mathrm{GSH}$. 
3.11 Spectrophotometric determination of GSH-dependent enzyme catalysed reaction with sporidesmin for the Romney selection lines.

3.12 HPLC analysis of the reaction of sporidesmin with GSH. 115

3.13 Analysis of GST activities using model substrates. 117

3.13.1 CDNB and DCNB.

3.13.2 p-NBC.

3.13.3 EPNP.

3.13.4 Statistical analysis for GST activities using model substrates.

3.13.4.1 GST-CDNB activity.

3.13.4.2 GST-DCNB activity.

3.13.4.3 GST-p-NBC.

3.13.4.4 GST-EPNB.

122

3.13.4.5 GST-Sporidesmin.

3.14 1-D PAGE of liver supernatant from undosed susceptible and undosed resistant Romneys.

3.15 Analysis of protein variation by 2-D PAGE.

3.15.1 Protein spot variation between resistant and susceptible lines.

3.16 Analysis of $100,000 \mathrm{~g}$ cytosolic liver supernatant using 2-D gel electrophoresis and MALDI -TOF.

3.16.1 MALDI - TOF analysis and identification of supernatant protein.

DISCUSSION 
4.1 Effect of sporidesmin on liver histology.

4.2 Metabolism of sporidesmin by liver microsomes.

152

4.3 Enzyme activities in Romney sheep from the

153 resistant and susceptible selected lines.

4.3.1 Cytochrome P-450.

4.3.1.1 O-Demethylase enzyme assay.

4.3.1.2 N-Demethylase enzyme assay.

4.4 Analysis of microsomal cytochrome $\mathrm{c}$ reductase.

4.5 Spectrophotometric determination of cytochrome P-450. 160

4.6 Electrophoresis and Western blotting of microsomal protein. 163

4.7 GSH dependent metabolism of sporidesmin. 164

4.7.1 Spontaneous reaction between sporidesmin 164 and GSH.

4.7.2 Spectrophotometric analysis of the reaction of GSH with 165 sporidesmin.

4.7.3 Spectrophotometric determination of GSH-dependent enzyme catalysed reaction with sporidesmin for the Romney selection lines.

4.8 Analysis of GST using model substrates.

4.8.1 CDNB and DCNB. 168

$\begin{array}{ll}4.8 .2 & p-N B C\end{array}$

4.9 Analysis of GST isoforms by 1-D PAGE of liver supernatant. 172

4.10 Analysis of protein variation by 2-D PAGE. 172

4.11 Analysis of supernatant proteins using 2-D PAGE and 174 MALDI - TOF mass spectrometry. 
4.12 Conclusions

4.13 Future studies

4.14 References 


\section{LIST OF TABLES}

$\underline{\text { Table }}$

$\underline{\text { Title }}$

$\underline{\text { Page }}$

1.1 The major mammalian classes of cytochrome P-450 isoforms and their subunits.

1.2 The GST subunits are designated according to the class based 24 subunit nomenclature.

1.3 Conditions for spectrophotometric enzyme assay towards various substrates in $0.1 \mathrm{M}$ potassium phosphate and $5 \mathrm{Mm}$ $\mathrm{GSH}$ at $25^{\circ} \mathrm{C}$.

3.1 Microsomal metabolism of sporidesmin

3.2 O-Demethylase activity in liver microsomes from Romney lambs born 1994.

3.3 O-Demethylase activity in liver microsomes from Romney lambs born 1995.

3.4 O-Demethylase activity in liver microsomes from Romney lambs born 1997.

3.5 N-Demethylase activity in liver microsomes from Romney lambs born 1994.

3.6 N-Demethylase activity in liver microsomes from Romney lambs born 1996.

3.7 N-Demethylase activity in liver microsomes from Romney lambs born 1997.

3.8 Number of animals for each year used in the statistical analysis. 
3.9 Triplicate measurements for O-demethylase activity of 95 1994 born, undosed resistant animals.

3.9 Summary for the repeated O-demethylase assays for 1994,1995 and 1997 born animals.

3.11 Triplicate measurements for $\mathrm{N}$-demethylase activity for 1997 born, undosed and dosed resistant animals.

3.12 Summary for the repeated N-demethylase for 1994, 1995 and 1997 born animals.

3.13 Partial purification of cytochrome P-450 from microsomes of $50 \mathrm{~g}$ control sheep liver.

3.14 Partial purification of P-450 from microsomal samples. 103

3.15 Partial purification of P-450 from microsomal samples. 103

3.16 Enzyme catalysed reaction of sporidesmin with GSH. 113

$\begin{array}{ll}3.17 & \text { GST activity towards CDNB. }\end{array}$

$\begin{array}{ll}3.18 & \text { GST activity towards DCNB. }\end{array}$

3.19 Liver cytosolic GST activity towards p-NBC for undosed 120 Romneys born in 1995 and 1997

3.20 Liver cytosolic GST activity towards EPNP as a substrate 120 for animals born 1997. 


\section{LIST OF FIGURES}

Figure

Title

$\underline{\text { Page }}$

1.1 Structure of sporidesmin A. 2

1.2 The production of oxygen free radicals by redox 7 cycling of sporidesmin.

Proposed reaction between sporidesmin and GSH.

1.4 Three representative reaction pathways for the conjugation of xenobiotics with GSH.

3.1 $\quad H$ \& E stained section of Romney liver from an undosed susceptible Romney. susceptible Romney.

3.3 H \& E stained section of liver from an undosed resistant Romney. resistant Romney.

3.5 H\& E stained section from the liver of a sporidesmindosed susceptible Romney.

3.6 HPLC analysis of sporidesmin by liver microsomes.

3.7 Effect of enzyme, substrate concentration and time incubation on the O-demethylase enzyme activity.

3.8 The standard curve for 4-nitrophenol.

3.9 Effect of enzyme, substrate concentration and time incubation on the $\mathrm{N}$-demethylase enzyme activity. 
3.10 The standard curve for formaldehyde.

3.11 Cytochrome P-450 O-demethylase : box plots of resistance, dose and year; data for all years.

3.12 Cytochrome P-450 O-demethylase: interaction plot of resistance by year. Cytochrome P-450 O-demethylase: interaction plot of dose by resistance; data for all years.

3.14 Cytochrome P-450 O-demethylase: box plots of resistance, dose for 1994.

3.15 Cytochrome P-450 O-demethylase: interaction plot of dose by resistance; data for 1994 .

Cytochrome P-450 O-demethylase box plots of resistance, dose for 1995.

3.17 Cytochrome P-450 O-demethylase: interaction plot of dose by resistance for 1995 .

3.18 Cytochrome P-450 O-demethylase: box plots of resistance and dose for 1997 born animals.

3.19 Cytochrome P-450 O-demethylase: interaction plot of dose by resistance, for 1997 born animals.

3.20 Aminopyrine $\mathrm{N}$-demethylase: box plots of resistance, dose and year; data for 94 and 97.

3.21 Aminopyrine N-demethylase: interaction plot of dose by year; data for 94 and 97 .

3.22 Aminopyrine N-demethylase: interaction plot of dose by resistance; data for 1997 . 

P-450. undosed susceptible and two undosed resistant animals. sporidesmin in $3 \mathrm{ml}$ buffer. sporidesmin and $5 \mathrm{mM}$ GSH.

GSH at $230 \mathrm{~nm}$ in the presence of $80 \mathrm{mg}$ liver supernatant protein.

3.31 The interaction of a cytosolic enzyme with sporidesmin in the presence or absence of GSH and the interaction of sporidesmin with GSH alone. susceptible and four undosed resistant Romneys.

3.33 The scanned images of regions (12 - $28 \mathrm{kDa})$ contained potential GST subunit.

3.34 2-D PAGE of pooled liver homogenates from five undosed susceptible Romneys. undosed resistant Romneys. 
3.36a Spots showing differences in abundance between undosed susceptible and undosed resistant Romneys.

3.36b Spots showing differences in protein abundance between undosed susceptible and undosed resistant Romneys.

3.36c Spots showing differences in abundance between undosed susceptible and undosed resistant Romneys. undosed susceptible and undosed resistant Romneys.

3.37a Quantitative analysis for eighteen homogenate proteins that varied between the selection lines.

3.37b Quantitative analysis of ten liver homogenate proteins that did not appear to vary between the resistant and susceptible Romneys lines. from liver of 2 susceptible and 2 resistant Romneys with quantitative analysis of 8 protein spots. spots. 


\section{ABBREVIATIONS}

\begin{tabular}{|c|c|}
\hline BSA & Bovine serum albumin \\
\hline Bis & N,N'-Methylene-bis-acrylamide \\
\hline CDNB & 1-Chloro-2,4-dinitrobenzene \\
\hline CHAPS & 3 -[ (3-Cholamidopropyl)dimethylammonio -1- propanesulfonate \\
\hline DCNB & 1,2-Dichloro -4-nitrobenzene \\
\hline DTT & DL-Dithiothreitol \\
\hline EDTA & Ethylene diamine tetra acetic acid \\
\hline EPNP & 1,2 Epoxy-3-p-nitrophenoxy propanol \\
\hline FE & Facial eczema \\
\hline GGT & $\gamma$-Glutamyltransferase \\
\hline GSH & Glutathione \\
\hline GST & Glutathione S-transferase \\
\hline$H \& E$ & Haematoxylin and eosin \\
\hline HEPES & $\mathrm{N}^{\prime}$-2-Hydroxyethylpiperazine-N' -2ethanesulphonic acid \\
\hline HPLC & High pressure liquid chromotography \\
\hline HRP & Horseradish peroxidase \\
\hline IEF & Isoelectric focusing \\
\hline IPG & Immobilized pH gradient \\
\hline 1-D PAGE & One-dimensional polyacrylamide gel electrophoresis \\
\hline PEG & Polyethylene glycol \\
\hline $\mathrm{p}-\mathrm{NBC}$ & p-Nitrobenzyl chloride \\
\hline $\mathrm{pl}$ & Isoelectric point \\
\hline SDS & Sodium dodecyl sulphate \\
\hline
\end{tabular}


2-D PAGE Two-dimensional polyacrylamide gel electrophoresis

TCA Trichloroacetic acid

TEMED N,N,N',N'-tetramethylethylene diamine

Tris Trishydroxymethylaminomethane 


\section{CHAPTER I \\ INTRODUCTION}

\subsection{Facial eczema}

FE is a hepatotoxic disease affecting ruminant animals such as sheep, cattle, and deer. It is caused by a mycotoxin named sporidesmin (Mortimer and Ronaldson, 1983). The source of sporidesmin is Pithomyces chartarum, a saprophytic fungus that grows on decaying plant material in pasture. Pithomyces

chartarum has a worldwide distribution but FE occurs mainly in the North Island and the northern part of the South Island of New Zealand. The high rate of FE in New Zealand is due to the use of pasture for animal production. Growth of fungal spores is rapid during the summer and autumn when the weather is warm and humid. FE has also been reported as an outbreak disease in farm animals in Australia, South Africa, and France (Bezille et al., 1984). The fungus is capable of producing a complex mixture of sporidesmin A (Figure 1.1) and closely related metabolites that affect animals in field outbreaks or when introduced experimentally by dosing or feeding. Campbell et al. (1981) and Morris et al. (1994) suggested that the susceptibility of animals, especially sheep, to FE is very variable and this variability is heritable. Therefore, if resistant flocks can be selected without exposing the animals to toxic challenge, breeding programmes could largely decrease the incidence of FE. Selection of FE resistant livestock has been in progress since 1975-1981 when Campbell and his co-workers conducted test trials at Ruakura Agricultural Research Centre to group animals on the basis of of liver damage 
scores after sporidesmin challenge. Attempts to identify genetic markers of FE resistance have been only partially successful.

FE affected animals, with dysfunctional livers, accumulate the chlorophyll degradation product phylloerythrin in the circulatory system, and later in skin, leading to the sensitivity of skin to ultraviolet light. This causes local lesions particularly around exposed facial tissues. Effects have been described in guinea pigs (Bonnefoi et al., 1989; Mortimer, 1970), mice (Mortimer, 1970; Bhathal et al., 1990), rabbit (Peters, 1966), rats (Rimington et al., 1962; Slater et al., 1964; Hove and Wright, 1969), chickens (Mortimer, 1967), sheep (Mortimer and Taylor, 1962; Smith and Payne, 1991), goats (Smith and Embling, 1991), cattle and deer (Mortimer, 1971; Mortimer and Smith, 1981).

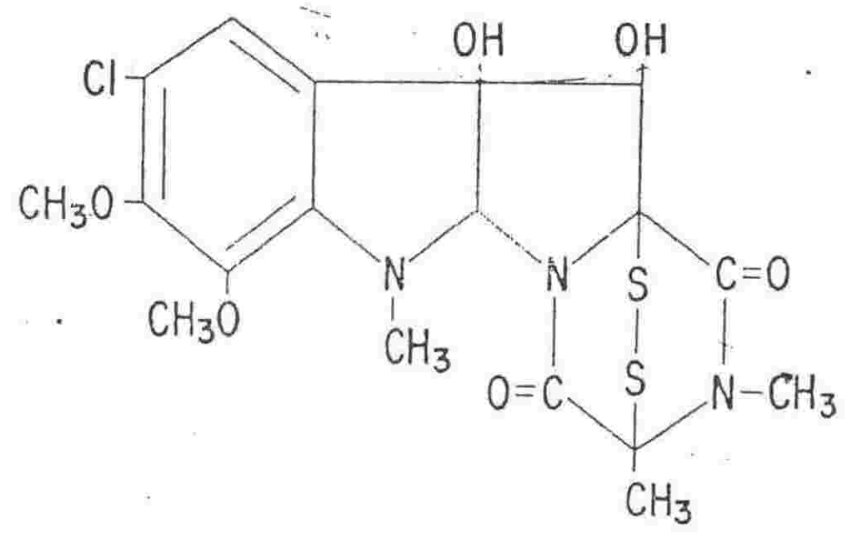

Figure 1.1: Structure of sporidesmin A 


\subsection{Pathological effects of sporidesmin}

Experimental intoxication of sheep by oral administration of sporidesmin produced similar lesions to those of naturally affected animals (Mortimer, 1963; Mortimer and Smith, 1981; Mortimer and Ronaldson, 1983). The liver of dosed sheep was firmer in texture than normal and the lobular morphology was somewhat exaggerated, especially in the left lobe which was characterised by fibrous edges. Mortimer (1963) also found that on slicing the liver, the large and medium sized bile ducts were moderately thickened with fibrous connective tissues to a degree, which caused reduction in the size of their lumina. Closer examination showed fine granular fibrosis throughout the substance of the liver. The gallbladder showed an abnormal appearance with histological changes similar to that of liver lesions. The urinary bladder displayed sub-mucosal petechial haemorrhage and cortical enlargement of the adrenal gland was noted. No lesions were found in other organs. Similar lesions were obtained by experimental dosing of sporidesmin to rabbits (Worker and Dodd, 1960), guinea pigs (MacKinnon and Te Punga, 1960; Bonnefoi et al., 1989), rats and mice (Mortimer et al., 1977).

Liver from sheep affected by a natural outbreak of FE showed numerous areas of focal necrosis involving small groups of hepatocytes. Lymphocytes and polymorphonuclear leukocytes accumulated around the necrotic cells (Done et al., 1960). The portal triads were also obvious sites of necrosis, and some liver cells showed basophilic staining of cytoplasm with pyknotic nuclei. The intra-lobular bile canaliculi showed distension and irregularity. The Kupffer cells were swollen and many contained bile pigment. The smaller portal tracts were infiltrated with inflammatory cells, mainly lymphocytes and histiocytes, and fibroblasts were 
proliferating with fibrous connective tissues through the enlarging portal tracts. Bile ductules were also proliferating

The most obvious changes in larger portal tracts were oedema, necrosis of biliary epithelial cells and fibrosis. The epithelial lining cells of the bile ducts showed mild to severe necrosis. The portal vein and hepatic artery also showed signs of degeneration of the muscle cell nuclei of the wall. In severe cases necrosis of the intima occurred and the lumen of the portal vein and hepatic array were occluded by oedema infiltrated with fibrous tissue. The extrahepatic bile duct and gall bladder showed the same lesions including oedema and necrosis of the epithelial cells, especially the mucosal layer.

The adrenal gland showed a hyperplasia of the cells in the zona fasciculata and isolated necrosis areas in the zona reticulata, while the spleen showed no significant changes. In severely jaundiced conditions bile pigments were precipitated in the epithelial cells of the proximal convoluted tubules, while the bladder showed oedema and haemorrhage beneath the mucosal layer.

Mortimer (1963) produced lesions experimentally by dosing a group of Romney sheep with sporidesmin. He found that necrosis and inflammation of the bile ducts were the primary lesions in FE. Some minor changes were noticed such as vacuolation and accumulation of triglycerides in hepatocytes within 48 hours of dosing with sporidesmin (Mortimer, 1962). Mortimer (1962, 1963) found widespread necrosis of the epithelium of the bile ducts associated with oedema of the inflammatory cells such as leukocytes. Also, in the advanced stages, he noticed numerous proliferation of fibrous connective tissue and granulation tissue which had accumulated and replaced the necrotic ducts. 
Other studies indicate that sporidesmin can produce similar damage in the liver and the biliary tract of rabbits (Dodd, 1960; Clare, 1969), lactating dairy cows (Mortimer, 1971), deer (Mortimer and Smith, 1981) and mice (Bhathal et al., 1990).

\subsection{Sporidesmin toxicity in animals}

Sporidesmin is thought to be directly toxic to cells, either by interaction with protein thiols or through generation of oxygen radicals (Munday, 1989). The liver is an active organ in metabolising foreign compounds such as sporidesmin. Although the biotransformation reactions generally parallel a detoxification process, there are many cases in which drug metabolism causes deleterious effects to cells due to the production of reactive metabolites (electrophiles, radicals, active oxygen species) which in turn react with macromolecules or initiate radical chain reactions within cells (Boobis et al., 1989; Zimmerman and Ishak, 1995; Castell et al., 1997). Hepatic injury is a common feature of many intrinsic hepatotoxins and is shown by morphological changes in hepatocytes such as vacuolation, steatosis and acidophilia and is accompanied by a large increase of serum hepatic enzymes (Zimmerman and Ishak, 1995).

\subsection{Mechanism of sporidesmin toxicity in sheep}

\subsubsection{Mechanism of action of sporidesmin on hepatocytes and bile duct cells.}

Sporidesmin appears to have immediate effects on hepatocellular function followed by hepatocellular necrosis, possibly secondary to bile duct and blood 
vessel damage. Peters (1963) showed that sporidesmin inhibited or destroyed one or more steps in the conversion and secretion of liver triglyceride to plasma lipoprotein which led to a decrease in the level of plasma triglycerides and increased the liver triglyceride levels. Clear evidence was provided by Mortimer (1963) of the biochemical effects of sporidesmin on sheep liver, suggesting that one of the highly important facets of sporidesmin intoxication was injury to cell membranes which caused increasing permeability of the cells. It was also reported that sporidesmin has the ability to alter adrenaline stimulated glucose output from hepatocytes (Cordiner et al., 1983). Jordan (1986) studied the effects of sporidesmin on the plasma membrane function of hepatocytes and found that sporidesmin can alter membrane function either by direct attack on membranes or by modification of processes which control membrane composition and function. In 1986 Jordan and Pedersen demonstrated that the effects of sporidesmin on cultured liver cells included changes in liver actin microfilament organisation.

Mortimer (1970) found that the toxic effect of sporidesmin appeared to be mainly directed against the epithelial cells that line the bile ducts. More recently Bhathal et al. (1990) confirmed that sporidesmin was more toxic to bile duct cells, causing coagulative necrosis of the large segmental bile duct and periductal connective tissue, than to hepatocytes after four days of a single dose of sporidesmin.

The cytotoxic effects of sporidesmin were studied in cell culture (Done et al., 1960; Ferguson et al., 1992). Sporidesmin toxicity in cell culture was associated with an intact epidithiodioxopipiperazine ring. Alteration to the disulphide bridge resulted in a marked reduction of the biological activity of sporidesmin.. Munday (1982, 1984, 1987 and 1989) demonstrated formation of superoxide from 
sporidesmin in vitro and suggested that toxicity was due to formation of active oxygen species including superoxide, hydrogen peroxide and hydroxyl radicals. Munday suggested that sporidesmin is reduced to sporidesmin dithiol by GSH and that auto-oxidation of sporidesmin leads to superoxide production. Munday suggested that when sporidesmin dithiol undergoes metal $(M)$ ion catalysed autooxidation to the disulphide, reactive superoxide be produced in a cyclic reaction, as shown in Figure 1.2 below:

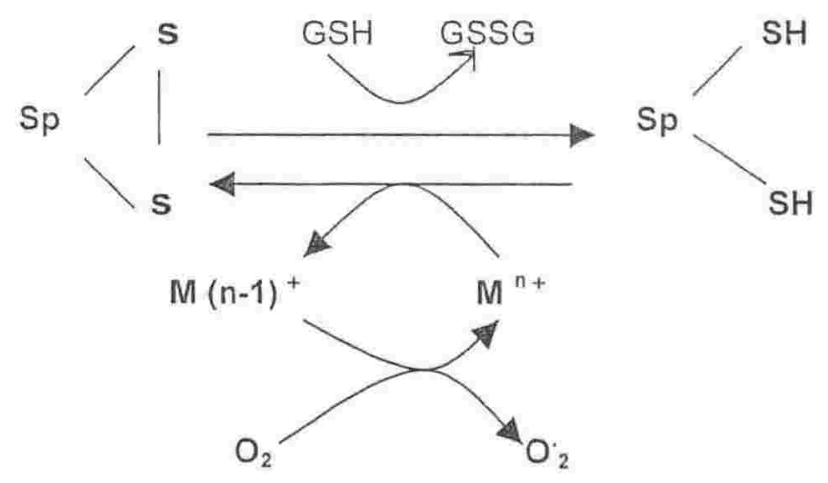

Figure 1.2: The production of oxygen free radicals by redox cycling of sporidesmin (Munday, 1982, 1989).

The superoxide then, either by itself or through generating other reactive oxygen species such as hydrogen peroxide or hydroxyl radical, may react with tissue molecules to produced tissue damage (Munday, 1989; White, 1991). Lipid peroxidation (Poli et al., 1987) is a frequent phenomenon in the course of toxin induced liver injury in which free radical processes lead to the oxidative degeneration of lipid present in cell membranes. This can lead to alteration of the physico-chemical properties of the membrane and indirectly affect functionality of membrane enzymes (Ross, 1989). 
Ames (1989) has shown that mutagenicity and carcinogenesis are caused by many naturally occurring or synthetic toxic compounds that produce oxidative damage of DNA. The finding that sporidesmin produced oxygen radicals in vitro therefore caused concern about possible mutagenic effects of this toxin. Munday et al. (1993) showed that sporidesmin, however, was not genotoxic in vivo although it caused DNA damage in vitro (Ferguson et al., 1992).

An alternative hypothesis is that the disulphide bridge of sporidesmin may react with protein thiol groups, which are essential for normal function (Cordiner et al., 1983). One possibility is that sporidesmin interacts with protein thiols to form mixed disulphides.

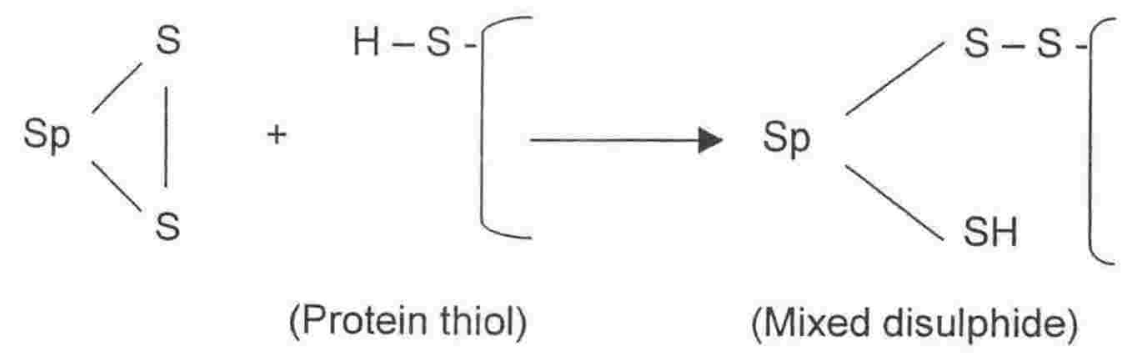

Slater (1981) reported that electron micrographs of sporidesmin infused rat livers showed bile canalicular distortion and loss of microvilli. Other changes in the structure of biliary canalicular membranes were observed by Bullock et al. (1974). It was also found that the degeneration of the canalicular membrane was accompanied by an inhibition of bile flow and bile acid secretion. Similarly, Middleton (1974a) confirmed that sporidesmin produced rapid and reversible swelling of guinea pig liver mitochondria by altering the permeability of mitochondrial membranes. This action of sporidesmin on swelling and respiration of liver mitochondria, and the inhibition of this toxic effect by dithiothreitol, but not by a 
number of other mono or dithiols (Middleton, 1974b), could imply some reactions between the disulphide group of sporidesmin and reactive thiol groups of membrane proteins. Cordiner et al. (1983) exposed rat hepatocytes to sporidesmin and studied changes in membrane function. They found that the toxin inhibited a number of plasma membrane functions including bile acid transport and hormone stimulated glucose efflux which is a sensitive measure of plasma membrane integrity (Cordiner et al., 1983).

It has been suggested that sporidesmin might act directly on cytoskeletal microfilament proteins (Bullock et al., 1974; Cordiner and Jordan, 1983; Jordan, 1986; Jordan and Pedersen, 1986). Jordan (1986) also demonstrated changes in liver microfilament organisation in $\mathrm{BALB} / \mathrm{C}$ and $\mathrm{C} 57 \mathrm{BL} / 6$ mice that had been exposed to sporidesmin, but subsequent studies indicated that sporidesmin did not directly affect aggregation of the microfilament protein actin in vitro (Jordan and McLean unpublished observations). More recently Dentri and Bhathal (unpublished) have shown that sporidesmin is substantially more toxic to bile duct cells than to hepatocytes in vitro but the molecular basis of this phenomenon is still unclear.

\subsection{Metabolism of sporidesmin in sheep}

The role of enzymatic transformation in detoxification of foreign compounds is well established. Aust (1977) and Mortimer et al. (1978) showed that hepatic cytochrome P-450 mixed function oxidase enzymes play a role in the inactivation of sporidesmin. Sissons, Clark and Ronaldson (1980) found that sporidesmin interacted directly with cytochrome P-450 and gave unusual binding spectra 
indicating a direct interaction of P-450 with the sporidesmin sulphur atoms. Sporidesmin metabolism in sheep was studied by incubation of extracted sheep liver microsomes with $\left[{ }^{35} \mathrm{~S}\right]$-labelled sporidesmin in the presence of an NADPH generating system (Fairclough et al., 1978). They found eight different metabolites but only monohydroxy and dihydroxy derivatives of sporidesmin were identified. Two other metabolites did not contain sulphur atoms and were of low toxicity. The results of Fairclough et al. (1978) showed a 2 to 3 - fold difference in the rate of metabolism of sporidesmin among sheep and greater metabolism in Merinos than in Romneys. Differences observed between animals in response to sporidesmin challenge may therefore be due in part to differences in detoxification of sporidesmin (Wright and Forrester, 1965; Towers, 1972). Sissons and Fairclough (1978) showed that sporidesmin metabolism was likely to be greater in hepatic microsomes taken from liver biopsies of FE resistant Romneys than from FE susceptible animals. Resistance to FE might also be affected by the ability of animals to excrete sporidesmin (Towers, 1970a, 1970b).

Sissons et al. (1980) suggested that sporidesmin may react spontaneously with GSH and that this reaction may be catalysed by GSTs. The products of this reaction may be sporidesmin-GSH mixed disulfide or reduced sporidesmin (Figure 1.3)

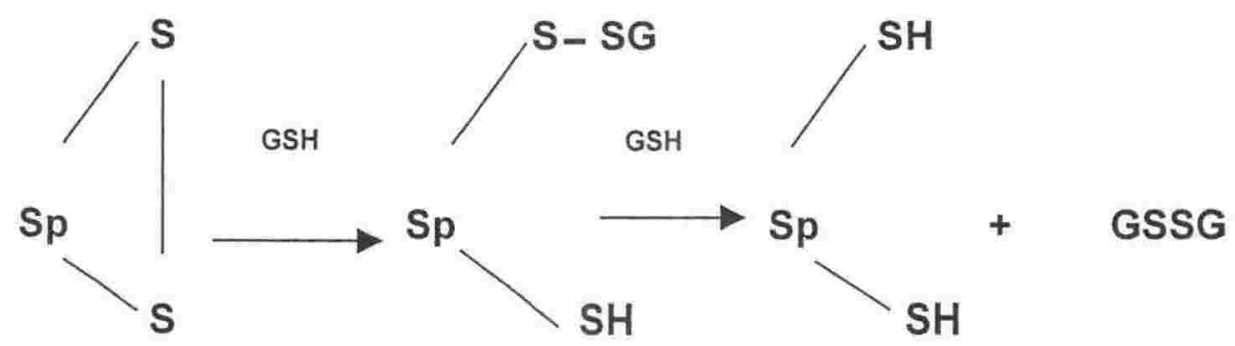

Figure 1.3: Proposed reaction between sporidesmin and GSH (Sissons et al., 1980). 
Since GSH is present at high concentrations $(5-10 \mathrm{mM})$ in cells, the metabolism of sporidesmin by the enzyme GST may be a major feature of cellular sporidesmin metabolism. Sissons et al. (1980) established that sheep have at least four forms of GST, with different substrate specificities, and that these enzymes catalysed a sporidesmin-GSH reaction.

\subsection{Cytochrome P-450}

It is usual now to refer to detoxification as being divided into three phases: phase 1 modification through oxidation, reduction or hydrolysis, phase 2; conjugation with a hydrophilic residue (Gilman et al., 1990) and phase 3; an efflux transport mechanisms (e.g. GS-X pump) for xenobiotic metabolites that can act synergistically with phase II conjugating glutathione S-transferases (GST) (Awasthi et al. 1997; Morrow et al. 2000). Accordingly the enzymes responsible are classed as phase 1 or phase 2 enzymes, and the effects of drugs and toxins on the mammalian organism depend in great measure on the activity of the corresponding enzymes (Gilman et al., 1990).

The cytochrome P-450 dependent mono-oxygenase is an important system in the metabolism of a vast array of structurally unrelated substrates. Oxidation of toxic compounds by P-450 often leads to excretion of undesirable foreign xenobiotic compounds. The cytochrome P-450 system is a membrane bound haem-carrying protein of $52-55 \mathrm{kDa}$, which has a cysteine residue as an axial ligand co-ordinated to the iron atom of its porphyrin ring. The cytochromes P-450 are arranged in multigene families which together constitute a cytochrome P-450 gene superfamily (Nebert and Gonzalez, 1987; Nebert et al., 1991). The eukaryotic enzymes are 
widely distributed throughout the organism and are located in two cellular components, the mitochondria and endoplasmic reticulum (De Waziers et al., 1990). The mitochondrial P-450s utilise electrons from adrenodoxin to activate molecular oxygen and catalyse initial steps in the conversion of cholesterol into steroid hormones. In the case of the endoplasmic reticulum P-450s (microsomal P450s) the flavo-protein cytochrome P-450 reductase catalyses the electron transfer from NADPH to the microsomal P-450 enzymes. Each P-450 isozyme exhibits its own, although overlapping, substrate specificity which may be quite broad (Ryan and Levin, 1990).

The cytochrome P-450 system plays three distinct roles in the living organism. Firstly, this enzyme system is a major route by which a living organism can convert lipophilic foreign compounds into water-soluble products, which can be eliminated from the body, i.e. detoxification. Secondly, P-450 may convert xenobiotics to more toxic products (Swick, 1984). The P-450 system also metabolises numerous body constituents including certain steroids, biogenic amines, pheromones, fatty acids, bile acids and prostaglandins (Gonzalez and Nebert, 1990; Ryan and Levin, 1990). Lu and Coon (1968) resolved this system into its two protein components, namely cytochrome P-450 and NADPH cytochrome $\mathrm{P}-450$ reductase. Further purification of the cytochrome $\mathrm{P}-450$ system resulted in a heat stable component which was identified as phosphatidylcholline (Lu et al., 1969; Strobel et al., 1970). The reconstituted cytochrome P-450 system which contains the three major components, namely, cytochrome P-450, cytochrome P-450 reductase and phosphatidylcholine, was found to have the ability to catalyse the oxidation of a variety of drugs and fatty acid substrates (Lu et al., 1969, 1970), as shown below in the illustrated hydroxylation reaction. 
$\mathrm{RH}+\mathrm{NADPH}+\mathrm{H}^{+}+\mathrm{O}_{2} \longrightarrow \mathrm{ROH}+\mathrm{NADP}^{+}+\mathrm{H}_{2} \mathrm{O}$

$\mathrm{RH}$ is the substrate which represents a large variety of compounds including $\mathrm{N}$ - and O-alkyl drugs, polycyclic aromatic hydrocarbons, alkanes, fatty acids, pesticides and chemical carcinogens (Gillette, 1979; Conney, 1982). NADPH is a required cosubstrate and $\mathrm{ROH}$ is the hydroxylated product.

The cytochrome P-450 dependent drug metabolism system is present in a wide range of animal and plant species as well as in many microorganisms. In mammals the highest concentration is in the liver but expression of the P-450 system has been reported in all tissues including lung (Guengerich, 1977a), small intestine (Stohs et al., 1976), kidney (Ellin et al., 1971), colon (Fang and Strobel, 1978) and brain (Bergh and Strobel, 1992; Hodgson et al., 1993). Cytochrome P450 was recognised as existing in multiple forms by purification and definition of catalytic activities (Ryan et al., 1975; Guengerich, 1987). Nelson et al. (1996) reported more than 400 forms of cytochrome P-450 when they studied the gene mapping and sequence homologies of the P-450 super-family, and classified it into families and sub-families. P-450 isoforms have been classified into major classes of families such as, Cyp1, 2, 3, 4, 7, 11, 17, 19, 21, 27, on the basis of sequences (Nebert et al., 1987; Nebert et al., 1989; Nebert et al., 1991; Nelson et al., 1993; Nelson et al., 1996). Each family consists of a number of subfamilies (Table 1.1). 


\begin{tabular}{|c|c|c|c|}
\hline P-450 isoform & $\begin{array}{c}\text { Tissue or } \\
\text { subcellar location }\end{array}$ & Subfamily & References \\
\hline Сур 1 & $\begin{array}{l}\text { Liver (human) } \\
\text { Liver (human) }\end{array}$ & $\begin{array}{l}1 \mathrm{~A} 1 \\
1 \mathrm{~A} 2\end{array}$ & $\begin{array}{l}\text { Jaiswal et al. (1985) } \\
\text { Jaiswal et al. (1987) }\end{array}$ \\
\hline Cyp 2 & $\begin{array}{l}\text { Liver (human) } \\
\text { Liver (human) }\end{array}$ & $\begin{array}{l}2 \mathrm{~A} \\
2 \mathrm{~B}\end{array}$ & $\begin{array}{l}\text { Miles et al. (1990) } \\
\text { Miles et al. (1988) }\end{array}$ \\
\hline & Liver (human) & $2 \mathrm{C}$ & Shephard et al. (1989) \\
\hline & Liver (rat) & $2 \mathrm{D}$ & Gonzalez et al. (1988) \\
\hline & Liver (human, rat) & $2 \mathrm{E}$ & Song et al. (1986) \\
\hline & Lung (human) & $2 \mathrm{~F}$ & Nhamburo et al. (1990) \\
\hline Cyp 3 & Liver (human) & $3 A$ & Nebert et al. (1987) \\
\hline Cyp 4 & Liver (human, rat) & $4 \mathrm{~A}$ & Shet et al. (1996) \\
\hline & Lung (human) & $4 B$ & Nhamburo et al. (1989) \\
\hline Cyp 7 & Liver & $7 \alpha$ (Rat) & Li et al. (1990) \\
\hline Cyp 11 & Mitochondria & A & Moore et al. (1990) \\
\hline & $\begin{array}{c}\text { Mitochondria } \\
\text { (adrenal, human) }\end{array}$ & B & Mornet et al. (1989) \\
\hline Сур 17 & adrenal cortex & $17 \alpha$ (Cow) & Bhasker et al. (1989) \\
\hline CYP 19 & $\begin{array}{l}\text { Osteoblast cells } \\
\text { (human) }\end{array}$ & & $\begin{array}{l}\text { Harada et al. (1990) } \\
\text { Enjuanes et al. (2003) }\end{array}$ \\
\hline CYP 21 & $\begin{array}{l}\text { Adrenal tissue } \\
\text { (Human) }\end{array}$ & & Goto et al. (2002) \\
\hline Cyp 27 & $\begin{array}{l}\text { Mitochondria } \\
\qquad \text { (Rabbit) } \\
\text { Liver (Hamster) }\end{array}$ & & $\begin{array}{l}\text { Anderson et al. (1989) } \\
\text { Matsuzaki et al. (2002) }\end{array}$ \\
\hline
\end{tabular}

Table 1.1: The major mammalian classes of cytochrome P-450 isforms and their subfamily (Nebert et al, 1991). 


\subsection{Species and strain differences in expression of cytochrome P-450}

Cytochrome P-450 multiple forms are differentially expressed among tissues of different animals (Ryan et al., 1975; Guengerich, 1987; Porter and Coon, 1991). There are species, strain and organ differences in the expression of cytochrome $\mathrm{P}$ 450 (Guengerich et al., 1981; Vlasuk et al., 1982; Guengerich et al., 1982b). Studies carried out by Haugen et al. (1975); Ryan et al. (1975) showed that many of the major differences in the metabolism of various substrates seen under various conditions (i.e. age, sex, and species, pre-treatment with various compounds) were due to the presence of different forms of cytochrome P-450.

As previously indicated cytochrome P-450 is a superfamily of proteins consisting of a number of families (Nelson et al. 1993). They have considerable differences in their amino acid sequences and in substrate specificity (Beaune et al., 1980; Krynetskii, 1996). Several studies showed that multiple forms of cytochrome P-450 were present in the liver microsomes of animals treated with different inducers or in different animals treated with the same inducers. For example, cytochrome P-450 purified from phenobarbital-treated rats and rabbits, and cytochrome P-448 from 3-methylcholanthrene-treated rats and rabbits, differ from one another in catalytic, spectral, electrophoretic or immunological properties (Ryan et al., 1975; Thomas et al., 1976). The presence of multiple forms of liver microsomal P-450 in the same animal either treated with an inducer, or untreated, has also been reported (Haugen et al., 1975; Huang et al., 1976; Bridges and Fennell, 1980). A study by Krynetskii (1996) reported that inherited polymorphism of drug metabolising enzymes including P-450 was an important determinant of individual reactions to drug administration. 
The variable enzyme activities observed in microsomes of animals treated with different inducing agents suggested that numerous forms of cytochrome P-450 might be involved (Porter and Coon, 1991). Different types of cytochrome P-450 were also found in the same species using the same inducer. Gemzik et al. (1992) reported that an antibody against purified P-450 3A1 recognised two electrophoretically distinct proteins $(50$ and $51 \mathrm{kDa}$ ) in liver microsomes from male and female rats, as determined by Western immunoblotting techniques. The $51 \mathrm{kDa}$ protein corresponded to $\mathrm{P}-4503 \mathrm{~A} 1$ and / or $3 \mathrm{~A} 2$ while the other protein $(50 \mathrm{kDa})$ belonged to other members of the P-450 3A gene family. Both proteins were induced by dexamethasone, pregnenolone-16 $\alpha$-carbonitrile, troleandomycin or chlordane (Gemzik et al., 1992). Cytochrome P-450 has been purified to apparent homogeneity from rabbit liver (Coon et al., 1977), rat liver (Ryan et al., 1975; Guengrich, 1978; Guengrich et al., 1982; Okita et al., 1980), mouse liver (Huang et al., 1976) and human liver (Beaune et al., 1980, 1985a).

\subsection{The role of cytochrome P-450 as a biomarker of susceptibility and} resistance to environmental toxicity.

All organisms are exposed to toxic chemicals. Many of these toxic chemicals are found naturally in the environment. To ensure survival in the face of a wide spectrum of harmful chemicals, various defense mechanisms have evolved to protect cells against noxious compounds. Such protective mechanisms include drug efflux pumps (Gottesman and Pastan, 1993), drug sequestration (Hanna et al., 1993; Satoh et al., 1993), drug metabolism (Jakoby, 1980) and repair of drug-target sites (Fox and Roberts, 1987; Sancar and Sancar, 1988; Tanaka and Wood, 1994). 
Although these processes provide protection against different groups of chemicals, drug metabolism represents a particularly versatile protective mechanism. As a major enzyme system in xenobiotic metabolism cytochrome P-450 enzymes are responsible for the metabolism of numerous xenobiotics and endogenous compounds, including the metabolic activation and/or inactivation of environmental toxic chemicals and carcinogens (Guengerich, 1977a). Guengerich (1977b) studied the role of cytochrome P-450 towards representatives of several classes of compounds of environmental concern, and found that toxic compounds are activated or metabolised by different forms of microsomal cytochrome P-450. In some cases, cytochrome P-450 catalysed metabolism leads to the detoxification of toxic chemicals. Of 15 human cytochrome P-450 enzymes so far characterised, 7 forms of cytochrome P-450 (Cyp1A1, 1A2, 2A6, 2C9, 2D6, 2E1, and 3A4) have been shown to be polymorphic at the phenotypic or genetic level, or both (Daly et al., 1994; Pelkonen and Raunio, 1997). In addition to metabolising various drugs, these polymorphic cytochrome enzymes are involved in metabolising a large number of environmental carcinogens and toxic compounds (Guengerich, 1992). Because of individual differences in capability to metabolise, differences among the genes coding for detoxicating enzymes can be used as biomarkers of susceptibility to environmental carcinogenesis and toxicity. Hong and Yang (1997) showed that cytochrome $\mathrm{P}-450$ can be characterised in vivo by determining metabolic ratios; the ratio of blood or urinary amount of the parent drug over its metabolite. In vitro, polymorphism of cytochrome P-450 can be determined by enzyme activity, enzyme protein levels detected by immunological methods such as immunoblot and immunohistochemical analyses, cytochrome P-450 mRNA levels measured by Northern and slot blotting, RNase protection, in situ hybridization and recently by 
RT-PCR techniques to detect cytochrome P-450 mRNA in small amounts of tissue samples (Hong and Yang, 1997).

\subsection{GST enzymes}

\subsubsection{Functions of GST}

GSH S-transferases (GSTs; EC 2.5.1.18) are an important phase 2 enzyme system in the detoxification of electrophilic alkylating agents. They are a family of multifunctional dimeric proteins that catalyse the conjugation of the sulphur atom of GSH with a large variety of electrophilic compounds of both endobiotic and xenobiotic origin, such as halogenoalkanes, quinones and isothiocyanates (Chasseaud, 1979). The GSH conjugates thus formed are transported to the kidney where they are transformed into the corresponding mercapturic acids by the action of (1) $\gamma$-glutamyl-transpeptidase, which removes the $\gamma$-glutamic acid, (2) cysteinylglycine dipeptidase, which splits off the glycine moiety and (3) $\mathrm{N}$-acetyl transferase, which acetylates the residual cysteine derivative (Inoue, 1985). For some classes of substrates the initial conjugates are broken down by a second reaction with $\mathrm{GSH}$, for example organic hydroperoxides (Prohaska, 1980) and alpha-halogeno ketones (Anders and Pohl, 1985). In the latter case the result is the replacement of a halogen atom by hydrogen; in the former, alcohol is formed in addition to GSH disulphide (GSSG) as shown in Figure 1.4. 
1) $\mathrm{R}-\mathrm{X}+\mathrm{GSH} \longrightarrow \mathrm{R}-\mathrm{SG}+\mathrm{XH}$

(2) $\mathrm{R}-\mathrm{O}-\mathrm{OH}+\mathrm{GSH} \longrightarrow \mathrm{R}-\mathrm{OSG}+\mathrm{H}_{2} \mathrm{O}$

$\mathrm{R}-\mathrm{OSG}+\mathrm{GSH} \longrightarrow \mathrm{ROH}+\mathrm{GSSG}$

(3) $\mathrm{R}-\mathrm{CO}-\mathrm{CH}_{2}-\mathrm{X}+\mathrm{GSH} \longrightarrow \mathrm{R}-\mathrm{CO}-\mathrm{CH}_{2}-\mathrm{SG}+\mathrm{XH}$

$\mathrm{R}-\mathrm{CO}-\mathrm{CH}_{2}-\mathrm{SG}+\mathrm{GSH} \longrightarrow \mathrm{R}-\mathrm{CO}-\mathrm{CH}_{3}+\mathrm{GSSG}$

Figure 1.4: Three representative reaction pathways for the conjugation of xenobiotics with GSH. In case (2) (organic hydroperoxides and case) (3) (alpha-halogenoketones) a second reaction with GSH gives rise to the observed products.

The end products of the above reactions are excreted as less toxic and watersoluble metabolites through the bile and urinary systems (Jakoby, 1978; Habig, 1983; Mannervik and Danielson, 1988).

The role of GSTs is not limited to detoxification by conjugation of GSH with electrophilic substrates and excretion of the products as mercapturic acids. The GST enzymes also play a role in the intracellular binding, both covalently and noncovalently, of a variety of chemicals. Compounds that are bound covalently by GSTs include reactive metabolites formed from carcinogens such as dimethylaminoazobenzene and 3-methylcholanthrene (Ketterer et al., 1967; Litwack et al., 1971). However, not all compounds that are bound covalently by GST are carcinogens, for example the diuretic ethacrynic acid can also be bound covalently by GST isoenzymes other than ligandin (Phillips and Mantle, 1993; Ploemen et al., 1994). Compounds that bind by non-covalent interactions include a range of neutral or anionic lipophilic chemicals, including thyroid hormones, bile acids, bilirubin, heme, fatty acids and penicillin (Ketley et al., 1975; Kirsch et al., 1975; Bhargava et 
al., 1978; Jackoby, 1978; Chasseud, 1979; Hayes and Chalmbers, 1983; Hayes and Mantle, 1986; Boyer, 1986; Mannervik and Danielson, 1988; Ishigaki et al., 1989; Coles and Ketterer, 1990; Danger et al., 1992; Listowsky, 1993). Noncovalent binding contributes to the transport of these compounds across the liver and facilitates their elimination into bile. Similarly, GSTs in the kidney and small intestine are also involved in the transport of lipophilic compounds.

In addition to their catalytic properties, the GST enzyme systems have ability to participate as anti-oxidants in the protection of tissues against free radical damage to membrane lipids (Mannervik and Danielson, 1988; Pickett and Lu, 1989; Coles and Ketterer, 1990). GST appears to be involved in the metabolism of compounds that are produced by the body including prostaglandins, steroid hormones and the leukotrienes (A review by Clark, 1982). Listowsky (1993) has suggested that as GSTs constitute a high-capacity intracellular-binding pool for hormones, they might function as a binding reserve in target organs possibly serving a buffering role to minimise the effects of transient fluxes in extra-cellular hormone levels. In support of this putative role for GSTs, it has been pointed out that GSTs are the predominant cytosolic proteins labelled by steroid hormone and thyroxine photoaffinity probes (Ishigaki et al., 1989; Danger et al., 1992).

\subsubsection{GST isoforms in eukaryotes}

Eukaryotes possess multiple cytosolic and membrane bound GST isoenzymes, each of which display distinct catalytic as well as non-catalytic binding properties. Mammalian cytosolic GSTs occur as homo or heterodimers (Ketterer et 
al., 1988). The cytosolic enzymes form at least eight main classes, according to their sequence homologies and enzymatic, physico-chemical and immunological properties (Mannervik, 1985; De Jong et al., 1988; Meyer et al., 1991). The classes are named Alpha, Mu, Pi, Sigma, Theta, Zeta and Omega (Mannervik et al., 1985; Meyer et al., 1991; Board et al., 1995, 1997) whereas the membrane bound enzymes, microsomal GST and leukotriene C4 synthetase are all encoded by single genes (Morgenstern et al., 1982; Anderson et al., 1994). A mitochondrial specific class of GST has been isolated from the mitochondrial membranes of rat liver by Harris et al. (1991). Little is known of the structure, function or evolution of this class, which was described and designated as class Kappa GST (Pemble et al., 1996). These classes contain more than 20 subunits that have been detected and reported in the literature (Table 1.2).

\subsection{Tissue distribution of GSTs}

Conjugation of xenobiotics with GSH has been shown to occur in mammals, birds, reptiles, amphibians, fish, insects and other invertebrates (Boyland and Chasseaud, 1969). A wide variety of organs have been tested for the activity of GSTs. The enzymes have been found mainly in the soluble fractions of liver and/or kidney in vertebrates. Multiple forms of GSTs have been isolated and purified from different species and from most organs of mammals (Mannervik and Danielson, 1988; Board et al., 1990) including rat liver, kidney, brain, testes, ovaries, placenta (Habig, 1983; Satoh et al., 1985; Singh et al., 1987; Hsieh et al., 1997; Roman-Rao and Indira, 1997), mouse liver and lungs (Sherratt et al., 1997), sheep liver (Miller et al., 1994; Lenartova et al., 1996), cattle liver (Smith and Watkins, 1984), porcine 
liver (Smith et al., 1984; Kunze, 1997), rabbit liver (Primiano and Novak, 1993) and human liver, lung, heart, brain, placenta, skeletal muscles, pancreas, testis, ovaries, uterus, platelets, leukocytes (van der Jagt et al., 1981; Federici et al., 1985; Seidegard et al., 1986; Raney et al., 1992; Grant and Ironside, 1995; Jemth and Mannervik, 1997).

\subsection{Properties of GSTs}

Several properties of the GSTs have been used to classify these enzymes (Mannervik et al., 1985). These properties are:

\subsubsection{Molecular weight and subunit structure}

The cytosolic GSTs in vertebrates are dimers with molecular weights that usually vary between 38,000 and 50,000 (mean 43,000) and with mean subunit molecular weight of $24,900 \pm 3100$. The molecular weights of both mammalian and non-vertebrate GST enzymes have been determined using gel permeation chromatography and SDS-PAGE. The apparent molecular weights were noted to be affected by factors such as $\mathrm{pH}$ and ionic strength, which may have contributed to the variety of the molecular weights (Motoyama and Dauterman, 1979). Mannervik et al. (1985) studied the main properties of the three main classes (Alpha, Mu and Pi) of mammalian GSTs and found differences in the molecular weights among the classes. They noticed that the subunits of class Pi showed the lowest apparent molecular weight, class Alpha subunits had an intermediate molecular weight, while the subunits of class Mu exhibited the highest molecular weight, with an exception 
in rat subunit 2 of class Alpha which revealed the highest molecular weight. 


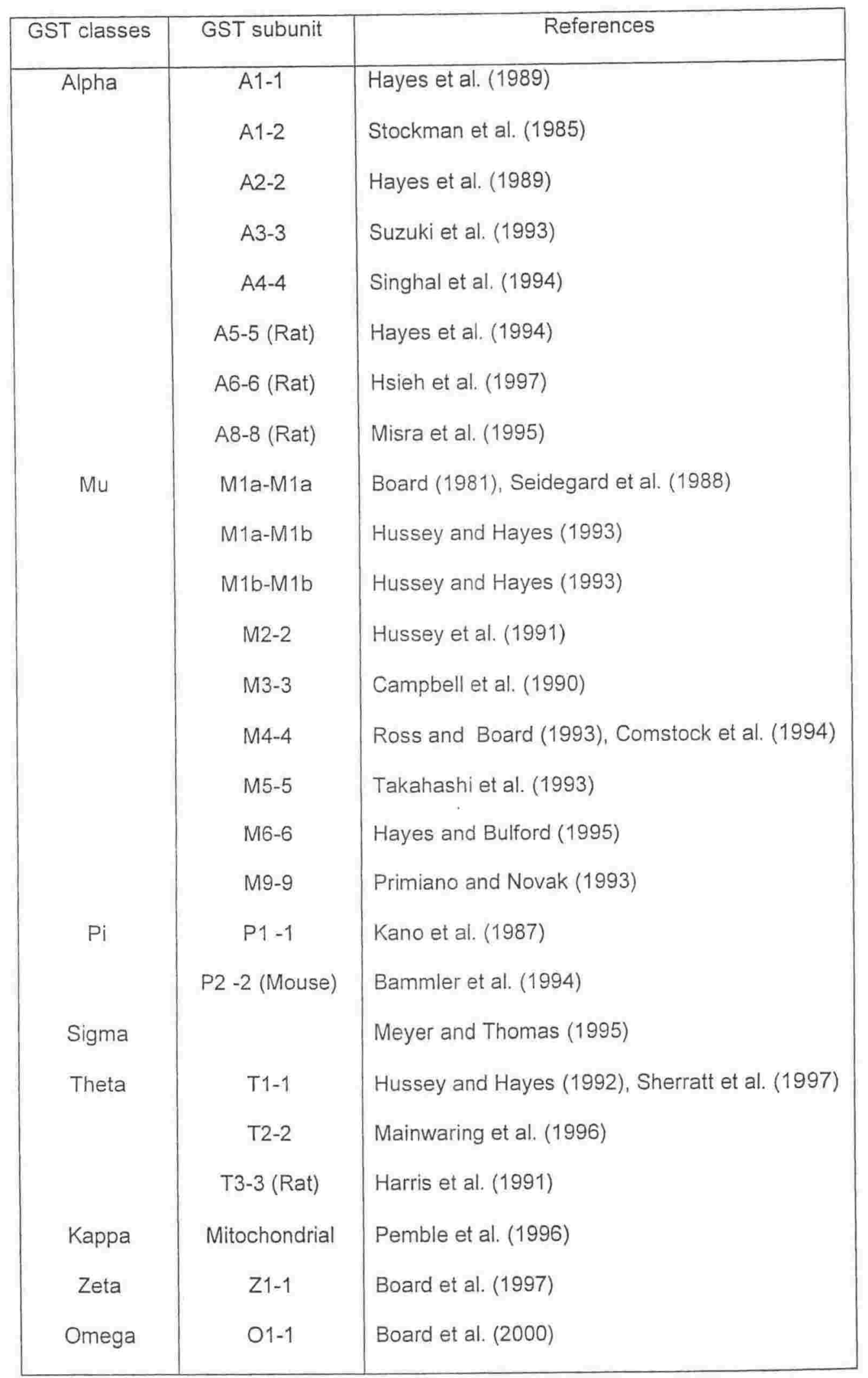

Table 1.2: The GST subunits are designated according to the class based subunit nomenclature proposed by Mannervik et al. (1992). 


\subsection{1 .2 Isoelectric points}

The isoelectric points of GSTs were studied using the isoelectrofocussing method (Hales et al., 1978; Clark, 1989) or by chromatofocussing (Dierickx, 1985; Keeran and Lee, 1987). Mannervik et al. (1985) found that the Alpha GST class can be isolated by chromatofocusing in a basic media, class $\mathrm{Mu}$ in a neutral $\mathrm{pH}$ media, while class Pi was isolated in acidic media, and the new class of GST, Theta was isolated in a basic pH buffer (Mainwaring et al., 1996).

\subsubsection{Catalytic activities}

The GSTs are a family of enzymes that catalyse a number of distinct GSH dependent reactions. In addition to their ability to catalyse the formation of conjugates, GSTs can also serve as peroxidases and isomerases (Mannervik and Danielson, 1988). The fundamental basis for all the various catalytic activities of GST is the ability of the enzyme to lower the $\mathrm{pK}_{\mathrm{a}}$ of the sulfhydryl group of reduced GSH from 9.0 in aqueous solution to about 6.5 when bound in the active site (Armstrong, 1994). Chen et al. (1988), Graminski et al. (1989) and Huskey et al. (1991) found that GSH exists as the thiolate (GS') anion at neutral pH when complexed with GST. X-Ray crystallographic studies showed that tyrosine (in classes Alpha, Mu, Pi and Sigma), or serine (class Theta), was involved in stabilising $\mathrm{GS}^{-}$through hydrogen bonding (Reinemer et al., 1991; Ji et al., 1992; Liu et al., 1992; Sinning et al., 1993; Wilce et al., 1995). Jakoby (1978) proposed that once $\mathrm{GS}^{-}$is formed in the active site of GST it becomes capable of reacting spontaneously, by nucleophilic attack, with electrophilic xenobiotics that is situated 
in close proximity. The catalytic function of GST will take place through the combined ability of the enzyme to promote the formation of $\mathrm{GS}^{-}$and to bind hydrophobic electrophilic compounds at a closely adjacent site (Jakoby, 1978). The GSH-binding site and the hydrophobic substrate-binding site have been called the G- and H-sites, respectively (Mannervik, 1985).

\subsection{General and specific substrates of GSTs}

The GST isoenzymes display marked differences in their abilities to conjugate GSH with various electrophiles. The range of compounds acting as substrates for these enzymes is very wide, including xenobiotic and endogenous compounds. The GST isoenzymes individually show a lack of specificity for electrophilic substrates so that each isoform may catalyse conjugations with a wide range of compounds. These include alkyl, aryl, halides, carboxylate, sulphate, phosphate esters, epoxides, organic nitrates, thiocyanates and hydroxyperoxides (Clark, 1989).

A number of substrates have commonly been used for enzyme assays. The most widely used substrate to study GST is CDNB. When conjugated with GSH it gives S-2, 4-dinitrophenylglutathione (Habig and Jakoby, 1981). However other types of GST show relatively low activity toward CDNB, such as Theta class enzymes which lack detectable activity toward this substrate (Meyer et al., 1991). Other general substrates used include DCNB, EPNP and p-NBC (Table 1.3) 


\begin{tabular}{lcccc}
\hline Substrate & Substrate & pH & Wavelength & $\varepsilon$ \\
& Conc.(mM) & $(\mathrm{mM})$ & $(\mathrm{nm})$ & $\left(\mathrm{mM}^{-1} \mathrm{~cm}^{-1}\right)$ \\
& & & & \\
\hline 1,2-Dichloro-4-nitrobenzene & 1.0 & 7.5 & 345 & 8.5 \\
1-Chloro-2,4-dinitrobenzene-a & 1.0 & 6.5 & 340 & 9.6 \\
4-Nitropyridine-N-oxide & 0.2 & 7.0 & 295 & 7.0 \\
p-Nitrophenethyl bromide & 0.1 & 6.5 & 310 & 1.2 \\
p-Nitrobenzyl chloride & 1.0 & 6.5 & 310 & 1.9 \\
1,2-Epoxy-3-(p-nitrophenoxy) & 0.5 & 6.5 & 360 & 0.5 \\
propane. & & & & 8.1 \\
1,2-Naphthalene oxide & 0.1 & 8.5 & 260 & 4.5 \\
Bromosulphophthalein & 0.03 & 7.5 & 330 & 2.5 \\
1-Menaphthyl sulphate & 0.5 & 7.5 & 298 & -24.8 \\
Trans-4-phenyl-3-buten-2-one & 0.05 & 6.5 & 290 & 5.0 \\
Ethacrynic acid & 0.2 & 6.5 & 270 & \\
\hline & & & & \\
\hline
\end{tabular}

Table 1.3: Conditions for spectrophotometric enzyme assay towards various substrates in $0.1 \mathrm{M}$ potassium phosphate and $5 \mathrm{mM}$ GSH at $25^{\circ} \mathrm{C}$ (Habig and Jakoby, 1981).

-a. At a GSH concentration of $1 \mathrm{mM}$.

-. At a GSH concentration of $0.25 \mathrm{mM}$.

Although substrate selectivities of the GST isoenzymes are generally described as broad and overlapping, major differences between GST classes (Alpha, Mu, and Pi) were found. Some substrates are specific enough to be used for the classification of the isoenzymes (Mannervik, 1985). Class Alpha isoenzyme generally exhibited 
high peroxidase activity with 1-methyl-1-phenylethyl hydroperoxide (cumene hydroperoxide). Class $\mathrm{Pi}$ isoenzymes showed high activity toward ethacrynic acid while trans-4-phenyl-3-buten-2-one, bromosulfophthalein or DCNB were used for the classification of class Mu isoenzymes (Mannervik et al., 1985; Van Ommen et al., 1990). The model substrates that display selectivity for particular subunits were also used in a diagnostic sense to identify isoenzymes (Hayes and Pulford, 1995). Compounds that were used for this purpose were: $\Delta^{5}$ androstene-3,17-dione, selective for rat GST A1 and / or A2 subunits; 4-hydroxynonenal, selective for rat GST A4; DCNB selective for rat GST M1; trans-4-phenyl-3-buten-2-one selective for rat GST M2; EPNP selective for rat GSTT1; and 1-menaphthyl sulphate selective for rat GSTT2. GST isoenzymes can demonstrate remarkable stereospecificity. It has, for example, been observed that rat GST containing the A5 subunits had high activity for aflatoxin $B_{1}$ exo-8,9-epoxide, but essentially no activity toward aflatoxin $\mathrm{B}_{1}$ endo-8,9-epoxide. Conversely, rat GSTM2-2 exhibited about 10-fold greater activity toward aflatoxin $B_{1}$ endo-8,9-epoxide than the exo-8,9-epoxide (Raney et al., 1992). Stereospecificity had been observed with other epoxides besides those of aflatoxin. All rat GSTs displayed a $97 \%$ selectivity for $(+)-7 \beta, 8 \alpha$-dihydroxy$9 \alpha, 10 \alpha$-oxy-7,8,9,10-tetrahydrobenzo [a] pyrene rather than (-)-7 $\beta, 8 \alpha$-dihydroxy$9 \alpha, 10 \alpha-0 x y-7,8,9,10$-tetrahydrobenzo [b] pyrene (Robertson et al., 1986).

\subsection{Development and variation of GST isoenzymes}

\subsubsection{Developmental patterns}

Amino acid sequence studies of three main classes of mammalian 
GSTs were carried out by Mannervik et al. (1985). In their studies they demonstrated similarities in sequences within a class as well as between classes. However, Mannervik et al. (1985) also found that the differences between the three main classes of GST within a species were greater than the differences between the enzymes within a class from different species. They explained the observation by saying that the classes probably diverged before the evolution of different mammalian species.

In foetal liver and the adrenal gland a major Alpha-class isoenzyme in addition to the Pi-class transferase has been observed as a representative of the GSTs (Guthenberg et al., 1986; Faulder et al., 1987). Foetal liver expressed a decline in the relative contribution of the Pi-class enzyme to total GST activity during the gestation period, so at birth this isoenzyme was only expressed weakly. Warholm et al. (1981) found only one type of Alpha-class was detected in foetal liver, whereas several isoenzymes were expressed in adults.

Faulder et al. (1987) studied the development of basic, neutral, and acidic isoenzymes of GST in human liver, adrenal, kidney and spleen and found that, in kidney, the Pi-class isoenzyme was constantly expressed at a high level until approximately 40 weeks post-natal age, after which a relative decline was noticed in favour of the development of Alpha-class transferases.

The Mu-class GSTs are generally not detected in foetal tissues until approximately 30 weeks of gestation (Strange et al., 1985). The level of these enzymes is variable in adrenal gland, kidney and spleen, and no developmental patterns have been observed for these tissues (Faulder et al., 1987). 


\subsubsection{Factors influencing GST class expression}

\subsubsection{Hormonal influences:}

Some evidence exists that GST isoenzyme patterns may be subject to hormonal influence. Igarashi et al. (1987), McLellan and Hayes (1987), Singhal et al. (1992) noticed differences in the expression and subunit composition of hepatic GST in female and male rats and mice. They postulated that hormonal differences could be responsible. Later studies showed that both the male rat and the male mouse demonstrated higher specific activities in the liver than their female counterparts.

A study carried out by Williams et al. (1986) found that the intraperitoneal injection of triidothyronine caused significant changes in the isoenzyme pattern in the liver of female mice. Pickett and Lu (1988) demonstrated that surgical thyroidectomy in the rat results in a $30 \%$ increase in isoenzyme A1-1. Prolonged oral administration of thyroxine or tri-iodothyronine causes a decline in GST activity in rat liver. They suggested that the decline in GST activity was partly due to decrease in the levels of expression of isoenzymes A1-1, A2-2 and M3-3.

\subsubsection{Induction:}

It has been speculated that the isoenzyme patterns can be subjected to modulation by external factors. Thus, the activity of a set of isoenzymes can be affected and may be modified by the presence of specific inhibitors or the level of expression of each of these isoenzymes could be changed as a result of exposure 
to an inducing agent (Igarashi et al., 1987; McLellan et al., 1992). The diversity of the organisms in which induction has been observed, and the spectrum of xenobiotics that can serve as inducing agents, suggest that GST induction is part of an adaptive response mechanism to chemical stress that is widely distributed in nature. The induction of individual isoenzymes in rat liver has been studied extensively using phenobarbital and 3-methylcholanthrene as inducers (Hales and Neims, 1977; Ding and Pickett, 1985; Pickett et al., 1987). They found that both compounds were involved in the activation of mRNA translation causing an elevation of subunits $A 1-1$ and M3 -3 which is an indication of a relative increase of the isoenzymes containing those subunits (Hales and Neims, 1977; Bhargava, 1983; Ding et al., 1986). Ding and Pickett (1985) and Pickett et al. (1987) studied the effects of phenobarbital and 3-methylcholanthrene on the transcription of the genes encoding GST enzyme subunits. A study carried out by Hayes and Pulford (1995) found that many inducers affect transcriptional activation of GST genes through either the anti-oxidant responsive element (ARE), the xenobiotic responsive element (XRE), the GST P enhancer 1 (GPE) or the glucocorticoid-responsive element (GRE). Many of the compounds that induce GSTs are themselves substrates for the enzymes, or are metabolised by cytochrome P-450 monooxygenases to compounds that can serve as GST substrates suggesting that GST induction represents part of an adaptive response mechanism to chemical stress caused by electrophiles. 


\subsubsection{Tissue selective expression of GST subunits}

In rats and humans, the highest amount of total GST protein is present in the liver, and is reported to account for up to $5-10 \%$ of the total soluble protein (Van Ommen et al., 1990). The major protein consists of subunits A1-1, A2-2, M3-3 and M4-4 and only trace amounts of subunit P7-7 are present. The studies on tissue distribution of subunits of GST in humans indicate a number of similarities to the distribution of GSTs in rats. Fryer et al. (1986) found that the class-Pi isoenzyme was rare in liver tissue, but it was present in large amounts in other organs, e.g. placenta, kidney and intestine. The human lung was found to contain relatively low amounts of Alpha-class subunits (Fryer et al., 1986).

\subsubsection{Genetic variation in the expression of GST}

Genetic variation in the expression of GST isoenzymes has been studied in humans (Van Ommen et al., 1990). They found a considerable polymorphism in Alpha-class isoenzymes of human liver, with two subunits, B1 (A1-1) and B2 (A2-2). For class-Mu GST isoenzymes in humans, Board (1981) demonstrated a clear polymorphism. They were expressed in $60 \%$ of samples analysed. Singh et al. (1987) indicated the presence of a second class of Mu isoenzymes when they examined six liver samples. A study carried out by Seidegard and Pero (1985) using trans-stilbene oxide as a model substrate for conjugation confirmed the existence of two isoenzymes in human cytosolic class Mu GST. A marked interindividual variation also exists in human liver for the Alpha subunit containing GSTs (i.e. GST A1-1, GST A1-2, and GST A2-2) (Hussey et al., 1986; Stockman et al., 
1987).

In rats a Pi-class isoenzyme was found at a very low level in normal liver, but it was expressed to a considerable extent in pre-neoplastic nodules of hepatocellular carcinoma (Kitahara et al., 1984). A similar observation was made in human hepatic tumours with regard to Pi class (Di llio et al., 1989).

\subsection{Drug metabolising enzymes in sheep liver}

Information concerning the development of hepatic enzyme activities in sheep is limited to comparative data involving liver enzymes in adult ewes and foetal lambs (Dvorchik et al., 1986; Wang et al., 1986) or between different ruminant species (Smith and Watkins, 1984; Wisniewski et al., 1987). Kaddouri et al. (1990) reported the development of hepatic monooxygenases in liver microsomes and cytosolic drug metabolising enzymes prepared from foetal, neonatal (one and four week old), growing (several month old), pregnant (eleven month old) and adult (six years old) female Lacaune sheep selected from the same flock. The ontogenesis of sheep liver cytochrome subfamilies, P-450 2B and P-450 3A was studied in female sheep by Kaddouri et al. (1992). They found that, the two types of P-450 were involved in the metabolism of progesterone after measuring both the $6 \beta$ and $16 \alpha$, 21-hydroxylations of the hormone and it's reduction at the 20-position leading to 20 $\alpha$-hydroxy progesterone. Cytochrome P-450 2B was found to be at low level after birth. In contrast, the isoenzyme P-450 3A was detected in sheep foetal liver at $48 \%$ of total P-450 content in one and four week old lambs. However, the percentage of P-450 3A was only about $20 \%$ of total P-450 in older animals (Braun et al., 1992; Kaddouri et al., 1990). In other studies, it was noticed that the 
development of mono-oxygenase activities was variable during growth, some increased regularly to adult levels, including aminopyrine, ethylmorphine $\mathrm{N}$ demethylase, ethoxycoumarin O-deethylase and benzopyrene hydroxylase. Benzphetamine $\mathrm{N}$-demethylation remained constant and was correlated with cytochrome P-450 2B levels. Erythromycin N-demethylation and aniline hydroxylation levels decreased from four weeks of age to adulthood and their evolution paralleled that of isoenzyme P-450 3A (Galtier et al., 1991).

The investigation of phase 2 enzymes of sheep liver indicated that UDPglucuronyl transferase activity toward p-nitrophenol was present in foetal sheep liver and increased at birth and decreased in adult animals (Wang et al., 1986). This developmental pattern was found to be similar to that of hepatic $\gamma$-glutamyltransferase in ovine liver (Braun et al., 1992). The cytosolic GSH S-conjugation of CDNB was found to be constant during the first seven months of life and rapidly increased by 8 -fold during pregnancy, while cytosolic $\mathrm{N}$-acetyltransferase using isoniazide as a substrate was found to be below the detection limit of the method ( $0.05 \mathrm{nmol} / \mathrm{mg} / \mathrm{min}$ ) (Kaddouri et al., 1990, 1992). It was concluded that there were similarities in ovine hepatic drug metabolising capabilities with those of other mammals (Galtier and Alvinerie, 1996). The activities of the different P-450 dependent mono-oxygenases did not increase in sheep at the same rate since only some could directly be correlated to the development of the total microsomal P-450. Such an uneven development of the various MFO pathways in neonates and adult animals (Kaddouri et al., 1990) had also been described in rats (Cresteil et al., 1986), calves (Shoaf et al., 1987) and pigs (Short and Stith, 1973). 


\subsection{Aims of this study}

This thesis contains a study of possible differences in the liver enzymes and other proteins between the selected lines of FE resistant and susceptible Romneys.

The aims of this thesis were therefore:

1. To investigate the activities of liver microsomal cytochrome $P-450$ and cytosolic GST in FE resistant and susceptible Romneys.

2. To study the ability of these enzymes to metabolize sporidesmin.

3. To investigate differences in potential sporidesmin metabolising enzymes, including $\mathrm{O}$ and $\mathrm{N}$-demethylase and GSTs, between FE resistant and susceptible Romneys.

4. To identify any differences and variation in protein expression between susceptible or resistant Romneys using the 2-D SDS-PAGE analysis method.

5. To identify a biochemical marker for inherited resistance or susceptibility of Romneys to sporidesmin. 


\section{CHAPTER II}

\section{MATERIALS AND METHODS}

\subsection{Sources of Materials}

\subsubsection{Sources}
AJAX
AJAX Chemicals Ltd; Sydney, Australia
$\mathrm{BDH}$
BDH Chemical Ltd; Poole, England
Bio-Rad
Bio-Rad Laboratories; CA, U.S.A
BMGB
Boehringer Mannheim; GmBH Biochemica; Mannheim,
Germany
$M \& B$
May and Baker Ltd; Dagenham, England
Schleicher \& Schuel
Dassel, Germany
Sigma
Sigma Chemical Co; Missouri, U.S.A
XFORD
XFORD Biochemical Research INC. MI, USA

\subsubsection{Materials and their sources}

The following chemicals were obtained from the sources listed below:

Chemical

Company Code

Acetonitrile-210

AJAX

Acrylamide

$\mathrm{BDH}$

Agarose

Sigma 
Amonium persulphate

Aminopyrine

Bis

Bromophenol blue

CHAPS

CDNB

4-Chloro-1-naphthol

Coomassie brilliant blue G-250

Dexamethasone

DCNB

DTT

EPNP

GSH reduced

Glucose-6-phosphate

Glucose-6-phosphate

dehydrogenase.

HEPES

lodoacetamide

2-Mercaptoethanol

Molecular weight markers

NADPH

Nitrocellulose

PEG

Resolyte

SDS

Sodium cholate

Sporidesmin
$\mathrm{BDH}$

Sigma

Sigma

$\mathrm{BDH}$

Sigma

$\mathrm{BDH}$

Bio-Rad Laboratories

$\mathrm{BDH}$

XFORD

$\mathrm{BDH}$

BMGB

$\mathrm{BDH}$

Boehringer Mannhem

Sigma

Sigma

Sigma

Aldrich

$\mathrm{BDH}$

Sigma

Sigma

Schleicher \& Schuel

$\mathrm{BDH}$

$\mathrm{BDH}$

Bio-Rad

Sigma

AgResearch, Ruakura, Hamilton, N.Z. 
TEMED

Tris

Tween-20

Urea
$\mathrm{BDH}$

Bio-Rad

$\mathrm{BDH}$

Sigma

\section{$\underline{2.2 \text { Animals }}$}

\subsubsection{Selection of the R and S flocks}

The animals used were from two Romney flocks, which had been selected for susceptibility (S flock) or resistance ( $\mathrm{R}$ flock) to sporidesmin induced liver damage (Campbell et al., 1975; Morris et al., 1989) at Ruakura Agricultural Research Centre, Hamilton, New Zealand. The details of their selection have been described by Morris et al. (1989). Briefly, the selection was based on identifying the more resistant and susceptible sires from the resistant and susceptible flocks, initially using a progeny-testing program. From 1981 onwards a performance test was used to select sires by monitoring the elevation in serum of the liver enzyme GGT as an indication of the severity of liver injury after sporidesmin dosing. Selected sires were only allowed to mate with ewes from their own flock. A control, unselected, "(C)" flock was also established in 1982. Animals in these flocks had breeding values (Morris et al., 1989) from 0.8 to -1.03 for the resistant "R" flock, and from 0.43 to 0.59 for the susceptible "S" flock. These values were based on the amount of GGT elevation in the blood after dosing the animal with sporidesmin. The most negative values were found in most resistant animals and reflect the smallest increases in serum GGT after dosing. Breeding values can only be compared for animals dosed with same amount of sporidesmin. Because different dose rates were used to select the 
susceptible and resistant flocks, direct comparisons between these flocks can not be made. Morris et al. (1989) indicated that within each experimental flock a difference in breeding value of 0.1 was equivalent to a difference in resistance of $3.8 \%$.

\subsubsection{Animals used}

Romney ram lambs weighing between $17-20 \mathrm{~kg}$ and aged between 4-8 months old were used in this study. The breeding values of the animals ranged between -1.296 to -1.496 for resistant, and 0.952 to 1.214 for susceptible animals. There were four groups of animals used in this experiment. Two groups contained twenty animals each, born in 1994, 1995. Each group of twenty animals contained four experimental subgroups. Two of the four subgroups were undosed and contained ten animals, five from resistant and five from susceptible lines. The remaining two subgroups also contained ten animals, Five animals from the resistant (R) and five animals from the susceptible (S) and were dosed by ruminal intubation with sporidesmin in 10\% (v:v) ethanol:water, and were killed two days after the sporidesmin administration. The doses were $0.35 \mathrm{mg} / \mathrm{kg}$ live body weight for resistant and $0.15 \mathrm{mg} / \mathrm{kg}$ live body weight for susceptible animals. The third group contained four animals born 1996, two animals were from the FE resistant line (Ruakura resistant flock), and two were from the FE contemporary control (unselected) flock (Ruakura control flock) (Morris et al., 1994). Finally, the fourth group were born in 1997, and contained sixteen animals. Ten of these animals were undosed and they were divided into two subgroups, five susceptible and five resistant. The other six animals were a dosed group, and were divided into two subgroups, each contained three animals, three resistant and three susceptible. 


\subsection{Preparation of liver microsomes}

Liver samples were collected within 5 min of animals being killed in the Ruakura abattoir and were either snap frozen in liquid nitrogen for storage or were processed immediately for preparation of microsomes and post microsomal supernatant. Subcellular fractionation was carried out using 20 - 40 g portions of liver suspended in ice cold $0.25 \mathrm{M}$ sucrose. Liver samples were diced into $5-10 \mathrm{~cm}^{3}$ pieces and the medium was then removed and replaced with fresh $0.25 \mathrm{M}$ sucrose. Homogenisation was carried out in 4 volumes of sucrose using a Polytron Kinematica GmbH (Luzern, Switzerland) homogeniser at speed setting $4-5$ for $30 \mathrm{sec}$. Homogenates were initially centrifuged at $4^{\circ} \mathrm{C}$ and $5000 \mathrm{rpm}$ for five min. The supernatants were transferred to clean polycarbonate tubes and were centrifuged at $10.000 \mathrm{~g}$ for fifteen min. Microsomal pellets were prepared from the supernatant fractions by centrifugation at $105,000 \mathrm{~g}(35,000 \mathrm{rpm})$ for one $\mathrm{h}$ in a Ti60 rotor and the microsomal pellets were suspended in $0.1 \mathrm{M}$ phosphate buffer $\mathrm{pH} 7.4$ containing $10 \%(w / v)$ glycerol for storage at $-80^{\circ} \mathrm{C}$.

\subsubsection{Partial purification of cytochrome P-450}

Microsomal samples were diluted to a protein concentration of $7 \mathrm{mg}$ protein per $\mathrm{ml}$ using a buffer solution containing $20 \%$ glycerol $0.1 \mathrm{M}$ phosphate $\mathrm{pH} 7.4$ and $1 \mathrm{mM}$ EDTA. A solution of $10 \%$ sodium cholate, adjusted to $\mathrm{pH} 7.5$, was added, dropwise, to the microsomal suspensions with stirring to give a final concentration of $3 \mathrm{mg}$ cholate/mg protein. After gently stirring on ice for $30 \mathrm{~min}$, a solution of $50 \%$ PEG 6000 was added to a final concentration of $7 \%$ and 
stirred for an additional $30 \mathrm{~min}$ prior to centrifugation at $21,000 \mathrm{rpm}(63,000 \mathrm{~g})$ for $30 \mathrm{~min}$. The supernatant was decanted, and more 50\% PEG solution was added to a final concentration of $15 \%$ PEG. After stirring for $30 \mathrm{~min}$ at $4^{\circ} \mathrm{C}$, the suspension was centrifuged at $105,000 \mathrm{~g}(35,000 \mathrm{rpm})$ for $60 \mathrm{~min}$ in a Ti60 rotor. The $7-15 \%$ PEG pellet was collected for analysis.

\subsection{Electrophoresis}

Two-dimensional electrophoresis can be used to resolve complex protein mixtures. This includes the separation of proteins according to charge, by isoelectric focusing, and molecular mass, by SDS PAGE. In this study isoelectric focusing was carried out using the immobilized $\mathrm{pH}$ gradient technique.

\subsubsection{IPG focusing}

First dimension IPG focusing was carried out using AP biotech, $\mathrm{pH} 3$ - 10 IPG strips.

Rehydration was performed overnight by placing the IPG strips in the Pharmacia reswelling cassette with $25 \mathrm{ml}$ of a solution containing $8 \mathrm{M}$ urea, $2 \%$ CHAPS, $0.15 \%$ DTT, $2 \%$ Resolyte $\mathrm{pH} 3.5-10$. After the rehydration the strips were transferred to the Pharmacia strip tray which contained a plastic liner sheet. The electrodes were attached to the IPG strips using paper wicks and the sample cups were placed near the anode region, the strips and cups were covered with low viscosity paraffin oil.

The first dimension procedure was run using four programmed stages. The first stage was for $0.1 \mathrm{~h}$ at voltages ranging between $300-500 \mathrm{~V}$. The second 
stage was for $3 \mathrm{~h}$ also at $500 \mathrm{~V}$, followed by the third stage that was for $5 \mathrm{~h}$ at $3500 \mathrm{~V}$. The fourth stage lasted $12.5 \mathrm{~h}$ at $3500 \mathrm{~V}$. Focused IPG strips were equilibrated in two solutions to reduce disulphide bonds and alkylate cysteine residues. The first solution consisted of $10 \mathrm{ml}$ of $0.5 \mathrm{M}$ Tris-HCL $\mathrm{pH} 6.8,30 \mathrm{ml}$ glycerol, $36 \mathrm{~g}$ of $6 \mathrm{M}$ urea, $1 \mathrm{~g}$ of $1 \% \mathrm{SDS}$ and $1 \mathrm{~g}$ of $1 \% \mathrm{DTT}$. The second solution was the same as the first solution except that $2.5 \mathrm{~g}$ of iodoacetamide replaced the DTT.

\subsubsection{2-D SDS PAGE}

Electrophoresis was carried out at room temperature in the presence of SDS at a constant current of $35 \mathrm{~mA} / \mathrm{gel}$ for approximately 4-5 h until the tracking dye reached the lower end of the gel. The SDS discontinuous buffer system of Laemmli (1970) was used. The glass plates $(185.5 \mathrm{~mm} \times 180 \mathrm{~mm})$ for casting the gels were washed with detergent in hot water and were air-dried. The surfaces of the plates were wiped with soft tissue and distilled water just before use. The gel plates were set up as a sandwich with $1 \mathrm{~mm}$ thick Teflon spacers. Vaseline was used to help to seal the joints.

Resolving gels contained $12 \%$ acrylamide $-0.3 \%$ Bis, $0.325 \mathrm{M}$ Tris- $\mathrm{HCl} \mathrm{pH}$ 8.8. The solution was mixed in a vacuum flask and was degassed using a Buchi vacuum system for $15 \mathrm{~min}$. Immediately after degassing, $0.6 \mathrm{ml}$ of $10 \%$ SDS and $30 \mu \mathrm{l}$ of TEMED were added to the gel mixture, and finally $0.3 \mathrm{ml}$ of $10 \%$ ammonium persulphate was added to start the gel polymerisation. The solution was then quickly poured into the gel plate sandwich to the desired level, and $0.1 \%$ aqueous SDS was sprayed over the top of the gel as an overlay. The gel was allowed to polymerise for 30 - $45 \mathrm{~min}$, then the overlay was removed and distilled water was used to wash off the remaining overlay solution. The 
stacking gel solution $\mathrm{pH} 6.8$ was made from $24.4 \mathrm{ml}$ of distilled water, $5.2 \mathrm{ml}$ of $30 \%$ acrylamide stack and $10 \mathrm{ml}$ of stacking gel buffer. The solution was degassed for $10 \mathrm{~min}$ before adding $15 \mu \mathrm{l}$ TEMED and $0.4 \mathrm{ml}$ of $10 \%$ SDS solution. Finally $0.2 \mathrm{ml}$ of $10 \%$ ammonium persulphate was added to initiate polymerisation of the stacking gel. A Pasteur pipette was used to add the stacking gel solution to the space above the resolution gel. Immediately a Teflon spacer bar was inserted at the left end of the stacking gel to form a well for the molecular weight markers. The stacking gel was set $1-2 \mathrm{~cm}$ below the top edge of the glass plate, to make space so that the equilibrated strip could be laid directly on the stacking gel. Melted agarose (1\%) solution was poured on top of the equilibrated strip to maximise the contact between the strip and the stacking gel below. For 1-D gel analysis, a Teflon comb with thirteen teeth was inserted into the gel solution to create sample wells. After this $0.1 \%$ SDS was sprayed over the top of the gel as an overlay. The gel was left for 30 min to polymerise, then the spacer bar or the comb was removed and the wells were washed with distilled water. The bottom rubber spacer was later removed and soft tissues were used to wipe off the remaining Vaseline. Focused, equilibrated, IPG strips, or the samples for 1-D analysis, were then loaded onto the gel and the plates were fixed to the gel chamber. Diluted electrophoresis buffer (1x) with tracking dye (10\% bromophenol blue), was poured into the top chamber, slowly, in order not to disperse the samples loaded in the wells in case of 1-D analysis. The bottom chamber was filled with electrophoresis buffer. The gels were electrophoresed at $70 \mathrm{~mA}$ constant current. Electrophoresis was terminated when the tracking Bromophenol dye reached the bottom of the gel after about 4$5 \mathrm{~h}$.

Proteins were detected on 2-D gels by staining with either colloidal Coomassie blue G-250 or Coomassie blue R-250. For colloidal Coomassie blue 
G-250 staining, the gels were fixed overnight in water:ethanol (1:1) containing $2 \%(\mathrm{v} / \mathrm{v})$ orthophosphoric acid, washed 3 times with distilled water and then in aqueous $34 \%(\mathrm{v} / \mathrm{v})$ methanol - $2 \%(\mathrm{v} / \mathrm{v})$ orthophosphoric acid containing $17 \%$ $(\mathrm{w} / \mathrm{v})$ ammonium sulphate for an $\mathrm{h}$ before the addition of $0.1 \%(\mathrm{w} / \mathrm{v})$ Coomassie blue G-250. Gels were stained to equilibrium with gentle agitation for 4 days. Gels were scanned using a Molecular Dynamics scanner and the images were analysed using ImageQuant ${ }^{\mathrm{TM}}$ software version 4.2. For staining with Coomassie blue R-250, the gels were stained for 3 - 4 days, destained overnight, and washed several times with distilled water.

\subsubsection{SDS molecular weight markers}

Two types of molecular weight markers were used. A Sigma molecular weight marker contained seven proteins with molecular weights from 14,000 to 70,000. The proteins were bovine serum albumin (MW 66,000), egg albumin (MW 45,000), rabbit muscle glyceraldehyde-3-phosphate dehydrogenase (MW 36,000 ), bovine erythrocyte carbonic anhydrase (MW 29,000), bovine pancreas PMSF treated trypsinogen (MW 24,000), soybean trypsin inhibitor (MW 20,000), and bovine $\propto$-lactalbumin (MW 14,200). The lyophilized mixture, containing 3.5 $\mathrm{mg}$ of protein, was dissolved in $1.5 \mathrm{ml}$ of $2 X$-sample buffer. The mixture was mixed by inversion, and then vortexed for five sec to complete the solubilisation. The mixture was then divided into aliquots of $30 \mu \mathrm{l}$, which were stored at $-20^{\circ} \mathrm{C}$ until required. Aliquots were incubated for $60 \mathrm{sec}$ in a boiling water bath before the application of the markers to the gel. Life Technologies BenchMark ${ }^{\mathrm{TM}}$ prestained protein ladders contained ten proteins ranging from approximately 10 to $200 \mathrm{kDa}$. 


\subsection{Sample preparation for MALDI -TOF mass fingerprinting}

All preparations were carried out in a laminar flow hood, wearing latex gloves and using MilliQ water and high quality Eppendorf Safe Lock tubes.

\subsubsection{Coomassie blue stained gels}

Approximately $2 \mathrm{~mm}$-sided triangular pieces of gel were cut from the spots to be identified. Spots were cut using a sharp scalpel blade avoiding overlaps between adjacent spots. The gel pieces were transferred to $0.5 \mathrm{ml}$ Eppendorf tubes. The gel pieces were washed in $100 \mu \mathrm{l}$ of $100 \mathrm{mM}$ ammonium hydrogen carbonate and were vortexed for $10 \mathrm{~min}$. The wash solution was then discarded carefully so that the gel pieces were retained. The gel pieces were destained in 50-100 $\mu \mathrm{l}$ of $100 \mathrm{mM}$ ammonium hydrogen carbonate / acetonitrile (DNA Synthesis Grade, Perkin Elmer, USA) (1:1 by vol.) by vortexing for $30 \mathrm{~min}$. The destain solution was discarded and the destain process was repeated 2-3 times until the Coomassie blue colour disappeared from the gel pieces. The destain solution was then removed and the gel pieces were dried in a centrifugal concentrator (Labconco centrevap concentrator, Kansas, Missouri, USA) for 30 $\min$ at $45{ }^{\circ} \mathrm{C}$. The gel pieces were swollen in $20 \mu \mathrm{l}$ of $100 \mathrm{mM}$ ammonium hydrogen carbonate, and the reswollen gel pieces were crushed with a pipette tip. Two microlitre $(0.5 \mu \mathrm{g})$ trypsin (modified sequencing grade, Roche Diagnostic GmbH Mannheim, Ge1100-mM) in $100 \mathrm{mM}$ ammonium hydrogen carbonate was added to each Eppendorf tube containing the crushed gel pieces. Each digest tube was capped and incubated in a heating block overnight at 37 ${ }^{\circ} \mathrm{C}$. The digestion solution was then transferred to a fresh $0.5 \mathrm{ml}$ Eppendorf 
tube, excluding the gel pieces. Residual peptide in the remaining gel pieces in the original tubes was then extracted with $20 \mu$ l of $0.5 \%$ TFA - acetonitrile (1:1) with vortexing continuously for $10 \mathrm{~min}$. The supernatant solution from the extracted gel pieces was added to the previous extracts. Care was taken not transfer any of the gel pieces. The combined extracts were lyophilised to dryness by vacuum centrifugation for $1 \mathrm{~h}$ at $45^{\circ} \mathrm{C}$. The residue was then resuspended in $10 \mu$ of $0.5 \%$ TFA for MALDI.

\subsubsection{MALDI-TOF plate preparation and sample crystallisation}

PerSeptive Biosystems 100 well MALDI-TOF plates were cleaned with Analar acetone (BDH, Poole, England). The rest of the washing process consisted of a few sec wash in a 1:50 dilution of RBS-35 detergent (Pierce, Biotechnology, Rockfield, IL, USA) followed by a gentle rub with a Kimwipe (Kimberly-Clark, Australia, NSW). The plate was then washed with water, followed by MilliQ water $(2 x)$ and dried with a Kimwipe. Finally the plate was washed with Analar acetone for few sec and was left to air dry in the laminar flow hood.

The matrix solution was $10 \mathrm{mg} / \mathrm{ml} \alpha$-cyano-4-hydroxycinnamic acid (CHCA) in acetonitrile, $0.5 \%$ TFA (1:1 by vol.). This mixture was vortexed for a minute and centrifuged in a Sigma microfuge at $1000 \mathrm{rpm}$ for a minute. Two $\mu$ of CHCA matrix supernatant and $2 \mu$ of the resuspended tryptic lyophilisate were mixed in a new Eppendorf tube and vortexed for a few sec. Care was taken to keep the Eppendorf cap closed to prevent evaporation. One $\mu$ of the matrixprotein solution was spotted in duplicate onto the MALDI-TOF plate. The spots were spread out to facilitate quicker drying and crystallisation. An external 
calibration mixture was made by mixing $1 \mu \mathrm{l}$ of angiotensin $1 \mathrm{~m} / \mathrm{z} 1296.68$ and ACTH peptide $18-39 \mathrm{~m} / \mathrm{z} 2465.20$ with $20 \mu \mathrm{CHCA}$ matrix. One $\mu \mathrm{l}$ of the mixture was spotted close to the sample spots on the MALDI-TOF plate.

\subsubsection{Sample purification with ZipTips ${ }^{\mathrm{TM}}$}

To clean and concentrate the samples for MALDI-TOF, C 18 $_{18}$ ZipTips $^{\text {TM }}$ (Millipore Corporation, Bedford, MA, and USA) were used. One ZipTip ${ }^{\mathrm{TM}}$ was $^{\text {win }}$ used for each sample. The ZipTip ${ }^{T M}$ was washed in the following order with 10 $\mu \mathrm{l}$ of $\mathrm{ACN}, 10 \mu \mathrm{l}$ of ACN: $0.1 \%$ TFA (1:1 by vol.), $10 \mu \mathrm{l}$ of $0.1 \%$ TFA and again with $10 \mu \mathrm{l}$ of $0.1 \%$ TFA. Eight $\mu$ l of the re-suspended tryptic digested in $0.5 \%$ TFA was sucked up and down the tip several times to allowed the sample to bind to the $\mathrm{C}_{18}$ matrix. The ZipTip ${ }^{\mathrm{TM}}$ was washed with $10 \mu \mathrm{l}$ of $0.1 \%$ TFA three times. Finally 2 to $3 \mu \mathrm{l}$ of $\mathrm{CHCA}$ matrix solution was sucked up and down the ZipTip $^{T M}$ several time to elute the peptide, and then approximately $1 \mu$ spots were spotted onto a MALDI -TOF plate.

\subsubsection{MALDI-TOF Mass Spectrometry}

The examination of samples was carried out using a PerSeptive Voyager$D^{T}{ }^{T M}$ PRO Biospectrometry ${ }^{T M}$ Workstation (MALDI-TOF mass spectrometer). A U.V. laser beam was used to ionise the peptides crystallised in the matrix prior to time-of-flight (TOF) based separation, which is proportional to the mass/charge ratio $(\mathrm{m} / \mathrm{z})$ of the peptides. Spectra were collected using positive ion mode, with use of the reflector to increase mass accuracy and the mass gate set at 500 Da to exclude low mass matrix ions. 


\subsubsection{Analysis of MALDI -TOF spectra}

Analysis of the spectra was carried out using PerSpective Biosystem Data Explorer Version 3.4 software. Sample and calibration peptide (angiotensin and ACTH peptides were collected within 1-2 min of each other. External calibration using the external standards was applied to the peptide mass fingerprint spectra. The trypsin autolysis peaks in the peptide digest were checked (expected $\mathrm{m} / \mathrm{z} 2163.05$ and 2273.15 ) to monitor mass accuracy, and if necessary these peaks were also used for internal calibration of the spectra. Peak detection was set for peaks greater than $5 \%$ of the highest peak intensity. The ion $\mathrm{m} / \mathrm{z}$ values were cut and pasted into the protein identification tool ProFound (http://129.85.19.192/profound bin/WebProfound.exe) and were used for mass fingerprint identification, using the SWISS-PROT and NCBInr databases. Proteins were identified using the databases of mammalian proteins. The tolerance of the monoisotopic input masses was set to $0.1 \mathrm{Da}$ and the number of allowed missed cleavages was 2. The primary criteria that were used to asses the likelihood of correct identification included the Probability and $Z$ scores, the difference in probability of the first and second matches and percent coverage of sequence. A Z score of 1.65 means the search is in the $95^{\text {th }}$ percentile, while a score of 2.33 is in the $99^{\text {th }}$ percentile (http://129.85.19.192/profound/help.htm|\#ZSCORE). Secondary criteria included comparison of the predicted and observed $\mathrm{pl}$ and mass and information about the known tissue distribution of the matched proteins. 


\section{$\underline{2.6 \text { Immunoblotting techniques (Western blotting) }}$}

Sheep liver microsomes were analysed by Western blotting (Towbin et al., 1979). Dexamethasone induced rat liver microsomes containing P-450 3A1 were used as a positive control for cytochrome P-450. 1-D SDS-PAGE was performed in a Bio-Rad mini-electrophoresis cell for $45 \mathrm{~min}$, at a constant of 200 Volts in $12 \%$ polyacrylamide gels, as previously described in Materials and Methods. The sandwich was then disassembled and removed from the glass, after removing and discarding the stacking gel. The gels were then equilibrated for $30 \mathrm{~min}$ at room temperature in the transfer buffer $\left(0.5 \mathrm{M} \mathrm{Na}_{2} \mathrm{HPO} 4\right.$ with $0.5 \mathrm{M}$ $\mathrm{NaH}_{2} \mathrm{PO} 4$ made up to 2 litre with $1900 \mathrm{ml}$ distilled water, $\mathrm{pH}$ adjusted to 6.6) to remove the excess SDS detergent, and to prevent a change in the size of the gel during the transfer. The transfer of protein to the nitrocellulose paper was adopted from the method of Towbin et al. (1979). The blotting chamber was filled with transfer buffer after the $\mathrm{pH}$ was adjusted to 6.6. The electrophoretic transfer was accomplished at 999 Volts and a constant current of $200 \mathrm{~mA}$, for 16 $-18 \mathrm{~h}$ in a cold room $\left(4^{\circ} \mathrm{C}\right)$. After the electrophoresis transfer was completed, the SDS-gel was stained with Coomassie blue R-250 to asses the completeness of the transfer. Also one of the nitrocellulose papers was stained with $0.1 \%$ Amido black in $10 \%$ methanol/ $2 \%$ glacial acetic acid (v:v) to detect protein.

\section{$\underline{\text { 2.6.1 Immunoprobing with HRP conjugated secondary antibody }}$}

After electrophoretic transfer to the nitrocellulose membrane, the immobilized proteins were probed with specific antibodies to identify any antigens present. The procedure for immunoblotting was started by immersing 
the nitrocellulose membrane in $5 \%$ skimmed milk blocking buffer and it was incubated for one $\mathrm{h}$ at room temperature, on a shaker, to fill all protein-binding sites with a non-reactive protein. The nitrocellulose membrane was then washed with TBS-Tween-20 buffer (50 mM Tris, $0.15 \mathrm{M} \mathrm{NaCl}, 0.1 \%$ Tween 20 , distilled water, $\mathrm{pH}$ 7.6) for 2 times quick wash and then 2 times for 10 min each. Next to identify the cytochrome P-450 the membrane was treated with a solution containing the primary antibody (anti-human cytochrome p450 3A4) polyclonal Rabbit IgG, at a dilution of $1 / 1000$ in TBS-Tween-20 buffer and it was incubated with this primary antibody for approximately one $\mathrm{h}$. After the one $\mathrm{h}$ incubation the blotted membrane was washed as before, with TBS-Tween-20 buffer, and then incubated with the secondary antibody for one h (HRP conjugated goat antiRabbit IgG) from Vector Laboratories, at a dilution of $1 / 1000$. Finally, after discarding the secondary antibody, the blotted membrane was washed with TBS-Tween-20 buffer, and the bound antigens were visualised by using a mixture of chromogenic substrate which consisted of $3 \mathrm{ml}(3 \mathrm{mg} / \mathrm{ml}) 4$-chloro-1naphthol (Bio-Rad Laboratories) solution, $9 \mathrm{ml}$ of TBS-Tween-20 buffer and 150 $\mu$ of $1 \%$ hydrogen peroxide. The membrane was incubated with the chromogenic solution for $30 \mathrm{~min}$ at room temperature to develop a purple colour at the site of immunoreactive antigens. Detection of immunoreactive cytochrome P-450 was also achieved by using enhanced chemiluminescence with reagents from Amersham Life Science.

\subsection{Computerised densitometry}

\subsubsection{Gel scanning}


Colloidal Coomassie blue G-250 stained proteins on polyacrylamide gels were scanned using a Molecular Dynamics model 375A laser densitometer. The scanned gels were analysed using Molecular Dynamics ImageQuant ${ }^{\mathrm{TM}}$ software version 4.2

\subsubsection{Image display}

The ImageQuant software displays the scan image of gels showing the position of each detected band or protein spot. Each pixel of the display contains densitometric absorbance information corresponding to the amount of protein staining at that position. Scanned images were manipulated by setting the lowest absorbance range to remove the background, and setting the higher absorbance ranges to maximise spot detection. Images of gels were often magnified two to four fold so that the perimeters of protein spots could be most clearly defined for quantitation. To obtain the most suitable absorbance range, image tools were used to measure the lowest and highest points of absorbance in the area of interest of the scanned image.

\subsubsection{Drawing tools and integration}

Several ImageQuant tools were used to define scanned images of protein spots for quantitation. For differentiation of proteins separated by 1-D PAGE, a line tool was used to mark the regions of interest. The marked regions were scanned using the attribute manager method of imageQuant ${ }^{\mathrm{TM}}$ software version 4.2. The width of the scanned region for each lane of the sample was selected to be 20 pixels. For analysis of proteins separated by 2-D PAGE, each gel was divided into 5 rectangles, using a grid tool, and the individual protein spots, or 
groups of proteins, were visualised in each rectangle and their borders were defined using the ellipse drawing tool. The protein spots were generally numbered in the order of molecular weight and $\mathrm{pl}$ from upper left to lower right.

Quantitative analysis of proteins contained within the selected ellipses was carried out using the method recommended by the suppliers of the software. Integrated volumes were calculated using the 'volume report' option with background calculated as the local average (the average absorbance at each pixel in the perimeter of the object line). The results of the analysis were saved and transferred to Excel for further analysis.

\subsubsection{Quantitative analysis of 2-D gels}

The amount of each selected protein was calculated as described above. The abundance of each protein was expressed as a percentage of the total abundances of all proteins measured on the gel. This method was used to minimise variation due to differences in the amount of protein loaded on different gels or to differences in staining.

\subsection{Protein assays}

Protein concentrations in liver homogenates and in microsomal and cytosolic preparations were determined using the colorimetric method of Petersen (1977). Samples containing homogenate or soluble fractions in distilled water (total volume 1 $\mathrm{ml}$ ) was mixed with $2 \mathrm{ml}$ of copper-tartrate-carbonate (CTC): $(0.1 \%$ (w/v) copper sulphate, $0.2 \%(\mathrm{w} / \mathrm{v})$ potassium sodium tartrate, $10 \%(\mathrm{w} / \mathrm{v})$ sodium carbonate), $0.8 \mathrm{M}$ sodium hydroxide, $10 \%$ SDS and distilled water in the ratio 1:1:1:1. After ten $\min 1 \mathrm{ml}$ of Folin-Ciocalteu reagent was added and the tubes were mixed and incubated for 30 
min at room temperature. Absorbance was measured at $750 \mathrm{~nm}$ and the amount of protein was calculated by reference to standards containing up to $200 \mu \mathrm{g}$ of bovine serum albumin.

\subsection{Spectrophotometric determination of cytochrome P-450 concentrations}

Cytochrome P-450 was measured as the carbon monoxide difference spectra using an E450-490 value of $91 \mathrm{mM}^{-1} \mathrm{~cm}^{-1}$ (Omura and Sato, 1964). Liver microsomal fractions and sub-fractions were diluted in $0.1 \mathrm{M}$ potassium phosphate buffer $\mathrm{pH} 7.4$, containing $20 \%(\mathrm{v} / \mathrm{v})$ glycerol to $2 \mathrm{mg}$ protein per $\mathrm{ml}$. Two $\mathrm{ml}$ aliquots of the diluted samples were added to test sample and reference cuvettes, and a base line was recorded between 400 and $500 \mathrm{~nm}$. Reduction was achieved by the addition of a few grains of solid sodium dithionite to both test and reference cuvettes, with gentle stirring, and the test sample cuvette was gently bubbled with carbon monoxide for approximately one minute. Difference spectra were measured from $400-500 \mathrm{~nm}$.

\subsection{Spectrophotometric determination of NADPH cytochrome c reductase activity in sheep hepatic microsomal fractions}

Sheep liver microsomal fractions (60 $\mu \mathrm{g}$ protein) were incubated in $3 \mathrm{ml}$ of $72 \mathrm{mM}$ Tris- $\mathrm{HCl} \mathrm{pH} 7.4$ containing $1.25 \mathrm{mg}$ cytochrome c. Reactions were started by the addition of $25 \mu \mathrm{l}$ of $0.5 \mathrm{M} \mathrm{NADPH}$ to the test cuvette, and the absorbance was measured at $550 \mathrm{~nm}$ in a Cary ${ }^{\circledR} 1 \mathrm{E}$ spectrophotometer. Enzyme activities were calculated using an extinction coefficient of $19.6 \mathrm{mM}^{-1}$ $\mathrm{cm}^{-1}$ for the calculation of cytochrome $\mathrm{c}$ reduction. 


\subsection{Enzyme assays for cytochrome P-450}

\subsubsection{Assay for 4-nitroanisol O-demethylase activity}

Sheep liver microsomal aliquots $(0.1 \mathrm{ml})$ were added to $2 \mathrm{ml}$ of $0.1 \mathrm{M}$ Tris$\mathrm{HCl} \mathrm{pH} 7.4$, and incubated at $37^{\circ} \mathrm{C}$ for 2 min in a heating block (Techne Dri-block DB-1) in $5 \mathrm{ml}$ glass test tubes. One $\mathrm{ml}$. of NADPH generating cofactor solution, containing $0.1 \mathrm{M}$ Tris- $\mathrm{HCl} \mathrm{pH} 7.4,0.15 \mathrm{M} \mathrm{MgCl}_{2}(1 \mathrm{ml}), 0.5 \mathrm{M}$ nicotinamide (1 ml), 40 mg glucose-6-phosphate, glucose-6-phosphate dehydrogenase (40 units), and NADP ( $8 \mathrm{mg}$ ) was added to the mixture above. Finally $10 \mu \mathrm{l}$ of the substrate $500 \mathrm{mM}$ 4-nitroanisole was added to initiate the reaction and the mixture was incubated for $15 \mathrm{~min}$ at $37^{\circ} \mathrm{C}$. The blank incubation was prepared as above but without the microsomal solution. The reaction was terminated by the addition of $1 \mathrm{ml}$ ice cold $20 \%$ TCA solution and the mixture was allowed to stand on ice for $5 \mathrm{~min}$. The mixture was then centrifuged to obtain a clear supernatant, using a bench centrifuge at maximum speed for $5 \mathrm{~min}$. One $\mathrm{ml}$ of the supernatant was added to $50 \mu \mathrm{l}$ of $10 \mathrm{M} \mathrm{NaOH}$ and the absorbance of the released 4-nitrophenol was measured at $400 \mathrm{~nm}$. Enzyme activity was calculated by reference to a standard curve for 4-nitrophenol (Figure 3.8).

\subsubsection{Assay for aminopyrine $\mathrm{N}$-demethylase activity}

Incubation was as for the 4-nitroanisole O-demethylase assay except that $0.1 \mathrm{M}$ semicarbazide was present to trap the $\mathrm{HCHO}$ product of the reaction and the substrate was $0.2 \mathrm{mM}$ aminopyrine. The incubation period for the reaction was $30 \mathrm{~min}$ at $37^{\circ} \mathrm{C}$. The reaction was stopped by adding $0.5 \mathrm{ml} 25 \% \mathrm{ZnSO}_{4}$ solution followed by $0.5 \mathrm{ml}$ of saturated $\mathrm{Ba}(\mathrm{OH})_{2}$ solution and stored on ice for 5 
min. The sample then was centrifuged at $2000 \mathrm{~g}$ for $5 \mathrm{~min}$ using a Sorvall RC 5B centrifuge. Finally $1 \mathrm{ml}$ of the clear supernatant was added to $2 \mathrm{ml}$ of Nash reagent $(30 \mathrm{~g}$ ammonium acetate mixed with $0.4 \mathrm{ml}$ of acetylacetone made up to $100 \mathrm{ml}$ with distilled water), mixed well and left to incubate for $30 \mathrm{~min}$ in sealed tubes at $60^{\circ} \mathrm{C}$ in a heat block (Techne Dri-block ${ }^{(} \mathrm{DB}-1$ ). Released formaldehyde was measured at $415 \mathrm{~nm}$ by reference to a standard curve constructed from $0.1 \mathrm{mM}$ formaldehyde (Figure 3.10).

\subsection{HPLC assay for the metabolism of sporidesmin by cytochrome P-450}

HPLC was used to measure the interactions of sporidesmin as a substrate with sheep liver cytochrome P-450 enzyme in the presence of NADPH as cofactor. The assay was carried out in a total volume of $0.32 \mathrm{ml}$. The mixture contained $0.2 \mathrm{ml}$ of $0.1 \mathrm{M}$ Tris- $\mathrm{HCl}$ buffer $(\mathrm{pH} 7.4), 10 \mu \mathrm{l}(1 \mu \mathrm{g})$ of sporidesmin in ethanol and $0.1 \mathrm{ml}$ of NADPH cofactor mixture. The cofactor was made of 4.25 $\mathrm{ml}$ of $0.1 \mathrm{M}$ Tris- $\mathrm{HCl}$ buffer $\mathrm{pH} 7.4,0.5 \mathrm{ml}$ of $0.15 \mathrm{M} \mathrm{MgCl}_{2}, 50 \mu \mathrm{l}$ of $0.5 \mathrm{M}$ nicotinamide, $20 \mathrm{mg}$ of glucose-6-phosphate, $120 \mu \mathrm{ll}$ (1 unit) of glucose-6phosphate dehydrogenase and finally $4 \mathrm{mg}$ of $\mathrm{NADP}^{+}$. The cofactor mixture was prepared and kept on ice until used. The assay was started by adding $10 \mu \mathrm{l}$ of sheep liver microsome fraction containing $70-80 \mu \mathrm{g}$ protein, to the mixture assay, and was incubated for 30 min at $37^{\circ} \mathrm{C}$, using a thermostatic control heat block (Techne Dri-block ${ }^{\circledR}$ ). At the end of 30 min incubation, the enzyme reaction was stopped by adding $0.5 \mathrm{ml}$ of ethanol (95\%) to each assay tube. The assay mixture was then mixed well by using a vortex mixer for a few sec and the mixture in each tube was transferred to an Eppendorf tube and centrifuged for 5 min at $1000 \mathrm{~g}$ in a Biofuge $\mathrm{A}$ microcentrifuge (Heraeus Sepatech). The 
centrifuged mixtures were then filtered using $0.4 \mu \mathrm{m}$ polypropylene disposable filters, before analysis by HPLC.

HPLC was carried out on a $5 \mu \mathrm{m}$ C18 Microsorb MV column (Rainin, Waters, MA) with a dimension of $240 \times 4 \mathrm{~mm}$ using a Waters (600 E) instrument. Aliquots of the reaction mixture $(100 \mu \mathrm{l})$ were analysed at a flow rate of $1 \mathrm{ml} \mathrm{min}{ }^{-1}$ using acetonitrile: water (1:1) as the eluting solvent. Detection was by UV absorption at 230 and $260 \mathrm{~nm}$ using a Waters $490 \mathrm{E}$ detector.

\section{$\underline{2.13 \text { GST assays }}$}

Spectrophotometric measurement of GSTs was carried out in a Cary ${ }^{\circledR} 1 \mathrm{E}$ spectrophotometer using $3 \mathrm{ml}$ assay systems at $25^{\circ} \mathrm{C}$. Liver 100,000 $\mathrm{g}$ supernatant (cytosol fraction) was used as a source of GST and controls from which GSH or enzyme were omitted were carried out. Both sporidesmin and the synthetic substrates CDNB, DCNB, p-NBC and EPNP (see abbreviations) were used to test for differences in activity of various GST isoforms. Assays using the synthetic substrates were carried out as described by Habig and Jakoby (1981) (Table 1.3).

\subsubsection{Assays with synthetic substrates}

GST activity with DCNB as substrate was measured in $0.1 \mathrm{M}$ phosphate buffer $\mathrm{pH} 7.5$, using $1 \mathrm{mM}$ DCNB and $1 \mathrm{mM} \mathrm{GSH}$. Absorbance changes were measured at $345 \mathrm{~nm}$. Enzyme activity was measured after addition of $50 \mu \mathrm{l}$ of liver cytosolic fraction containing $40-50 \mu \mathrm{g}$ protein. Blank reactions from which enzyme was omitted were subtracted from the enzyme rates for activity 
calculation. Specific activities were calculated by dividing enzyme activity by the amount of protein measured as described in section 2.7 .

Assay conditions for other substrates were:

CDNB - $1 \mathrm{mM}$ CDNB, $1 \mathrm{mM} \mathrm{GSH}, 0.1 \mathrm{M} \mathrm{pH} 6.5$ phosphate buffer, $340 \mathrm{~nm}$.

EPNP - $0.5 \mathrm{mM}$ EPNP, $1 \mathrm{mM}$ GSH, $0.1 \mathrm{M} \mathrm{pH} 6.5$ phosphate buffer, $360 \mathrm{~nm}$.

p-NBC - 1 mM p-NBC, 1 mM GSH, 0.1 M pH 6.5 phosphate buffer, $310 \mathrm{~nm}$.

\subsubsection{Spectrophotometric analysis of sporidesmin metabolism by liver cytosolic} fraction.

To directly investigate the metabolism of sporidesmin by sheep liver cytosolic fraction $50 \mu \mathrm{l}$ of liver $100,000 \mathrm{~g}$ supernatant was incubated in $3 \mathrm{~m} /$ of $0.1 \mathrm{M}$ potassium phosphate buffer $\mathrm{pH} 7.5$ containing $5 \mathrm{mM}$ GSH. Ten $\mu \mathrm{l}$ of an ethanol solution containing $1 \mu \mathrm{g}$ sporidesmin was added to the mixture. The reaction was carried out at $25^{\circ} \mathrm{C}$ and absorbance change was measured between 220 and $280 \mathrm{~nm}$.

\section{$2.14 \mathrm{GSH}$ dependent metabolism of sporidesmin}

Sheep liver $100,000 \mathrm{~g}$ supernatant fractions (50 $\mu \mathrm{g}$ protein) were incubated at $37^{\circ} \mathrm{C}$ in $2.25 \mathrm{ml}$ of $0.1 \mathrm{M}$ phosphate buffer $\mathrm{pH} 7.4$ in the presence or absence of $5 \mathrm{mM} \mathrm{GSH}$ and $1 \mu \mathrm{g}$ sporidesmin. After $30 \mathrm{~min}$ the reaction was stopped by cooling in ice and $100 \mu \mathrm{l}$ aliquots were used for HPLC on the C18 Rainin column. Elution was carried out using acetonitrile - Milli-Q water (1:1) at a flow rate of $1 \mathrm{ml} \mathrm{min}^{-1}$. 


\section{$\underline{2.15 \text { Histopathology }}$}

Liver tissue samples were collected immediately after the sheep were killed and before autolysis could take place. All tissues taken were placed, within 10 min of slaughter, in $10 \%$ formalin as a fixative solution, and left for $24-48 \mathrm{~h}$ in the fixative before processing. Two changes of the fixative were made on subsequent days. Small pieces, $1-2 \mathrm{~cm} \times 2-3 \mathrm{~cm}$, were selected for slide preparation. The tissues were passed through a series of alcohol solutions for complete dehydration and then through a clearing agent, before embedding in paraffin. Thin $(5-6 \mu \mathrm{m})$ paraffin sections were cut using a microtome. The thin slices of tissue were floated on water and were picked up on slides and dried for staining. Paraffin-wax slide sections of the chosen tissues were stained using the Ehrlich haematoxylin and eosin stain.

\subsection{Statistical analysis}

Statistical analysis was carried out by Edith Hodgen of the Department of Mathematics and Computing Science, Victoria University of Wellington. Initially a linear model, including interaction effects, was fitted to test for the effect of dose, resistance and year on enzyme activities among the four experimental groups - undosed and dosed, susceptible and resistant Romneys. Such models require an assumption of normality and constant variance (homocedasticity). An examination of the residuals for the analyses for each of the untransformed response variables indicated that these assumptions could not be substantiated, and by using a combination of trial and error, examination of the residuals, and an algorithm for the selection of a suitable transformation given on page 11-34 
of "S-PLUS guide to Statistical and Mathematical Analysis", 1995, Stat. Sci division, MathSoft, Inc, Seattle, Washington, it was determined that suitable transformations were as follows:

\begin{tabular}{ll} 
Variable $(y)$ & Transformation $f(y)$ \\
\cline { 2 - 2 } $\begin{array}{l}\text { O-demethylase } \\
\text { N-demethylase }\end{array}$ & inverse square root $f(y)=1 / \sqrt{y}$ \\
EPNP & similar to O-demethylase \\
& undosed 97 samples only, so non parametric 2-sample \\
& test used. \\
p-NBC & inverse square root: $f(y)=1 / \sqrt{y}$ \\
CDNB & $\log$ (natural): $f(y)=\ln (y)$ \\
DCNB & no transformation used. \\
GST- sporidesmin & $\log$ (natural): $f(y)=\ln (y)$ \\
& inverse square root: $f(y)=1 / \sqrt{y}$
\end{tabular}

In most (but not all) cases the design was unbalanced, as in 1994 and 1995 there were 10 dosed sheep and 10 undosed sheep, but in 1997 there were 6 dosed sheep and 10 undosed sheep. For this reason a general linear model (SPLUS Im function) was used. Once the full model had been fitted and residuals were examined for goodness of fit and found to be acceptable, the interaction terms in the model were examined. In those cases where the interaction was not significant, it was removed from the model and a reduced main - effects model was fitted. This process was repeated and any non-significant main effects that were not involved in an interaction term retained in the model were also removed. A new model was then fitted. For some of the variables, a simple main effect remained in the model (this was always the case for EPNP) and in this case, because of the possible violation of the assumptions of normality and homoscedasticity, a non parametic test requiring fewer 
assumptions but having almost equal power was performed. For those response variables for which several years of data were available, and where there appeared to be differences of some sort across the years an equivalent analysis was done within each year where first a model including interaction was fitted and this model was then simplified by removing any effects that were not significant.

\subsubsection{Test of resistant vs susceptible where the interaction was significant}

In the tests where the interaction between dose and resistance was significant, such as in O-demethylase, and where the year 1997 was included in the analysis (so that the design of the experiment was unbalanced), tests to determine which categories of animals had significantly different results were non-standard. Because of the lack of balance, the pair-wise post hoc tests for difference between the resistant and susceptible animals were conducted within each of the dosed and undosed groups.

To maintain an experiment - wise significance level of at most $5 \%$, a Bonferroni correction was made to the significance level used for individual tests. Thus the individual test significance zero level was $2.5 \%$, and the experiment - wise significance level was at least $5 \%$.

The method employed to conduct the pair-wise tests was to fit a complete model, in which the means of the four combinations of the factor levels (dosed resistance, dosed susceptible, undosed resistance, undosed susceptible) were allowed to be different, and a reduced model in which the two means (resistant and susceptible sheep) of the undosed sheep were assumed to be equal. The difference between the Error Sums of Squares of the two models is the Sum of Squares due to the difference between resistant and susceptible sheep, and an 
F-test was used to test the statistical significance of this (the Error Mean Square from the complete model was used in the denominator of the F-statistic). The same method was used to test for a difference between the resistant and susceptible dosed sheep, in which the two means for dosed sheep were assumed to be equal in the reduced model. 


\section{CHAPTER III}

\section{RESULTS}

\subsection{Liver histology in sheep experimentally dosed with sporidesmin}

The effects of toxins include cellular degeneration, cell death by necrosis and apoptosis. Toxins have a tendency to affect certain organs and types of cells. They often cause acute or chronic damage by modification of cell metabolism and function in subtle ways that take some time to develop, or by outright destruction of organelles and cells. The susceptibility of animals to toxic compounds is often related to age, sex, species and strain, as well as the activities of enzymes that detoxify the particular compounds.

Mortimer (1963) carried out a histological study of orally dosed sheep. He found lesions similar to those in animals affected naturally with facial eczema. The hepatic cells of dosed animals showed vacuolation in the periportal zone of the lobules. Oedema with signs of epithelial degeneration of the medium and large bile ducts was accompanied by lymphocytic infiltration. There was focal necrosis involving small groups of cells with lymphocytes, polymorphonuclear leucocytes, fibroblasts and histiocytes that were the prominent inflammatory cells. In smaller portal tracts bile ductule proliferation, which was often associated with the canals of Herring, seemed to destroy and replace the isolated liver cells. Kupffer cells were swollen and contained bile pigments and similar lesions were also found in the large portal tract regions. Bhathal et al. (1990) found that there were relatively few changes among parenchymal cells two days after dosing mice with sporidesmin. 
Mortimer (1963) reported little early damage to hepatocytes in sporidesmin affected sheep. One goal of the current study was to examine sporidesmin induced changes in the expression of enzymes and other proteins in liver that might affect responses of the liver to the toxin. The experimental design therefore included groups of undosed animals and animals dosed for two days, from the resistant or susceptible lines. Two days was chosen so that histological changes due to necrosis, inflammation or repair should be minimal and so that changes in protein expression might reflect initial responses to sporidesmin.

In our study, four groups of Romney lambs were used. The four groups were susceptible, dosed and undosed, and resistant, dosed and undosed. To study the histological changes in liver tissue, animals were dosed with $0.15 \mathrm{mg}$ sporidesmin / $\mathrm{kg}$ body weight for the susceptible line and $0.35 \mathrm{mg}$ sporidesmin / $\mathrm{kg}$ body weight for the resistant line. The dosed groups were killed two days after dosing.

\subsubsection{Undosed Romneys}

No pathological changes were found in liver from undosed susceptible sheep (Figures 3.1 and 3.2). The livers contained normal polygonal intact hepatocytes with a clear boundary of cytoplasm. The hepatocytes surrounding the central vein showed the normal fashion of hepatic cords (Figure 3.1) with clear rounded nuclei. The nuclei of the hepatocytes were centrally located. No vacuolation was found in the cytoplasm of the hepatocytes. Figure 3.2 shows the portal region with normal bile ducts and a slightly dilated portal vein. A few inflammatory mononuclear and 
red blood cells were noticed in the portal region. Several Kupffer cells were present in the sinusoidal spaces.

Normal hepatocellular architecture was present in the undosed resistant animals (Figures 3.3 and 3.4). The hepatocytes surrounding the central vein showed normal structure with clear, rounded and centrally located nuclei. The sinusoidal spaces showed normal outlines. The endothelial cells of the central veins also showed normal arrangement in the tunica intima layers. No fibrosis or bile duct proliferation was observed in the portal region (Figure 3.4).

\subsubsection{Dosed Romneys}

Histological examination of the livers from dosed susceptible animals showed moderate pathological lesions two days after sporidesmin dosing. The lesions were mild vacuolation of hepatic cells mainly in the area surrounded the portal vein (Figure 3.5). The portal vein was dilated with some exudate that occupied the central part of the portal vein as shown in Figure 3.5. No proliferation of bile ducts was observed. No pathological change was detected in sections from liver of dosed resistant animals. The minimal histological change observed in livers from the dosed animals indicates that any protein changes detected later in this thesis were not responses to major cellular injury. 


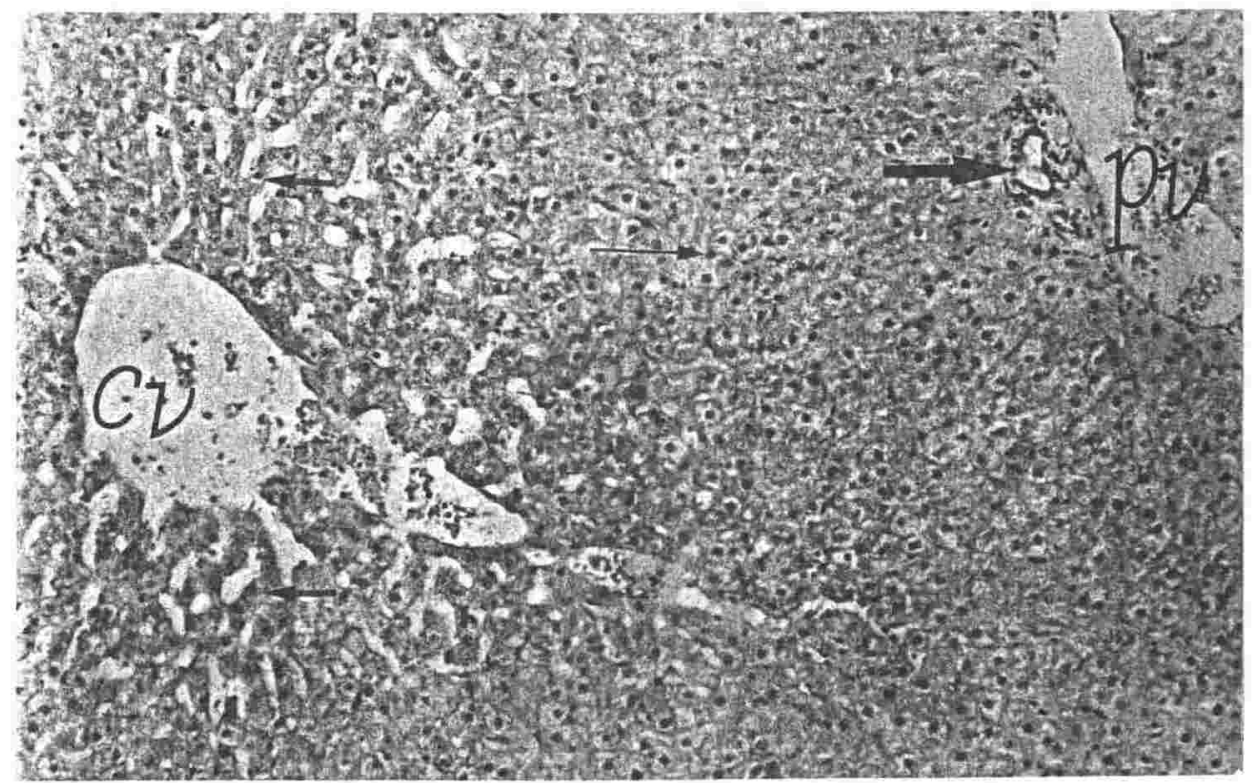

Figure 3.1: H \& E stained section of Romney liver from an undosed susceptible Romney ( $\times 10 \times 64)$.

The figure shows a central vein (CV) surrounded by normal polygonal hepatocytes (medium arrows).

The hepatocyte nuclei are intact and centrally located (thin arrow). The thick arrow shows a normal bile duct. The portal vein (PV) is dilated with red blood cells.

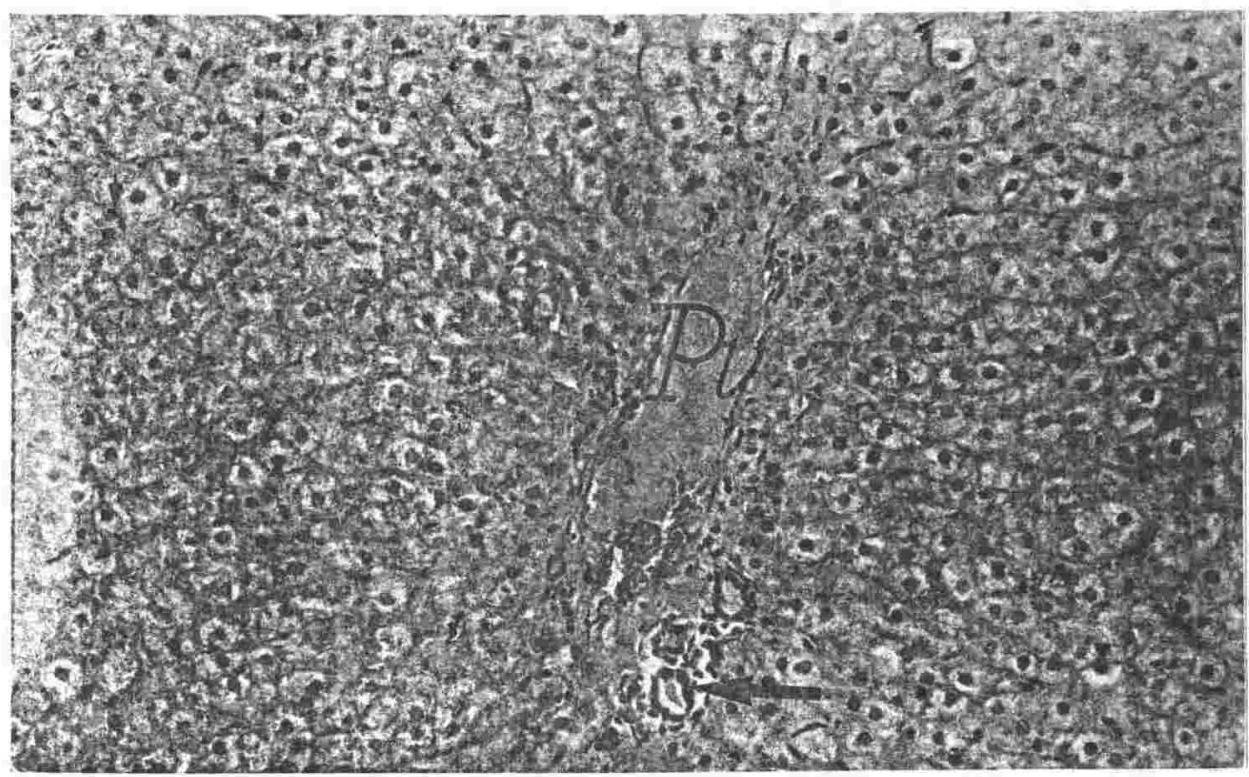

Figure 3.2: $\mathrm{H}$ \& $\mathrm{E}$ stained section of liver from an undosed susceptible Romney (x10 x 65). The figure shows a portal area with a normal bile duct (thick arrow). The portal vein (PV) is dilated with a few inflammatory cells. A few Kupffer cells are in the sinusoidal spaces (arrowhead). 


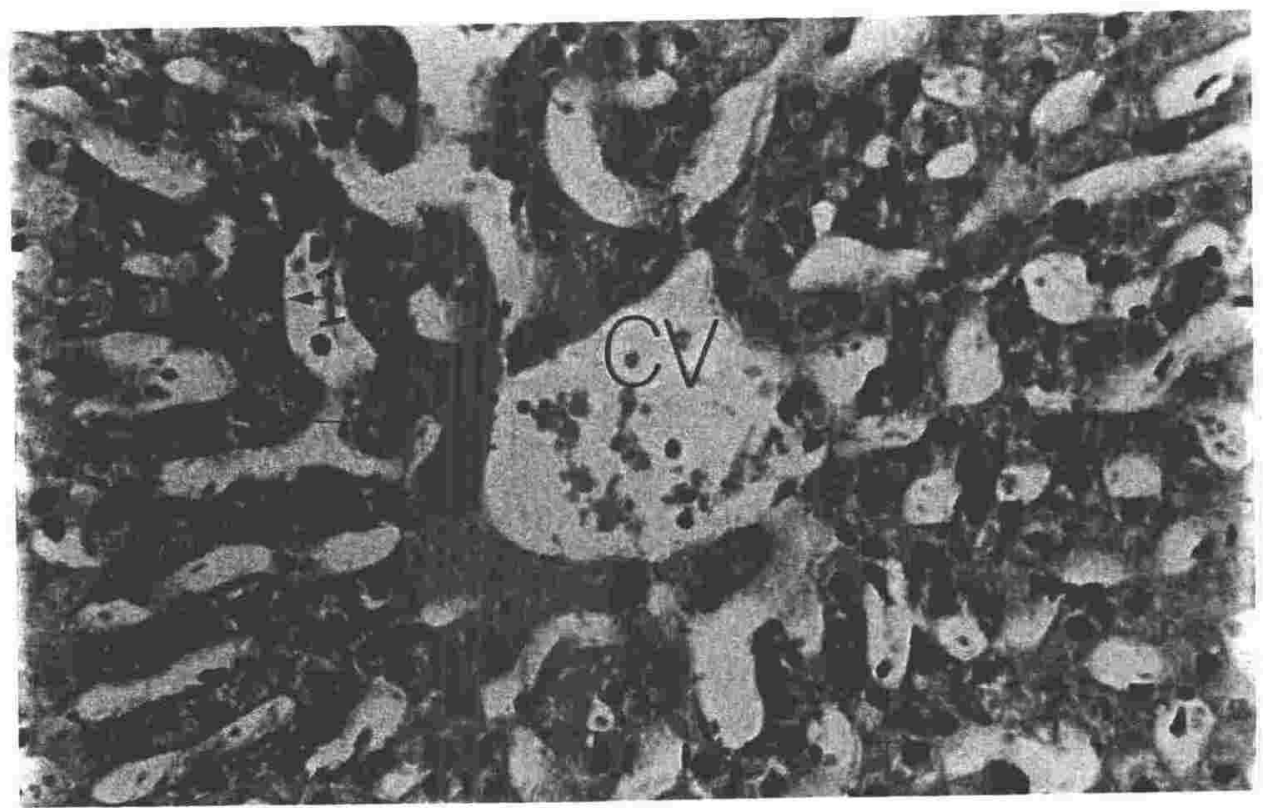

Figure 3.3: $\mathrm{H} \& \mathrm{E}$ stained section of liver from an undosed resistant Romney ( $\times 40 \times 80$ ). The figure shows normal hepatocytes with centrally located nuclei (thin arrow), surrounding the central vein (CV). The sinusoidal spaces show normal outlines (arrow 1).

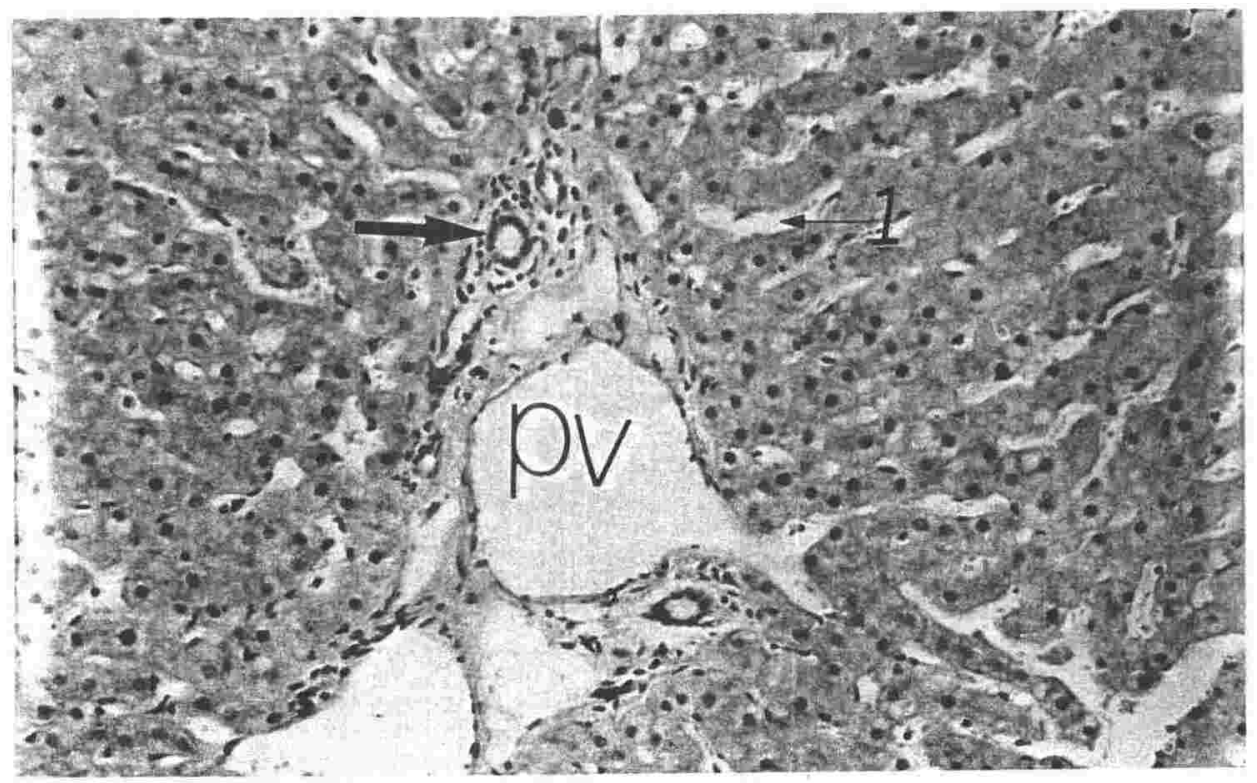

Figure 3.4: H \& E stained section of liver from an undosed resistant Romney (x10 x 91.5). The figure shows a normal portal area containing a normal bile duct (thick arrow) and dilated portal vein (PV). The sinusoidal spaces show normal outlines (arrow 1). 


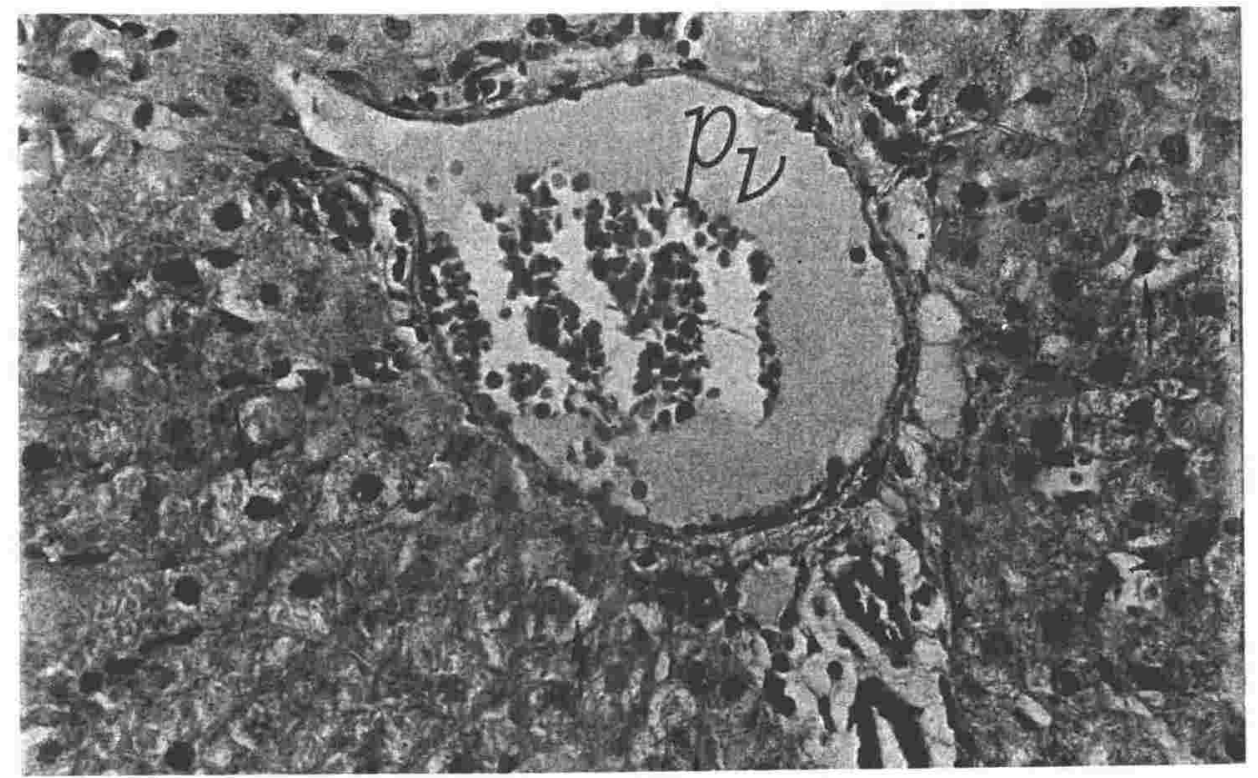

Figure 3.5: H \& E stained section from the liver of a dosed susceptible Romney showing dilated portal vein occupied with some exudate (PV). A few vacuolated cells were present around portal vein (thin arrow). 


\section{$\underline{3.2 \text { Metabolism of sporidesmin by liver microsomes }}$}

Sporidesmin was incubated with liver microsomes, and loss of sporidesmin was measured by HPLC as described in the Methods. Microsomal metabolism of sporidesmin was measured as a reduction in the HPLC peak height for sporidesmin as shown in Table 3.1 and Figure 3.6. Part A of Figure 3.6 shows the HPLC peak from $10 \mu \mathrm{l}(1 \mu \mathrm{g})$ sporidesmin. Part $B_{1}$ and $B_{2}$ shows the HPLC analysis of sporidesmin after incubation with NADPH generating system in the absence of microsomal enzyme. No change in the peak height of sporidesmin was observed after incubation with the cofactor NADPH. Part $\mathrm{C}_{1}$ and $\mathrm{C}_{2}$ shows duplicate analysis of sporidesmin after incubation with microsomal enzyme alone. There was some loss of sporidesmin after incubation with the microsomal fraction alone (Figure 3.6). This result may indicate that microsomal protein could bind or metabolise sporidesmin. There was greater loss of sporidesmin after incubation with microsomal fraction plus NADPH generating system (Part $E_{1}, E_{2}$ ). This result may indicate that adding the NADPH cofactor enhanced the metabolism of sporidesmin. Part $D_{1}$ and $D_{2}$ shows the HPLC analysis from microsomal fraction incubated with NADPH generating system in the absence of sporidesmin.

Analysis of rates of NADPH dependent metabolism of sporidesmin by liver microsomes showed some differences between 1997 born resistant and susceptible animals. Loss of the sporidesmin peak was approximately $0 \%, 8.9 \%, 53.1 \%$, $35.8 \%$ and $11.7 \%$ (mean $=27.4 \%, S D= \pm 21$.) of the original sporidesmin plus microsomes plus NADPH (minus the control) peak height for five undosed resistant 
Romneys, and $36 \%, 11.4 \%, 5.5 \%, 18.6 \%$ and $13.8 \%($ mean $=17.1 \%, S D= \pm 11.6)$ for five undosed susceptible Romneys. Duplicate measurements for each sample varied by less than $10 \%$, for example for animal 7305 (mean loss $53.1 \%$ ) the duplicate values were $46.7 \%$ and $59.4 \%$. The results indicate individual variation in sporidesmin metabolism within the resistant and susceptible Romney lines as shown in Table 3.1 , but no significant difference between the resistant and the susceptible animals.

\begin{tabular}{|c|c|}
\hline $\begin{array}{c}\text { Undosed } \\
\text { resistant samples } \\
\text { Animal }\end{array}$ & $\begin{array}{c}\text { \% of sporidesmin loss } \\
\text { minus cofactor control }\end{array}$ \\
\hline 7182 & 0.0 \\
\hline 7350 & $10.7,7.1$ \\
\hline 7305 & $46.7,59.4$ \\
\hline 7022 & $36.7,34.9$ \\
\hline 7348 & $10.9,12.5$ \\
\hline $\begin{array}{c}\text { Undosed } \\
\text { Animal }\end{array}$ & \\
\hline 7086 & $36.9,35.1$ \\
\hline 7265 & $10.6,12.1$ \\
\hline 7052 & $7.6,3.3$ \\
\hline 7197 & $18.7,18.5$ \\
\hline 7211 & $13.0,14.6$ \\
\hline
\end{tabular}

Table 3.1: Microsomal metabolism of sporidesmin. Results are for duplicate microsomal assays. The \% sporidesmin lost is calculated by comparison of peak heights for measurements in which sporidesmin was incubated with microsomes in the presence or absence of the NADPH generating system. 
An attempt was made to detect possible sporidesmin metabolites that were expected to be more polar and have shorter retention times than sporidesmin. This was difficult because of the large cofactor peak that eluted earlier than sporidesmin. The cofactor peak was 5-10 times larger than the sporidesmin peak and could not be separated from sporidesmin on the C18 column even when the percentage of acetonitrile was decreased to $10 \%$, or removed from the solvent mixture (Figure 3.6a). Potential metabolite peaks were not detected. 


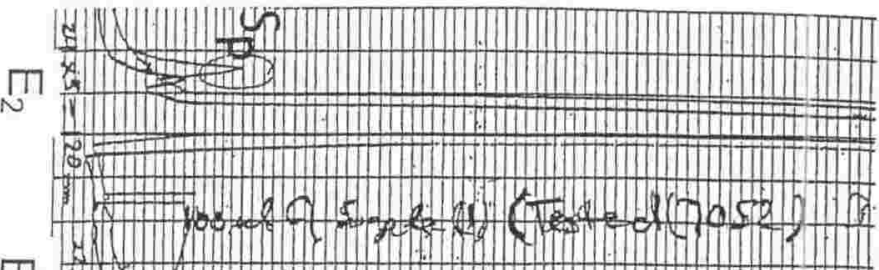

$\underset{\rightarrow}{m}$

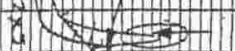

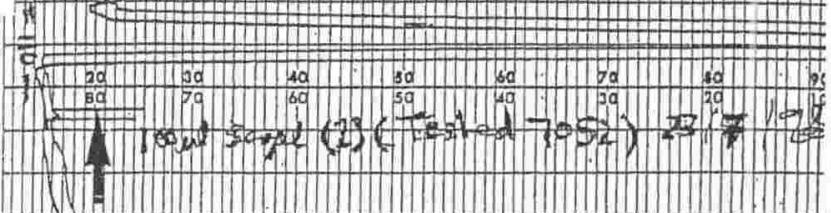

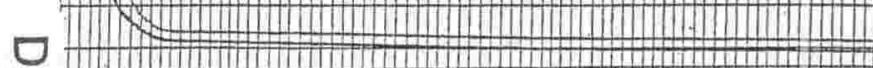

○

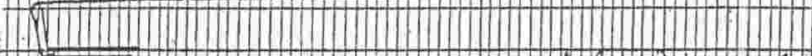

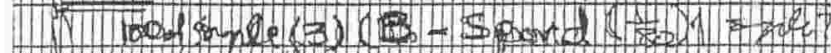
- | | | | | ||

$\square$ |

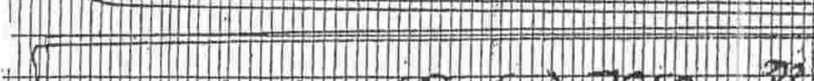

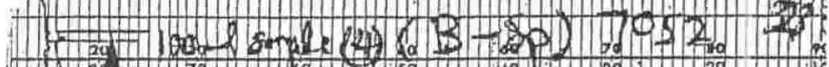

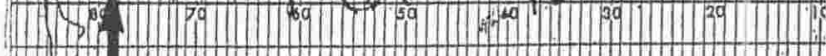

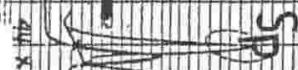

$\Omega$ $x^{x}$ (1)

1

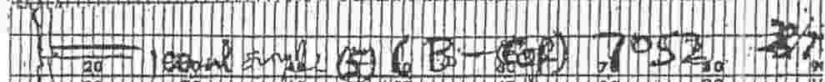
13. (1) - . -

$\Omega$ |

$\rightarrow$ \begin{tabular}{|c|c|}
\hline \\
\hline
\end{tabular}

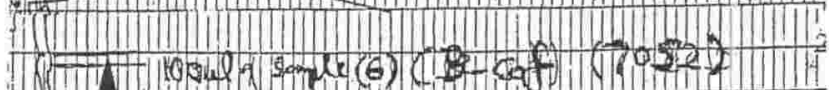

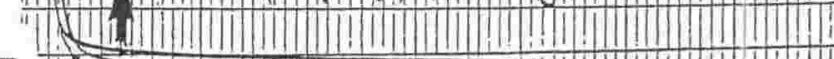

W

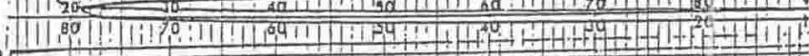

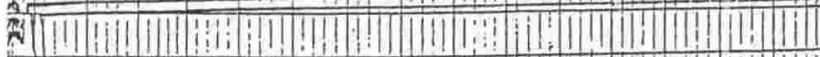

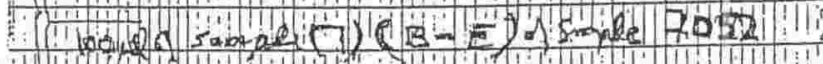

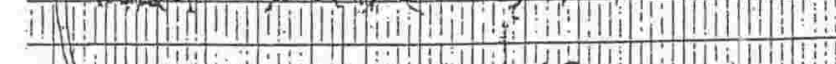

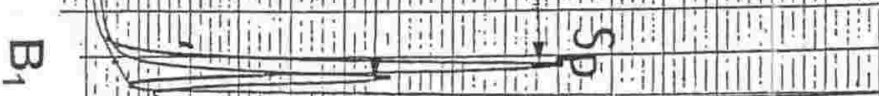

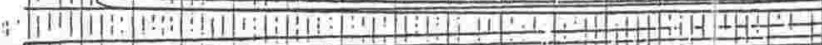

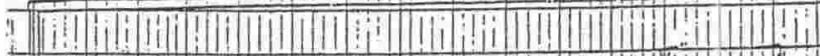

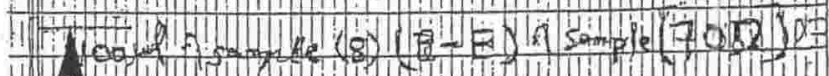

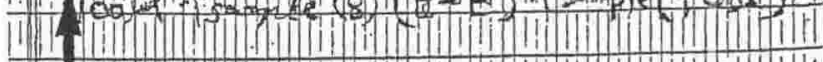

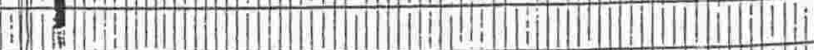

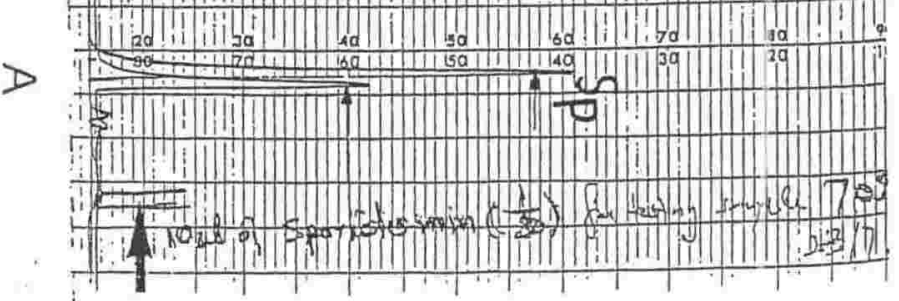




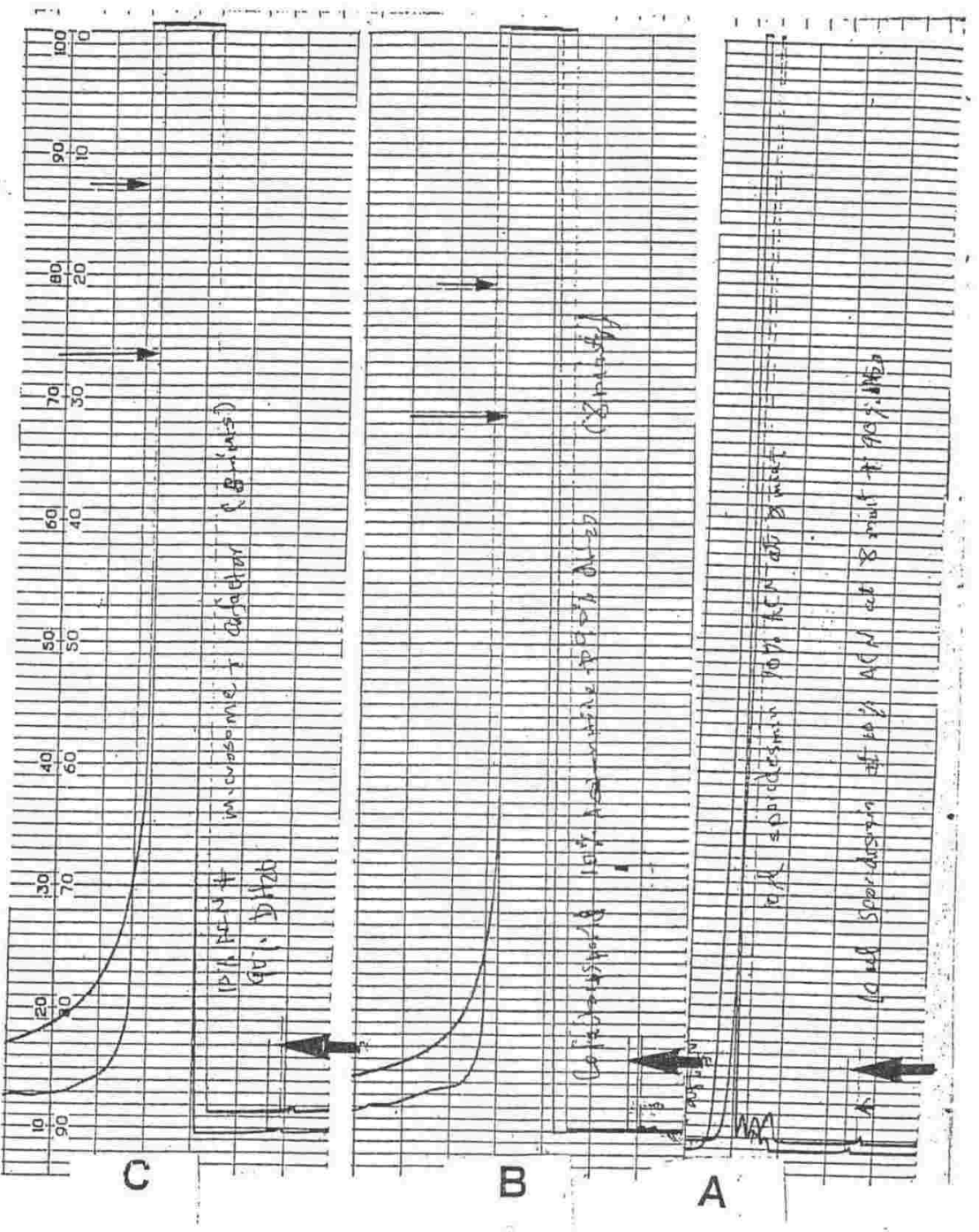

Figure 3.6a: HPLC of sporidesmin and NADPH generating system

A. Peak of sporidesmin alone $(10 \mu$ injection).

B. The large cofactor peak dominated the sporidesmin peak even after the acetonitrile was removed from the solvent mixture to enhance the separation.

C. The large cofactor peak dominated the microsomal fraction peak after the acetonitrile was removed from the solvent mixture.

Thin short arrows: refer to $230 \mathrm{~nm}$ wavelength.

Thin long arrows: refer to $260 \mathrm{~nm}$ wavelength.

Thick short arrows: refer to injection point. 


\subsection{Analysis of P-450 enzyme activities using model substrates}

Potential routes of P-450 dependent metabolism of sporidesmin include Odemethylation and $\mathrm{N}$-demethylation. Both reactions may modify the toxicity of sporidesmin. Model substrates, 4-nitroanisole (O-demethylase) and aminopyrine ( $\mathrm{N}$-demethylase), were therefore used to measure potential differences in oxidative metabolism of sporidesmin between the resistant and susceptible lines. Enzyme activities were measured using microsomal preparations from 4-8 month old Romneys born in 1994, 1995, and 1997.

\subsubsection{The effect of enzyme, substrate concentration and time of incubation on $\mathrm{O}$ -} demethylase assay

Although an established assay for liver microsomal O-demethylase was used, the validation of the effect of enzyme and substrate concentrations (Figure 3.7a), (Figure 3.7b) and time of incubation (Figure 3.7c) were investigated. Enzyme amount, substrate concentration and incubation time was each varied while maintaining other conditions as for the standard assay. The investigation showed that the maximum rate of reaction occurred when $0.7 \mathrm{mg}$ of protein (Figure 3.7a) and $1.67 \mathrm{mM}$ nitroanisole (Figure 3.7b) were used. With these parameters, the study found that the maximum rate of reaction obtained when the incubation time was $15 \mathrm{~min}$ (Figure $3.7 \mathrm{c}$ ). 


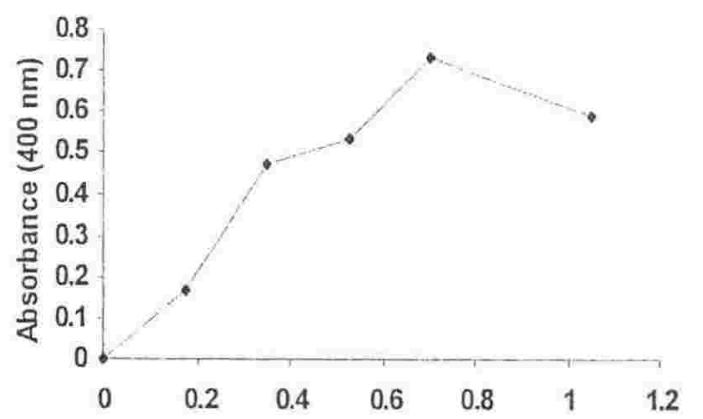

Microsomal protein $(\mathrm{mg})$

Figure 3.7a: Effect of enzyme amount on nitroanisole demethylase.

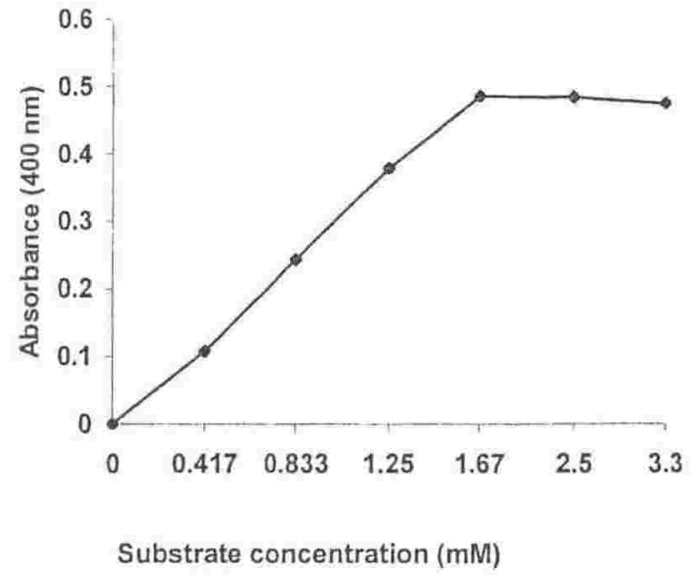

Figure 3.7b: Effect of nitroanisole concentration on the rate of enzyme reaction.

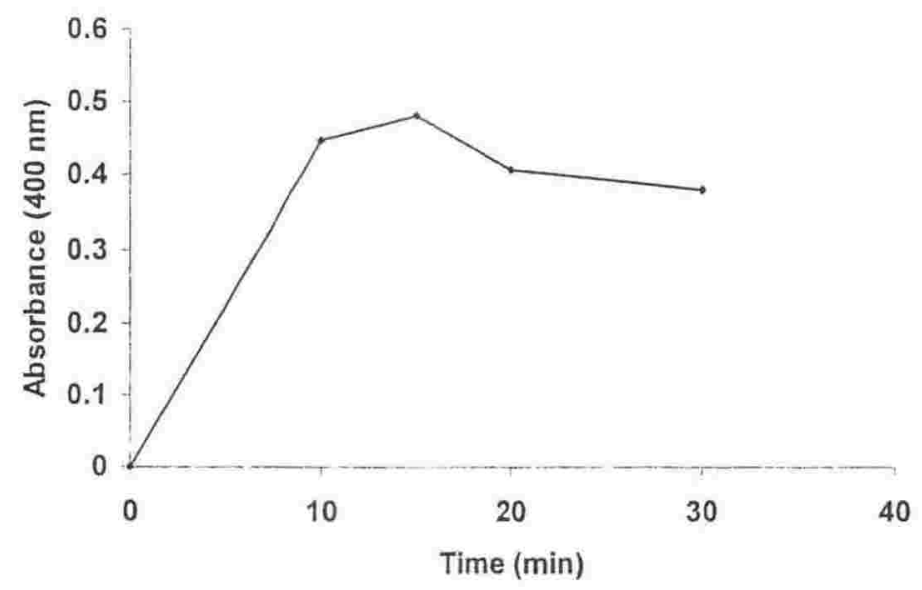

Figure 3.7c: Effect of incubation time on product formation. 


\subsubsection{4-Nitroanisole O-demethylase}

Figure 3.8 shows the standard curve for the 4-nitrophenol product of 4nitroanisole O-demethylase activity. O-demethylase activity was calculated from the absorption of 4-nitrophenol produced by the enzyme reaction.

Tables 3.2, 3.3, 3.4 show O-demethylase activity in Romney lambs born $1994,1995,1997$ ( $n=5$ for all experimental groups). Differences between individuals in their specific activity toward the substrate 4-nitroanisole can be clearly seen within the susceptible and resistant groups of animals, dosed or undosed, from all three years. Tables 3.2 and 3.4 also show differences in specific activity between the undosed susceptible and the undosed resistant animals born in 1994 and 1997. The undosed resistant groups show a mean increase of 1.17 fold in enzyme activity compared to susceptible for animals born in 1994, and an increase of 1.4 fold for animals born in 1997. Table 3.3 shows differences between the dosed groups, susceptible and resistant animals born 1995.

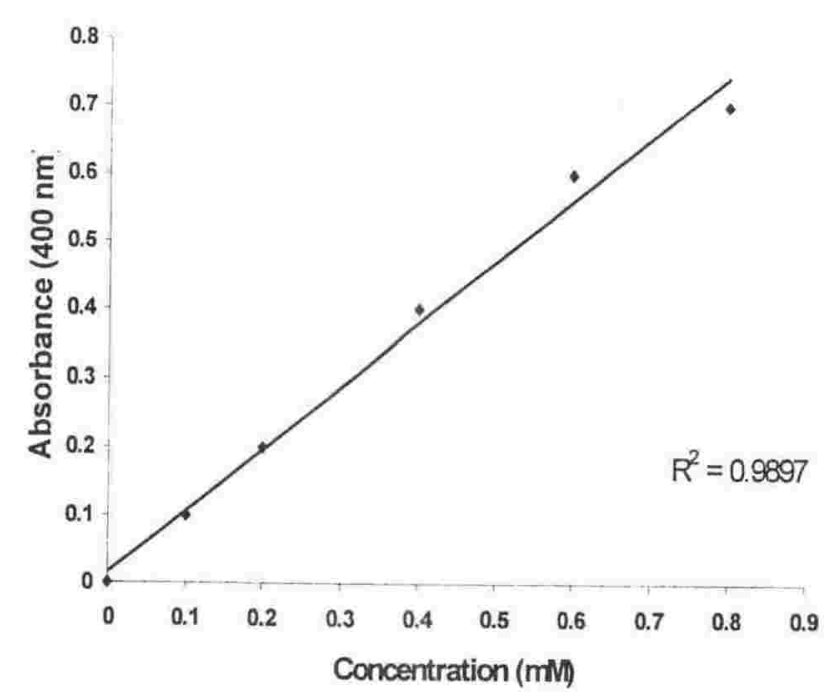

Figure 3.8: The standard curve for 4-nitrophenol. 
In all three years $\mathrm{O}$-demethylase activity was greater in dosed resistants compared to undosed resistants and was lower in dosed susceptibles compared to undosed susceptibles. A two fold increase in enzyme activity after dosing occurred in resistant animals born 1997 and a 1.5 fold increase in resistant animals born 1995, compared to the undosed resistant groups. A decrease in the enzyme activity of $35 \%$ occurred after dosing in the susceptible groups for the years 1994 and 1997 and by $8 \%$ in 1995 .

\begin{tabular}{|l|c|}
\hline Animals born 1994 & $\begin{array}{c}\text { O-Demethylase }(\mu \mathrm{mol} / \mathrm{h} / \mathrm{mg} \text { protein) } \\
\text { Mean } \pm \mathrm{SD}\end{array}$ \\
\hline Undosed susceptible & $20.16 \pm 6.2$ \\
\hline Undosed resistant & $23.56 \pm 4.3$ \\
\hline Dosed susceptible & $13.27 \pm 3.3$ \\
\hline Dosed resistant & $26.71 \pm 6.1$ \\
\hline
\end{tabular}

Table 3.2: O-Demethylase activity in liver microsomes from Romney lambs born 1994. 


\begin{tabular}{|l|c|}
\hline Animals born 1995 & $\begin{array}{c}\text { O-Demethylase }(\mu \mathrm{mol} / \mathrm{h} / \mathrm{mg} \text { protein) } \\
\text { Mean } \pm \mathrm{SD}\end{array}$ \\
\hline Undosed susceptible & $16.68 \pm 4.3$ \\
\hline Undosed resistant & $19.46 \pm 6.3$ \\
\hline Dosed susceptible & $15.41 \pm 10.2$ \\
\hline Dosed resistant & $30.21 \pm 14.5$ \\
\hline
\end{tabular}

Table 3.3: O-Demethylase activity in liver microsomes from Romney lambs born 1995.

\begin{tabular}{|l|c|}
\hline Animals born 1997 & $\begin{array}{c}\text { O-Demethylase }(\mu \mathrm{mol} / \mathrm{h} / \mathrm{mg} \text { protein) } \\
\text { Mean } \pm \mathrm{SD}\end{array}$ \\
\hline Undosed susceptible & $10.24 \pm 2.7$ \\
\hline Undosed resistant & $14.46 \pm 6.6$ \\
\hline Dosed susceptible & $6.79 \pm 1.6$ \\
\hline Dosed resistant & $27.22 \pm 8.1$ \\
\hline
\end{tabular}

Table 3.4: O-Demethylase activity in liver microsomes from Romney lambs born 1997. 


\subsubsection{The effect of enzyme, substrate concentration and time of incubation, on}

\section{$\underline{\mathrm{N} \text {-demethylase assay }}$}

Although an established assay for liver microsomal $\mathrm{N}$-demethylase was used, the effect of enzyme (Figure 3.9a), and time of incubation (Figure 3.9b) were investigated. The reaction was approximately linear up to $30 \mathrm{~min}$ incubation.

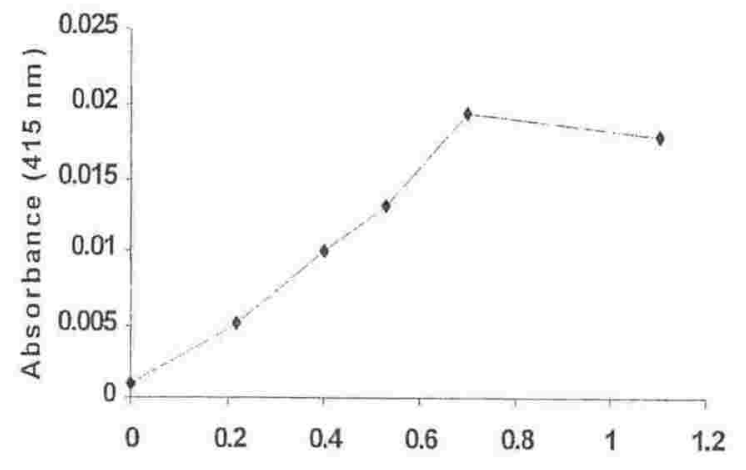

Microsomal protein ( $\mathrm{mg}$ )

Figure 3.9a: Effect of enzyme amount on aminopyrene demethylase.

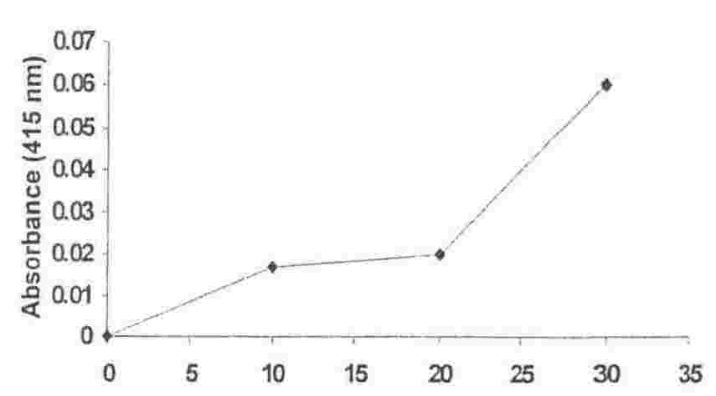

Time (min)

Figure 3.9b: Effect of incubation time on product formation. 


\subsubsection{Aminopyrine $\mathrm{N}$-demethylase}

Aminopyrine $\mathrm{N}$-demethylase activity was measured in animals born 1994, 1996 and 1997. The standard curve for the formaldehyde product of $\mathrm{N}$ demethylase activity is shown in Figure 3.10.

Tables 3.5, 3.6, 3.7 show N-demethylase activity in Romney lambs born 1994, 1996 and 1997. Differences among individuals in their specific activity toward the substrate aminopyrine were found within the susceptible and resistant groups of dosed and undosed Romneys from the years 1994 and 1997. In 1996 two groups were examined, undosed control and undosed resistant, with two animals in each group.

The Tables show that no differences in specific activity occurred between the undosed susceptible and undosed resistant groups of animals born 1994 and 1997, There were differences between the two groups from 1996, the resistant group showing a 1.5 fold increase compared to the unselected control group. The dosed susceptible and resistant groups also showed similar activity toward the substrate aminopyrine. $\mathrm{N}$-demethylase activity was greater in dosed animals. Both dosed resistant and dosed susceptible groups from 1994 showed a 1.3 fold higher activity after dosing. The resistant and susceptible groups from 1997 showed a 2 fold greater activity after dosing. The 1996 born animals showed an apparent difference but the number of the animals were too small for statistical comparison. 


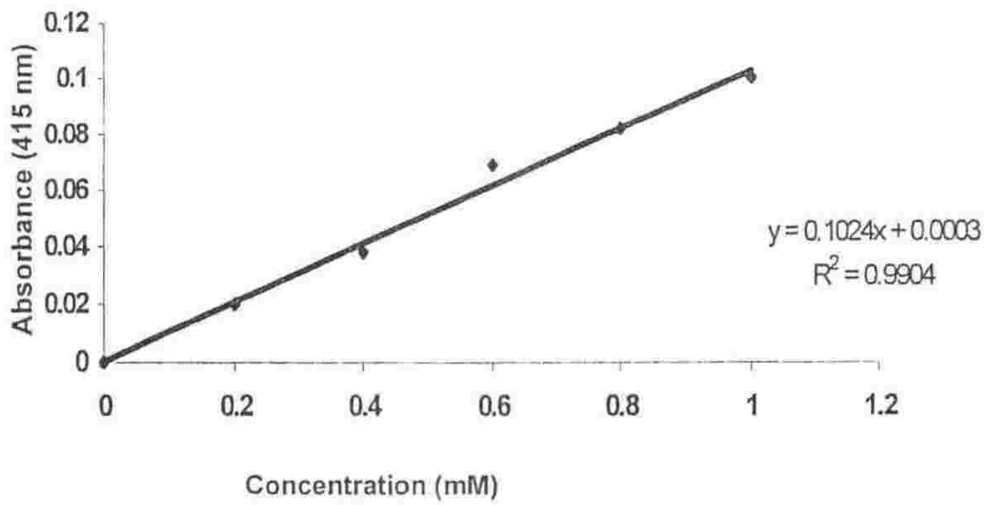

Figure 3.10: The standard curve for formaldehyde. 


\begin{tabular}{|l|c|}
\hline \multicolumn{1}{|c|}{ Animals born 1994 } & $\begin{array}{c}\text { N-Demethylase }(\mu \mathrm{mol} / \mathrm{h} / \mathrm{mg} \text { protein }) \\
\text { Mean } \pm \mathrm{SD}\end{array}$ \\
\hline Undosed susceptible & $7.72 \pm 2.3$ \\
\hline Undosed resistant & $7.96 \pm 4.7$ \\
\hline Dosed susceptible & $10.01 \pm 3.7$ \\
\hline Dosed resistant & $10.92 \pm 6.8$ \\
\hline
\end{tabular}

Table 3.5: N-Demethylase activity in liver microsomes from Romney lambs born 1994.

\begin{tabular}{|l|c|}
\hline Animals born 1996 & N-Demethylase $(\mu \mathrm{mol} / \mathrm{h} / \mathrm{mg}$ protein) \\
& Mean $\pm \mathrm{SD}$ \\
\hline Undosed control & $14.02 \pm 11.8$ \\
\hline Undosed resistant & $21.48 \pm 18.6$ \\
\hline
\end{tabular}

Table 3.6: N-Demethylase activity in liver microsomes from Romney lambs born 1996 .

\begin{tabular}{|l|c|}
\hline \multicolumn{1}{|c|}{ Animals born 1997 } & $\begin{array}{c}\text { N-Demethylase }(\mu \mathrm{mol} / \mathrm{h} / \mathrm{mg} \text { protein) } \\
\text { Mean } \pm \mathrm{SD}\end{array}$ \\
\hline Undosed susceptible & $10.31 \pm 4.0$ \\
\hline Undosed resistant & $10.40 \pm 5.7$ \\
\hline Dosed susceptible & $19.95 \pm 1.6$ \\
\hline Dosed resistant & $20.54 \pm 12.8$ \\
\hline
\end{tabular}

Table 3.7: N-Demethylase activity in liver microsomes from Romney lambs born 1997. 


\section{$\underline{3.4 \text { Statistical analysis }}$}

\subsubsection{O-demethylase}

The first set of analyses (analysis of variance) was carried out on all the sheep born in 1994, 1995 and 1997 (Table 3.8). The factors in the experiment were "dose", "resistance", "year" and an interaction between "dose" and "resistance". Box plots for each of the main effects are shown in Figure 3.11. There were statistically significant differences between the years $(p<0.0001)$, Figure 3.12. The interaction between dose and resistance was significant $(p<0.001)$, Figure 3.13. Because of the significance of the interaction, any statistically significant main effects (in this case "resistance" with $p<0.000002)$ must be interpreted with care, particularly as the design of the experiment was not balanced (there were fewer sheep in 1997).

A pair-wise test was conducted to test for differences between resistant and susceptible animals that were undosed. The results were not significant $(p=$ 0.1247). A similar test was conducted to test for differences between resistant and susceptible animals that were dosed. These results are illustrated in Figure 3.13. Because the responses differed among the different years the next set of analyses were carried out for each year separately.

\begin{tabular}{|r|c|c|c|c|}
\hline Years & Und. resistant & Und. susceptible & Dosed resistant & Dosed susceptible \\
\hline 1994 & 5 & 5 & 5 & 5 \\
\hline 1995 & 5 & 5 & 5 & 5 \\
\hline 1996 & 2 & 2 (control flock) & & 3 \\
\hline 1997 & 5 & 5 & 3 & 3 \\
\hline
\end{tabular}

Table 3.8: Shows number of animals for each year used in the statistical analysis. 


\subsubsection{Animals born 1994}

Box plots of the main effects (dose and resistance) are shown in Figure 3.14. The interaction effect (between dose and resistance) was significant $(p=0.038$, Figure 3.15) as was the resistance effect $(p<0.002)$. Again, because of the significant interaction, the pair-wise differences between the resistant and susceptible sheep were tested separately in the dosed and undosed groups. There was no significant difference between resistant and susceptible sheep in the undosed group ( $p=0.326$ ) but there was a significant difference between the resistant and susceptible sheep in the dosed group $(p<0.001)$.

\subsubsection{Animals born 1995}

The plots of the main effects (dose and resistance) are shown in Figure 3.16. In this year the interaction effect was not statistically significant at the $5 \%$ level ( $p=$ 0.106), although the observed differences between treatment means were similar to those in other years (compare Figures 3.15, 3.17, 3.19). The resistance effect was significant $(p=0.027)$. Although the interaction effect was not statistically significant, pair-wise differences between the resistant and susceptible Romneys were conducted as in the other years with the same results: for the undosed sheep there were no significant differences between the resistant and susceptible strains $(p=0.615)$ but for the dosed sheep there were significant differences $(p<0.01)$. 


\subsubsection{Animals born 1997}

Box plots of the main effects (dose and resistance) are shown in Figure 3.18. The interaction was statistically significant $(p=0.011)$ Figure 3.19 , as was the resistance effect $(p<0.002)$. The test of pair-wise differences showed that for the undosed sheep there were no significant differences between the resistant and susceptible strains $(p=0.213)$ but for the dosed sheep there were significant differences $(p<0.0005)$.

\subsubsection{Summary}

Statistical analysis of the results of enzyme measurement for O-demethylase showed significant difference between the resistant and susceptible lines $(p=$ $0.0000013)$ when all of the animals were included in the analysis, Figure 3.12. Analysis of the results for each birth year also showed significant differences between the lines of animals born in $1994(p=0.002), 1995(p=0.02)$ and $1997(p=$ 0.0017), Figure 3.12. There were also significant differences in enzyme activity among animals born in different years $(p=0.000096)$.

Sianificant differences hofweon dnced recistant animals were nhserved in 
showed that dosing affected both lines, the susceptible line by decreasing the enzyme activity compared to the resistant line which showed an increase in the Odemethylase enzyme activity. 

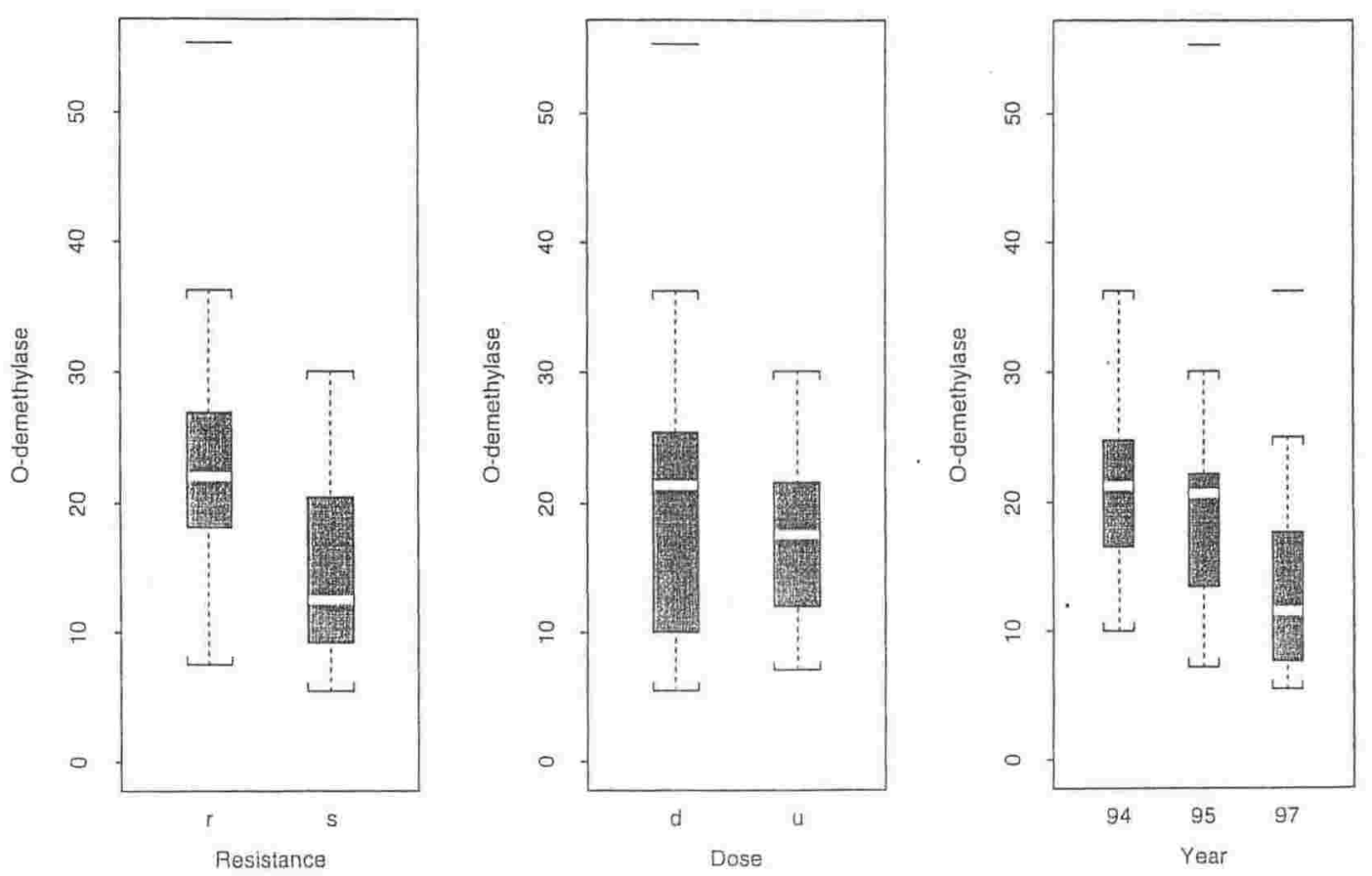

Figure 3.11: Cytochrome P-450 O-demethylase: box plots of resistance, dose and year; data for all years. There were significant effects for resistance, dose and year. Resistant animals(r), susceptible animals (s), dosed animals (d), undosed animals (u). Dosing factor affected the resistant and the susceptible animals by increasing the enzyme activity in the resistants and decreasing the enzyme activity in the susceptibles.

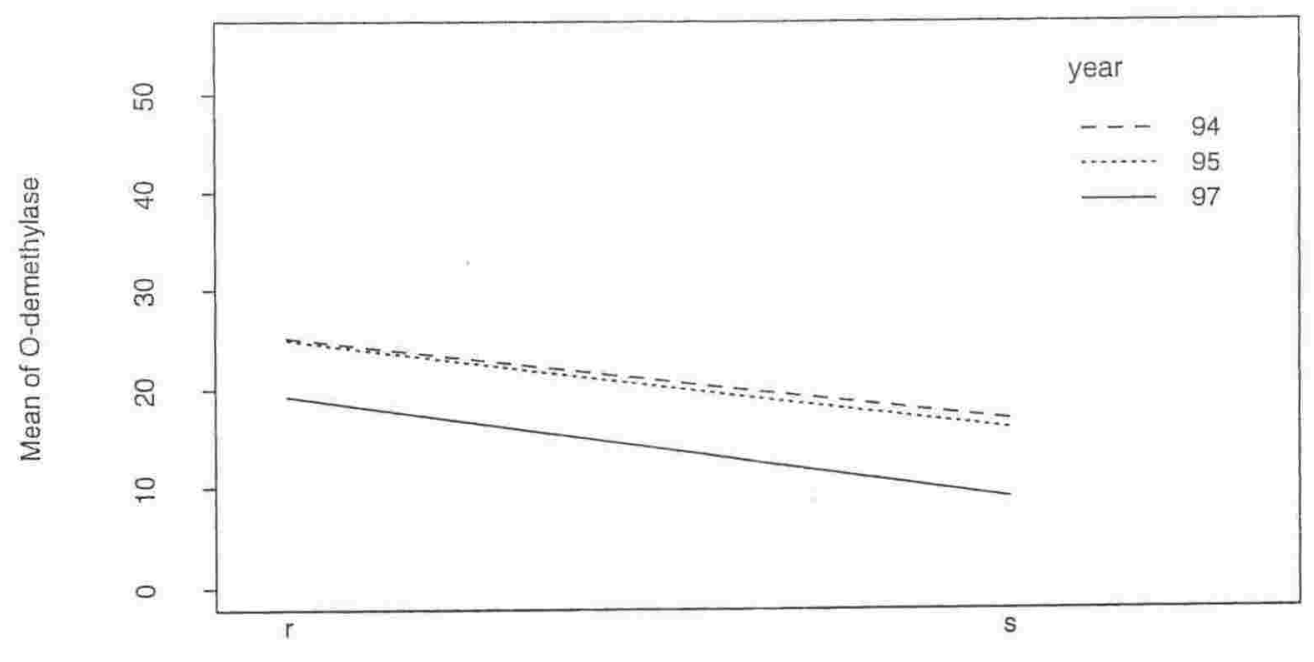

Resistance

Figure 3.12: Cytochrome P-450 O-demethylase: interaction plot of resistance by year. There were statistically significant differences between resistant and susceptible animals in all years. Resistant factor showed similar effect on animals born 1994 and 1995. 


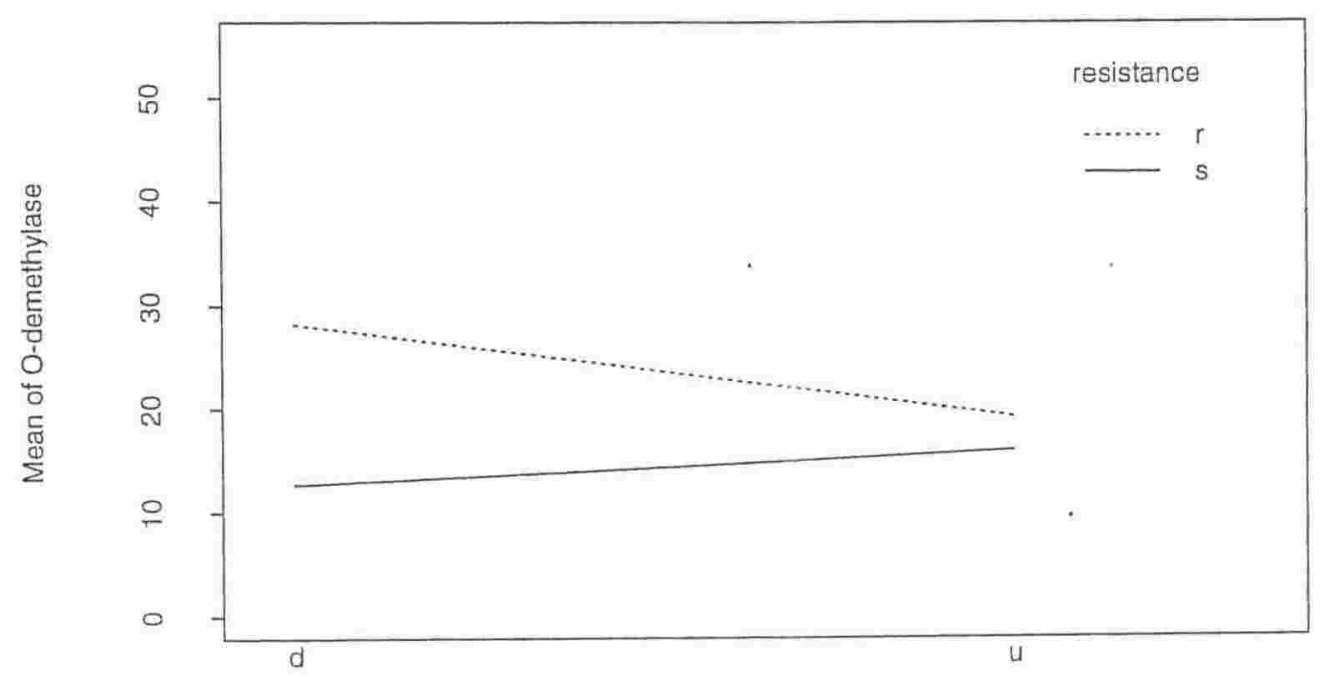

Dose

Figure 3.13: Cytochrome P-450 O-demethylase: interaction plot of dose by resistance; data for all years. The interaction between the dose and resistance factors was significant.

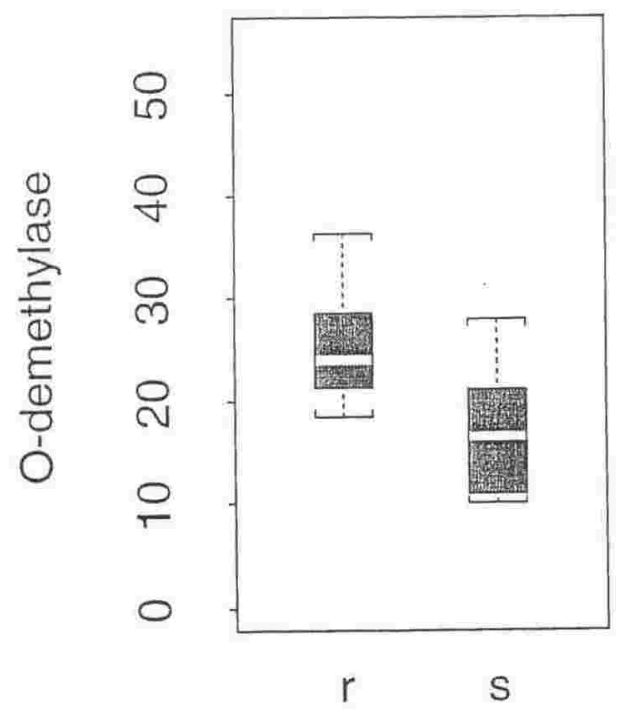

Resistance

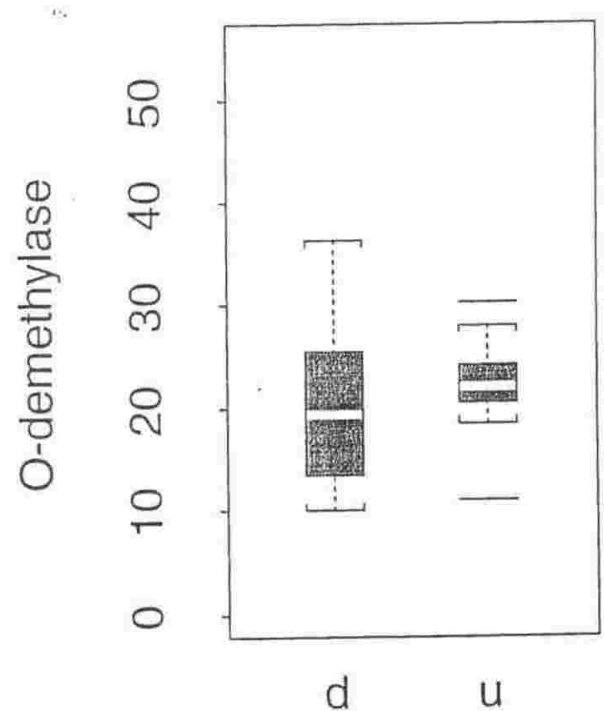

Dose

Figure 3.14: Cytochrome P-450 O-demethylase: box plots of resistance, dose for 1994. Effects of dose and resistance factors were statistically significant in resistant animals. 


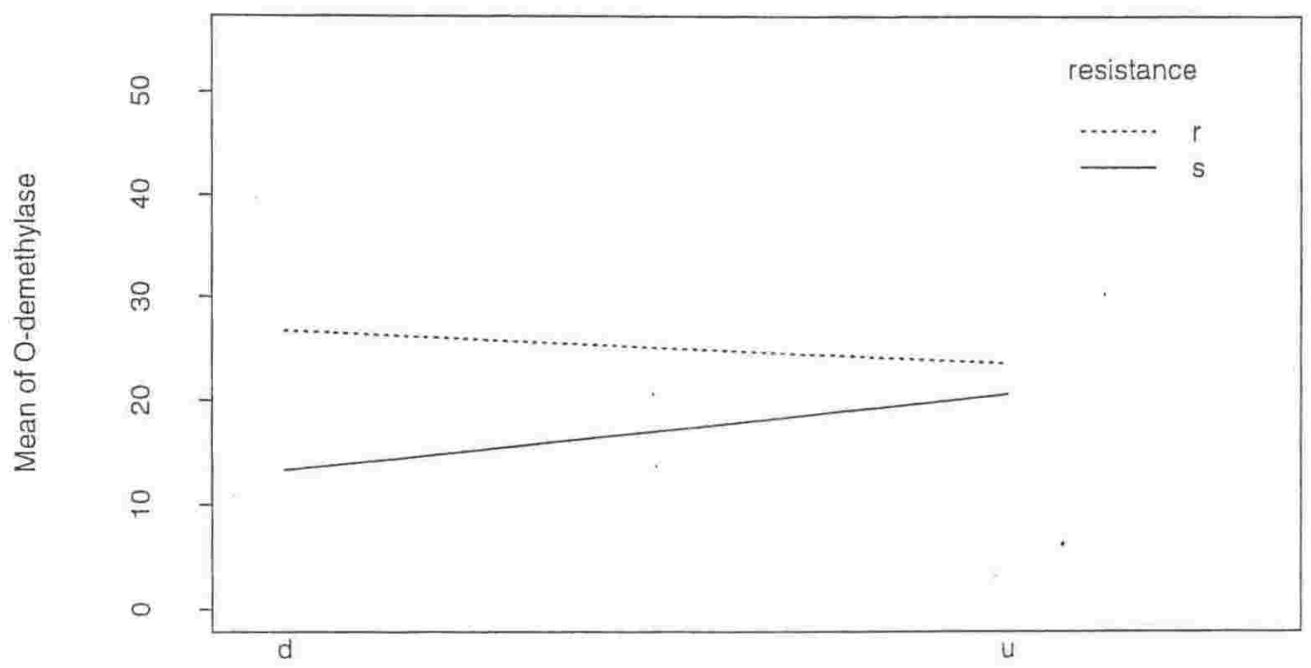

Dose

Figure 3.15: Cytochrome P-450 0-demethylase: interaction plot of dose by resistance; data for 1994. The interaction between the dose and resistance factors was significant.

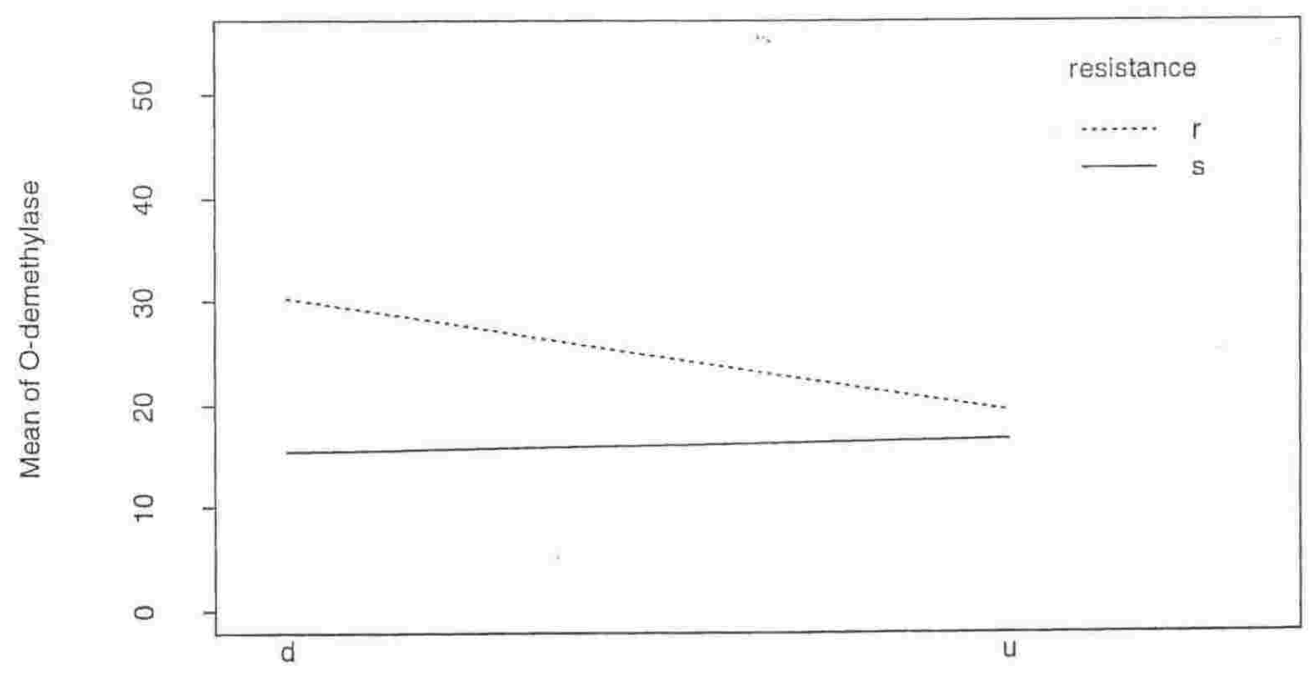

Dose

Figure 3.16: Cytochrome P-450 O-demethylase: box plots of resistance, dose for 1995. The interaction between dose and resistance factors was not statistically significant, only the resistance effect was significant. 


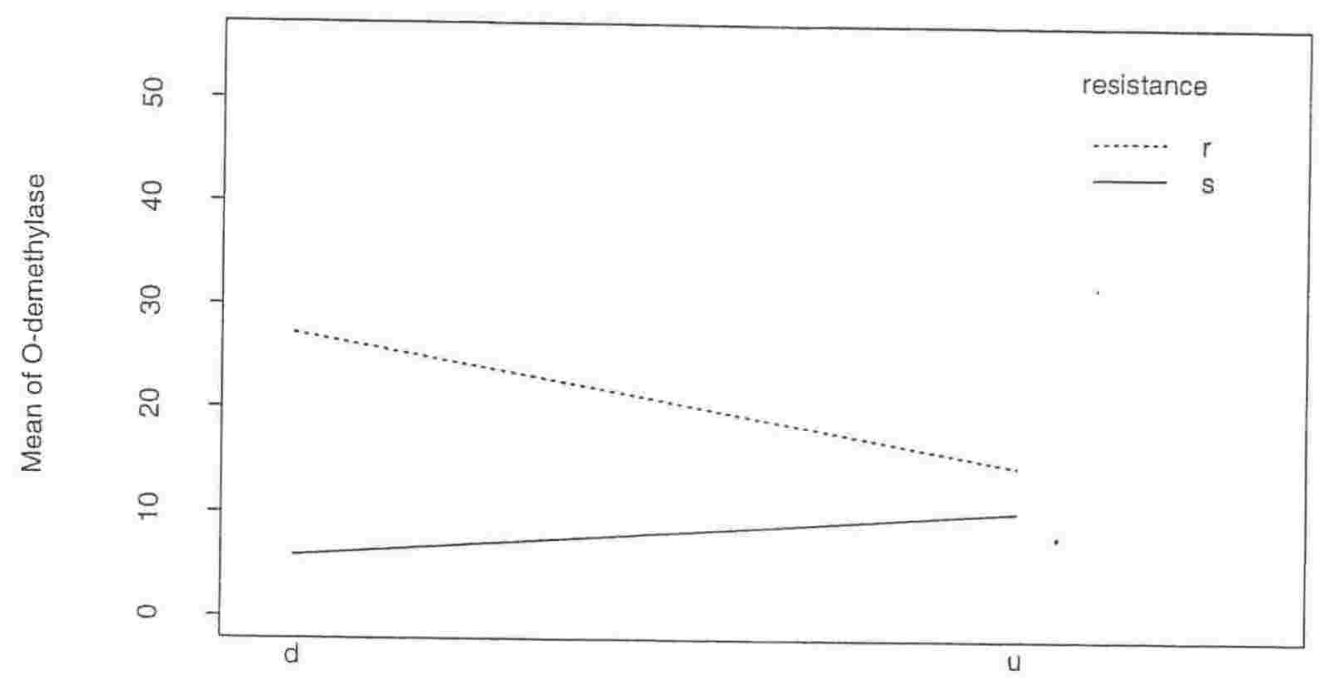

Dose

Figure 3.17: Cytochrome P-450 O-demethylase: interaction plot of dose by resistance for 1995. The effect of dose was only significant in resistant animals.

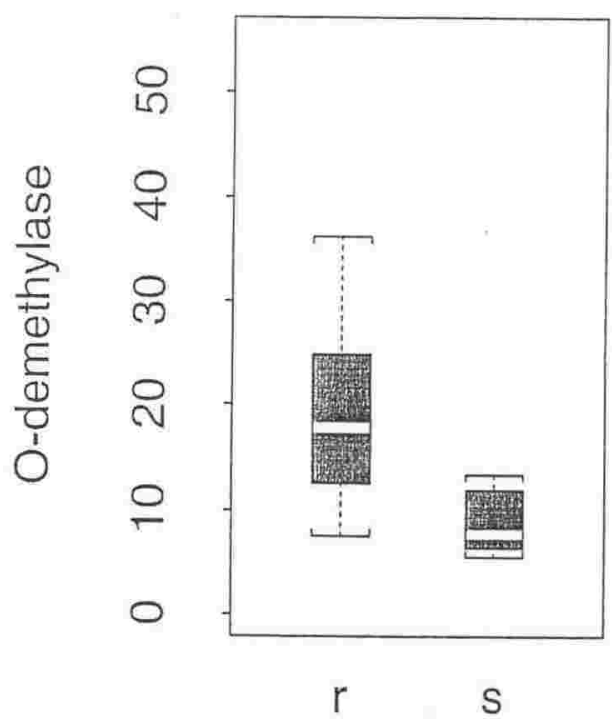

Resistance

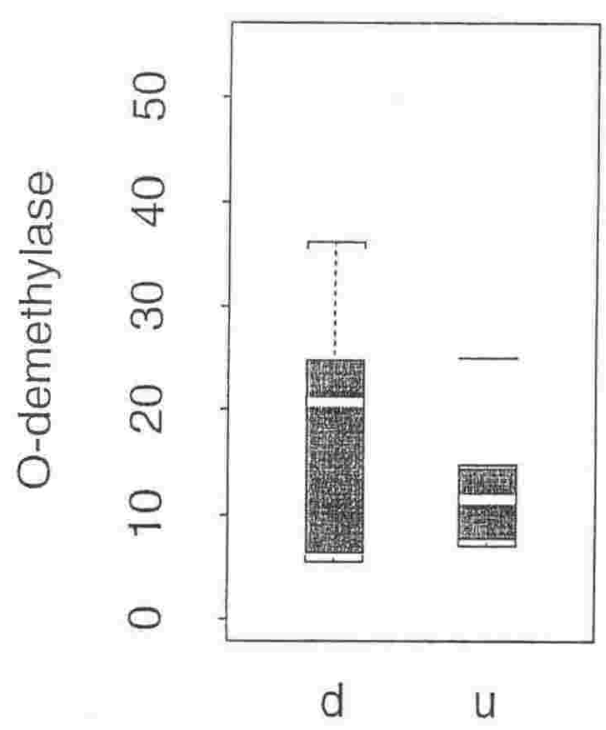

Dose 


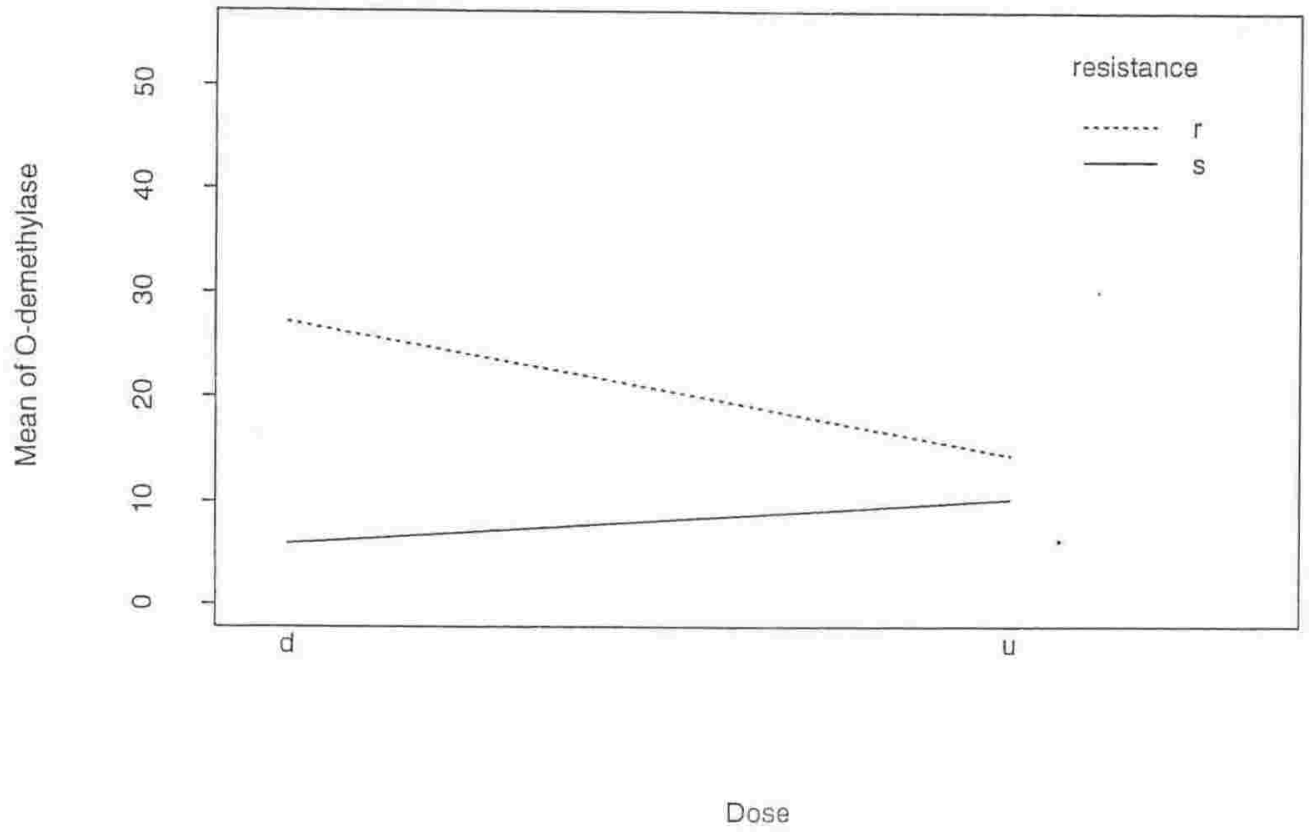

Figure 3.19: Cytochrome P-450 O-demethylase: interaction plot of dose by resistance, for 1997 born animals. The effect of dose was only statistically significant in resistant animals. 


\subsubsection{N-demethylase}

First, the data for all sheep born in 1994 and 1997 was analysed. The factors in the experiments were "dose", "resistance" and "year". Box plots for each of the main effects are shown in Figure 3.20. A full factorial model was fitted (including all 2 - way interactions and the 3 - way interaction dose, resistance and year). The only significant interaction effect was between dose and year $(p=0.006$, Figure 3.21). A reduced model of the main effects and the year and dose interaction was fitted. In this model there was no significant difference between the resistant and susceptible lines $(p=0.9457)$ but there were significant differences between the years $(p<0.02)$, Figure 3.22 . Because of the significant interaction, the analyses were repeated for the years separately.

\subsubsection{Animals born 1994}

As is shown in Figure 3.20, there were no significant differences between resistant and susceptible sheep $(p=0.94)$, nor between dosed and undosed sheep ( $p>0.22$ ) (Figure 3.21), nor was the interaction between dose and resistance significant $(p=0.87)$. 


\subsubsection{Animals born 1996}

No statistical tests were conducted for this group of animals because there was not enough data to be analysed as only a few animals were involved in the analysis.

\subsubsection{Animals born 1997}

As is shown in Figure 3.22, there was no significant interaction between dose and resistance $(p=0.95)$, nor was there a significant resistance effect $(p>0.8)$. There were significant differences between dosed and undosed sheep $(p<0.013)$. 

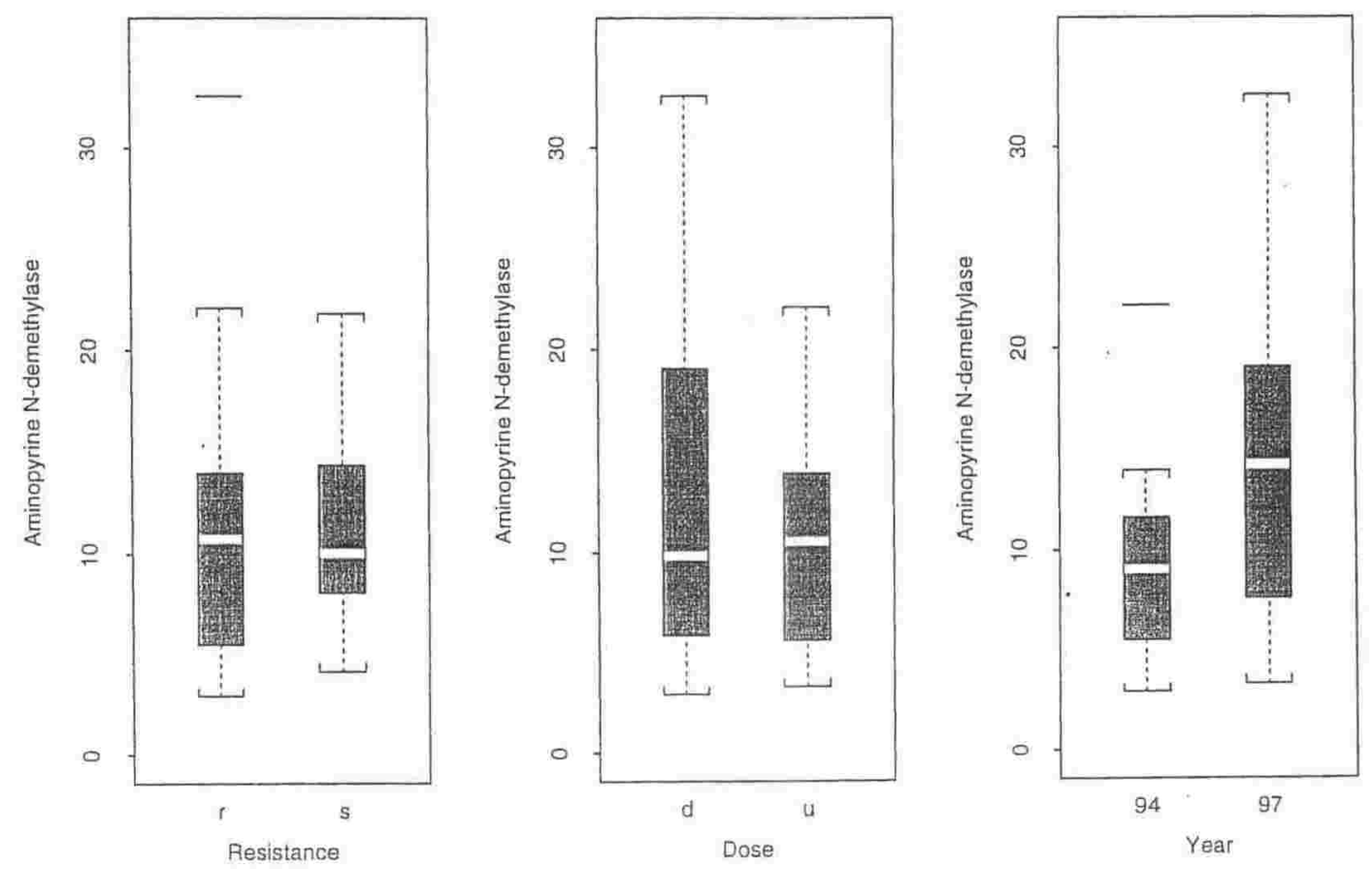

Figure 3.20. Aminopyrine $\mathrm{N}$-demethylase: box plots of resistance, dose and year; data for 94 and 97.

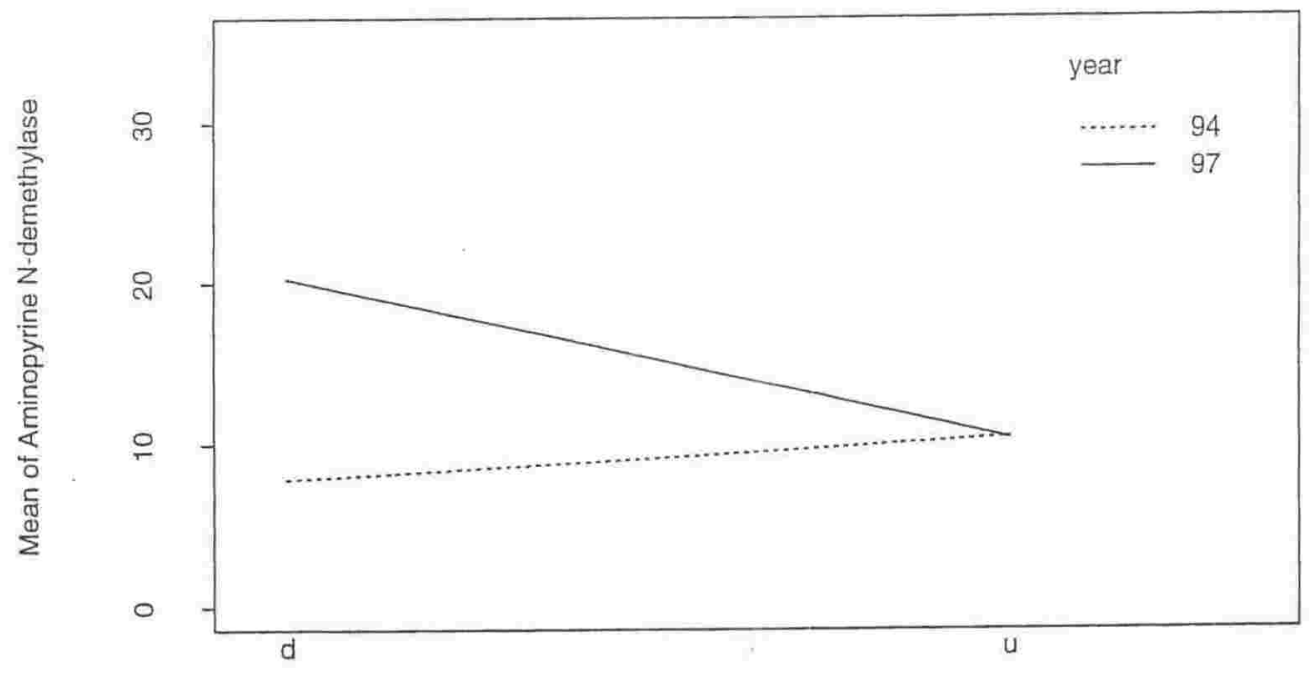

Dose

Figure 3.21: Aminopyrine N-demethylase: interaction plot of dose by year; data for 94 and 97. 


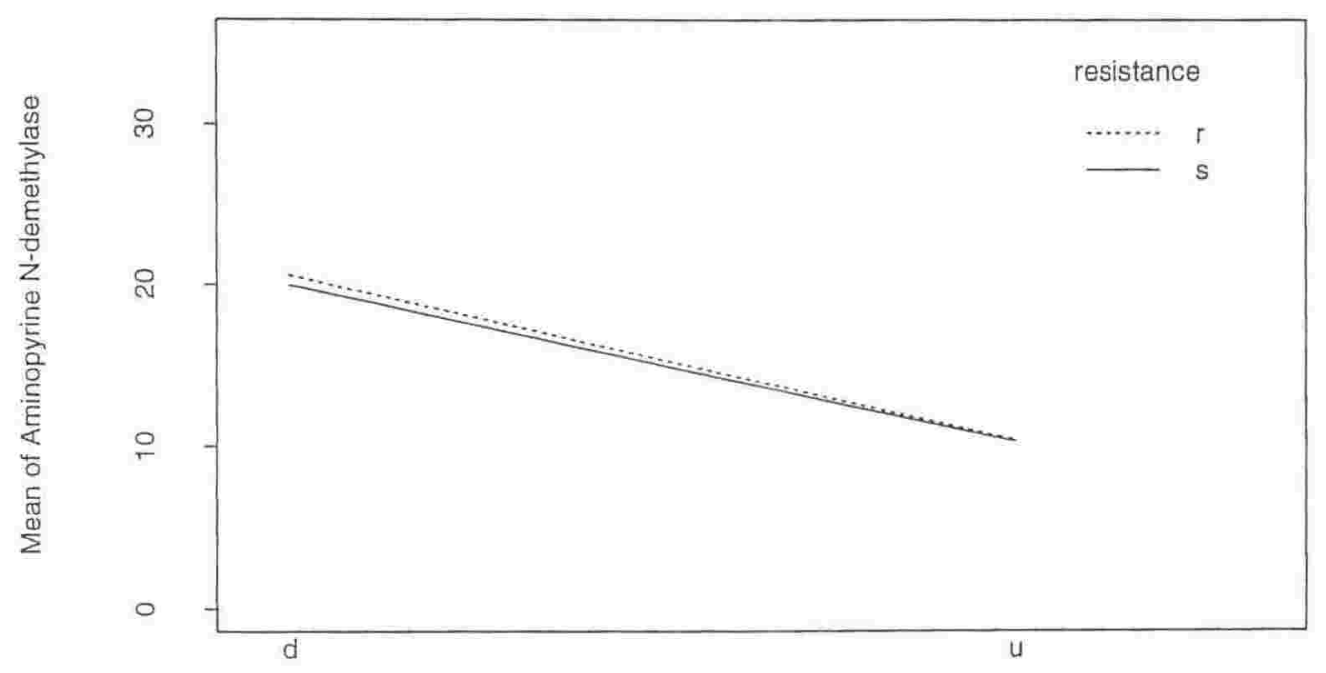

Dose

Figure 3.22: Aminopyrine $\mathrm{N}$-demethylase: interaction plot of dose by resistance; data for 1997. There were no significant interactions between dose and resistance factors. A significant effect of dosing was shown in the resistant and susceptible animals. 


\subsection{Repeat assays of $\mathrm{O}$ - and $\mathrm{N}$ - demethylase}

The O-and $\mathrm{N}$-demethylase assays were repeated in 2003 to check the previous results. The assays were carried out in triplicate for each animal using the microsomal fractions that had been stored at $-80^{\circ} \mathrm{C}$ for up to 8 years. Replicate assays varied approximately $10-5 \%$ from mean values. For example, for undosed resistant year 94 born Romneys the replicate assays for 0-demethylase are shown in Table 3.9:

\begin{tabular}{|c|l|}
\hline Animals No. & Absorbance \\
\hline 4110 & $0.4,0.44,0.44$ \\
\hline 4101 & $0.43,0.45,0.46$ \\
\hline 4040 & $0.5,0.5,0.51$ \\
\hline 4221 & $0.33,0.35,0.37$ \\
\hline 4304 & $0.45,0.43,0.48$ \\
\hline
\end{tabular}

Table 3.9: Triplicate measurements for O-demethylase activity of 1994 born, undosed, resistant animals.

Table 3.10 shows the summary for repeat measurement (duplicate assays) of all animals included in Tables 3.2 - 3.4. Although activities were, in general, unexpectedly greater than previously measured trends were similar, i.e. dosed resistants had greater activity than dosed susceptibles. 


\begin{tabular}{|l|c|}
\hline Animals born 1994 & O-Demethylase $(\mu \mathrm{m} / \mathrm{h} / \mathrm{mg}$ protein) \\
\hline Undosed susceptible & $24 \pm 4$ \\
\hline Undosed resistant & $23.9 \pm 7$ \\
\hline Dosed susceptible & $19.5 \pm 3.1$ \\
\hline Dosed resistant & $37.7 \pm 2$ \\
\hline & \\
\hline Animals born 1995 & $33.0 \pm 9.5$ \\
\hline Undosed susceptible & $43.7 \pm 5.1$ \\
\hline Undosed resistant & $28.3 \pm 9.7$ \\
\hline Dosed susceptible & $44.4 \pm 21.2$ \\
\hline Dosed resistant & $33.8 \pm 3.6$ \\
\hline & \\
\hline Animals born 1997 & $32.4 \pm 10.4$ \\
\hline Undosed susceptible & \\
\hline Undosed resistant & \\
\hline Dosed susceptible & \\
\hline Dosed resistant & \\
\hline
\end{tabular}

Table 3.10: Summary for the repeated O-demethylase assays for 1994,1995 and 1997 animals. 
For $\mathrm{N}$-demethylase (Tables $3.11,3.12$ ) rates were approximately $10-20 \%$ of those previously measured but were approximately proportional to the earlier measurements. Aminopyrine $\mathrm{N}$-demethylase therefore appeared to be less stable than nitroanisole O-demethylase. $\mathrm{N}$-demethylase showed no obvious differences between resistant and susceptible animals in the dosed or undosed samples for all years.

\begin{tabular}{|c|c|}
\hline Undosed resistant & Absorbance \\
\hline 7082 & $0.06,0.06,0.06$ \\
\hline 7022 & $0.08,0.04,0.06$ \\
\hline 7350 & $0.05,0.05,0.05$ \\
\hline 7348 & $0.04,0.05,0.03$ \\
\hline 7305 & $0.05,0.05,0.05$ \\
\hline Dosed resistant & \\
\hline 7231 & $0.07,0.06,0.06$ \\
\hline 7281 & $0.04,0.05,0.04$ \\
\hline 7330 & $0.06,0.06,0.06$ \\
\hline
\end{tabular}

Table 3.11: Triplicate measurements of $\mathrm{N}$-demethylase activity for 1997 born undosed and dosed resistant animals.

The results of the repeated assays for $\mathrm{O}$ - and $\mathrm{N}$-demethylase were not used for further statistical analysis. 


\begin{tabular}{|l|c|}
\hline Animals born 1994 & N-Demethylase (um/h/mg protein) \\
\hline Undosed susceptible & $1.41 \pm 0.4$ \\
\hline Undosed resistant & $1.4 \pm 0.4$ \\
\hline Dosed susceptible & $0.85 \pm 0.3$ \\
\hline Dosed resistant & $1.3 \pm 0.4$ \\
\hline & \\
\hline Animals born 1995 & $1.6 \pm 0.4$ \\
\hline Undosed susceptible & $1.56 \pm 0.3$ \\
\hline Undosed resistant & $1.97 \pm 0.6$ \\
\hline Dosed susceptible & $1.98 \pm 0.4$ \\
\hline Dosed resistant & $1.33 \pm 0.4$ \\
\hline & \\
\hline Animals born 1997 & $1.56 \pm 0.1$ \\
\hline Undosed susceptible & \\
\hline Undosed resistant & \\
\hline Dosed susceptible & \\
\hline Dosed resistant & \\
\hline
\end{tabular}

Table 3.12: Summary for the repeated N-demethylase assays for 1994, 1995 and 1997 born animals. 


\subsection{Analysis of cytochrome P-450}

Cytochrome P-450 can be detected by spectral analysis of the CO-binding hemoprotein (Omura and Sato, 1964). Cytochrome P-450 levels were compared in microsomal extracts from resistant and susceptible animals and after partial purification of P-450 from liver microsomes.

Figure 3.23 shows the CO-binding spectra of liver microsomes from undosed resistant animal 6379 using $2 \mathrm{mg}$ of liver microsomal protein per $\mathrm{ml}$. The CO absorption spectrum indicates the presence of both P-450 and P-420. P-420 is a degradation product of P-450. Addition of excess dithionite to the samples of both cuvettes lead to a loss of P-450 and relative increases in the P-420 peak (Figure $3.24)$

\subsubsection{Purification of cytochrome P-450}

Cytochrome P-450 heterogeneity has been previously detected using 1-D PAGE for separation of microsomal proteins (Huang et al., 1976; Guengerich, 1978). Undosed resistant and susceptible Romneys were therefore analysed by 1 -

D SDS PAGE of liver microsomal extracts and of partially purified cytochrome P. 450 isolated from microsomes by deoxycholate extraction and selective precipitation with PEG 6000. Separated proteins were detected by staining with Coomassie blue R-250 and by Western blotting using antibody to recombinant human cytochrome P-450 3A4. 


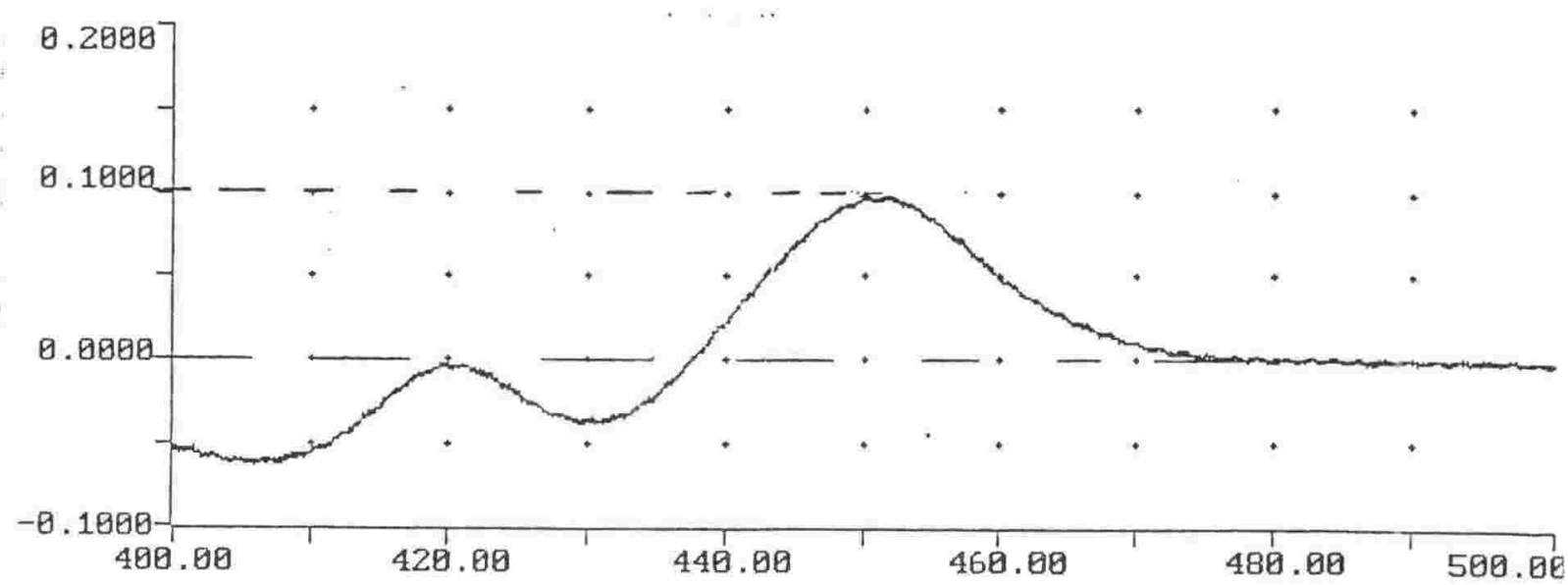

Figure 3.23: CO absorption spectrum of sheep liver cytochrome P-450. Liver microsomes, 2 $\mathrm{mg}$ protein/ml in $0.1 \mathrm{M}$ phosphate buffer $\mathrm{pH} 7.4$ were incubated with sodium dithionite. CO was bubbled through the test sample before measuring the difference spectra.

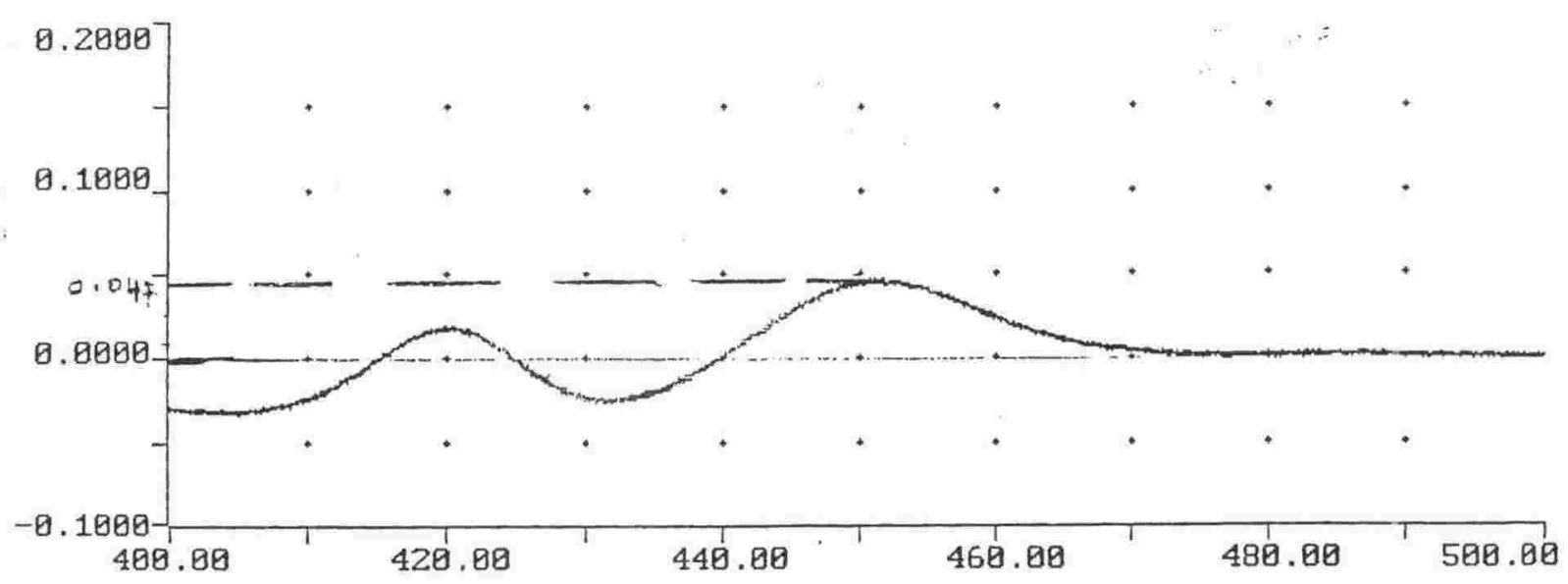

Figure 3.24: A reduction in the peak height of cytochrome P-450 and an increase in the peak height of cytochrome P-420 was observed after extra addition of dithionite to both cuvettes. 
3.6.1.1 Partial purification and analysis of cytochrome P-450 from control sheep liver microsomes

The total P-450 concentration in normal liver microsomes was determined from its CO difference spectra, obtained by gassing dithionite-reduced microsomal suspensions (2-10 $\mathrm{mg}$ of protein $/ \mathrm{ml}$ of $0.1 \mathrm{M}$ phosphate buffer, $\mathrm{pH} 7.4$ ), with $\mathrm{CO}$. The amount of cytochrome P-450 was calculated from the absorbance ( $A_{450}$ $A_{490}$ ), using a molar extinction coefficient of $91 \mathrm{mM}^{-1} / \mathrm{cm}^{-1}$ (Omura and Sato, 1964). Cytochrome P-450 concentrations were expressed as nmol/mg of microsomal protein. Table 3.14 shows the results of partial purification of cytochrome P-450 from liver microsomes of a sheep obtained from the Wellington abattoir. Approximately $23 \%$ of the microsomal P-450 were recovered in the $7-15 \%$ PEG pellet with a specific activity 2.3 times that of the deoxycholate extract.

\begin{tabular}{|l|c|c|c|c|}
\hline & $\begin{array}{c}\text { Volume } \\
(\mathrm{ml})\end{array}$ & $\begin{array}{c}\text { Total protein } \\
(\mathrm{mg})\end{array}$ & $\begin{array}{c}\text { Specific activity } \\
(\mathrm{nmol} \text { P-450/mg protein })\end{array}$ & $\begin{array}{c}\text { Total P-450 } \\
(\mathrm{nmol})\end{array}$ \\
\hline Deoxycholate extract & 200 & 1980 & 0.3 & 594 \\
\hline $7 \%$ PEG Pellet & 20 & 165 & 0.06 & 9.9 \\
\hline $15 \%$ PEG Pellet & 20 & 194 & 0.71 & 138 \\
\hline $15 \%$ PEG supernatant & 250 & 2083 & 0.01 & 12.5 \\
\hline
\end{tabular}

Table 3.13: Partial purification of cytochrome P-450 from microsomes from $50 \mathrm{~g}$ control sheep liver. P-450 content was determined by the $\mathrm{CO}$ method. The results are the means of duplicate measurements. The P-420 peak was excluded from calculation of total P-450. 


\subsubsection{Partial purification and analysis of cytochrome P-450 from undosed}

\section{susceptible and resistant animals born 1994, and undosed control and resistant} animals born 1996

Table 3.14 shows the results of partial purification of cytochrome P-450 from animals born 1994. The specific activity of cytochrome P-450 in the $7-15 \%$ PEG pellets was lower than achieved in the previous separation and did not vary between susceptible and resistant animals. Similar results were found for cytochrome P-450 from sheep liver by Smith et al. (1984) $0.490 \mathrm{nmol} / \mathrm{mg}$ protein, Smith and Watkins (1984) $0.316 \mathrm{nmol} / \mathrm{mg}$ protein and Dalvi et al. (1987) 0.323 $\mathrm{nmol} / \mathrm{mg}$ protein.

Table 3.15 shows the P-450 content of 7-15\% PEG pellets from unselected control and resistant animals born 1996. The Table shows that the specific activity and recovery of cytochrome P-450 was greater in the resistant animals compared to the unselected control animals. The cytochrome P-450 levels in the resistant animals born 1996 were greater than those observed in the resistant animals born 1994.

It was not clear whether the observed differences in specific activity reflected differences in liver cytochrome P-450 concentration or whether they were due in part to variability produced during partial purification of P-450. 


\begin{tabular}{|l|c|c|c|c|}
\hline 1994 born animals & $\begin{array}{c}\text { Volume } \\
(\mathrm{ml})\end{array}$ & $\begin{array}{c}\text { Total protein } \\
(\mathrm{mg})\end{array}$ & $\begin{array}{c}\text { Specific activity } \\
(\mathrm{nmol} \text { P-450/mg protein) }\end{array}$ & $\begin{array}{c}\text { Total P-450 } \\
\text { nmol (\%) }\end{array}$ \\
\hline Undosed susceptible & \multicolumn{5}{|l}{} & $647.5,644.8$ \\
\hline Deoxycholate extract & 15 & 1349,1349 & $0.48,0.48$ & $110.4,111.4$ \\
\hline $15 \%$ PEG Pellet & 5 & 460,462 & $0.24,024$ & $257.1,257.7$ \\
\hline Undosed resistant & \multicolumn{5}{|l}{$0.6,0.6$} & $52.5,54.9$ \\
\hline Deoxycholate extract & 5 & $428.5,429$ & $0.22,0.23$ & \\
\hline 15\% PEG Pellet & 3.5 & $238.75,238.82$ & &
\end{tabular}

Table 3.14: Partial purification of P-450 from microsomal samples. Microsomes were prepared from $30 \mathrm{~g}$ liver from undosed susceptible or resistant Romneys. P-450 content was calculated by the CO method. Measurements are in duplicate for two animals one from the resistant and one from the susceptible born flocks.

\begin{tabular}{|c|c|c|c|c|}
\hline 1996 born animals & $\begin{array}{c}\text { Volume } \\
(\mathrm{ml})\end{array}$ & $\begin{array}{c}\text { Total protein } \\
(\mathrm{mg})\end{array}$ & $\begin{array}{c}\text { Specific activity (nmol } \\
\text { P-450/mg protein) }\end{array}$ & $\begin{array}{c}\text { Total P-450 } \\
\mathrm{nmol}(\%)\end{array}$ \\
\hline Control sample & \multicolumn{5}{|c|}{} \\
\hline Deoxycholate extract & 8 & $779.2,779.2$ & $0.33,0.33$ & $257.1,257.1$ \\
\hline 15\% PEG Pellet & 4.1 & $226.3,226.4$ & $0.27,0.27$ & $61.11,61.4$ \\
\hline Undosed resistant & \multicolumn{5}{|c|}{} \\
\hline Deoxycholate extract & 8.4 & 410,410 & $0.37,0.37$ & $151.8,150.9$ \\
\hline 15\% PEG Pellet & 4.2 & $94.1,94.3$ & $0.5,0.5$ & $47.1,47.2$ \\
\hline
\end{tabular}

Table 3.15: Partial purification of P-450 from microsomal samples. Microsomes were prepared from $30 \mathrm{~g}$ liver from unselected control or resistant Romneys. P-450 content was calculated by the CO method. Measurements are in duplicate for one animal from the unselected control or resistant Romney lines. 


\subsection{Analysis of microsomal cytochrome c reductase}

Cytochrome P-450 is reduced by an enzyme system that can be measured as NADPH dependent reduction of cytochrome $\mathrm{c}$ in microsomal extracts. The activity of this enzyme was compared using microsomes from undosed susceptible and resistant Romneys to test whether differences in reduction of cytochrome P-450 might be responsible for different rates of P-450 dependent metabolism of sporidesmin. Analysis of five 1997 born undosed resistant Romneys (number 7348, 7182, 7305, 7350, 7022) and five 1997 born undosed susceptible Romneys (number $7086,7052,7265,7197,7211$ ), showed that there were not significant differences ( $t$ - test $p=0.14$ ) between the lines although the mean value for undosed resistant sheep $(8.98 \pm 1.84 \mathrm{nmol} / \mathrm{min} / \mathrm{mg}$ protein) was lower than for undosed susceptible animals $(10.90 \pm 1.04 \mathrm{nmol} / \mathrm{min} / \mathrm{mg}$ protein). The lack of significant differences shown in the t-test was confirmed by using an Exact Wilcoxon rank-sum test which showed no statistically significant difference between the resistant and the susceptible animals $(p=0.15)$. It is therefore unlikely that differences in cytochrome P-450 reductase are responsible for differences in P-450 mediated metabolism.

\subsection{1-D gel electrophoresis of microsomal proteins}

P-450 isoenzymes generally electrophorese in the $45-61.5 \mathrm{kDa}$ range. 1-D electrophoresis and Western blotting of microsomal fractions were therefore carried 
out to search for evidence of P-450 polymorphism between undosed resistant and susceptible Romneys. Figure 3.25 shows that there were some differences in the P-450 region of Coomassie Blue R-250 stained SDS - PAGE separations of liver microsomes between undosed resistant and susceptible animals.

The gel shown in Figure 3.25 resolved more than 40 discrete polypeptide bands, 5 of which were in the $45-61.5 \mathrm{kDa}$ region. These 5 bands, taken together, represented the most polypeptide dense area of the gel, as estimated from the intensity of Coomassie Blue staining. The bands were designated a - e (Figure 3.25), and assigned molecular weights relative to the standards with which they were electrophoresed. By comparison with electrophoresis of cytochrome P-450 from other species (Siekevitz, 1973; Haugen et al., 1975; Ryan et al., 1975; Welton et al., 1975) the bands designated c, d, and e might represent cytochrome P-450s. To test if there were any band abundance differences between undosed susceptible and undosed resistant Romneys, scanning of the gels was carried out as shown in Figure 3.25. The scanned images of the four samples were similar although there were some individual differences. These differences can be seen in the scanned region of the gel, region $b$ for example being less prominent in one of the susceptible Romneys. 


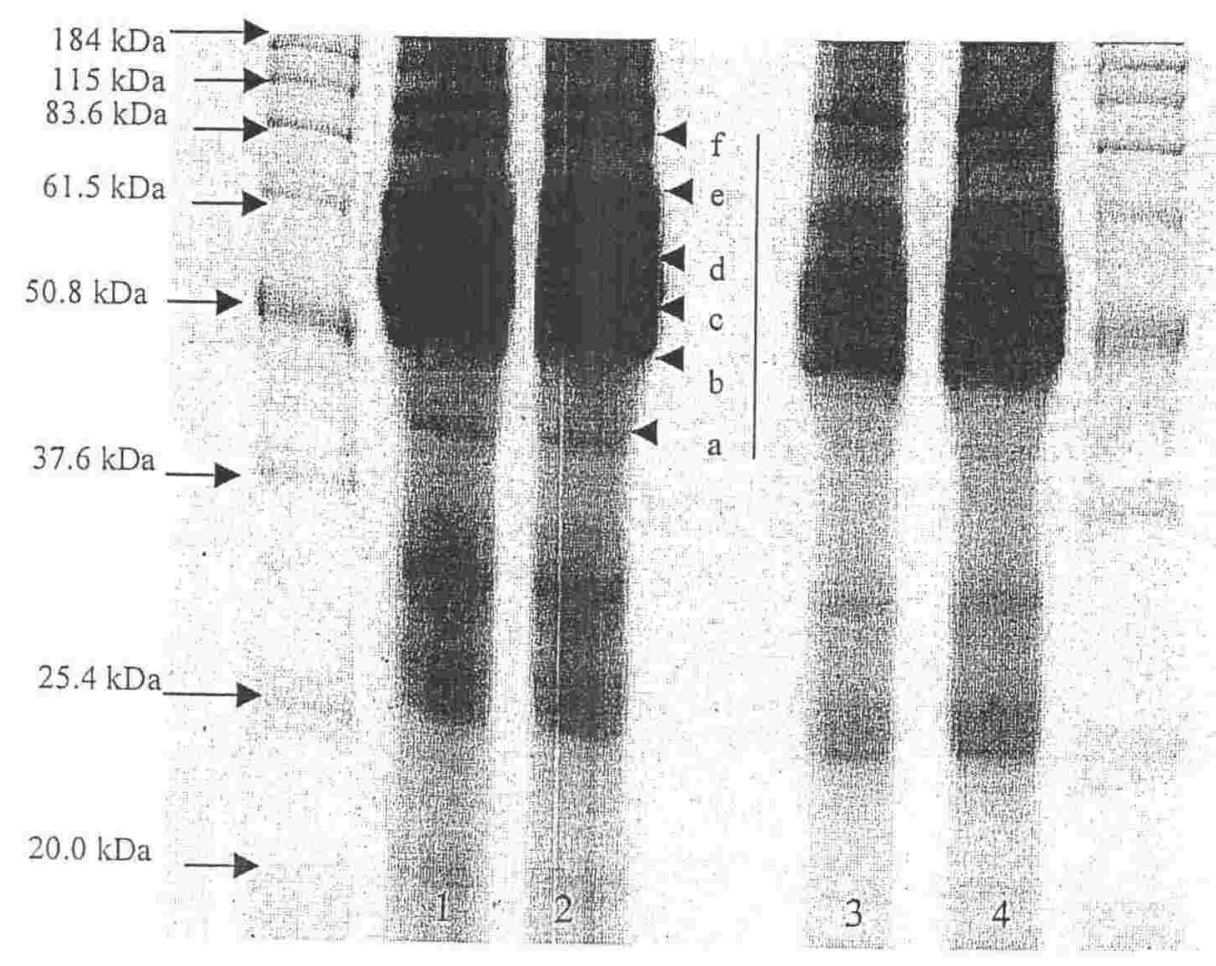

Figure 3.25: 1-D gel electrophoresis of microsomal samples. Lanes 1, 2 undosed susceptible Romneys. Lanes 3,4 undosed resistant Romneys. Molecular weight markers are arrowed. Lower panels show scans through the regions containing bands $a-f$.
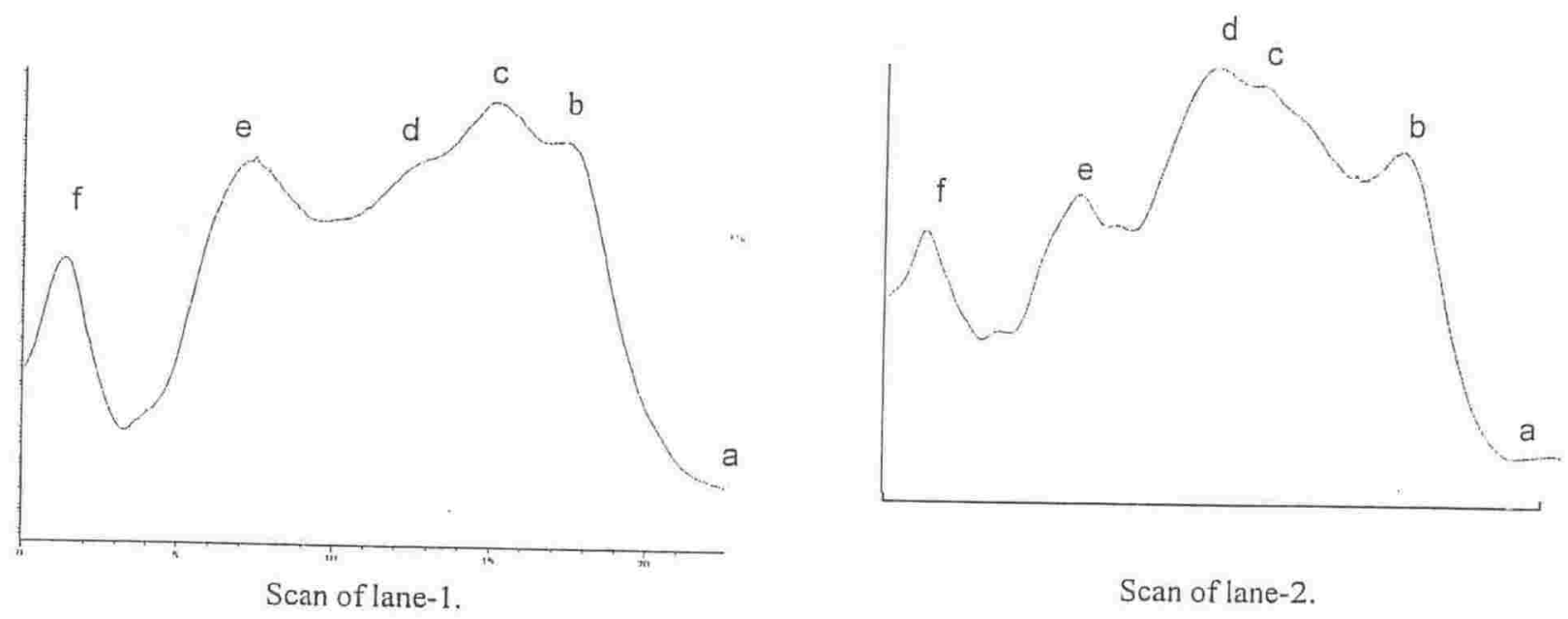

Scan of lane-2.
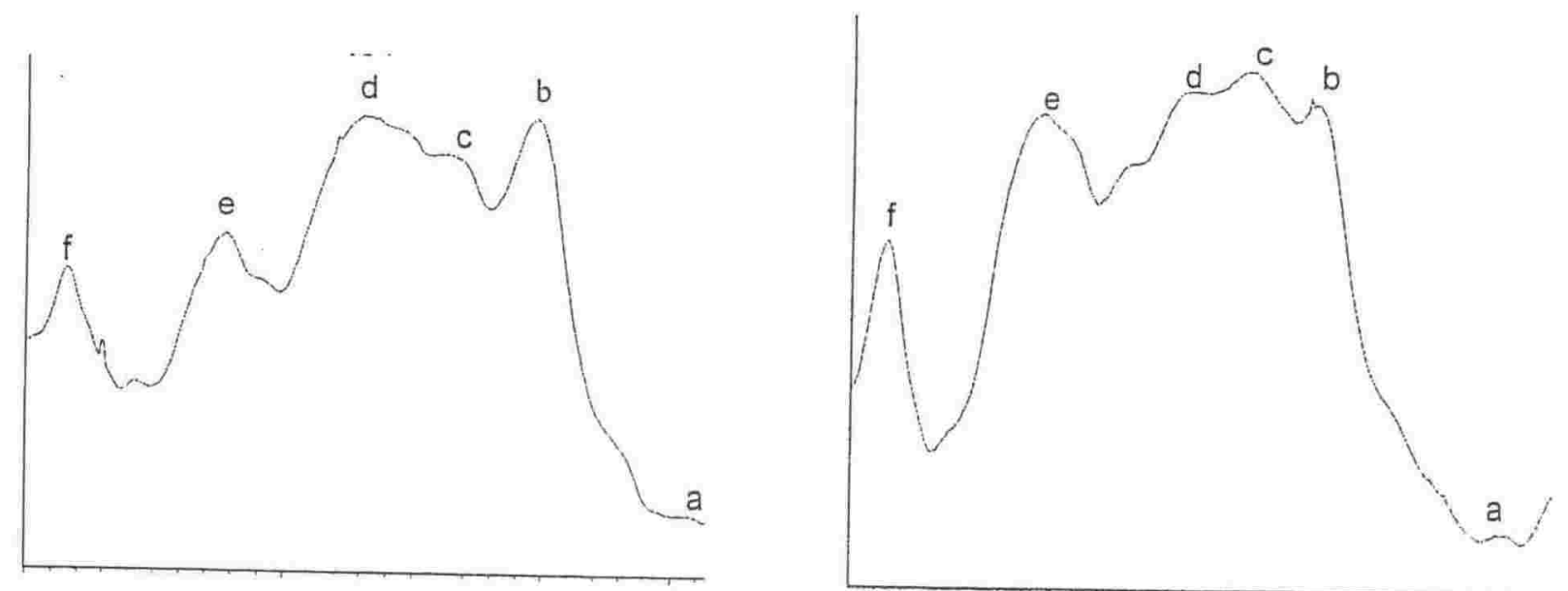

Scan of lane-3.

Scan of lane- 4 . 


\subsection{Analysis of $P-450$ by Western blotting}

Western blotting was performed to confirm the presence of cytochrome P450 in microsomal fractions from undosed susceptible and undosed resistant Romneys. Rabbit polyclonal anti-human cytochrome P-450 3A4 antibody was used as the primary antibody, and HRP conjugated goat anti-rabbit lgG was used as the secondary antibody. Dexamethasone - induced rat liver cytochrome P-450 3A1 was used as a standard for blotting, as described in Materials and Methods.

The results obtained by immunoblotting (Figure 3.26) show that anti-human cytochrome P-450 $3 \mathrm{~A} 4$ antibody bound to at least two immunoreactive bands in the sheep liver microsomal extracts. The two immunostained bands of each sample show a close similarity in pattern and intensity. The estimated apparent molecular weight of the stained protein bands was between 51-59 kDa. Because the four samples from the selected lines did not show any pattern or intensity differences a decision was made not to proceed further. 


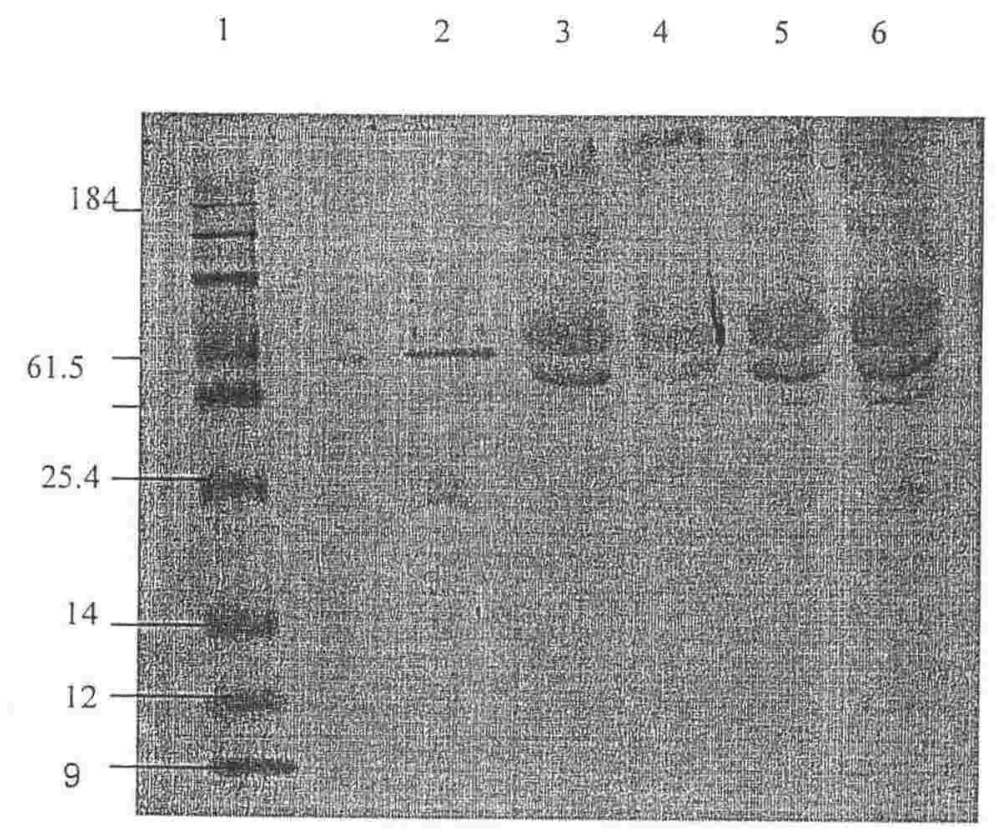

Figure 3.26: Immunoblot of sheep liver microsomal proteins from two undosed susceptible and two undosed resistant animals reacted with anti-human cytochrome P-450 3A4 antibody. Lane1 shows Benchmark molecular weight markers. Lane 2 positive control contains the dexamethazone induced rat liver cytochrome P-450 3A1. Lanes 3 and 4 contain undosed susceptible microsomal protein. Lanes 5 and 6 contain undosed resistant microsomal protein. 


\section{$3.10 \mathrm{GSH}$ dependent metabolism of sporidesmin}

\subsubsection{Spectrophotometric analysis of the reaction of sporidesmin with GSH}

GSH dependent interactions with sporidesmin were studied initially using a spectrophotometric assay. A spontaneous, non-enzymatic reaction between $G S H$ and sporidesmin was observed by Sissons et al. (1980) with a suggested pathway as shown below:

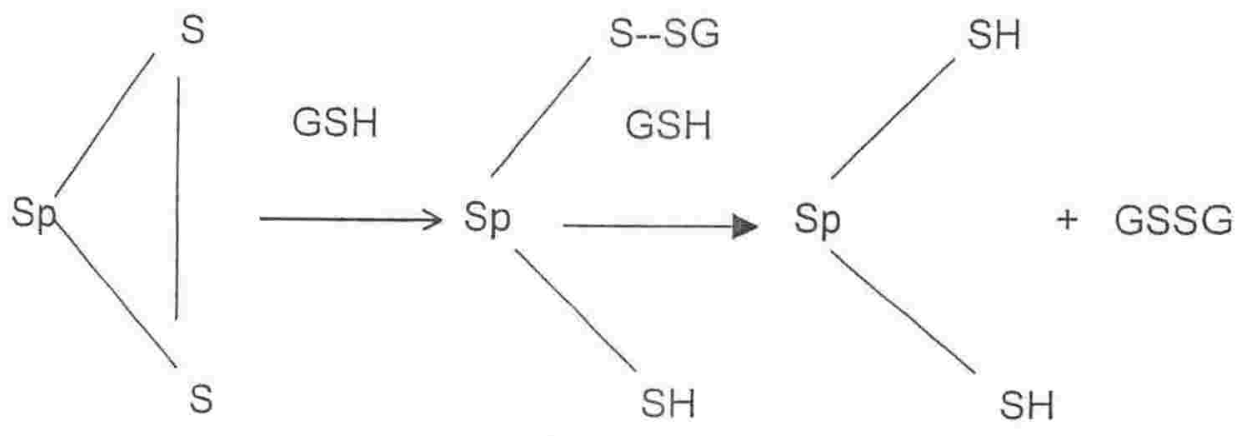

The initial aim of this study was to obtain absorption spectra for GSH and for sporidesmin, and to determine any spontaneous chemical reaction, between them prior to studying potential enzymatic catalysis of reactions. The interaction of 0.7 $\mu \mathrm{M}$ sporidesmin with $5 \mathrm{mM}$ GSH was initially examined by analysis of changes in the absorption spectrum in incubates containing $3 \mathrm{ml} 0.1 \mathrm{M}$ potassium phosphate buffer $\mathrm{pH} 7.4,5 \mathrm{mM} \mathrm{GSH}$ and $0.7 \mu \mathrm{M}$ sporidesmin at $25^{\circ} \mathrm{C}$. Figure 3.27 shows the absorption spectrum of $5.7 \mu \mathrm{M}$ sporidesmin in the absence of GSH. Sporidesmin 
absorbed maximally at approximately $254 \mathrm{~nm}$ with a smaller peak at around 300 $\mathrm{nm}$. The absorption spectrum of sporidesmin did not change with time.

Figure 3.28 shows the absorption spectrum of $5 \mathrm{mM}$ GSH alone with an absorption maximum less than $240 \mathrm{~nm}$. Spontaneous reaction of $0.7 \mu \mathrm{M}$ sporidesmin with 5 mM GSH (Figure 3.29) gave a progressive decrease in absorbance with greatest change in the region $230-260 \mathrm{~nm}$. The reaction products were not characterized. Potential products include mixed disulphides such as $\mathrm{Sp}(\mathrm{SH}) \mathrm{SSG}$, or possibly products of the reaction of GSH with the chlorine atom of sporidesmin.. 


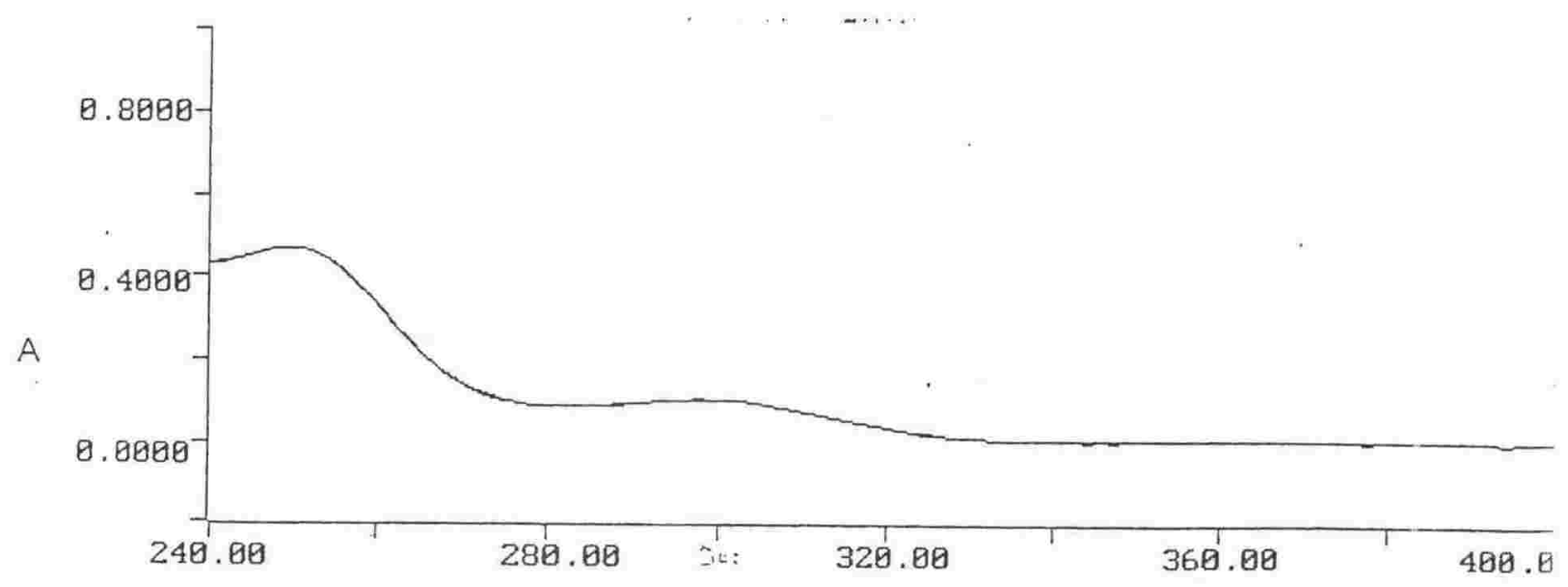

Wavelength $(\mathrm{nm})$

Figure 3.27: The absorption spectrum $(200-400 \mathrm{~nm})$ of $5.7 \mu \mathrm{M}$ sporidesmin in $3 \mathrm{ml}$ buffer.

There was an absorption maximum at $254 \mathrm{~nm}$, with a smaller absorption peak at approximately $300 \mathrm{~nm}$. The absorption spectrum of sporidesmin in buffer did not change with time.

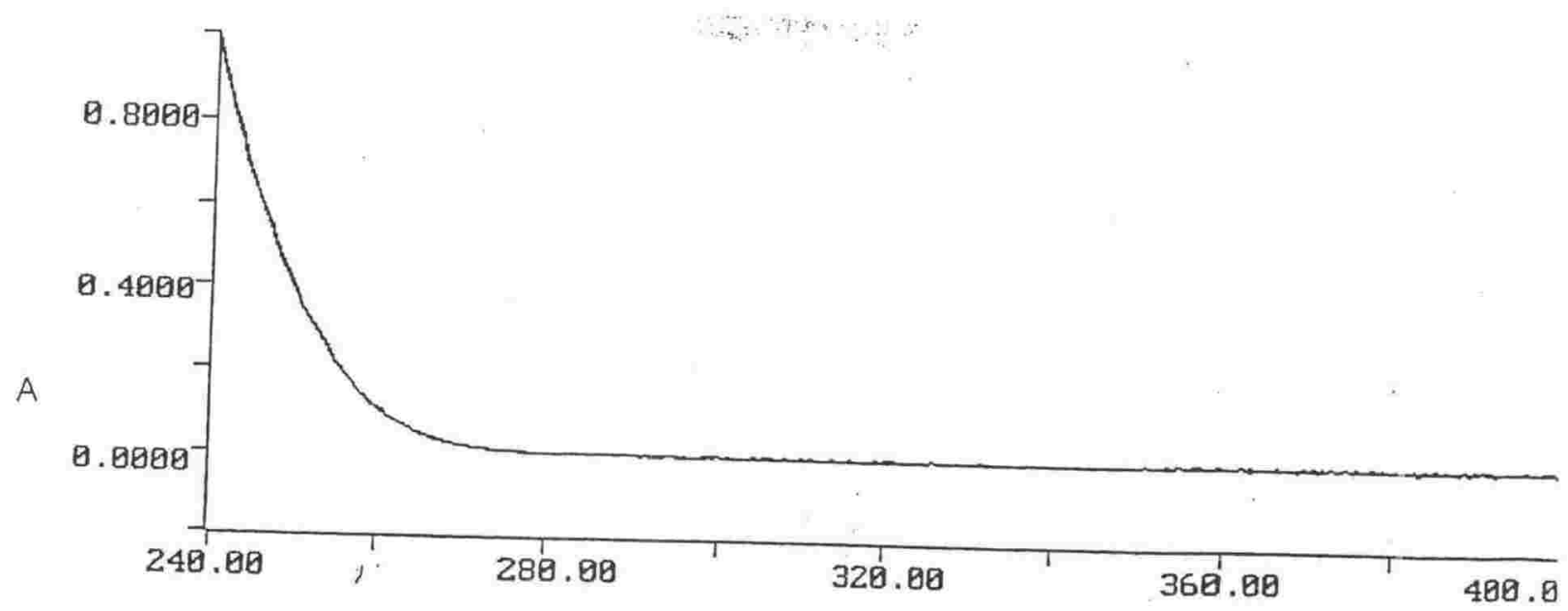

Wavelength $(\mathrm{nm})$

Figure 3.28: Absorption spectrum of $5 \mathrm{mM}$ GSH. 


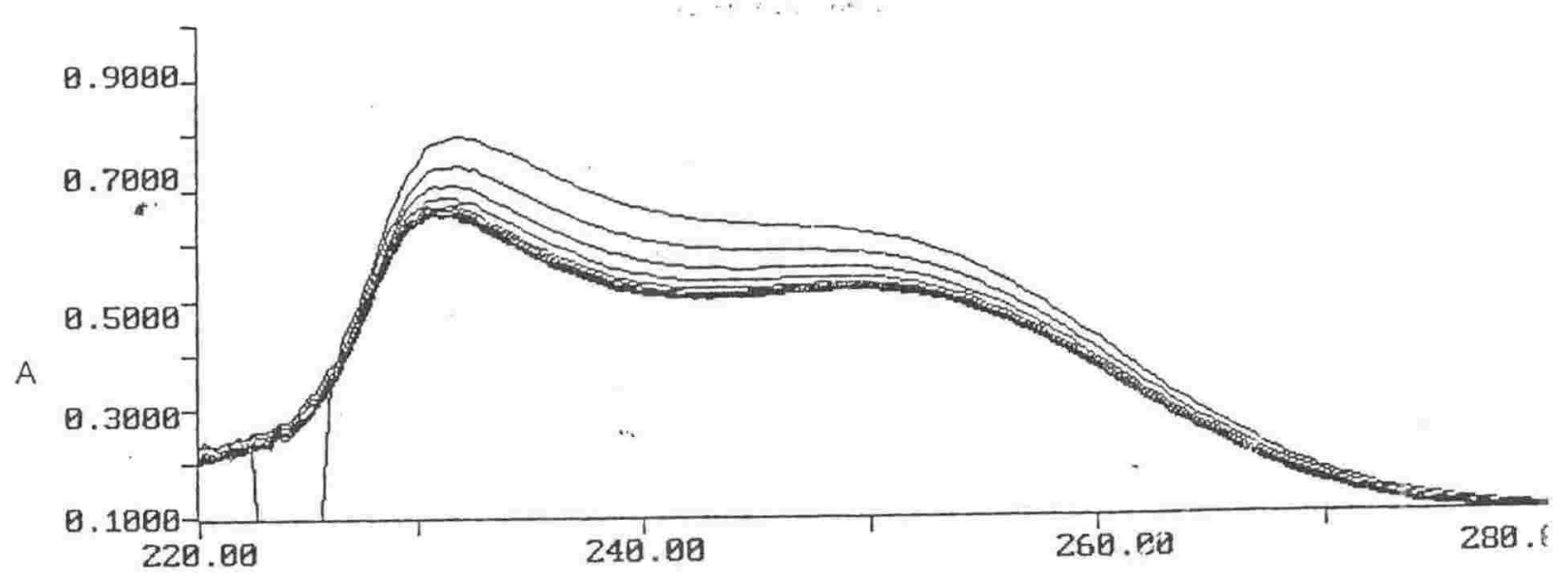

Wavelength $(\mathrm{nm})$

Figure 3.29: Analysis of the non-enzymatic reaction between $0.7 \mu \mathrm{M}$ sporidesmin and $5 \mathrm{mM}$ GSH. Sporidesmin was omitted from the reference cuvette. 


\subsubsection{Enzyme catalysed reaction between sporidesmin and GSH}

The effect of sheep liver cytosol on reaction between $0.7 \mu \mathrm{M}$ sporidesmin and $5 \mathrm{mM}$ GSH was examined by measuring the change in absorbance between $220-280 \mathrm{~nm}$ at $25^{\circ} \mathrm{C}$. The rate of reaction between $0.7 \mu \mathrm{M}$ sporidesmin and $5 \mathrm{mM}$ GSH doubled compared to the spontaneous reaction when $100 \mu \mathrm{l}(80 \mu \mathrm{g}$ protein) of sheep liver supernatant from sheep 7305 was added to the reaction as shown in Figure 3.30. The maximum decrease in absorbance occurred at the wavelength previously detected for the spontaneous reaction (Figure 3.29). There was no evidence of spectral differences reflecting formation of products other than those produced by spontaneous reaction of sporidesmin with GSH.

The reaction was further investigated by changing the amount of the cytosolic protein to see if there was any change in the rate of reaction. In a series of reactions in which the spontaneous non-enzymatic rate between sporidesmin and GSH was $0.083 \mathrm{~A} / \mathrm{min}$, the enzymatic reaction rates (spontaneous rate subtracted) were 0.095 and $0.19 \mathrm{~A} / \mathrm{min}$ for 40 and $80 \mu \mathrm{g}$ of cytosolic protein.

\begin{tabular}{|c|c|c|}
\hline $\begin{array}{c}\text { Spontaneous reaction } \\
(\mathrm{A} / \mathrm{min})\end{array}$ & $\begin{array}{c}50 \mu \text { enzyme } \\
(\mathrm{A} / \mathrm{min})\end{array}$ & $\begin{array}{c}100 \mu \mathrm{l} \text { enzyme } \\
(\mathrm{A} / \mathrm{min})\end{array}$ \\
\hline 0.086 & 0.1720 & 0.2540 \\
\hline 0.080 & 0.1841 & 0.2920 \\
\hline Mean: 0.083 & 0.1781 & 0.2730 \\
\hline
\end{tabular}

Table 3.16: Enzyme catalysed reaction of sporidesmin with GSH. Results are duplicate measurements with means for the spontaneous and enzymatic reaction of 40 and $80 \mu \mathrm{g}$ cytosolic protein. 


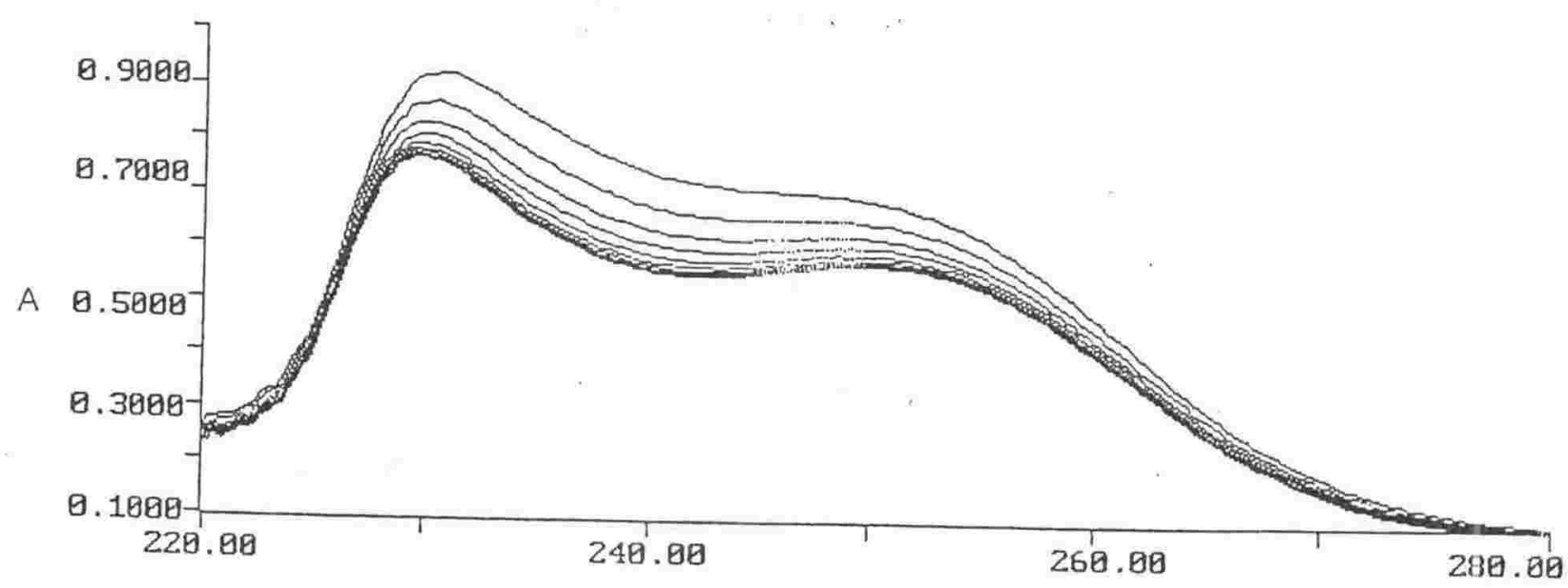

Wavelength (nm)

Figure 3.30: The enzyme catalysed reaction between sporidesmin and GSH. The test reaction contained $0.7 \mu \mathrm{M}$ sporidesmin and $5 \mathrm{mM} \mathrm{GSH}$ in the presence of $80 \mu \mathrm{g}$ liver supernatant protein. Enzyme was omitted from the reference cuvette. 


\subsection{Spectrophotometric determination of GSH-dependent enzyme catalysed reaction with sporidesmin for the Romney selection lines}

Rates of GSH-dependent reaction with sporidesmin were measured using liver supernatants from 1997 born undosed and dosed animals from the resistant and susceptible selection lines. Mean rates $(n=5)$ of absorbance change $(A /$ min $/$ mg protein) were $0.074 \pm 0.03$ for undosed resistants, $0.042 \pm 0.014$ for undosed susceptibles, $0.039 \pm 0.01$ for dosed resistants and $0.035 \pm 0.02$ for dosed susceptibles.

\subsection{HPLC analysis of the reaction of sporidesmin with GSH}

GSH dependent metabolism of sporidesmin was investigated using HPLC. Sporidesmin $(5.7 \mu \mathrm{M})$ was incubated at $37{ }^{\circ} \mathrm{C}$ for 30 min with approximately $50 \mu \mathrm{g}$ of liver cytosol protein with or without 5-10 mM GSH. Figure 3.31 shows separation of sporidesmin from GSH but loss of sporidesmin occurred to a similar extent in the presence of liver cytosol with or without added GSH. Cellular concentrations of GSH are typically $5-10 \mathrm{mM}$. It is therefore possible that endogenous GSH in the cytosolic extract (calculated to be 1-2 $\mathrm{mM}$ after dilution of tissue with homogenisation medium) was sufficient to catalyse reaction with sporidesmin in the absence of added GSH. No attempt was made to repeat this measurement with supernatant that had been depleted of GSH. It was decided instead to use model substrates to measure GST activities. 


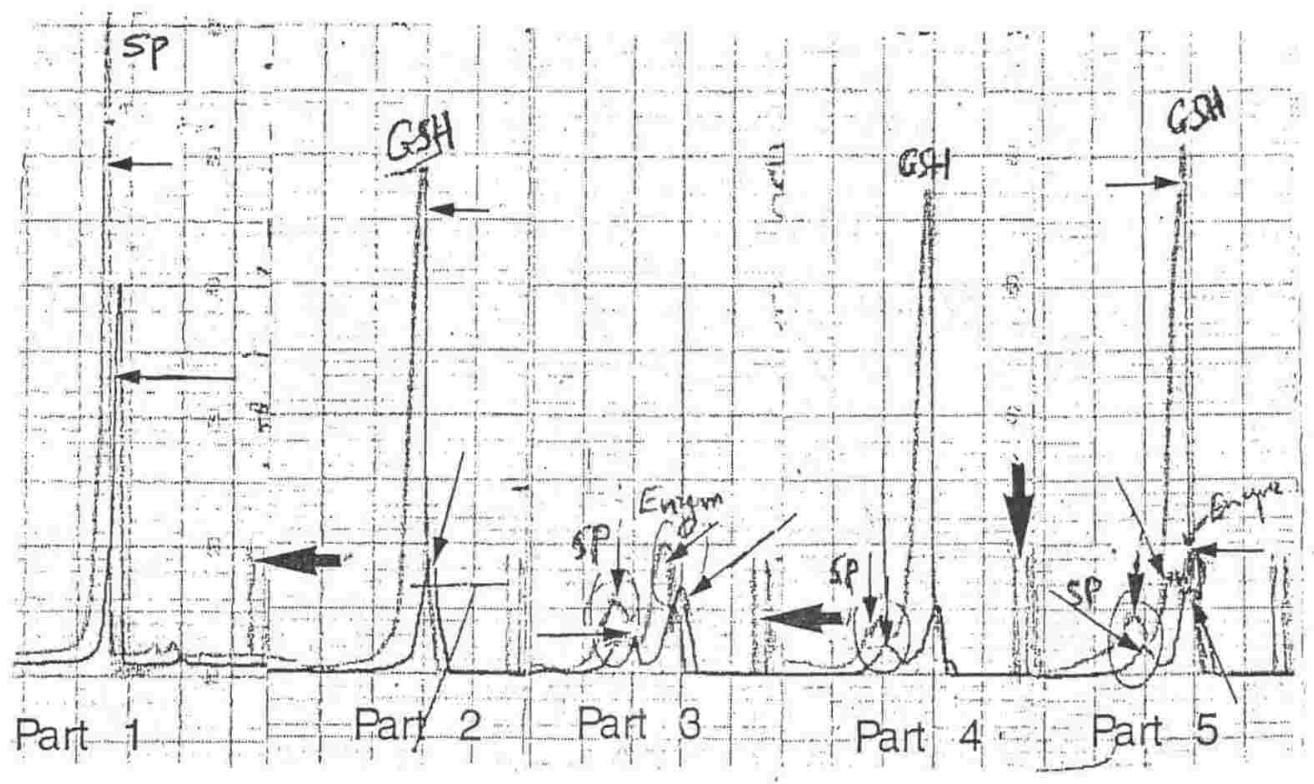

Figure 3.31: The interaction of a cytosolic enzyme with sporidesmin in the presence or absence of GSH and the interaction of sporidesmin with GSH alone. The measurement was carried out with detection at 230 and $260 \mathrm{~nm}$.

Part 1: Chromatogram of $5.7 \mu \mathrm{M}$ sporidesmin.

Part 2: Chromatogram of $5 \mathrm{mM} \mathrm{GSH}$.

Part 3: Chromatogram of sporidesmin in the presence of liver cytosol.

Part 4: Chromatogram of sporidesmin in the presence of GSH.

Part 5: Chromatogram of sporidesmin in the presence of liver cytosol and GSH.

Note:

Sp.: sporidesmin.

GSH: glutathione.

Thin short arrows refer to $230 \mathrm{~nm}$ wavelength.

Thin long arrows refer to $260 \mathrm{~nm}$ wavelength.

Thick short arrows refer to initial injection line. 


\subsection{Analysis of GST activities using model substrates}

\subsubsection{CDNB and DCNB}

\section{Animals born 1997}

GST activity toward CDNB and DCNB substrates was measured using the spectrophotometric method of Habig and Jakoby (1981). Assays contained approximately $50 \mu \mathrm{g}$ of sheep liver cytosol, $1 \mathrm{mM}$ CDNB or $1 \mathrm{mM}$ DCNB and 1 $\mathrm{mM}$ GSH for CDNB and $5 \mathrm{mM}$ GSH for DCNB. Activity with CDNB was greater than with DCNB but for each substrate, activities were similar among the four experimental groups as shown in Tables 3.17 and 3.18. No statistically significant differences were found among the groups for either substrate CDNB $(p=0.78$ for undosed susceptible and undosed resistant and $p=0.85$ for dosed susceptible and dosed resistant animals) or DCNB ( $p=0.1$ for undosed susceptible and undosed resistant and $p=0.84$ for dosed susceptible and dosed resistant animals). 


\begin{tabular}{|l|c|}
\hline \multicolumn{1}{|c|}{ CDNB } & $\begin{array}{c}\text { Specific activity }(\mu \mathrm{mol} / \mathrm{min} / \mathrm{mg} \text { protein) } \\
\text { Mean } \pm \text { SD }(n=5)\end{array}$ \\
\hline Undosed susceptible & $0.75 \pm 0.2$ \\
\hline Undosed resistant & $0.79 \pm 0.3$ \\
\hline Dosed susceptible & $0.82 \pm 0.2$ \\
\hline Dosed resistant & $0.67 \pm 0.2$ \\
\hline
\end{tabular}

Table 3.17: GST activity towards CDNB. Results are from duplicate measurements of rates for each animal born 1997.

\begin{tabular}{|l|c|}
\hline \multicolumn{1}{|c|}{ DCNB } & $\begin{array}{c}\text { Specific activity }(\mu \mathrm{mol} / \mathrm{min} / \mathrm{mg} \text { protein) } \\
\text { Mean } \pm \mathrm{SD}(\mathrm{n}=5)\end{array}$ \\
\hline Undosed susceptible & $0.14 \pm 0.1$ \\
\hline Undosed resistant & $0.16 \pm 0.04$ \\
\hline Dosed susceptible & $0.15 \pm 0.03$ \\
\hline Dosed resistant & $0.13 \pm 0.03$ \\
\hline
\end{tabular}

Table 3.18: GST activity towards DCNB. Results are from duplicate measurements of rates for each animal born 1997. 


\section{$\underline{3.13 .2 \mathrm{p}-\mathrm{NBC}}$}

Liver cytosolic GST activity towards p-NBC was measured at $310 \mathrm{~nm}$ and $25^{\circ} \mathrm{C}$. This substrate is preferentially used by GST class Theta in rat (rT1-1) (Meyer et al., 1991) and human (hT1-1) (Meyer et al., 1991; Sherratt et al., 1997). Activity was greatest in undosed resistants compared to undosed susceptibles for animals born in 1995 and 1997 although standard deviations were relatively large (Table 3.19).

\subsubsection{EPNP}

Table 3.20 shows the results of analysis of liver cytosolic enzyme from undosed susceptible and undosed resistant animals born 1997. EPNP is preferentially used to measure Theta class GST in rat (rT1-1) (Meyer et al., 1991) and human (hT1-1) (Meyer et al., 1991; Jemth and Mannervik, 1997; Sherratt et al., 1997). There was a 1.8 fold greater activity in undosed resistant animals compared to undosed susceptibles. The data also show a moderate variation in activity within each group. 


\begin{tabular}{|l|c|}
\hline \multicolumn{1}{|c|}{$p-N B C$} & $\begin{array}{r}\text { Specific activity (nmol/min/mg protein) } \\
\text { Mean } \pm \text { SD }(n=5)\end{array}$ \\
\hline Undosed susceptible & $244.6 \pm 59.7$ \\
\hline Born 1995 & $317.6 \pm 78.2$ \\
Born 1995 & \\
\hline Undosed susceptible & $235.87 \pm 106.8$ \\
Born 1997 & \\
\hline Undosed resistant & $388.72 \pm 149.5$ \\
Born 1997 & \\
\hline
\end{tabular}

Table 3.19: Liver cytosolic GST activity towards p-NBC for undosed Romneys born in 1995 and 1997.

\begin{tabular}{|l|c|}
\hline \multicolumn{1}{|c|}{ EPNP } & $\begin{array}{c}\text { Specific activity }(\mathrm{nmol} / \mathrm{min} / \mathrm{mg} \text { protein) } \\
\text { Mean } \pm \mathrm{SD}(\mathrm{n}=5)\end{array}$ \\
\hline Undosed susceptible & $23.53 \pm 7.3$ \\
\hline Undosed resistant & $41.21 \pm 11.1$ \\
\hline
\end{tabular}

Table 3.20: Liver cytosolic GST activity towards EPNP as a substrate for animals born 1997. 


\subsubsection{Statistical analysis for GST activities using model substrates}

\subsubsection{GST- CDNB activity}

The measurements were obtained from Romneys born in 1997. Analysis of variance (ANOVA) was used to test for differences between the levels of the factors "dose" and "resistance" and the interaction between "dose" and "resistance". The analysis was carried out on the raw data and on logtransformed data, and the results of these two analyses were very similar. The $p$ - values quoted are from the analysis on the log-transformed data. The interaction effect was not significant $(p=0.41)$, neither were either of the main effects (resistance: $p=0.66$; dose: $p=0.87$ ).

\subsubsection{GST-DCNB activity}

The measurements were obtained from Romneys born in 1997. Analysis of variance was used to test for differences between the levels of the factors "dose" and "resistance" and the interaction between "dose" and "resistance". The data were not transformed. The interaction effect was not significant $(p=0.84)$, nor was the resistance effect $(p=1.0$ as the means of the resistant and susceptible animals were in fact equal), nor was the dose effect ( $p>0.8)$. 


\subsubsection{GST-p-NBC}

ANOVA was carried out on the GSH-dependent enzyme measurement for p-NBC, with factors "resistance", "year" and the interaction between "year" and "resistance". The interaction effect was not significant $(p=0.55)$, nor was the year effect $(p=0.48)$. The resistance effect was significant $(p=0.01)$, a result confirmed by a Wilcoxon Rank - sum test (the mean for the resistant sheep was higher in both years than was the mean for the susceptible sheep).

\subsubsection{GST- EPNP activity}

Two sample t-test showed a significant difference $(p=0.0174)$ between the resistant and the susceptible animals, in the measurement of the enzyme activity toward the EPNP substrate, in animals born 1997. This result was confirmed by using the Exact Wilcoxon rank -sum test, which recorded a significant difference between the resistant and the susceptible animals at the level of $p=0.015$.

\section{$\underline{3.13 .4 .5 \text { GST- sporidesmin activity }}$}

Analysis of variance was carried out using the log-transformed data, with the factors "dose" "resistance" and the interaction between "dose" and "resistance". The interaction between dose and resistance was not significant at the $5 \%$ level $(p=0.08)$. Neither of the main effects was statistically significant $(p=$ 0.196 for resistance and $p=0.3$ for dose). 


\subsection{1-D PAGE of liver supernatant from undosed susceptible and undosed}

\section{resistant Romneys}

Multiple forms of GSTs have been isolated and purified from mammalian organs (Mannervik et al., 1985; Board et al., 1990) including sheep liver (Miller et al., 1994; Lenartova et al., 1996). Mammalian cytosolic GSTs have molecular weights of approximately 48,000 , with subunits of 23,000 to 25,000 (Mannervik et al., 1985).

1-D PAGE of liver $100,000 \mathrm{~g}$ supernatant from four undosed susceptible and four undosed resistant 1997 born Romneys was carried out to search for possible differences in GST. Figure 3.32 shows Coomassie Blue stained gels of four undosed susceptible and four undosed resistant 100,000 g supernatants. Two animals from each of the undosed susceptible and undosed resistant lines were analysed by scanning the 1-D gel lanes (Figure 3.33). The scanned region of each gel contained bands within the region $12-28 \mathrm{kDa}$ that was expected to show GST subunits. There were no consistent differences between the resistant and susceptible samples although there was some variation among individuals from each of the experimental groups. 


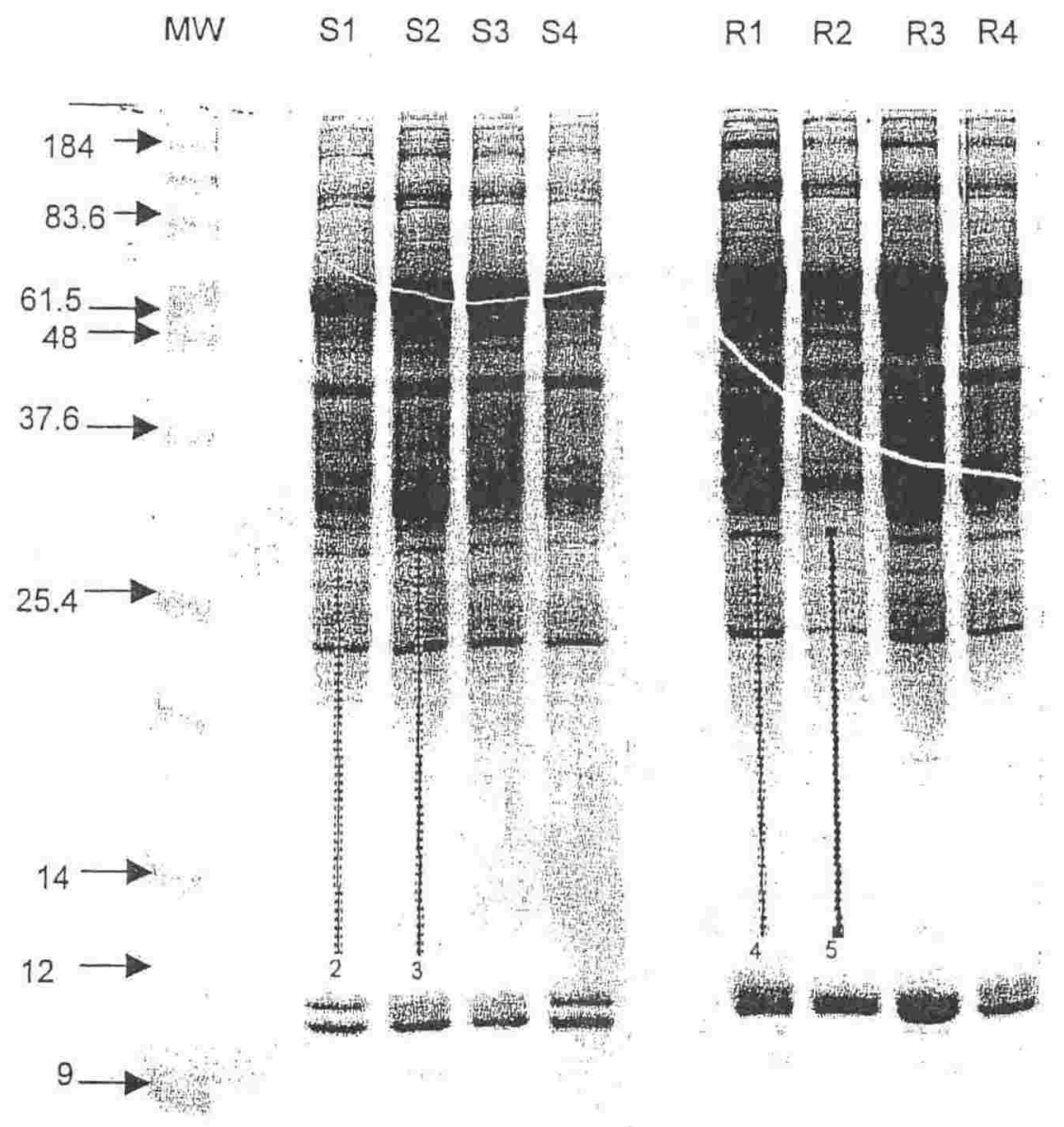

Figure 3.32: 1-D PAGE of liver 100,000 g supernatant from four undosed susceptible and four undosed resistant Romneys. Bars 2, 3, 4, and 5 show the scanned $12-28 \mathrm{kDa}$ protein regions. The MW lane contains protein markers where sizes are indicated in $\mathrm{kDa}$. 


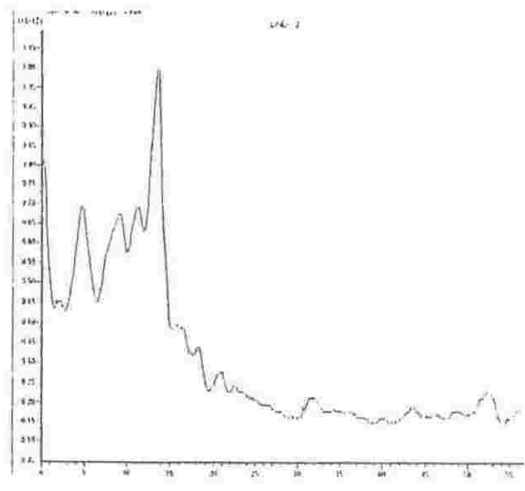

Analysis of lane 2, Figure 3.32

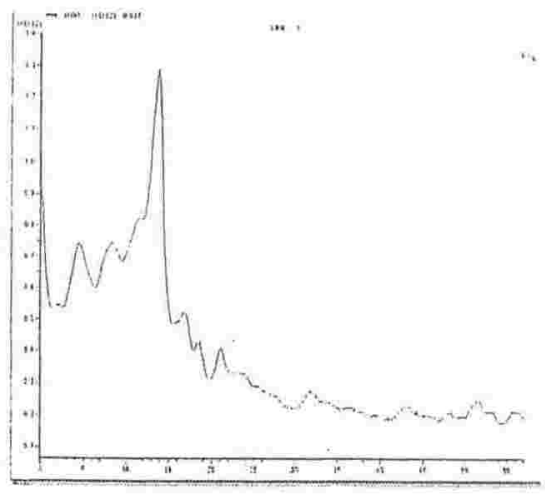

Analysis of lane 4, Figure 3.32

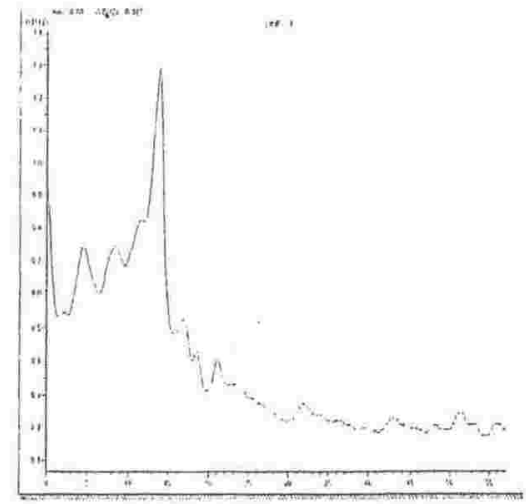

Analysis of lane 3, Figure 3.32

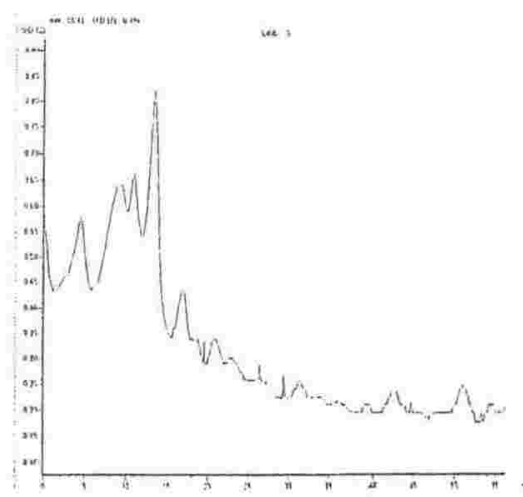

Analysis of lane 5, Figure 3.32

Figure 3.33: The scanned images of regions (12 - $28 \mathrm{kDa})$ that contained potential GST subunit. Lane 2 and 3: The analysis of scanned regions of the undosed susceptible samples S1 and S2. Lane 4 and 5: The analysis of scanned regions of the undosed resistant samples R1 and R2. 


\subsection{Analysis of protein variation by 2-D PAGE}

2-D PAGE was used to search for protein variation between the Romney lines. Initially a comparison was made of variation among total homogenate proteins using pools of liver from five resistant Romneys and from five susceptible Romneys and this was extended to analysis of $100,000 \mathrm{~g}$ supernatant protein. Variation among the GSTs may be detected in the whole homogenates although some of these enzymes have alkaline pls and would not be seen on the 2-D gels. It is also possible that P-450 isoforms might be detected but these microsomal proteins are expected to be low abundance in whole homogenates and many have alkaline pls and would not be detected in the focusing range used.

Figures 3.34 and 3.35 show pools of liver homogenate proteins from five undosed susceptible and five undosed resistant animals separated by 2-D PAGE. To simplify the analysis, a pooling protocol was used whereby the homogenates from five individuals in each group were pooled and examined on a single gel. This technique allows rapid comparison of variation among groups. Approximately 200-300 protein spots were observed on each gel and approximately 130 of the most abundant spots were chosen for quantitative analysis. The protein spots were located within a pl range of $3.5-7.5$, and within the size range 14 - $66 \mathrm{kDa}$. Spots were assigned a number that was consistently used for that protein on all of the gels prepared from the pools of the susceptible and resistant animals. Visual inspection of the separated proteins from the pooled susceptible and resistant animals showed few changes in protein pattern 
although eighteen proteins appeared to show some variation in amount between the susceptible and resistant lines (Figures $3.36 a-d)$. 


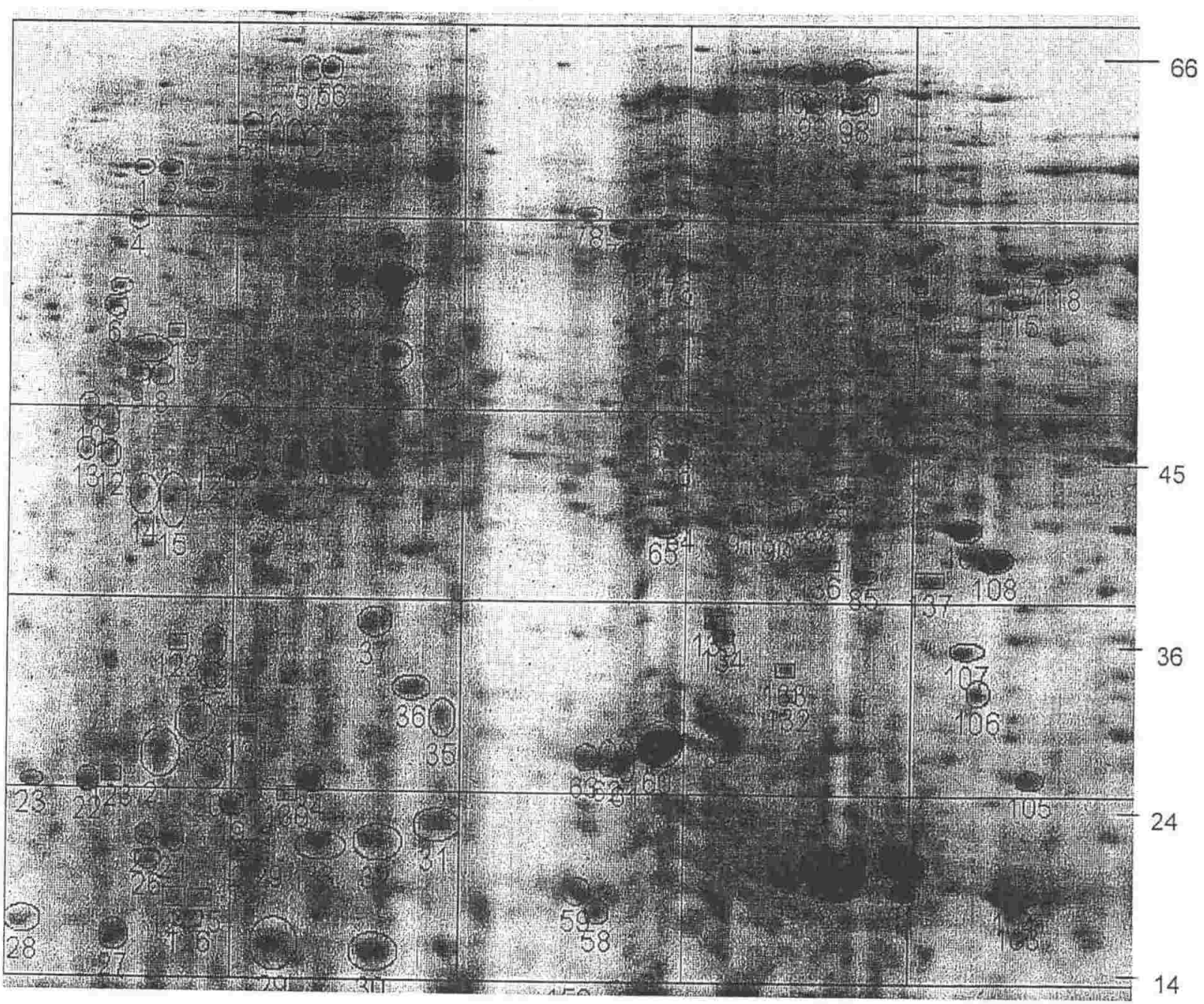

Figure 3.34: 2-D PAGE of pooled liver homogenates from five undosed susceptible Romneys.

Numbered objects show the spots selected for quantitative analysis. 


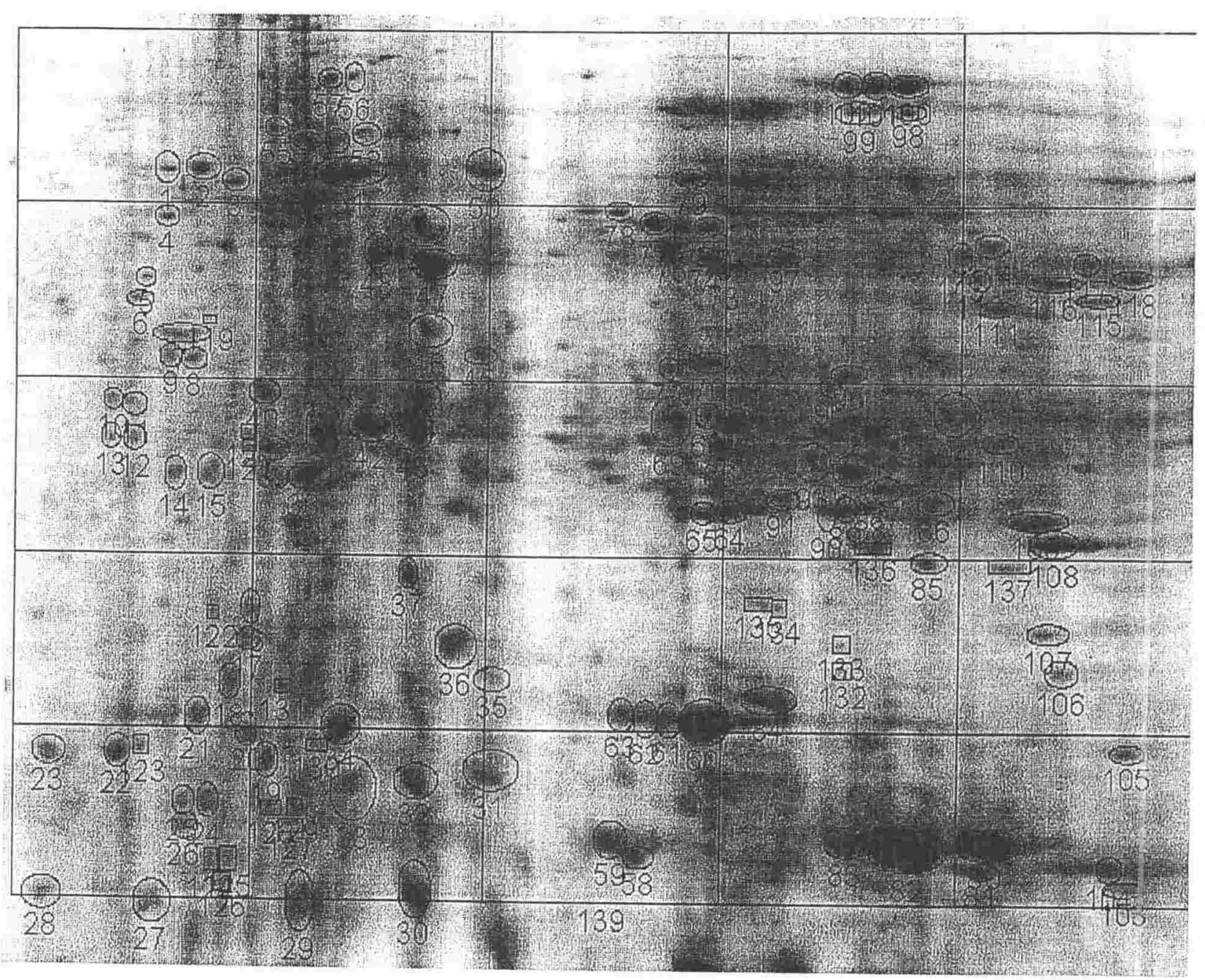

Figure 3.35: 2-D PAGE of pooled liver homogenates from five undosed resistant Romneys. Numbered objects show the spots selected for quantitative analysis. 


\subsubsection{Protein spot variation between resistant and susceptible lines}

To allow for reproducibility of spot detection, two gels from each pool were analysed separately. Quantitative analysis of protein variation was carried out on scanned images of the gels for 137 of the most abundant protein spots. This analysis included eighteen protein spots which appeared to vary in intensity between pools (Figures 3.36a, 3.36b, 3.36c, 3.36d). The amount of each protein spot was expressed as a percentage of the total amount of the 137 spots measured on each gel. The data plotted in Figure 3.37a shows the range of quantitative variation measured for the eighteen spots that had appeared to vary when the gels were inspected by eye. Most of those spots varied, on average, about two-fold between the resistant and susceptible lines. Results for ten spots that showed no quantitative variation between the undosed susceptible and the undosed resistant Romneys are shown in Figure 3.37b. Most of these spots varied less than $50 \%$ between the resistant and susceptible animals. Fourteen spots out of the eighteen selected variant spots showed higher abundance in the undosed resistant samples, while only four spots showed higher protein abundance in the undosed susceptible samples. From the undosed resistant samples, five spots $(4,7,46,55$ and 70$)$, showed more than 3-fold greater abundance compared to susceptibles. Two other spots (66 and 126) showed 2.5 -fold variation. The remaining seven spots $(15,30,51,82,83,110$ and 122), showed an average of 2 -fold variation between the lines. The four spots $(17,73$, 80 , and 131) that were more abundant in undosed susceptible animals showed 
an average of only 2 -fold quantitative variation. The abundance of each measured protein spot was calculated as a percentage of the abundance of all other measured protein spots on the gel. This method allows for any differences in staining between gels and allows for processing as compositional data (Aitchison, 1986).

Figures 3.34 and 3.35 show that most of the variant protein spots were present on the acidic side of the gels (eleven spots). Nine of these $(4,7,15,30$, $46,51,55,122$, and 126), were predominant in the undosed resistant sample. On the basic side of the gels seven spots showed differences in abundance between resistant and susceptible lines. Out of the seven variant spots, two spots only $(73,80)$ showed higher abundance intensity for the susceptible animals, while the other five spots $(66,70,82,83$ and 110) showed higher abundance intensity for the resistant animals as shown in Figure 3.37a. Some of the variation in protein abundance might reflect differences in the ability of the liver, from resistant or susceptible animals, to bind or metabolise compounds including sporidesmin. It is therefore possible that some of the variation between the undosed susceptible and undosed resistant animals may reflect segregation of genes which affect resistance or susceptibility to FE.

The whole homogenate gels were prepared prior to availability of mass spectrometry techniques at VUW so that no attempts were made to identify the variant proteins. 
Susceptible pool

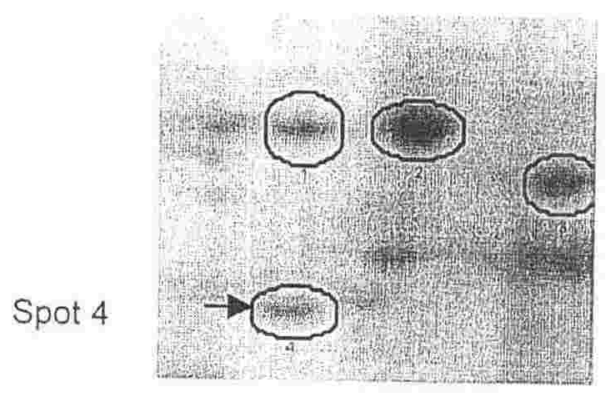

Spot 7

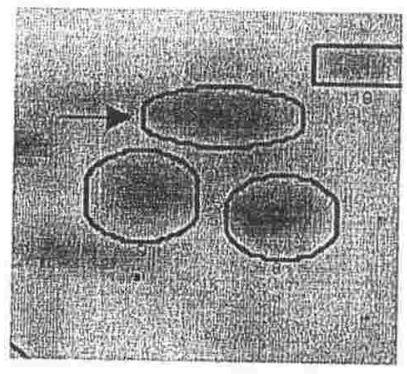

Spot 15

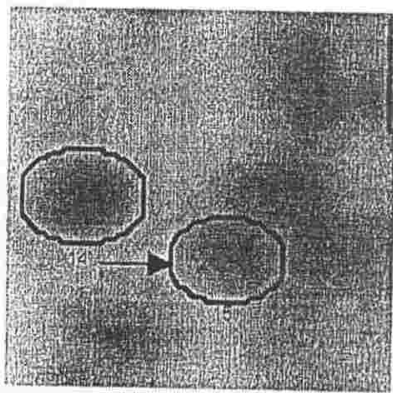

Spot 17

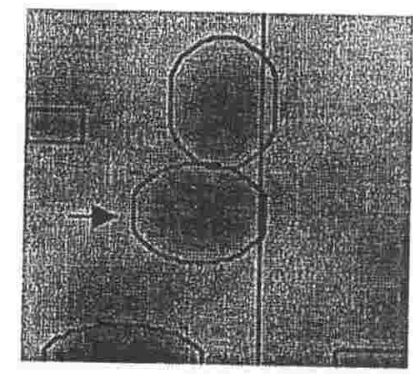

Resistant pool
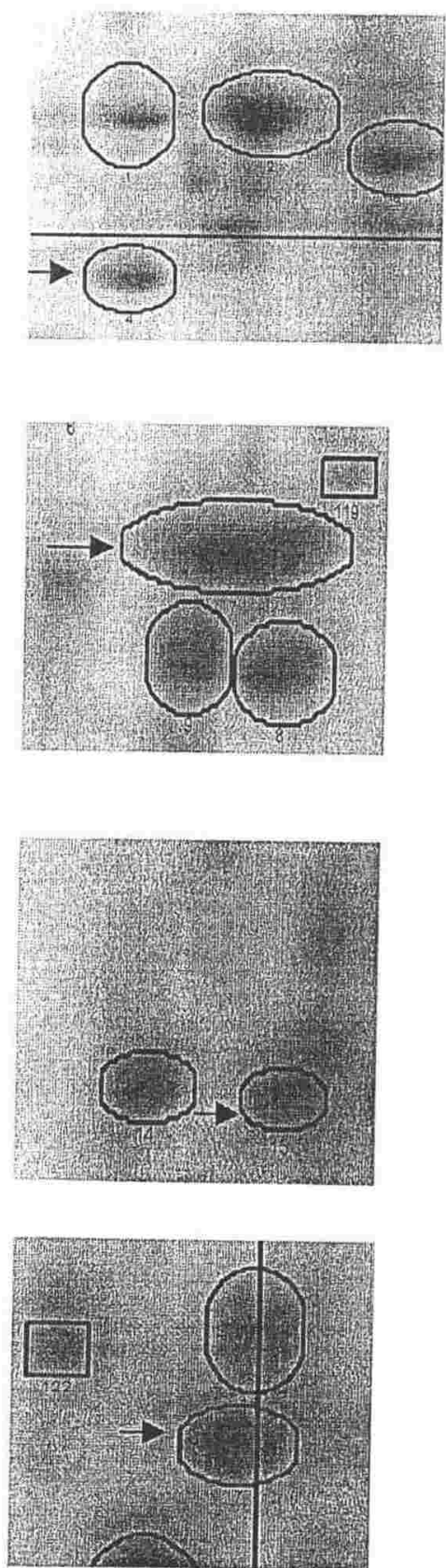

Figure 3.36a: Spots showing differences in abundance (arrows) between undosed susceptible and undosed resistant Romneys. 
Susceptible pool

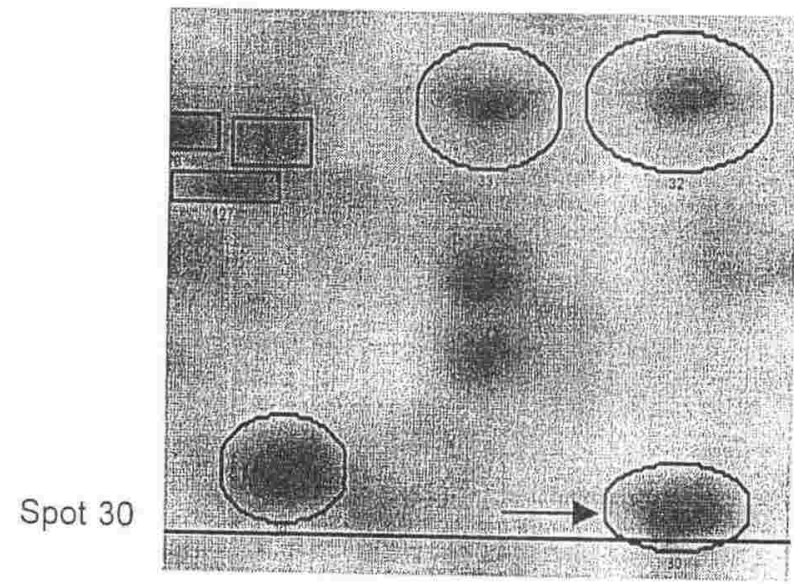

Spot 46

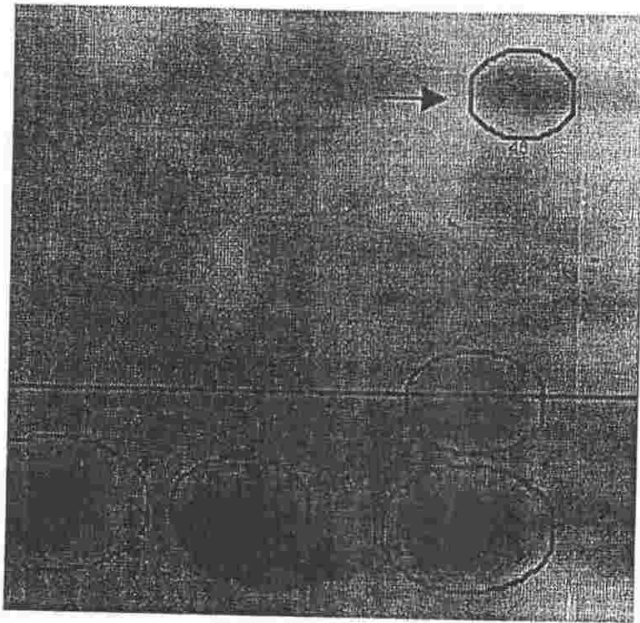

Spot 55

Spot 51

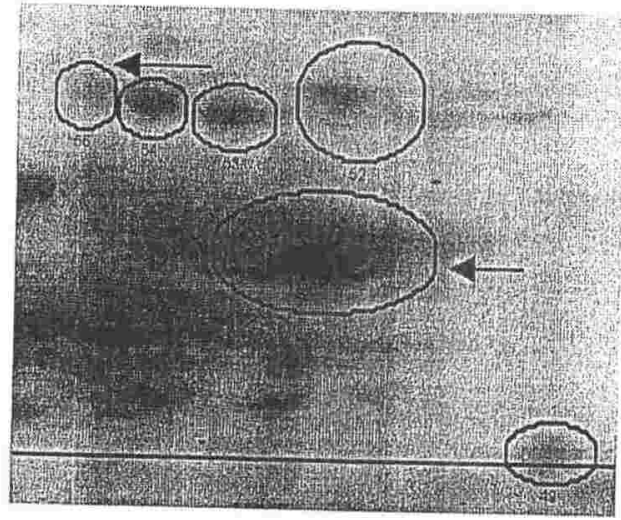

Resistant pool
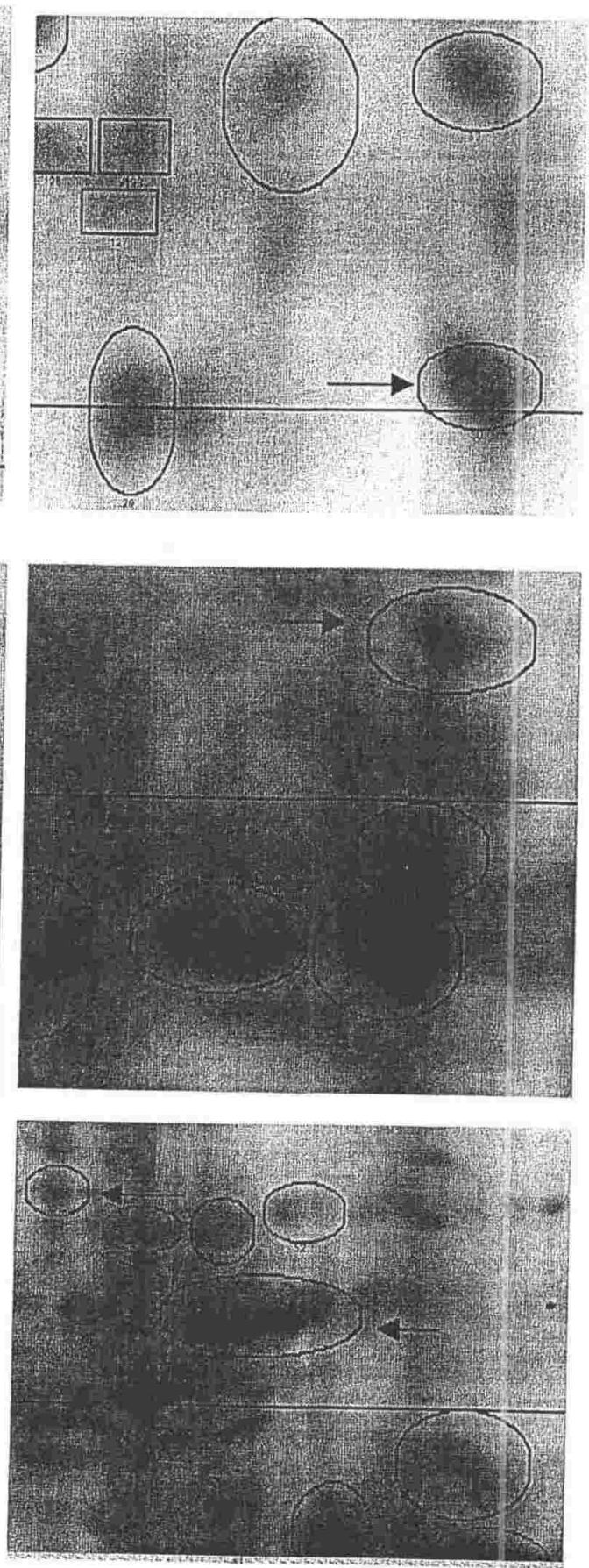

Figure 3.36b: Spots showing differences in abundance (arrows) between undosed susceptible and undosed resistant Romneys. 
Susceptible pool
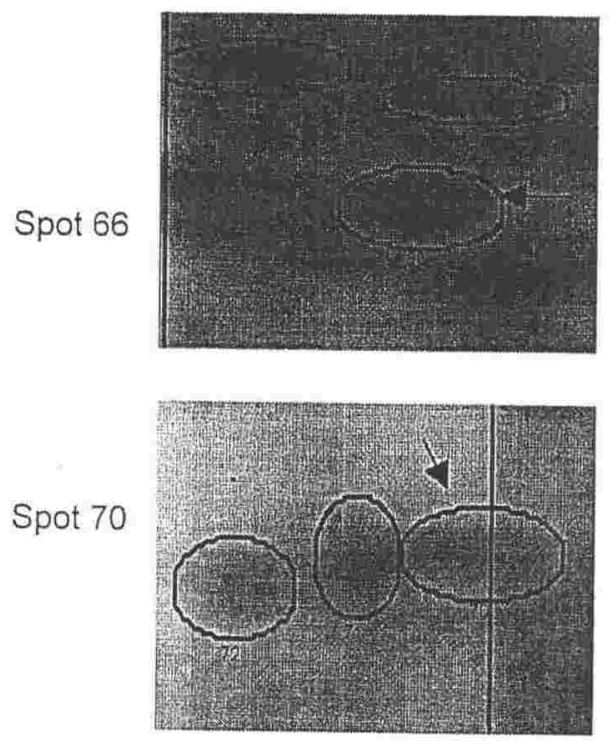

Resistant pool
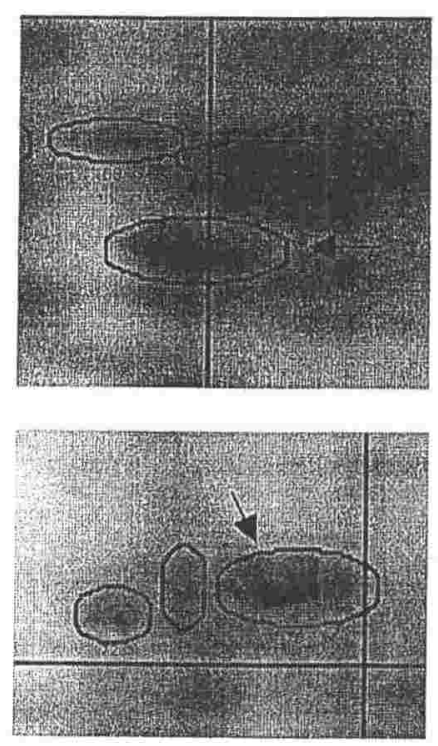
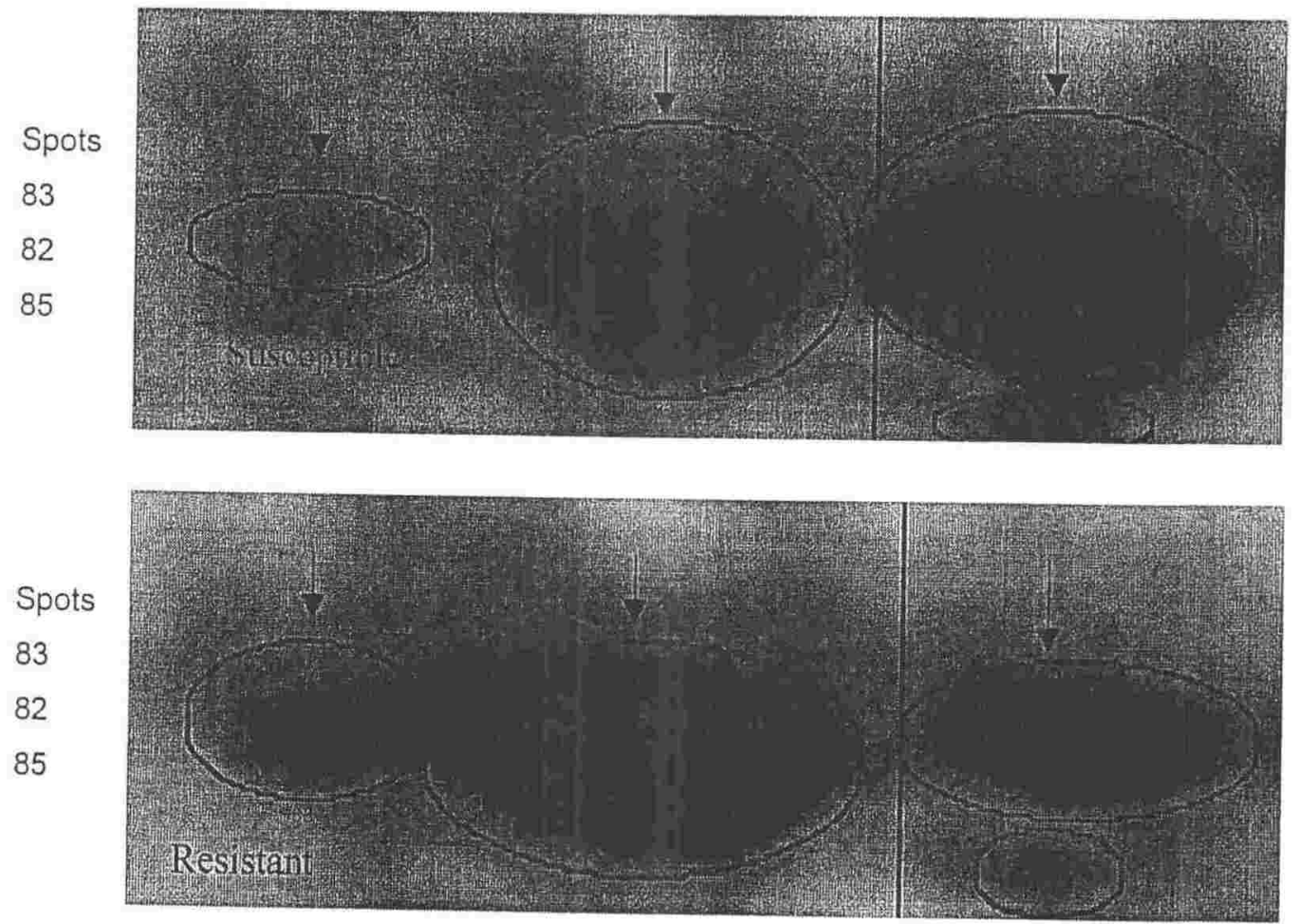

Figure 3.36c: Spots showing differences in protein abundance (arrows) between undosed susceptible and undosed resistant Romneys. 
Susceptible pool

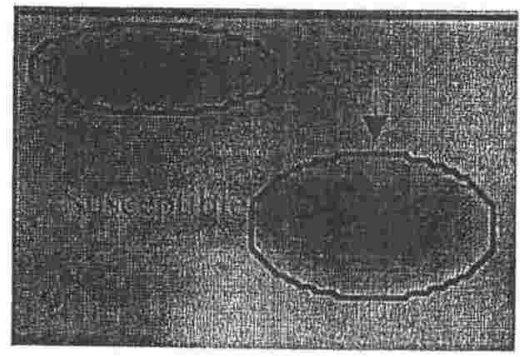

Resistant pool

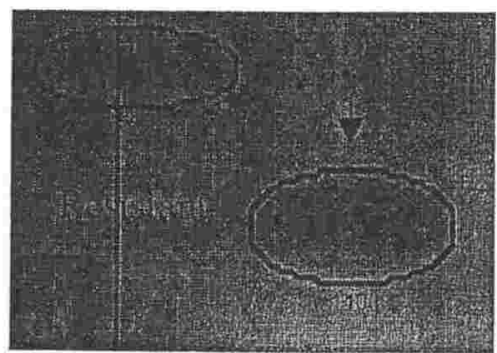

Spot 122

Spot 131

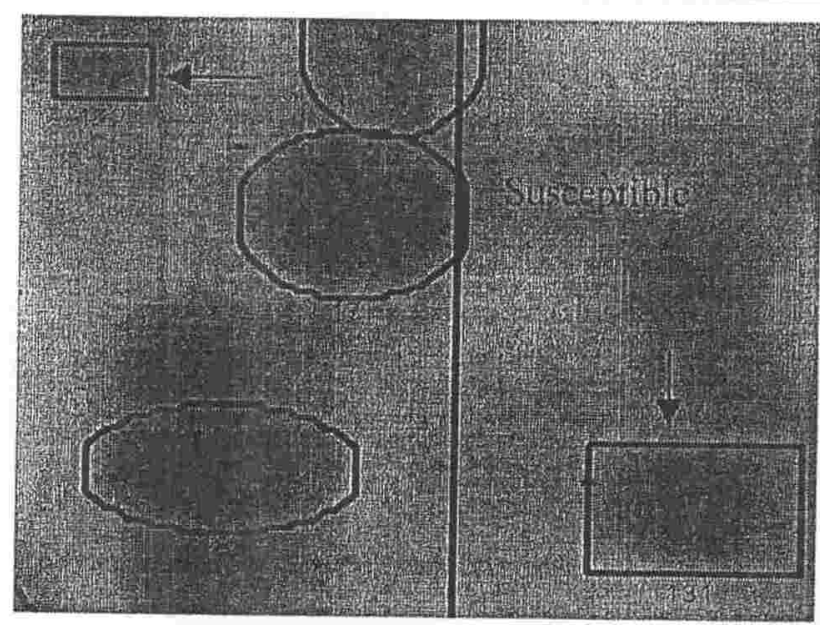

Spot 122

Spot 131

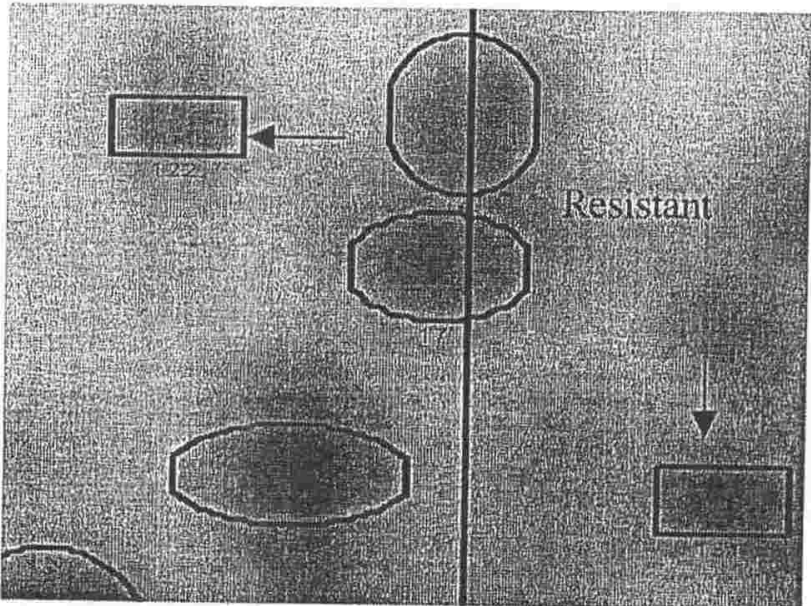

\section{Spot 126}
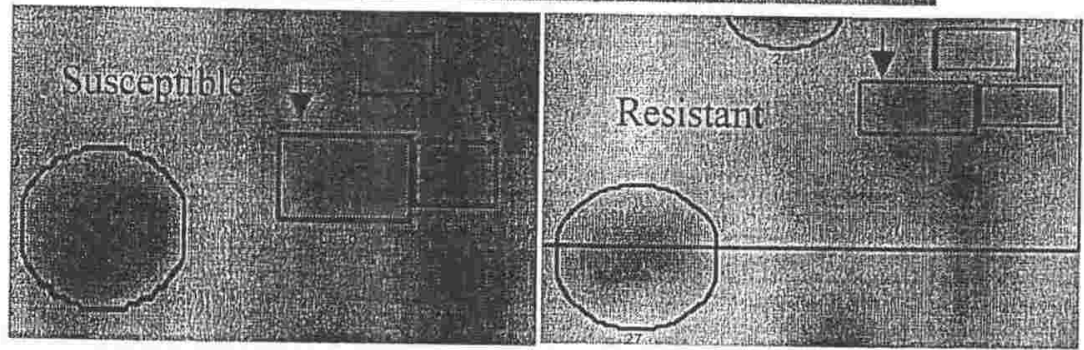

Figure 3.36d: Spots showing the difference in protein abundance (arrows) between undosed susceptible and undosed resistant Romneys. 


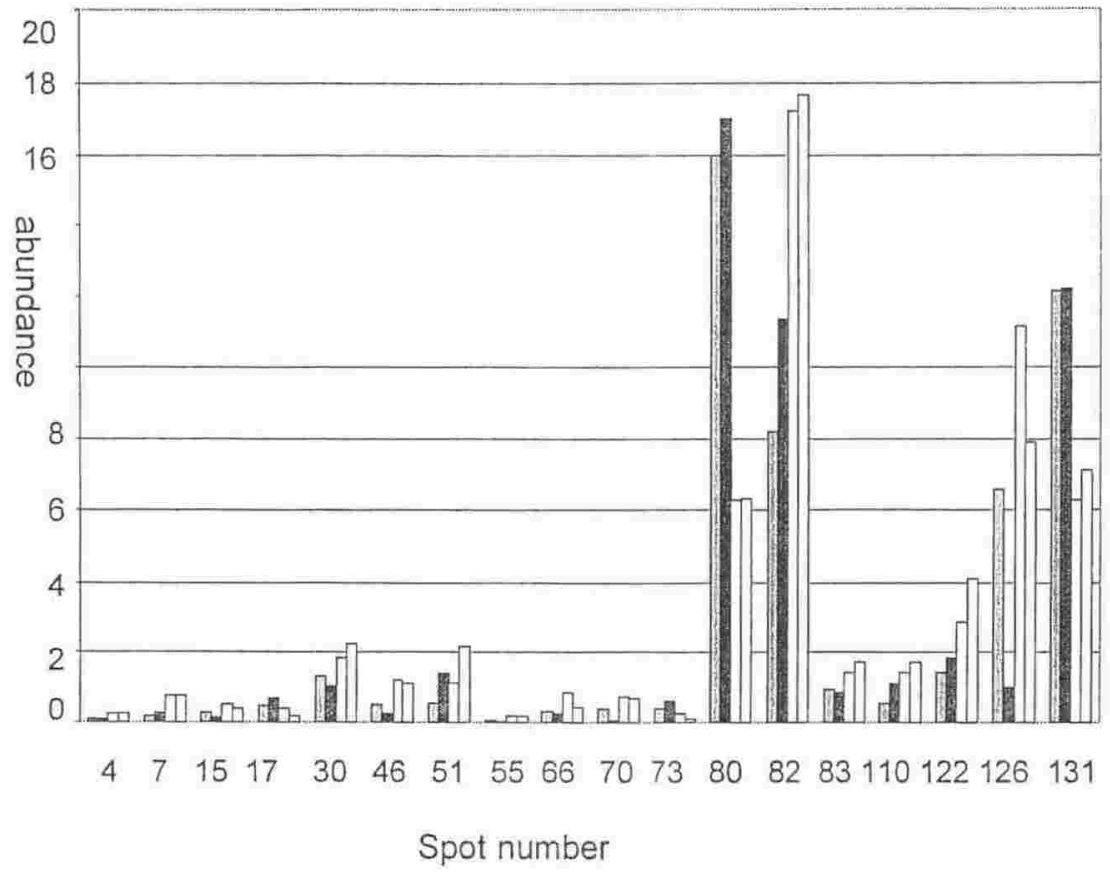

Figure 3.37a: Quantitative analysis for eighteen homogenate proteins that varied between the selection lines. The amount of each of the proteins was expressed as a percentage of the amount of the 137 proteins that were quantified on each gel. The results are for two gels from each pool of five animals. Light bars, undosed resistant pool. Dark bars undosed susceptible pool. 


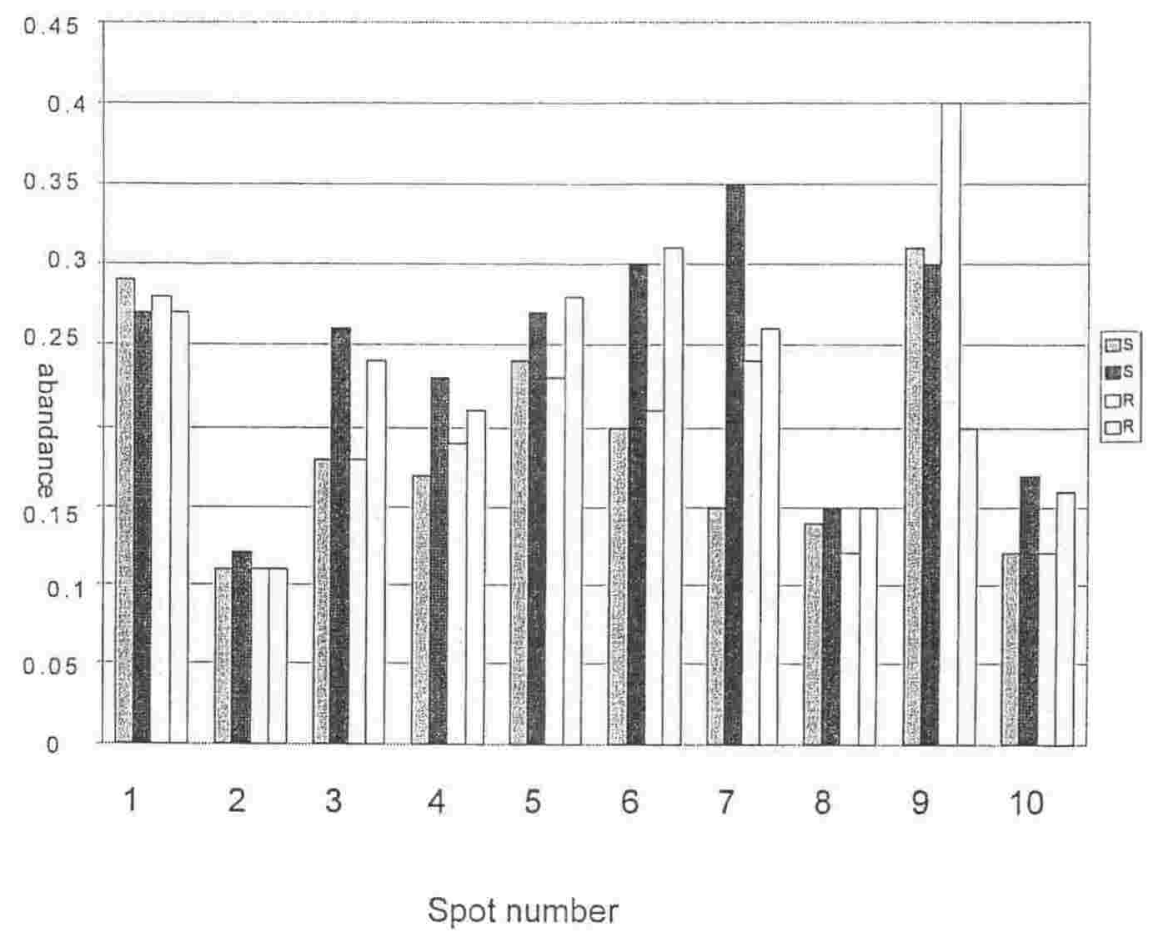

Figure 3.37b: Quantitative analysis of ten liver homogenate proteins that did not appear to vary between the resistant and susceptible Romney lines. Dark bars undosed susceptible pool. Light bars, undosed resistant pool. 


\subsection{Analysis of $100,000 \mathrm{~g}$ cytosolic liver supernatant using 2-D gel electrophoresis and MALDI-TOF mass spectrometry}

Differences among 100,000 $\mathrm{g}$ supernatant proteins were analysed using 2-D gels and MALDI-TOF techniques. This included a search for GST isoforms. The $100,000 \mathrm{~g}$ supernatants had been prepared at the time when liver was collected and the supernatants had been stored at $-80^{\circ} \mathrm{C}$. The 2-D gels of liver supernatant from two resistant and two susceptible animals were used to examine differences in protein expression between the resistant and susceptible lines (Figures 3.38, 3.39, 3.40, 3.41). Differences in protein abundance were quantified only for spots that showed obvious differences between resistant and susceptible samples when the gels were inspected by eye. Eight protein spots from each of the four gels were examined (Figures 3.42, 3.43). Four of the spots analysed from each of the four samples showed higher abundance in susceptible animals (spots $2 b, 3 b, 4 b, 5 b$ ), similarly four spots in the resistant samples showed higher abundance (spots 6, 7,8 and 9) than those in the susceptible animals (Figure 3.43). Three out of the eight spots (spots 6, 7 and 8) were chosen for further analysis as they were in the expected $\mathrm{pl}$ and molecular weight regions for GST isoforms. These spots were prominent in resistant animals compared to those spots from the susceptible animals (spots $6 b, 7 b$ and $8 b$ ). Spots 6,7 and 8 of the resistant samples were used for MALDI-TOF analysis for protein identification. 


\subsubsection{MALDI-TOF analysis and identification of supernatant proteins}

The predicted pl of some GST isoforms are between 5-8. These enzymes could therefore potentially be detected on 2-D gels but more alkaline isoforms would be excluded. Three protein spots that were more abundant in the resistant animals were processed for mass fingerprinting. The selected protein spots 6,7 and 8 were in the pl range 4-7 and molecular weight range approximately between $26-$ $30 \mathrm{kDa}$. The spectra collected for each protein were from duplicate spots. All spectra were calibrated using close external standard monoisotopic masses of $\mathrm{m} / \mathrm{z} 1296.68$ (angiotensin) and $\mathrm{m} / \mathrm{z} 2465.20$ (ACTH 18-39). The mass error range was also monitored with internal common peaks from tryptic self-digestion at $\mathrm{m} / \mathrm{z} 2163.05$ and 2273.15 .

The protein mass fingerprint tool ProFound (http://129.85.19.192/profound bin/WebProFound.exe) was used to identify proteins using the SWISS-PROT and NCBInr databases. The ProFound system ranks protein candidates using a Bayesian algorithm that takes into account the individual properties of the protein as well as other information relevant to the experiment (Zhang and Chait, 2000). The tolerance of the monoisotopic input masses were set to $0.1 \mathrm{Da}$, the number of allowed missed cleavages was 2 and the searched species databases were restricted to "Mammalian". The $\mathrm{pl}$ and Mr range constraints were 5-8 and $23-38$ $\mathrm{kDa}$ respectively. The primary criteria that were used to assess the likelihood of correct identification included the Probability and Z scores, the difference in probability of the first and second matches and percent coverage of sequence. A $Z$ score of 1.65 means the search is in the $95^{\text {th }}$ percentile, while a score of 2.33 is 
in the $99^{\text {th }}$ percentile http://129.85.19.192/profound/help.html\#zscore). Secondary criteria included comparison of the predicted and observed $\mathrm{pl}$ and mass.

Figures $3.44,3.45,3.46$ show the mass fingerprints and the ProFound search result summaries for the selected spots. The mass fingerprint spectrum of spot 6 (Figure 3.44) showed a moderate ion count and strong peptide signals were observed. The highest ranked protein was mouse glutathione Stransferase (Mu 5). A Z score of 1.51 and 1.00 probability was observed for the highest rank protein. The protein mass and $\mathrm{pl}$ corresponded with the approximate position of the protein spot on the gel and $35 \%$ sequence coverage indicated a reasonable match. The second ranked protein had probability value 5 orders of magnitude lower, allowing reasonable confidence in the top match.

The mass fingerprint spectrum of spot 7 (Figure 3.45) showed strong signal intensity. The highest ranked protein was glutathione S-transferase subunit 9Yc (Mu1), with a Z score of 1.66 and 1.00 probability. There was only one other match, to an unrelated protein. Protein mass and pl data for the matched protein corresponded with the approximate position of the protein spot on the gel and the coverage $21 \%$ of the matched sequence suggested a reasonable but not strong confidence in the match.

A good spectrum was observed for spot 8 (Figure 3.46) with low noise background. There was only one match, to Bos taurus ranked protein identified was $\mathrm{MHC}$ class II BDR3. The candidate protein showed a high Z score of 2.43 with a probability of 1.00 . The protein mass and $\mathrm{pl}$ of the matched protein 
corresponded to the approximate position of the protein spot on the 2-D gel and the $26 \%$ sequence coverage indicated reasonable confidence in the match. 


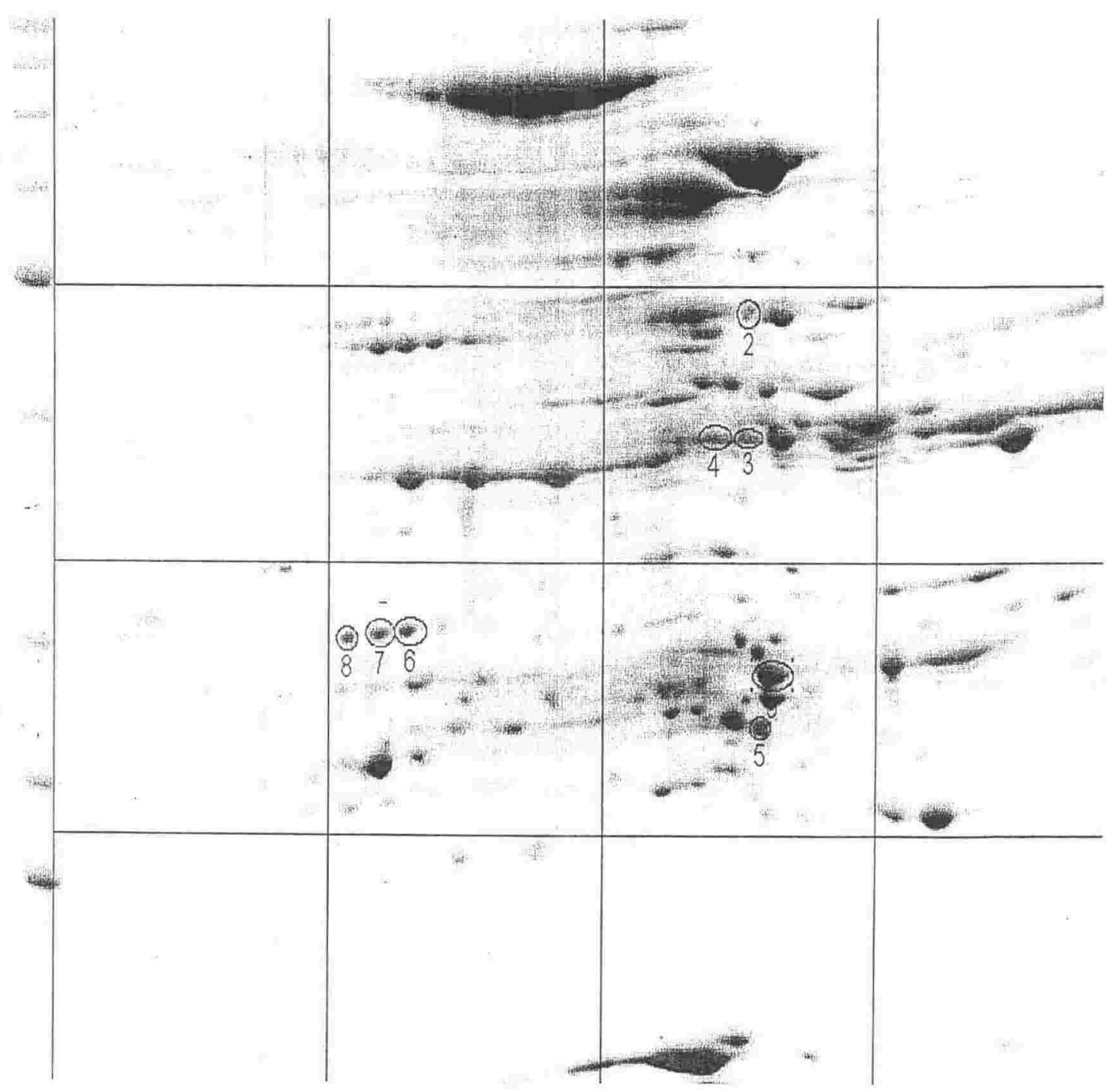

Figure 3.38: 2-D gel of 100,000 g supernatant from animal 7022 (resistant line). Circled regions show spots that differed in abundance between resistant and susceptible lines. 


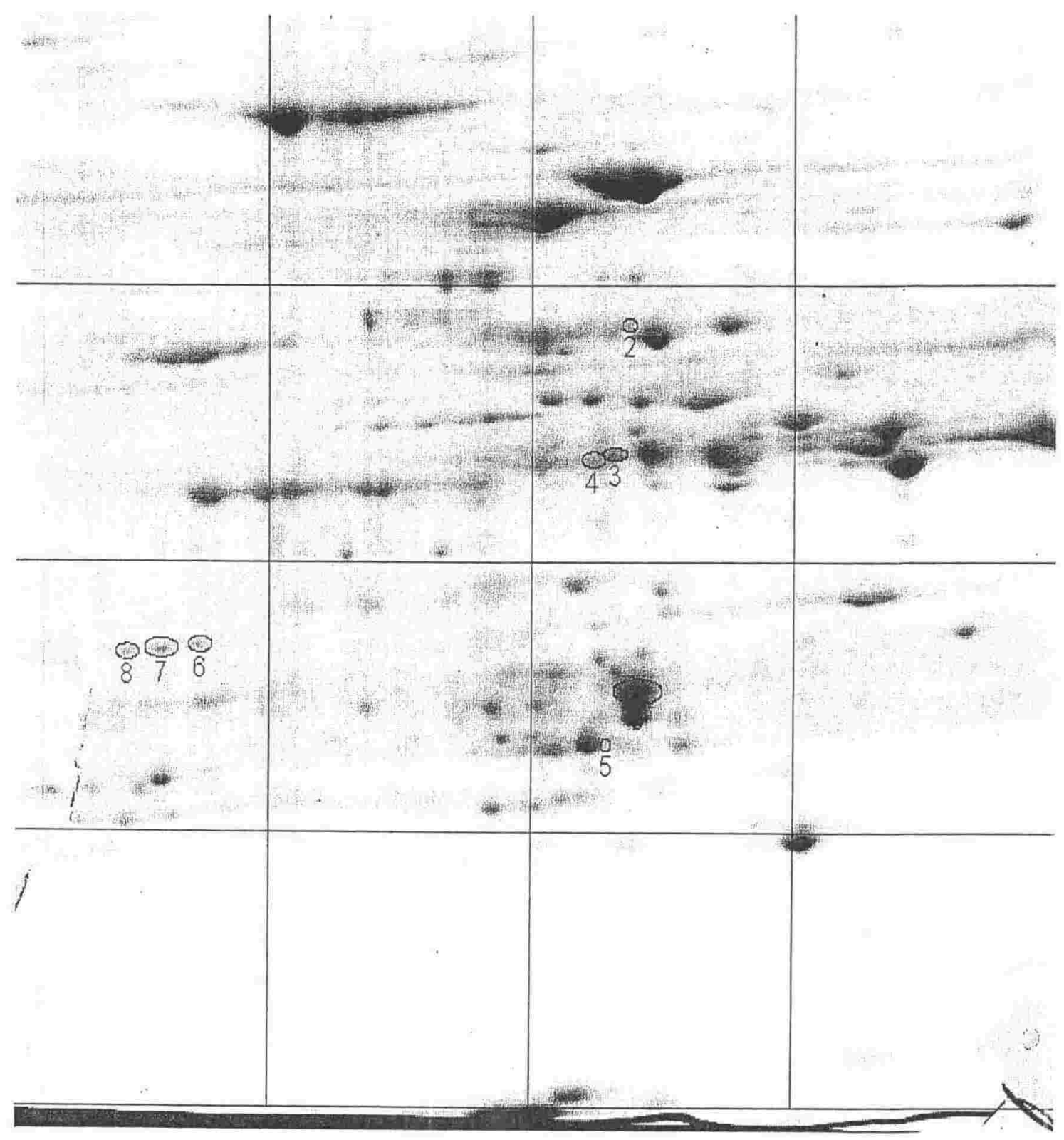

Figure 3.39: 2-D gel of 100,000 g supernatant from animal 7348 (resistant line). Circled regions show spots that differed in abundance between resistant and susceptible lines. 


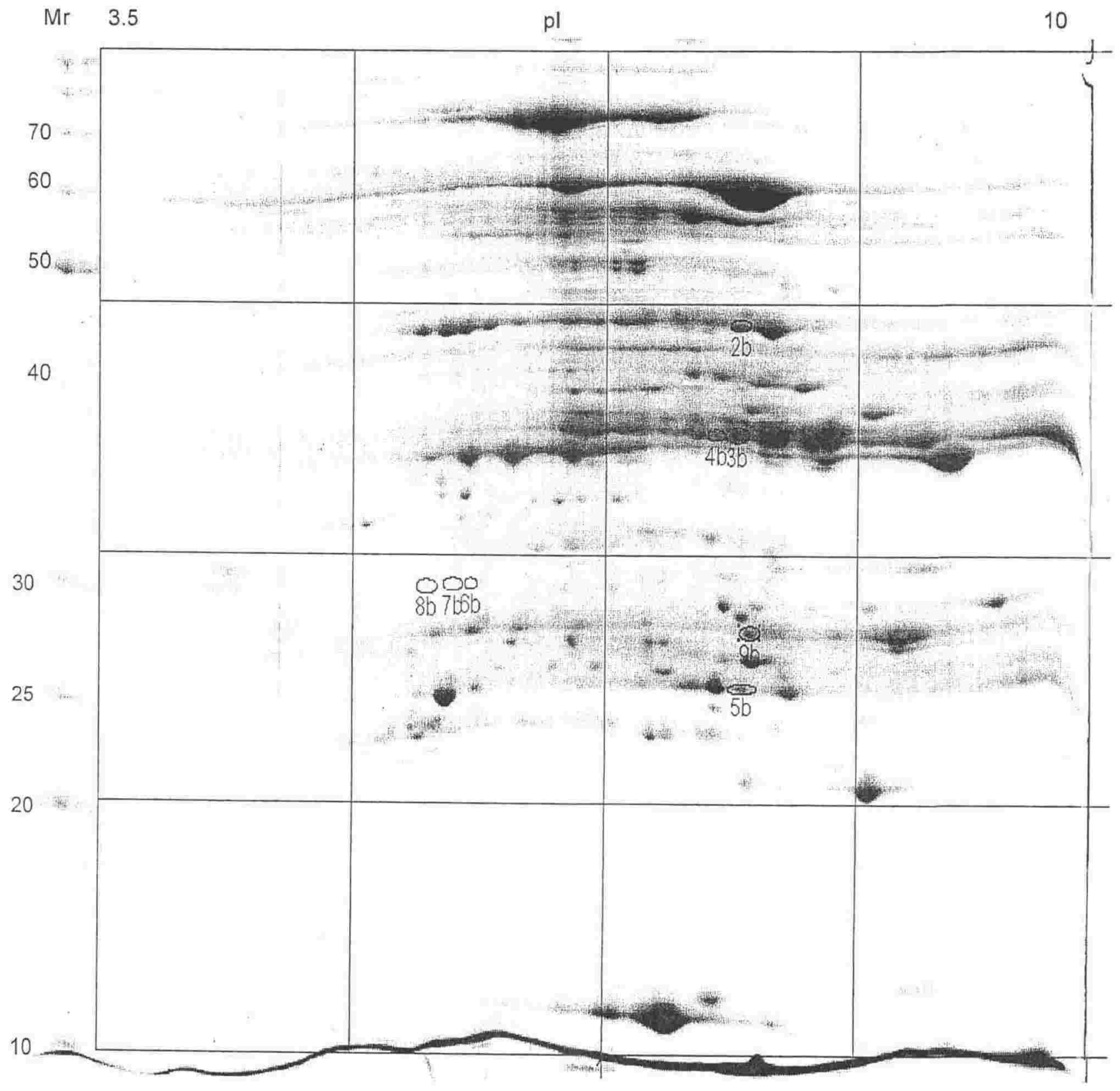

Figure 3.40: 2-D gel of 100,000 $\mathrm{g}$ supernatant from animal 7086 (susceptible line). Circled regions show spots that differed in abundance between susceptible and resistant lines. 


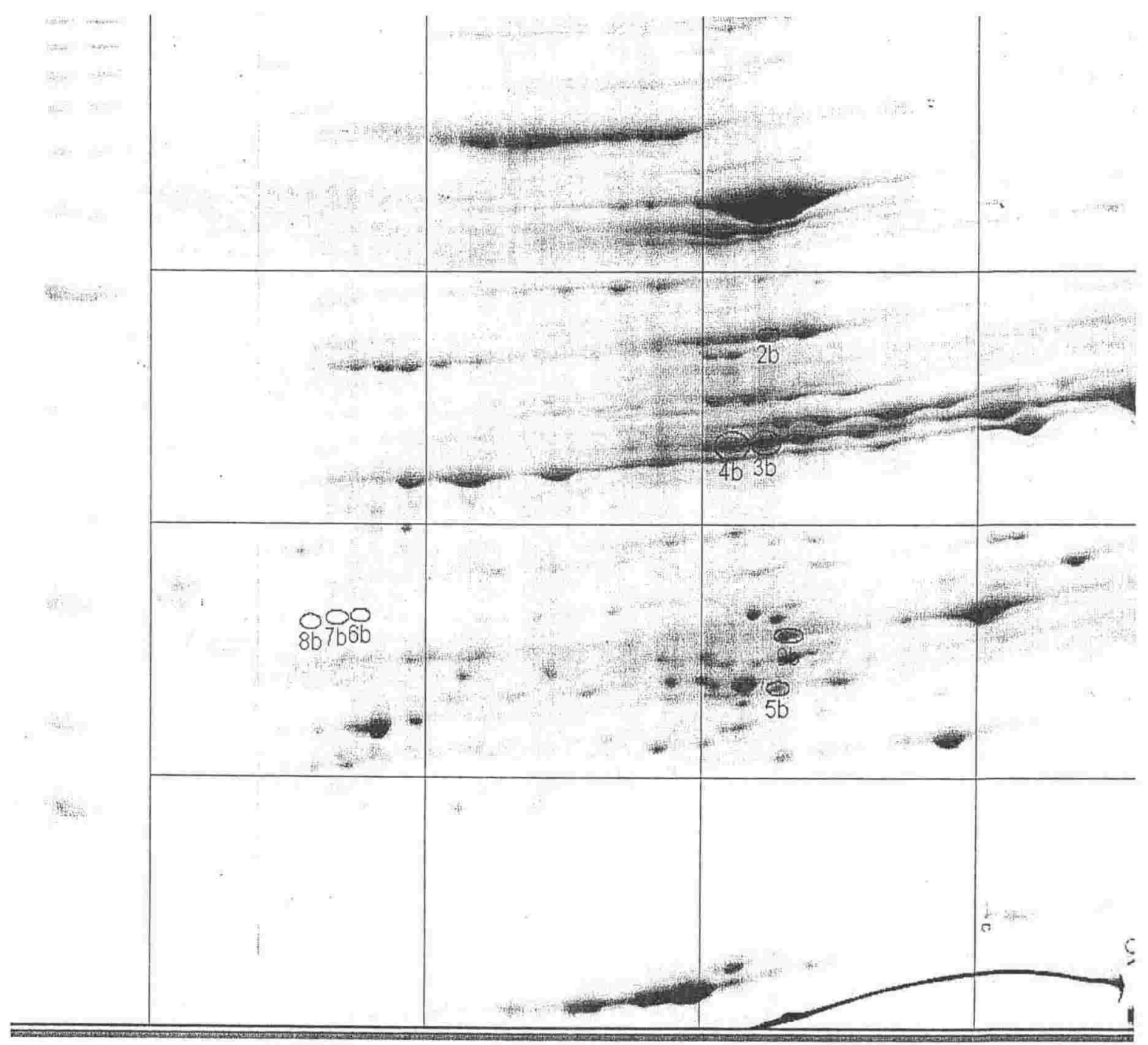

Figure 3.41: 2-D gel of $100,000 \mathrm{~g}$ supernatant from animal 7052 (susceptible line). Circled regions show spots that differed in abundance between susceptible and resistant lines. 
7022

Name Volume Percent

$\begin{array}{lll}\text { ELPS- } 2 & 22.1 \quad 0.89\end{array}$

ELPS- $3 \quad 97.1 \quad 3.9$

ELPS- $4 \quad 12.1 \quad 0.5$

ELPS- $5 \quad 250.2 \quad 10.0$

ELPS- $6 \quad 350.6 \quad 14.1$

ELPS- $7 \quad 343.5 \quad 13.8$

ELPS. $8 \quad 331.2 \quad 13.3$

ELPS- $9 \quad 1086.0 \quad 43.6$

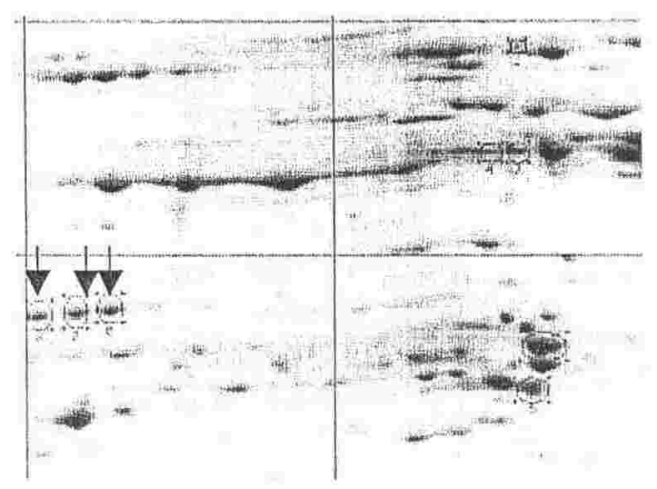

7348

Name Volume Percent

ELPS- $2 \quad 24.92 \quad 1.26$

ELPS- $3 \quad 106.71 \quad 5.41$

ELPS- $4 \quad 18.8 \quad 0.97$

ELPS- $5 \quad 133.86 \quad 19.5$

ELPS- $6 \quad 73.46 \quad 3.72$

ELPS- $7 \quad 136.9 \quad 6.94$

ELPS- $8 \quad 114.52 \quad 5.81$

ELPS. $9 \quad 1497.02 \quad 56.39$

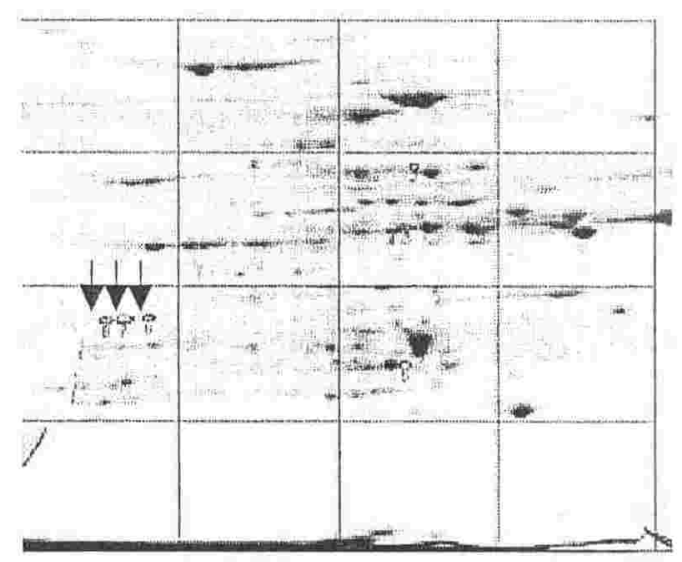

7052

$\begin{array}{ccc}\text { Name } & \text { Volume } & \text { Percent } \\ \text { ELPS- 2b } & 199.8 & 13.7 \\ \text { ELPS- 3b } & 466.7 & 32.0 \\ \text { ELPS- 4b } & 173.8 & 11.9 \\ \text { ELPS- 5b } & 239.1 & 16.4 \\ \text { ELPS- 6b } & 12.0 & 0.8 \\ \text { ELPS- 7b } & 10.1 & 0.7 \\ \text { ELPS- 8b } & 0.5 & 0.0 \\ \text { ELPS- 9b } & 347.3 & 24.4\end{array}$

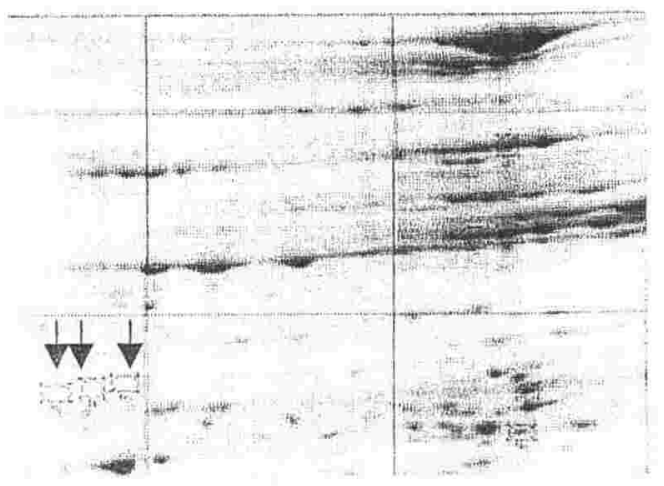

$\begin{array}{ccc}7086 & & \\ \text { Name } & \text { Volume } & \text { Percent } \\ \text { ELPS- 2b } & 107.8 & 17.5 \\ \text { ELPS- 3b } & 152.3 & 24.7 \\ \text { ELPS- 4b } & 23.4 & 3.8 \\ \text { ELPS- 5b } & 171.3 & 27.7 \\ \text { ELPS- 6b } & -8.2^{*} & 0.0 \\ \text { ELPS- 7b } & 22.1 & 0.9 \\ \text { ELPS- 8b } & 0.5 & 0.0 \\ \text { ELPS- 9b } & 348.4 & 25.5\end{array}$

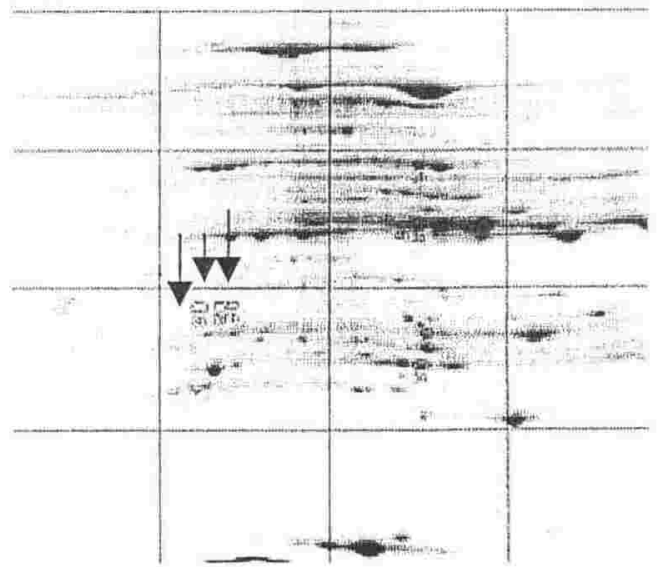

Figure 3.42: 2-D gel of soluble fractions $(100,000 \mathrm{~g}$ supernatant) from liver of two susceptibles $(7052,7086)$ and two resistant Romneys $(7022,7348)$ with quantitative analysis of eight selected protein spots that were present in each sample.

* The negative number represents the measurement of the background around spot

$6 \mathrm{~b}$ in the susceptible animal. Arrows indicate the locations of spots $6,7,8$. 


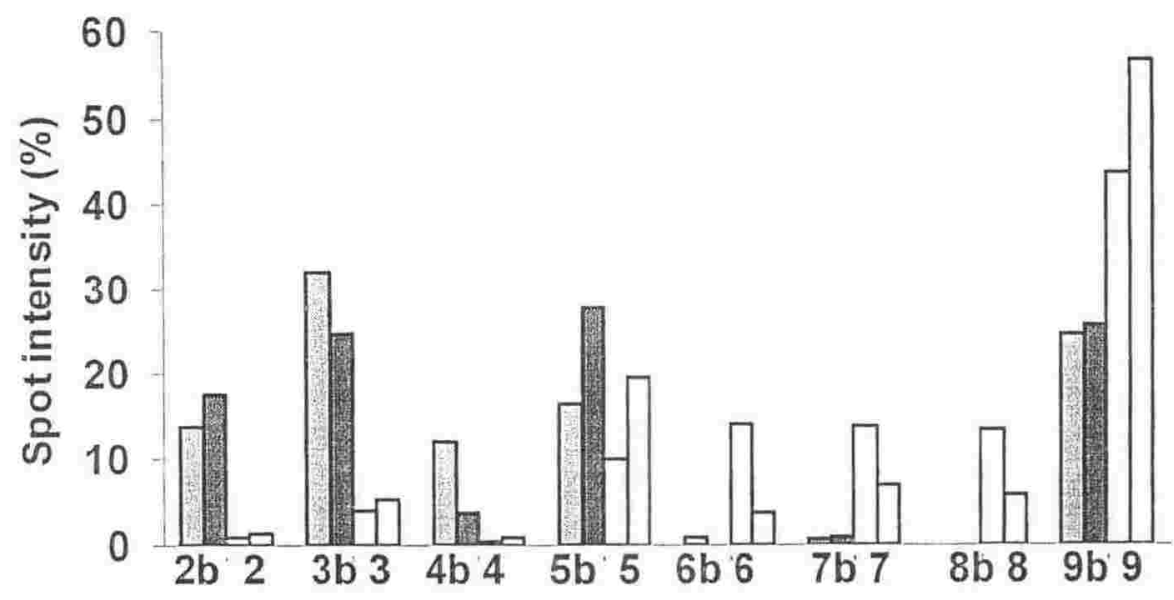

Figure 3.43: Comparison of protein abundance of eight protein spots that varied between the resistant and the susceptible lines. The $b$ series spots were from the susceptible animals. Results show abundances of the selected proteins from two animals from each line. 


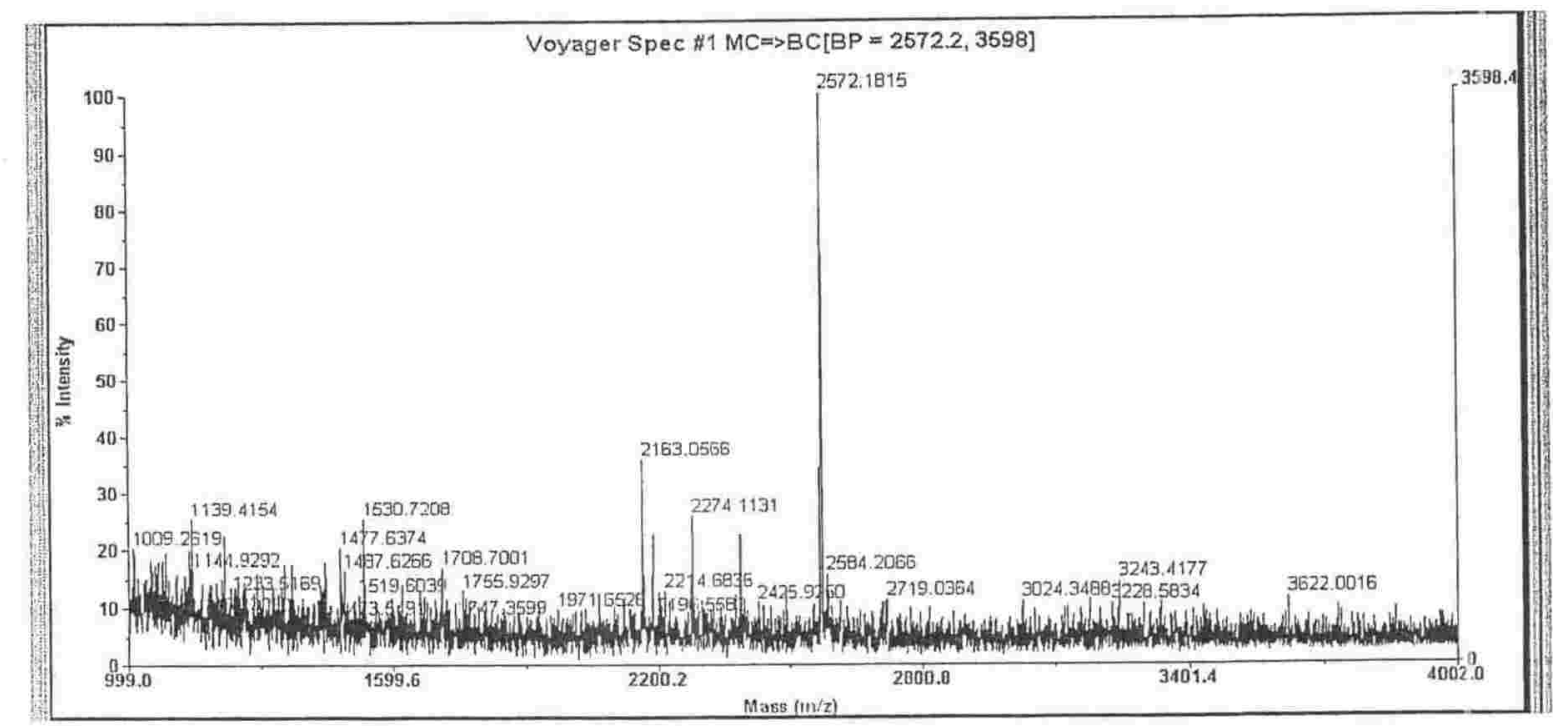

ProFound - Search Result Summary

Version 4.10 .5

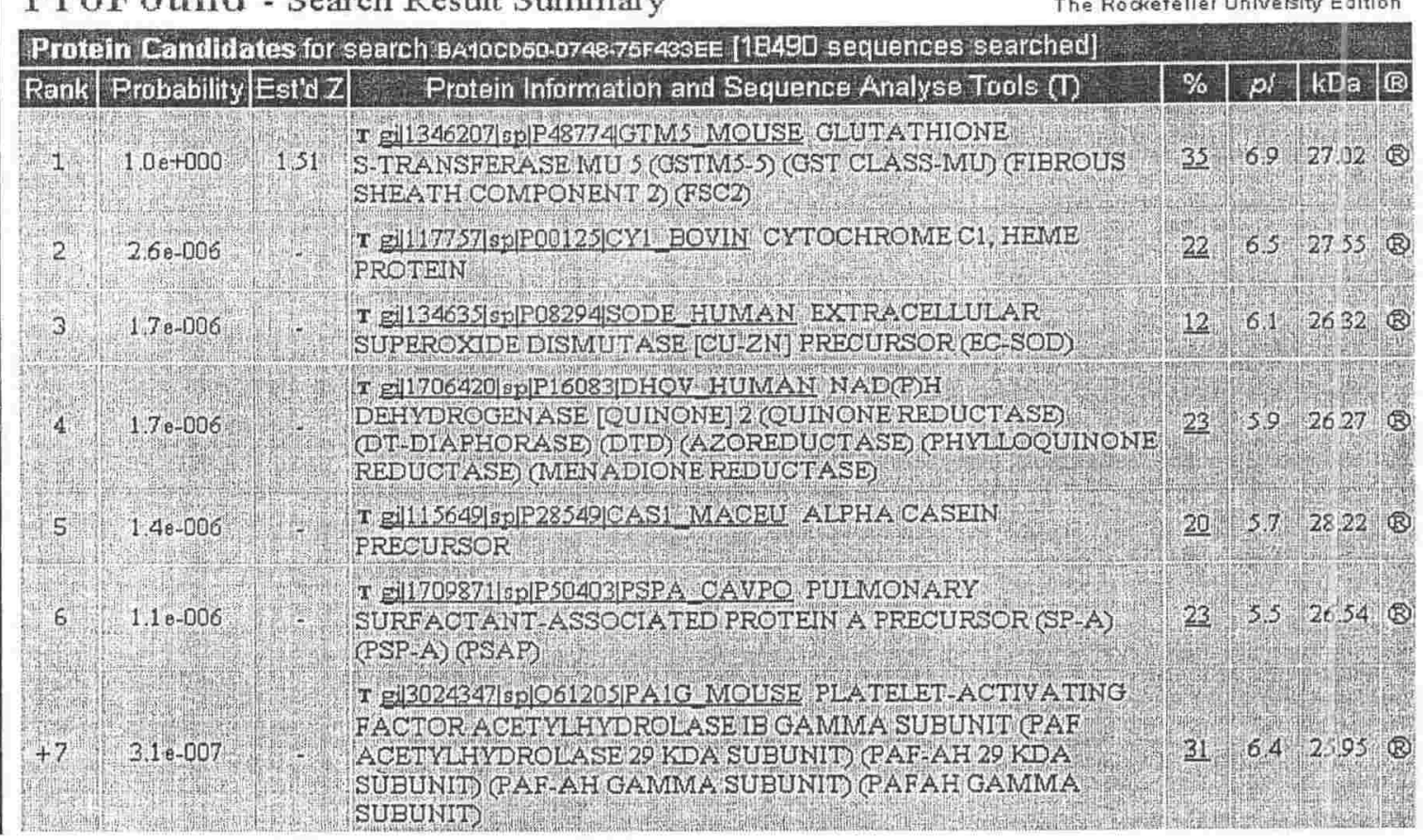

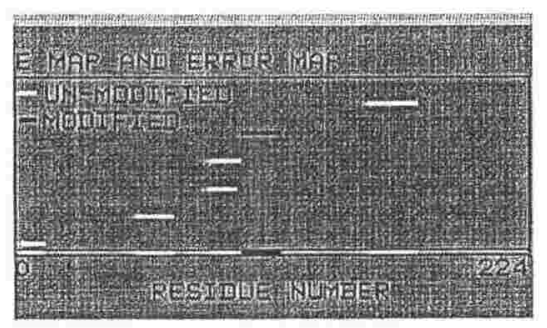

Figure 3.44: Mass fingerprint for spot 6 showing the MALDI spectrum (top), ProFound search result (middle) with murine GST Mu5 as the top ranked hit, and peptide coverage map (bottom, six matched peptides) for the match to Mu5. 


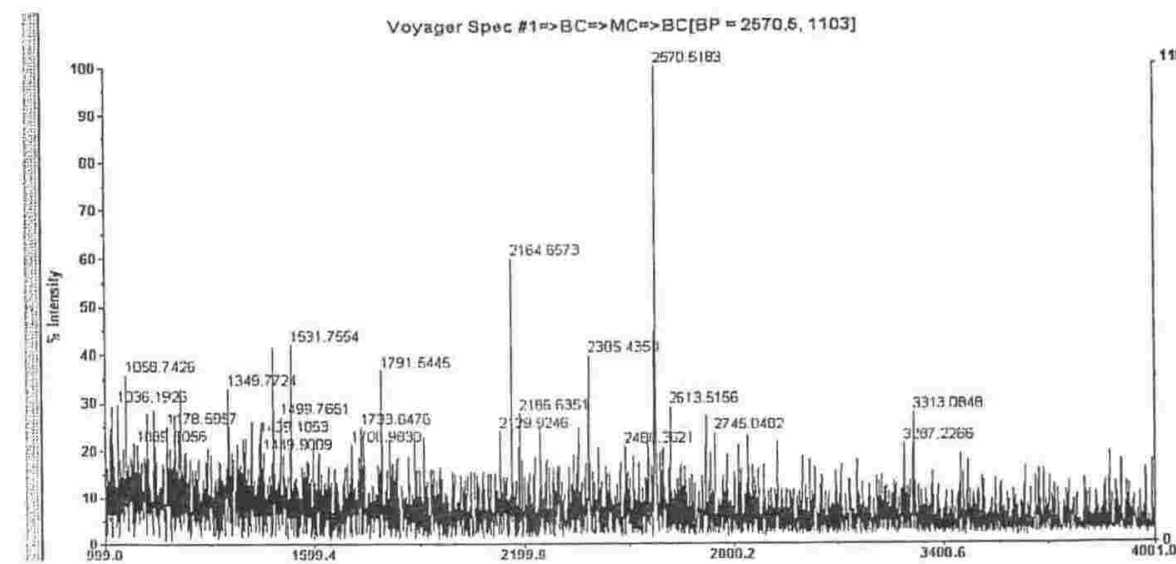

Profound - Search Result Summary

Version 4.10 .5

The Rodecteller University Edition
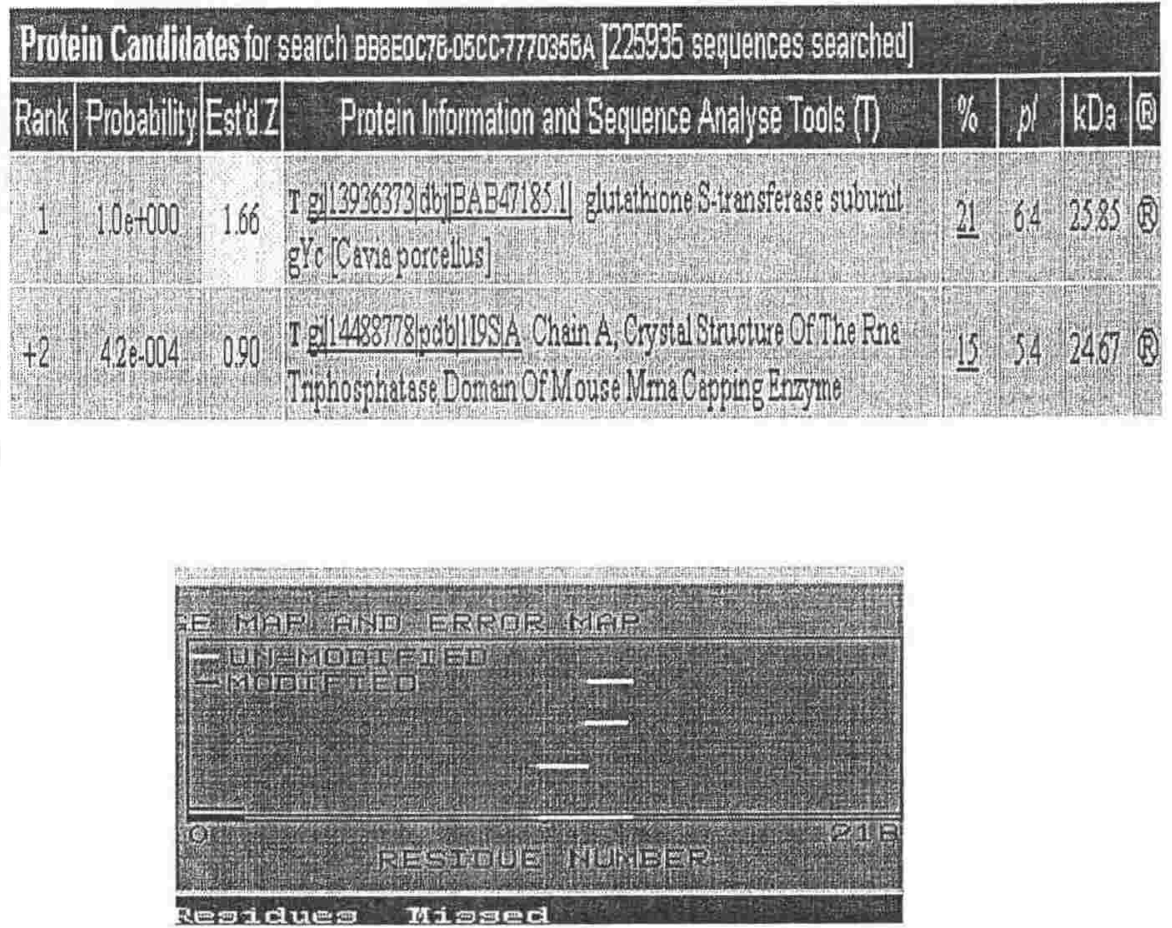

Figure 3.45: Mass fingerprint for spot 7 showing the MALDI spectrum (top), ProFound search result (middle) with Cavia porcellus GST Mu1 as the top ranked hit, and peptide coverage map (bottom, four matched peptides) for the match to Mu1. 


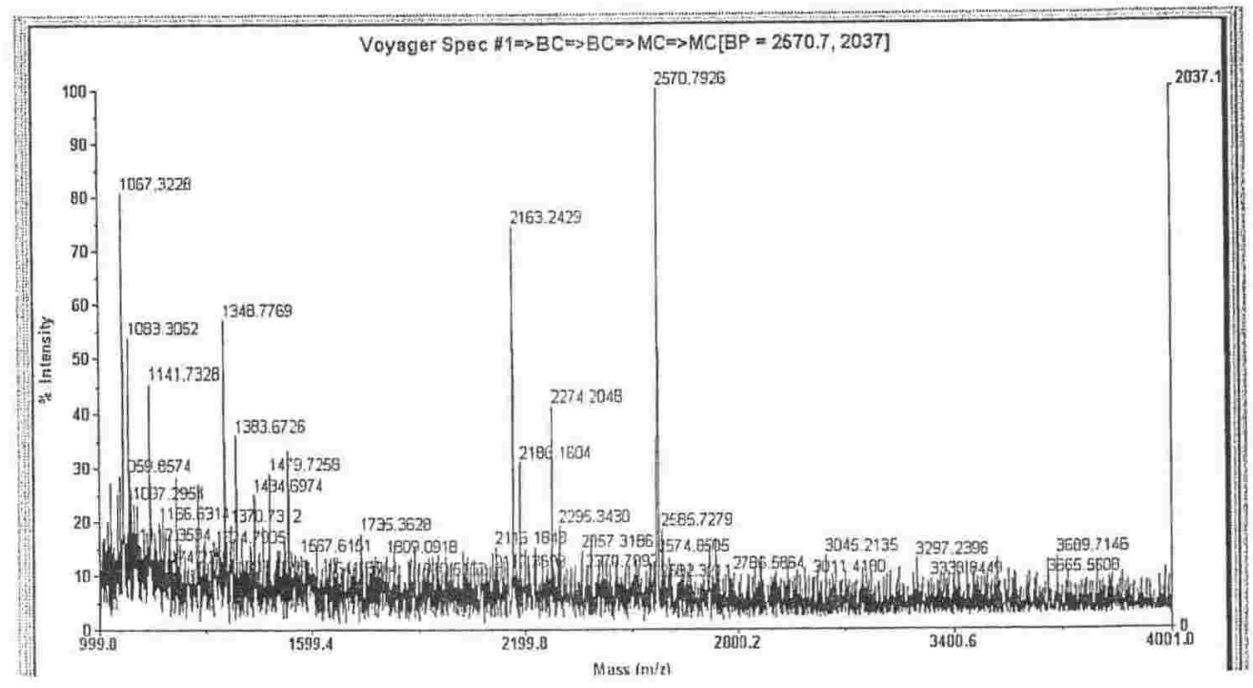

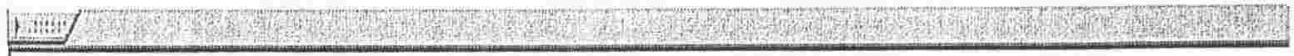

Repinits of our posters at the 48th ASMS Conference are avalable in PDF format (ThPBO96; ThPBO97).

ProFound - Search Resul Sunmary

Version 4.10 .5

The Rockefellet University Edition
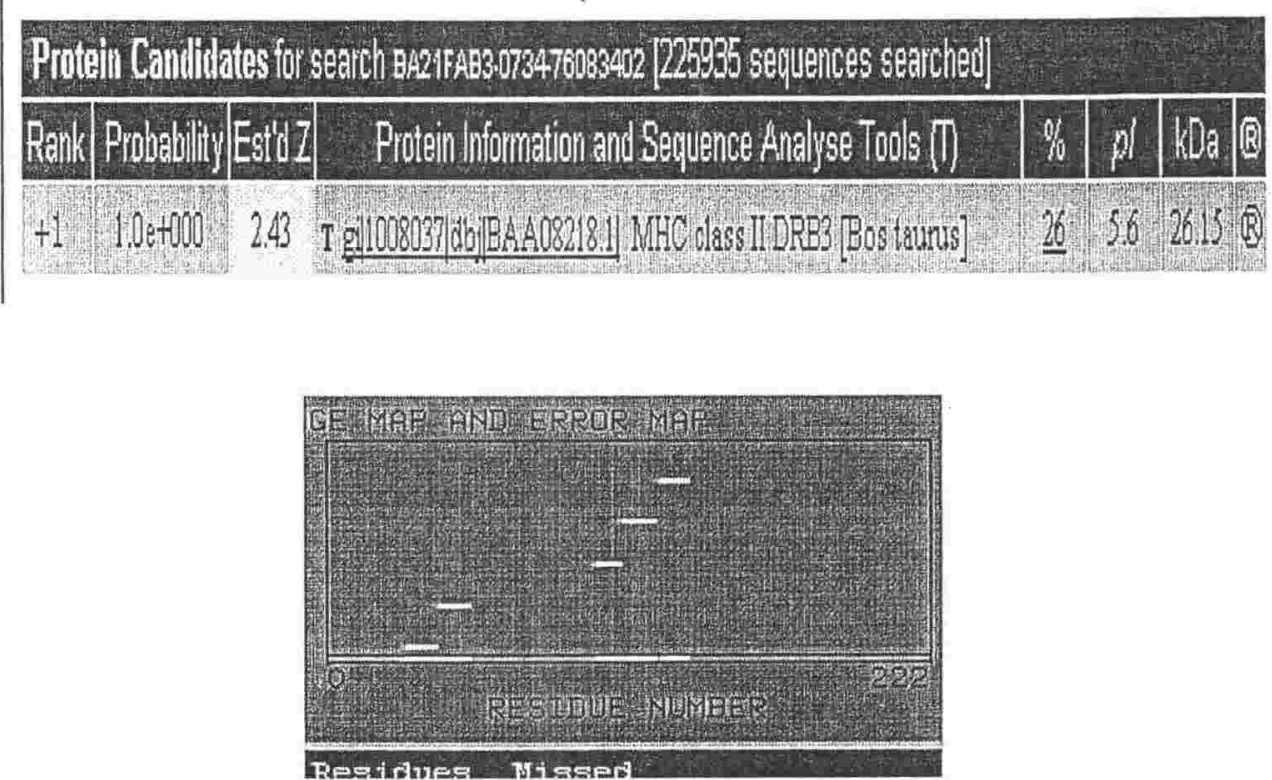

Figure 3.46: Mass fingerprint for spot 8 showing the MALDI spectrum (top),

ProFound search result (middle) with MHC class II as the top ranked hit, and peptide coverage map (bottom, five matched peptides) for the match to MHC class II. 


\section{CHAPTER IV}

\section{DISCUSSION}

\subsection{Effect of sporidesmin on liver histology}

A study was made of histological change in liver from susceptible and resistant Romneys dosed with sporidesmin. The sheep were orally dosed with 0.15 $\mathrm{mg} / \mathrm{kg}$ body weight for susceptible and $0.35 \mathrm{mg} / \mathrm{kg}$ body weight for resistant animals. Dosed animals were compared with undosed control animals from the undosed susceptible and the undosed resistant flocks.

Kellerman and Coetzer (1984) divided the hepatogenous photosensitization diseases into two main groups, one group with damage primarily to the biliary system and the other with damage primarily to the liver parenchyma. I wish to use a similar classification to discuss the pathological changes in this experiment.

This study showed that, two days after dosing of susceptible animals, there was moderate changes in the liver histology (Figure 3.5). Our finding is in agreement with a previous histological study of mice dosed with sporidesmin (Bhathal et al., 1990) that indicated little change one day after sporidesmin dosing. Changes had occurred mainly in hepatocytes, especially in the dosed susceptible animals (Figures 3.5). This result is also in accordance with the findings of Thompson et al. (1983) who found changes in the morphology of rabbit hepatocytes but no biliary lesions after one day of oral dosing with sporidesmin. The appearance of mild vacuolation in the hepatocytes surrounded the portal area in the dosed susceptible samples two days after dosing was in agreement with the finding of 
Mortimer (1963) who reported marked vacuolation and acidophilic cytoplasmic staining of the liver hepatocytes, together with the loss of cellular and sinusoidal outlines throughout the lobules. These changes were marked in the centrilobular and portal areas. The relatively minor histological change detected in Romney liver two days after dosing suggests that changes in enzyme activity in the sporidesmin dosed sheep may reflect a primary response to the toxin rather than the effects of cellular damage.

\subsection{Metabolism of sporidesmin by liver microsomes}

HPLC analysis was used to measure the extent of microsomal metabolism of sporidesmin in the presence or absence of the cofactor NADPH (Figure 3.6). Previous work (Fairclough et al., 1978) indicated the possibility of cytochrome P-450 dependent metabolism of the toxin. We therefore studied possible differences in oxidative metabolism between the resistant and susceptible lines. Microsomal extracts were incubated with sporidesmin in the presence or absence of NADPH and the reaction products were examined by HPLC. Incubation of sporidesmin with microsomes in the absence of NADPH produced some loss in the size of the sporidesmin peak possibly indicating some binding of the toxin to microsomal proteins (Figure 3.6). Further decreases in the size of the sporidesmin peak occurred when the toxin was incubated with microsomes in the presence of NADPH suggesting cytochrome P-450 dependent metabolism (Figure 3.6).

Differences in the extent of NADPH dependent metabolism of sporidesmin were detected using liver microsomes from five undosed susceptible and five undosed resistant animals. Loss of the sporidesmin peak was approximately $27.4 \%$, 
$S D= \pm 21$ of the minus NADPH control peak height for five undosed resistant Romneys and $17.1 \%, S D= \pm 11.6$ for five undosed susceptible Romneys. Although the mean values were slightly greater for resistant animals compared to the susceptibles, there was not a significant difference between the lines. The results also indicated variation in sporidesmin metabolism within the resistant and susceptible animals. It is possible that these variations may be due to differences in the activities of specific P-450 isoforms between the individuals in the same line. The HPLC conditions were modified in an attempt to detect possible spridesmin metabolites that we expected to be more polar and with a shorter retention time than sporidesmin. The attempt was not successful because it was not possible to separate the sporidesmin peak from the cofactor peak which was larger by $5-10$ times.

\subsection{Enzyme activities in Romney sheep from the resistant and susceptible} selected lines

\subsubsection{Cytochrome P-450}

Although pathological changes caused by sporidesmin are well described (Mortimer, 1963; Mortimer, 1969), there is still no clear understanding of the biochemical bases for heritable resistance to sporidesmin induced liver damage. Campbell et al. (1981) and Morris et al. (1995) suggested that the susceptibility of animals to $\mathrm{FE}$ is variable and heritable. Therefore, if resistant animals could be 
selected without exposing the animals to toxic challenge the incidence of FE could be decreased.

Some workers have suggested that resistance to FE may be due to metabolic inactivation of the toxin. Direct biochemical evidence was also obtained suggesting that sporidesmin was metabolised and detoxified by the liver microsomal mixed function oxidase system (Aust, 1977; Fairclough et al., 1978; Sissons, 1981). These studies also suggested differences in the metabolism of sporidesmin by liver microsomal enzymes in susceptible and resistant animals. Based on the previous preliminary finding of involvement of microsomal enzymes in the metabolism of sporidesmin, one of the main aims of our study was to develop a biochemical procedure by which we could differentiate between susceptible and resistant sheep. Sporidesmin has $\mathrm{O}$ - and $\mathrm{N}$-methyl groups that could be metabolised by cytochrome P-450 O- or N-demethylases. Model substrates for these enzymes were therefore used to test for differences in $\mathrm{O}$ - or $\mathrm{N}$-demethylation between the resistant and susceptible lines. Nitroanisole was used as a substrate for O-demethylase and aminopyrine was used as a substrate for $\mathrm{N}$-demethylase. Because it is known that cytochrome P-450 plays a role in the detoxification and transformation of foreign compounds into water soluble products, thereby facilitating elimination from the body, and that sporidesmin toxin targets the liver, we examined liver enzymes including the cytochrome P-450s. This is of importance as metabolism of sporidesmin is thought to inactivate the toxin. 


\subsubsection{O-Demethylase enzyme assay}

The results of studies of cytochrome P-450 enzyme activity towards the substrate nitroanisole are shown in Tables $3.2-3.4$. There was no significant statistical difference found between undosed resistant and the undosed susceptible animals from all years. Dosing appeared to increase O-demethylase activity in the resistant line but appeared to decrease activity in the dosed susceptibles, although it is possible that some of the variation was due to inter-individual differences. These results are in accordance with the finding of Sissons and Fairclough (1978) who showed that sporidesmin metabolism was likely to be greater in hepatic microsomes taken from liver biopsies of FE resistant Romneys than from FE susceptibles. Aust (1977) found that after sporidesmin administration mixed function oxidase activity decreased. The difference in response to sporidesmin dosing might be caused by variation in induction of isoenzymes of cytochrome P450 by sporidesmin in the resistant line and possibly by an interaction leading to inhibition or degradation of O-demethylase in the susceptible animals. In a previous study Sissons (1981) reported that sporidesmin gave an unusual binding spectrum with cytochrome P-450 and suggested interaction of the sporidesmin sulphur with P-450.

The presence of multiple forms of cytochrome P-450 in either untreated or induced animals, or different species of animals, is an important concept since it affects the interpretation of the results of drug metabolism studies. Variable expression of multiple forms may explain the complexity of differences in the metabolism of substrates due to different cytochrome P-450 activities (Huang et al., 1976). Guengerich et al. (1982) suggested a strong correlation between the inducer 
used and the type of cytochrome P-450 expressed. They indicated that P-450 isozymes responded differently to administration of a common inducer such as phenobarbital which induced four forms of P-450 (P-450-pb, P-450pb-b, P-450pb-c and P-450pb-d). Activities of cytochrome P-450 isoenzymes among different species of animals including sheep, rats, goats and cattle depend on the inducer and the substrate used (Johnson and Shiverick, 1982). Turner and Green (1974) found that sheep dosed with the inducer hexachlorobenzene showed increased activities of aniline hydroxylase and 4-nitroanisole O-demethylase.

Species differences in the activity of cytochrome P-450 using the Odemethylase substrates were reported in the study of Short et al. (1988). They found that sheep microsomal enzyme activity was higher $(24.4 \pm 4.8 \mathrm{nmol} / \mathrm{g}$ liverl $\mathrm{min})$ than that of cattle $(10.3 \pm 5.7 \mathrm{nmol} / \mathrm{g}$ liver/min $)$ and less than that of goats $(30.9$ $\pm 9.5 \mathrm{nmol} / \mathrm{g}$ liver/min). A similar result was obtained by Van'TKlooster et al. (1993,1994) using ethylmorphine as a substrate. They found that sheep microsomal enzyme activity was higher $(5.5 \pm 1.1 \mathrm{nmol} / \mathrm{mg}$ protein $/ \mathrm{h})$ than that of rats $(1.6 \pm 0.2 \mathrm{nmol} / \mathrm{mg}$ protein $/ \mathrm{h})$, cattle $(2.9 \pm 0.6 \mathrm{nmol} / \mathrm{mg}$ protein $/ \mathrm{h})$ and goats $(2.8 \pm 0.3 \mathrm{nmol} / \mathrm{mg}$ protein $/ \mathrm{h})$. These results are in the same range as our results of the O-demethylase cytochrome P-450 activity. Assuming that liver microsomal protein content is approximately $40 \mathrm{mg}$ protein per $\mathrm{g}$ liver (Lim and Jordan, 1981), microsomal enzyme activities calculated in my thesis can be multiply by 0.4 for approximate conversion to rates as $\mathrm{nmol} / \mathrm{min} / \mathrm{g}$ liver, the values are of the same order as those I measured. A study of hepatic drug metabolism in normal and vitamin E-deficient female Merinos (Gourlay et al., 1977) showed differences in the activity of hepatic microsomal enzymes towards p-nitroanisole O-demethylase. 
Gourlay et al. (1977) reported that pre-treatment of sheep with phenobarbital gave a significant increase in the activity of O-demethylase and other drug metabolism enzymes in normal and vitamin E-deficient-sheep. Similarly, Buening and Franklin (1976) reported an increase in p-nitroanisole O-demethylase activity in male rat hepatic microsomes after the administration of SKF 525-A.

In summary, the differences in O-demethylase activity between the dosed resistant and susceptible lines suggest that sporidesmin might induce 0 demethylase in the resistant animals. This difference in activity might contribute to enhanced resistance through greater metabolism and metabolic inactivation of sporidesmin.

\subsubsection{N-Demethylase enzyme assay}

$\mathrm{N}$-demethylase activity was similar in animals from the resistant and susceptible Romney lines (Tables $3.5,3.6,3.7$ ). There were no significant statistical differences in the metabolic activity of cytochrome P-450 towards the substrate aminopyrine, between the dosed resistant and the dosed susceptible animals. The statistical analysis indicated a significant interaction between dosing and resistance factors in liver from animals born 1997. The dosed resistant samples showed greater $\mathrm{N}$-demethylase $(P=0.012)$ than the undosed resistant samples (Tables 3.7). The small differences detected in the 1994 born animals may be due to normal variation.

Previous studies showed that $\mathrm{N}$-demethylase activities were substrate dependent and species variable (Dalvi et al., 1987; George et al., 1995). Kaddouri et al. (1990) and Galtier and Alvinerie (1996) reported a relationship between N- 
demethylase activity and age in sheep where aminopyrine $\mathrm{N}$-demethylase activity increased with age. A comparison study between different species, on the $\mathrm{N}$-demethylase activities of liver microsomes towards benzphetamine as a substrate, was carried out by Dalvi et al. (1987). They reported variable activity in the $\mathrm{N}$-demethylase pathway, with goats showing the highest activity $(9.4 \mathrm{nmol} / \mathrm{h} / \mathrm{mg}$ protein), followed by rabbits ( $7 \mathrm{nmol} / \mathrm{h} / \mathrm{mg}$ protein), sheep $(6.2 \mathrm{nmol} / \mathrm{h} / \mathrm{mg}$ protein), pigs $(6.1 \mathrm{nmol} / \mathrm{h} / \mathrm{mg}$ protein) and cattle $(4 \mathrm{nmol} / \mathrm{h} / \mathrm{mg}$ protein). The observation that $\mathrm{N}$-demethylase activity increased after dosing with sporidesmin is similar to the finding of Gourlay et al. (1977) who found an increase in the in vitro metabolism of aminopyrine after pre-treatment of the sheep with phenobarbital (control $=161$ $\mathrm{nmol} / 30 \mathrm{~min} / \mathrm{mg}$ protein, treated $=519 \mathrm{nmol} / 30 \mathrm{~min} / \mathrm{mg}$ protein). Similarly, Pineau et al. (1990) also reported an increase in the $\mathrm{N}$-demethylase activity of cytochrome P-450 using aminopyrine as a substrate, after an oral administration of troleandomycin to three adult male Lacaune sheep (control $=5.5 \mathrm{nmol} / \mathrm{min} / \mathrm{mg}$ protein, treated $=8.7 \mathrm{nmol} / \mathrm{min} / \mathrm{mg}$ protein) .

My results indicate that the undosed Romneys showed a metabolic activity towards the model substrate aminopyrine. These results correspond to the finding of Galtier et al. (1993) who reported aminopyrine N-demethylase activity in sheep liver microsomes under standard experimental conditions $(0.157 \mathrm{nmol} / \mathrm{min} / \mathrm{mg}$ protein). Similarly Kaddouri et al. (1990, 1992) showed low aminopyrine metabolism in female sheep $(6.9 \mathrm{nmol} / \mathrm{min} / \mathrm{mg}$ protein) compared with the high metabolic rate for benzphetamine $\mathrm{N}$-demethylation (19 $\mathrm{nmol} / \mathrm{min} / \mathrm{mg}$ protein). Shetty et al. (1972) reported that the rates of in vitro metabolism of aminopyrine Ndemethylation in phenobarbital treated Florida native sheep $(12.29 \mu \mathrm{mol} / \mathrm{h} / \mathrm{mg}$ protein) were higher than in saline - treated control sheep ( $4.66 \mu \mathrm{mol} / \mathrm{h} / \mathrm{mg}$ protein). 
Similarly Van'TKlooster et al. (1994) reported high N-demethylation activity, in sheep, towards the substrate ethylmorphine $(21.2 \mathrm{nmol} / \mathrm{h} / \mathrm{mg}$ protein).

In summary, although aminopyrine $\mathrm{N}$-demethylation increased after dosing with sporidesmin there did not appear to be significant differences in this enzyme activity between resistant and susceptible Romneys.

\subsection{Analysis of microsomal cytochrome c reductase}

NADPH cytochrome P-450 reductase is an essential component of the mixed function oxidase system as the flavoprotein transfers reducing equivalents from $\mathrm{NADPH}+\mathrm{H}^{+}$to cytochrome P-450:

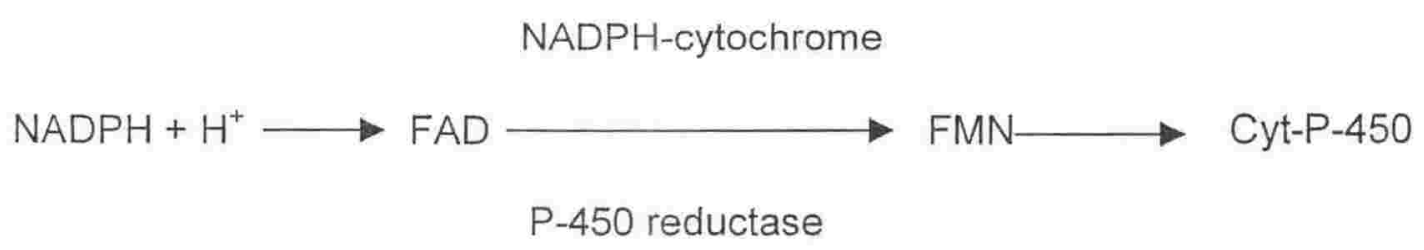

The reduction of cytochrome P-450 is relatively difficult to assay directly, therefore a simplified determination of enzyme activity is widely used, utilising exogenous cytochrome $\mathrm{c}$ as an artificial electron acceptor. It is well known that one of the striking characteristics of liver microsomal P-450 reductase is its ability to catalyse the reduction of cytochrome c with NADPH (Dignam and Stroble, 1975). Results from many laboratories demonstrated that mammalian P-450 reductase was able to bind NADPH and accept electrons in the absence of the terminal electron acceptor in order to support the P-450 activity (Murataliev et al., 1999). 
However Louerat-Oriou et al. (1999) reported that the efficiency of NADPHcytochrome $\mathrm{P}-450$ reductase to support $\mathrm{P}-450$ activities were not simply related to activities towards artificial acceptors like ferricyanide or cytochrome c. They suggested important parameters may control the reductase efficiencies to support $\mathrm{P}-450$ activities and these depend on the redox distribution of flavin species and reductase affinity for P-450. Accordingly, the reduction of cytochrome $c$ by NADPHcytochrome c reductase only partially mirrors the reduction of cytochrome P-450. There were no significant differences between the FE susceptible and resistant lines for NADPH dependent cytochrome c reductase although the mean value of undosed resistant Romneys $(8.98 \pm 1.84 \mathrm{nmol} / \mathrm{min} / \mathrm{mg}$ protein was lower than that for undosed susceptible Romneys (10.90 $\pm 1.04 \mathrm{~nm} / \mathrm{min} / \mathrm{mg}$ protein). Gourlay et al. (1977) also found no difference in NADPH cytochrome P-450 reductase and NADPH cytochrome $\mathrm{c}$ reductase values in their study on hepatic drug metabolism in normal $(4.95 \pm 0.1)$ and vitamin E-deficient $(5.07 \pm 0.6)$ female Merinos.

\subsection{Spectrophotometric determination of cytochrome P-450}

Cytochrome P-450 was also investigated by spectrophotometric determination of CO-binding spectra. The cytochrome P-450 concentration of liver microsomes was compared between control and resistant Romneys born 1996 and resistant and susceptible Romneys born 1997. The CO-difference spectrum of dithionite-reduced cytochrome P-450 in liver microsomes displayed an absorbance maximum at $450 \mathrm{~nm}$ (Figure 3.24). Under the conditions used to measure the spectra cytochrome-P-450 was partially converted to cytochrome-P-420 (Figure 3.25). The presence of a shoulder at $420 \mathrm{~nm}$ indicates significant amounts of 
cytochrome-P-420 (denatured inactive cytochrome P-450). The reason for this conversion to P-420 might be due to a lack of sufficient detergent for the protection of cytochrome P-450 hemoprotein against conversion to cytochrome P-420 (Ryan et al., 1984). Arlotto et al. (1989) reported that conversion of cytochrome P-450 to cytochrome P-420 can be controlled by recording the CO-difference spectrum of dithionite reduced cytochrome $\mathrm{P}-450$ in the presence of $1 \mu \mathrm{M}$ methyl viologen, which greatly accelerated the rate of formation of the complex between reduced cytochrome P-450 and CO.

Partial purification of P-450 was achieved using solubilisation with sodium deoxycholate and fractionation with PEG 6000. The P-450 concentration was determined from the CO-difference spectrum (Omura and Sato, 1964) using the molar extinction coefficient $91 \mathrm{mM}^{-1} \mathrm{~cm}^{-1}$. Although there appeared to be some differences in specific activity of liver cytochrome P-450 between resistant and susceptible or control sheep, it is likely that at least some of the difference was due to experimental variation. Assuming, however, that cytochrome P-450 mediated oxidation of sporidesmin contributes to resistance to the toxin, it is possible that specific activities of cytochrome P-450 would be greater in resistant animals although changes in specific isoforms may not contribute greatly to the total P-450 concentration.

Guengerich and Martin (1980) found that the P-450 content of a microsomal fraction was $2.5 \mathrm{nmol} / \mathrm{mg}$ protein, and this specific content increased to $3.0 \mathrm{nmol} / \mathrm{mg}$ protein when a deoxycholate extract was prepared. Cytochrome P-450 concentrations in our study were similar to those previously reported for sheep and other species. Wisniewski et al. (1987) reported P-450 concentrations $(0.67,0.64$ and $0.4 \mathrm{nmol} / \mathrm{mg}$ protein) in sheep, goat and cattle respectively. Shimada et al. 
(1994) reported that human cytochrome P-450 content measured spectrally varied among races and individuals. They found that Japanese men had cytochrome P450 content of $0.25 \pm 0.08$ and Japanese women had $0.29 \pm 0.13 \mathrm{nmol} / \mathrm{mg}$, compared to men $(0.43 \pm 0.18)$ and Caucasian women $(0.42 \pm 0.2 \mathrm{nmol} / \mathrm{mg})$. In addition they found a correlation between changes in age and cytochrome P-450 content in a comparison study of 60 human samples.

No significant differences in microsomal P-450 content (15\% PEG Pellet) were found between the undosed susceptible and undosed resistant 1994 born Romneys (Table 3.14). However there was greater specific activity (nmol P-450/mg protein) in 1996 born undosed resistant compared to control animals (Table 3.16). The differences in P-450 might be due to inter-individual variation or to age differences between the abattoir sheep (approximately 1year) and the other animals used in this study (approximately 4 months). Kaddouri et al. (1992) reported that changes in liver cytochrome P-450 concentration were age and isoform dependent when they studied the contribution of female ovine cytochrome P-450 2B and P-450 $3 \mathrm{~A}$ in the ontogenic development of liver progesterone metabolism. They found that cytochrome P-450 2B was detected in the foetal liver at a concentration below 0.01 $\mathrm{nmol} / \mathrm{mg}$ of microsomal protein and after birth was present at only low levels ranging from $0.03-0.07 \mathrm{nmol} / \mathrm{mg}$. By contrast, isozyme P-450 $3 \mathrm{~A}$ was detected in sheep foetal liver and represented $48 \%$ of the total P-450 in $1-4$ week old lambs $(0.33 \pm 0.05$ and $0.32 \pm 0.02 \mathrm{nmol} / \mathrm{mg}$ protein $)$, respectively. This percentage decreased in older animals (7-11 month) in which it represented $18-32 \%$ of the total P-450 at concentration of $0.18 \pm 0.04$ to $0.23 \pm 0.06 \mathrm{nmol} / \mathrm{mg}$ protein. 


\subsection{Electrophoresis and Western blotting of microsomal proteins}

A previous study of Welton et al. (1975) showed that P-450 polymorphism can be detected by 1-D gel electrophoresis of microsomal fractions. In our study 1D gel electrophoresis of microsomal proteins did not show consistent differences in 45-60 kDa possible P-450 bands between resistant and susceptible animals although some individual variation was detected in microsomal cytochrome P-450 activity. In contrast Murray (1991) reported differences in 1-D gel protein bands between untreated and dexamethasone or phenobarbital induced microsomes in sheep lines.

Siekevitz (1973) reported in his study of rat liver microsomal proteins, substantial variation of a band on 1-D gels at about $50 \mathrm{kDa}$. This was the major protein band of microsomal membranes and varied from approximately $10 \%-40 \%$ of the microsomal protein (Siekevitz, 1973). Variation of this magnitude was not detected among the sheep liver microsomal proteins.

Western blotting analysis of cytochrome P-450, from undosed susceptible and undosed resistant samples, was carried out using rabbit anti-human cytochrome P-450 3A4 antibody to detect the presence of the potential cytochrome P-450 3A4 bands in sheep liver microsomes. Two microsomal protein bands were recognized by the antihuman cytochrome P-450 3A4 antibody (Figure 3.26). Both bands were detected in each of the undosed susceptible and undosed resistant samples. It therefore appears that there are two major cross-reactive cytochrome P450s in susceptible and resistant Romney liver. In previous immunological studies, cytochrome P-450 3A4 antibody was used to recognize the cytochrome P450 isozymes involved in aflatoxin B1 metabolism in human liver (Forrester et al., 
1990). They found that polyclonal cytochrome P-450 3A4 antibody recognized three distinct antigenically related forms of recombinant human P-450 3A proteins. Our results are also similar to the results of VanT'Klooster et al. (1993) who found that polyclonal antibody against sheep cytochrome P-450 3A4 reacted with several 48-58 $\mathrm{kDa}$ liver proteins. They suggested that the presence of several stained bands might be an indication of an incomplete specificity of the antibody. Hostetler et al. (1987) found that cytochrome P-450 3A4 was expressed as two protein bands in rat colon samples, using an immunoblotting assay with polyclonal cytochrome P450 3A4 antibody. Similarly Gemzik et al. (1992) reported that an antibody against purified $3 \mathrm{~A} 1$ recognized two electrophoretically distinct proteins in liver microsomes from male and female rats as determined by immunoblotting techniques. Gemzik et al. (1992) found that the two identified proteins corresponded to P450 $3 \mathrm{~A} 1$ and/or $3 \mathrm{~A} 2$, and that both proteins were induced by dexamethasone. In contrast to our results, Pineau et al. (1990) and Kaddouri et al. (1992) found that antibodies to sheep liver P-450 3A, obtained from serum of immunized rabbits gave a single band on Western blots of sheep liver microsomes.

In summary, although there appeared to be line specific differences in $\mathrm{O}$ demethylase activity no consistent differences between resistant and susceptible animals were detected by electrophoresis or Western blotting with the anti P-450 antibody.

\subsection{GSH dependent metabolism of sporidesmin}

\subsubsection{Spontaneous reaction between sporidesmin and GSH}


The non-enzymatic reaction of GSH with sporidesmin was studied spectrophotometrically (Figure 3.29). There was a GSH - catalysed decrease in the absorbance of the substrate sporidesmin, with greatest change in the region of 230 $-260 \mathrm{~nm}$. This result is in agreement with the findings of Sissons et al. (1980) and Sissons (1981) who also found that GSH reacted with sporidesmin and that addition of GSH led to stimulation of the enzymatic reaction. Sissons et al. (1980) and Sissons (1981) reported that the non-enzymatic reaction rate alone would react at least $1 \%$ per minute of sporidesmin in the liver. Sissons et al. (1980) isolated dimercapto seco-sporidesmin as the product of the non-enzymatic reaction. They suggest that a thiol exchange occurred as shown below:

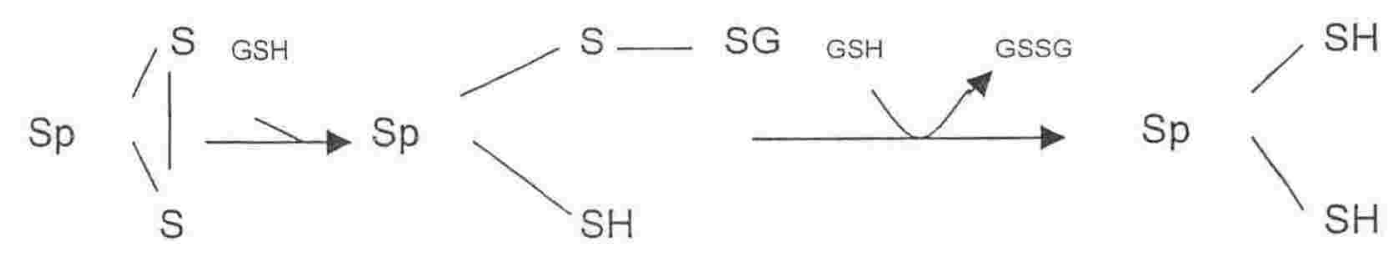

\subsubsection{Spectrophotometric analysis of the reaction of GSH with sporidesmin}

An increase in the rate of the GSH reaction with sporidesmin occurred when liver cytosol extracts were added to incubates containing GSH and the toxin (Figure 3.31). Sissons et al. (1980) also reported enzymatic reaction of GSH with sporidesmin and suggested that this might occur through thioltransferase (E.C.1.8.4.1) or GST (E.C.2.5.1.13) activities. Our results also showed that adding 
the enzyme to the sporidesmin-GSH mixture caused a decrease in the absorbance spectrum of the GSH-sporidesmin reaction in the same wavelength region previously detected for the spontaneous reaction. No evidence was seen of spectral differences between the enzymatic reaction and the non-enzymatic spontaneous reaction of GSH with sporidesmin. This finding indicated formation of similar reaction products in the enzymatic and non-enzymatic reactions.

\subsubsection{Spectrophotometric determination of GSH-dependent enzyme catalyzed} reaction with sporidesmin for the Romney selection lines

Analysis of 1997 born animals showed differences between the selection lines for the activity of liver cytosol to catalyse an enzymatic reaction between sporidesmin and GSH. Greater differences occurred in the undosed animals (resistants $0.074 \pm 0.03 \mathrm{~A} / \mathrm{min} / \mathrm{mg}$ protein, susceptibles $0.042 \pm 0.014 \mathrm{~A} / \mathrm{min} / \mathrm{mg}$ protein) than were seen two days after dosing where reaction rates appeared to be lower. It is possible that differences in GSH dependent metabolism of sporidesmin may be related to resistance or susceptibility to FE. It is also possible that exposure to sporidesmin may lead to variation of GSH dependent metabolism of sporidesmin. Srinivasan et al. (1997) have shown that the enzyme thioltransferase catalyses a GSH-dependent reaction with sporidesmin. In addition they demonstrated that thioltransferase is inactivated by sporidesmin in the absence of GSH. Hepatic levels of GSH are normally $5-10 \mathrm{mM}$ so it is unlikely that thioltransferase would be directly inactivated by sporidesmin in liver. Other possible mechanisms of inactivation of thioltransferase or GST might include free radical damage if sporidesmin generates oxidative reactants as suggested by Munday (1982, 1984, 
1987, 1989). Others have found differences in GST activity among selection lines or have shown that inherited differences in GST are responsible for differences in the hepatic metabolism of toxic compounds. Hohenboken and Blodgett (1997) and Hohenboken et al. (2000) selected mice for differences in susceptibility to endophyte toxin and found that resistant animals had greater GST activity than a susceptible line. Degen and Neumann (1981), Monroe and Eaton (1987) and Hayes et al. (1991) showed that mice resistant to the hepatocarcinogenic effects of aflatoxin B1 had enhanced levels of cytosolic GST that conjugated aflatoxin B1 epoxide. The greater resistance of mice than rats to aflatoxin B1 also appeared to be related to higher GST activity in mice. Similarly Mitchell et al. (1973) found that pretreatment of mice with cysteine, a GSH precursor, before dosing with acetaminophen prevented hepatic damage, whereas pretreatment of mice with diethyl maleate, which depleted hepatic GSH potentiated acetaminophen-induced hepatic necrosis.

In summary, inherited differences in GSH dependent metabolism of sporidesmin may be responsible in part for resistance or susceptibility to the toxin. Line specific differences in GST activities were therefore investigated using GST isoform selective substrates to further characterize a possible basis of resistance to FE. Our results also indicate small differences with CDNB (Table 3.17) after sporidesmin dosing, with the dosed resistant animals apparently showing a small increase in activity 1.14 times greater than the dosed susceptible animals. A similar result was obtained by Makary et al. (1988) after Aroclor 1254 administration to genetically inbred mice. They found that Aroclor 1254-treatment caused a 4.2 fold induction of GST in NFS/NCR mice, but only a 1.4 fold increase in AKR/NCR mice. They also found there were much larger differences in constitutive GST activities 
and their inducibility in the 12 strains of mice used. The highest constitutive and induced activity was observed in C57BL/6NHSD mice (8.9 and $23 \mu \mathrm{mol} / \mathrm{min} / \mathrm{mg}$ protein), whereas the lowest values (2.5 and $7.1 \mu \mathrm{mol} / \mathrm{min} / \mathrm{mg}$ protein) were observed in SJL/JCR mice. Variation in GST activity among inbred and line cross mice in response to fescue toxicosis has also been reported (Miller et al., 1994).

\subsection{Analysis of GST using model substrates}

\subsubsection{CDNB and DCNB}

The importance of GST in the hepatic detoxification of sporidesmin in sheep and the availability of GSH for cellular protection against the toxin have been reported by Sissons et al. (1980), Sissons (1981) and Fairclough et al. (1981).

To measure the GST activity of cytosolic liver enzymes in samples collected from undosed and dosed susceptible or resistant animals, the universal substrates CDNB and DCNB were used. CDNB and DCNB were chosen because they have been demonstrated to be substrates for many GST isoforms (Clark and Smith, 1975; Habig and Jackoby, 1981). Certain GST isoenzymes, however, have low activity towards either CDNB or DCNB, or both, as reported in a study by Meyer et al. (1991).

In our study differences in GST activity could not be detected between resistant and susceptible Romneys using these substrates (Tables $3.17,3.18$ ). In contrast to activities measured using sporidesmin as substrate, there was no decrease in activity for CDNB or DCNB in the dosed animals. These results suggest that the apparent effect of sporidesmin dosing of decreasing activity in the 
reaction between sporidesmin and GSH (section 3.13) may either be an artifact due to variation among the animals or that the activity measured in the assay with sporidesmin as substrate may be due to an activity that is not specifically distinguished from other isoforms using CDNB or DCNB. It is also possible that sporidesmin dosing might have initiated GST activity but it is not clear why sporidesmin would have a greater effect on GST from the susceptible line. It is therefore possible that a GST isoform not readily detected with either substrate might be responsible for the metabolism of sporidesmin. Although CDNB and DCNB are good substrates for GST Alpha, Mu and Pi, they have low activity with GST Theta in humans and some other mammals. Meyer et al. (1991) found that CDNB was a poor substrate for human Theta GST T1 and GST T2. Jemth et al. (1996) also reported that the T1 subclass of Theta GSTs showed a lack of ability to catalyse the reaction of GSH with CDNB, although rat GST Theta T2-2 showed activity with this substrate. They suggested that the low ability of class Theta GSTs to utilize the substrate CDNB could be due to separation of the hydrophobic binding pocket accommodating the benzene ring from the sulphydryl group of enzyme bound GSH in this class of GST. In the new work now added to the thesis GST Mu 1 and GST Mu 5 were shown to be more abundant in resistant Romneys. This may be related to greater activities with $\mathrm{p}-\mathrm{NBC}$ and EPNP in this selection line (Reddy et al. 1983), although there were no obvious difference in GST activities measured with CDNB and DCNB. Comstock et al. (1994) reported that human Mu class GST showed relatively low specific activity with the substrates CDNB (1.4 \pm 0.2 $\mu \mathrm{mol} / \mathrm{min} / \mathrm{mg}$ protein) or DCNB $(0.022 \pm 0.002 \mu \mathrm{mol} / \mathrm{min} / \mathrm{mg}$ protein). Lenartova et al. (1996), however, reported that Mu class GST induced in sheep liver exposed to pollutants showed a marked increase in activity with DCNB. Similarly, Primiano and 
Novak (1993) also reported that rabbit class Mu GST showed activity towards CDNB $(77.8 \pm 4.9 \mu \mathrm{mol} / \mathrm{min} / \mathrm{mg}$ protein $)$, and DCNB $(0.25 \mu \mathrm{mol} / \mathrm{min} / \mathrm{mg}$ protein $)$. These data are consistent with the findings of Alin et al. (1985), Mannervik et al. (1985) and Miyaura and Isono (1986) who reported that class Mu GSTs exhibited appreciable activity towards CDNB and DCNB. Carrillo et al. (1990) also reported an increase in activity towards the CDNB and DCNB substrates in male Wistar rats after oral administration of $100-500 \mu \mathrm{g}$ aflatoxin $\mathrm{B} 1 / \mathrm{kg}$ body weight.

Species variation in GST activity towards substrates CDNB and DCNB have also been reported. Smith et al. (1984) showed that sheep, cattle, rats and swine actively transformed the CDNB substrate but that sheep expressed less activity towards CDNB while DCNB activities were more than four times greater in sheep than in cattle. These differences may reflect species differences in the relative activity of GST isoforms and possibly also strain differences in GSTs within species.

\subsection{2 $\mathrm{p}-\mathrm{NBC}$ and EPNP}

The activity of the cytosolic enzyme collected from undosed susceptible and undosed resistant animals born 1995 and 1997 was further tested using model substrates p-NBC (Table 3.19) and EPNP (Table 3.20).

GST activity for both substrates was greatest in the resistant animals. P-NBC activity was 1.5 fold greater in resistance compared to susceptibles (Table 3.20 ) and EPNP was 1.8 fold greater in resistance compared to susceptibles (Table 3.21). These results suggest that the selection lines may differ in a GST activity that is detected with $\mathrm{p}-\mathrm{NBC}$ and EPNP. The importance of the influence of the selection line is shown in the ANOVA analysis. A significant difference was observed in the 
catalytic activity towards the model substrate $\mathrm{p}-\mathrm{NBC}$ in the undosed resistant samples $(p=0.0013)$ for animals born 1995 and 1997 compared to that of the undosed susceptible animals. There were no significant differences in $\mathrm{p}-\mathrm{NBC}$ activity between the susceptible samples from animals born 1995 and 1997 $(p=0.55)$. On the other hand a marked difference was recorded between the resistant groups, born 1995 and 1997, with the 1997 group showing much more activity ( $p=0.001$ ) than the 1995 group. It is possible that this might be due to greater resistance in the 1997 born animals. A t-test and Exact Wilcoxon rank sum - test, analysing the activity of GST towards the substrate EPNP also showed a difference between the resistant and susceptible lines for animals born 1997. The significant difference between the undosed resistance and the undosed susceptibles from the t-test was $p=0.00174$ and 0.015 from the Exact Wilcoxon test.

It is possible that differences observed with p-NBC and EPNP reflect greater GST activity in the resistant line. The subsequent identification of differences in abundance of two isoforms of GST, Mu 1 and Mu 5, between resistant and susceptible animals is consistent with differences in enzyme activity towards p-NBC and EPNP. Although p-NBC and EPNP are commonly used substrates for GST Theta isoforms (Sherratt et al. (1997), Jemth and Mannervik (1997) and Meyer et al. (1991) they also show activity towards GST Mu isoforms (Reddy et al., 1983). Although Mu isoform differences were detected using 2-D PAGE in my study it was not possible to exclude differences in the Theta isoforms as these alkaline pl enzymes would not have been detected on the 2-D gels. 


\subsection{Analysis of GST isoforms by 1-D PAGE of liver supernatant}

Changes in GST isoenzyme pattern in sheep liver exposed to environmental pollution were previously detected using 1-D PAGE (Lenartova et al., 1996). They separated GST subunit A1-1 (class Alpha) and GST subunit M3-3 (Mu class), from sheep grazed on polluted pasture, at 25.3 and $27 \mathrm{kDa}$ respectively and GST subunit A8-8 (class Alpha) and GST subunit 7 (Pi class) from control sheep at 27 and 27.2 kDa. Similarly Theta class subunit T1-1 and Zeta subunit Z1-1 was separated by 1D PAGE from human tissues at 28 and $24.2 \mathrm{kDa}$ (Meyer et al., 1991; Sherratt et al., 1996; Board et al., 1997).

We expected, from the observed enzyme variations between the selected susceptible and resistant Romney sheep, that GST band patterns might show differences on 1-D gels. However, 1-D PAGE of four undosed susceptible and four undosed resistant Romneys showed no consistent differences between resistant and susceptible lines in the potential GST subunits (Figures 3.32, 3.33). Line specific difference in GST expression could therefore not be detected, possibly due to the abundance of other proteins in this size range.

\subsection{Analysis of protein variation by 2-D PAGE}

2-D PAGE protein mapping is a technique that allows the separation and visualization of hundreds of proteins in a single analysis (O'Farrell, 1975; Anderson and Anderson, 1978a, b). Through computer analysis of 2-D gels (Anderson et al., 1981 ) it is possible to analyse the abundance of individual proteins. 2-D gel electrophoresis analysis was used in our study to search for any differences in 
proteins between the resistant and susceptible Romney lines. The initial analysis of whole homogenate proteins allowed detection of approximately 200 - 300 protein spots in the $\mathrm{pl}$ range $3.5-7.5$ and size range $14-70 \mathrm{kDa}$. Visual inspection of the 2D gels from the pools of undosed susceptible and undosed resistant samples did not reveal proteins that were found in only one pool. This is in agreement with a previous study of Lu et al. (1994) who found no qualitative protein variation between susceptible and resistant Romney ewes. There were, however, quantitative differences in abundance of individual proteins in Lu's study and in the present analysis (Figures $3.36 a-3.36 d$ ). In the present study an initial visual inspection of the gels was used to identify proteins that appeared to vary between the two pools. The abundances of these and other proteins were then measured using ImageQuant software. Seven spots out of the eighteen selected variant spots appeared to show greater than two-fold differences in expression between the resistant and susceptible Romney liver pools (Figure 3.37a). Ten spots that appeared by eye to be consistent in the resistant and susceptible pools showed less than about $50 \%$ quantitative variation between the undosed susceptible and the undosed resistant Romneys (Figure $3.37 \mathrm{~b}$ ). This is within the range of easy detection of protein spot abundance differences during visual inspection of gel.

Previous studies had indicated that natural resistance to sporidesmin induced liver damage might be derived from differences in the hepatic microsomal drug metabolising enzymes (Fairclough et al., 1978). Also, as the liver and biliary system are major targets for sporidesmin action (Mortimer, 1963 and Bhathal et al., 1990) it was thought that there might be some variation between the liver proteins of FE resistant and susceptible sheep. The variation in protein abundance detected in this study might be a reflection of the genetic variation between the susceptible and 
resistant samples, especially as the selected lines of these animals were based on the genetic variation in response to the sporidesmin challenge between the susceptible and resistant Romney sheep (Campbell et al., 1975 and Morris et al., 1989). Heterogeneity among wild populations of mice was also detected in 2-D PAGE studies of liver proteins (Racine and Langley, 1980; Aquadro and Avise, 1981). In addition, changes in microsomal protein abundance in rat liver treated with the hypoglycemic agent SDZ PGU 693 were reported in the study of Arce et al. (1998). They found major changes in several microsomal proteins including NADPH cytochrome P-450 reductase, cytochrome $b_{5}$, and serine protease inhibitor, which showed increases in abundance.

\subsection{Analysis of supernatant proteins using 2-D PAGE and MALDI-TOF mass} spectrometry

2-D polyacrylamide gel electrophoresis was used to separate supernatant samples from two resistant and two susceptible animals. The aim was to find protein differences including GST isoforms that might be in the pl 4 - 8 region resolved on these gels. Despite the use of a wide range $(3-10)$ focusing higher $\mathrm{pl}$ proteins $(\mathrm{pl}>7$ ) were either difficult to detect at the smeared basic end of the strip or were even too basic to focus. This limitation is typical of commercially available wide range focusing strips but alkaline range strips have become available recently and could be used in future studies.

Three protein spots that were more abundant in the liver of the resistant animals, and that were in the size range and position expected for GST isoforms, were used for MALDI mass fingerprinting. The peptide masses were submitted to 
ProFound for identification. Two proteins (spots 6,7 ) gave a good match to GST isoforms, Mu 5 and Mu 1, respectively. Spot 6 gave a best match to mouse Mu 5 . The probability and $Z$ statistic allow reasonable confidence in this match that had $35 \%$ coverage of the matched protein sequence based on size matched peptides. Mass fingerprinting is able to provide reasonable confidence matches for comparison to sequence databases from other species. In this case there were no ovine or bovine Mu 5 sequences for matching in the databases. The identification of spot 7 as GST Mu 1 was in agreement with the finding of Kitteringham et al. (2003), who identified GST Mu 1 as one of other major isoforms present in liver cytosol, representing $3.8 \%$ in wild type animals. The spot 7 GST matched to rabbit GST Mu 1 (pl 6.4, $25.3 \mathrm{kDa}$ ) and human GST Mu 1 (pl 6.3, 25.6 kDa). There was no ovine or bovine Mu 1 sequence in the databases. GST Mu 5 corresponded with mouse GST Mu 5 (p| 6.82, $26.6 \mathrm{kDa}$ ) in the ExPASY databases. In spite of the fact that all three spots were in close proximity on the 2-D gel, the third spot (spot 8) matched to a MHC class II protein with a high Z score and probability of 1.00 . The high $\mathrm{Z}$ score is probably due to matching to a sequence from a closely related species. It is possible that this MHC class II protein is associated with FE resistance although it may be artifact of the small sample size or FE selection strategy. It is possible that there is an association with response to sporidesmin induced liver damage such as macrophage responses (Pillarisetty et al. 2003) or some activity of liver sinusoidal endothelial cells (Knolle et al. 1999). MHC class II molecules are polymorphic peptide receptors of antigen presenting cells such as the inflammatory cells that digest foreign proteins. The presence of $\mathrm{MHC}$ class II in the resistant samples might be related to the capacity of these cells to respond to sporidesmin-induced damage. 


\subsection{Conclusions}

The research presented in this thesis indicated that there were differences in sporidesmin metabolism between the FE resistant and susceptible Romney lines. The resistant animals appeared to have greater rates of potential sporidesmin inactivation pathways that included P-450 mediated O-demethylation. Dosing the two lines with sporidesmin showed an increase in the activity of the O-demethylase pathway in resistant animals and decrease in the O-demethylase activity in the susceptible Romneys. The cytoplasmic GSH dependent inactivation pathway also appeared to play a role in the resistance towards the sporidesmin toxicity. In addition two cytoplasmic proteins spots that were abundant in resistant animals were identified as GST Mu 1 and Mu 5 isoforms and it is possible that these enzymes could inactivate sporidesmin. It is, however, not possible to exclude involvement of GST Theta as these isoforms show substantial species differences in sequence and $\mathrm{pl}$ and may be too basic to detect on the IPG strips that were used.

\subsection{Future studies}

The work presented in this thesis indicates that some GST isoforms and potentially some P-450s have greater activity in livers from the Ruakura FE resistant Romney line compared to the susceptible line animals. These findings should be investigated to determine the potential to develop blood DNA markers for selection of resistant animals. Initially this work could be continued using the Ruakura FE selection lines. There would be an advantage in collection of fresh tissue as the lines are now more divergent (Chris Morris, personal communication to Bill Jordan) 
than the animals that were used for my studies. The GST isoforms could be examined using an affinity chromatography approach for isolation but progress might also be made through further 2D-PAGE using both wide range pl 3-10 focusing and alkaline range (up to $\mathrm{pH} 12$ ) focusing of liver samples. The cytosolic fraction of liver should be examined for further evidence of line-specific variation among GSTs and a microsomal fraction could be studied to search for differences among P-450s, most of which have alkaline pls. It is also possible that this proteomics approach might identify other proteins that are segregating between the resistant and susceptible lines. Some of the proteins that segregate in a line specific manner may have roles in FE resistance while others may be in linkage with resistance or may be unrelated to FE, having resulted from the way the flocks were created from a small number of sires. It would therefore be useful to test the coding gene sequences using linkage analysis in the AgResearch FE gene mapping flocks (Phua et al. 1999). One way to do this would be to design PCR primers, from the peptide mass fingerprint sequences, for DNA markers to be used in the mapping studies. These studies could be used to test linkage of the proteins to $\mathrm{FE}$ resistance and to test whether the degree of linkage is sufficient to confirm a functional role for the proteins in responses to sporidesmin. DNA markers could then be used for trailing detection of resistant Romneys. If successful, use in other sheep breeds and other livestock species should be examined. 


\section{REFERENCES}

Aitchison, J. (1986). The statistical analysis of compositional data. Chapman and Hall, London and New York.

Alin, P., Jensson, H., Guthenberg, C., Danielson, U.H., Tahir, M.K. and Mannervik, B. (1985). Purification of major basic glutathione S-transferase isoenzymes from rat liver by use of affinity chromatography and fast protein liquid chromatofocusing. Analyt. Biochem. 146: $313-320$.

Ames, B.N. (1989). Mutagenesis and carcinogenesis: Endogenous and exogenous factors. Environ. Mol. Mutagen. 14, Suppl. 16: 66 - 75.

Anders, M.W. and Pohl, L.R. (1985). Halogenated alkanes, In: Bioactivation of Foreign Compounds. (Anders, M.W. ed.), pp. 283-315, Academic Press, Orlando, Florida.

Anderson, N.G. and Anderson N.L. (1978a). Analytical techniques for cell fractions. XXII. Two dimensional analysis of serum and tissue proteins: Multiple gradient slab electrophoresis. Anal. Biochem. 85: $341-354$.

Anderson, N.L. and Anderson N.G. (1978b). Analytical techniques for cell fractions. XXI. Two dimensional analysis of serum and tissue proteins: Multiple isoelectric focusing. Anal. Biochem. 85: $331-340$.

Anderson, C., Mosialou, E., Weinander, P. and Morgenstern, R. (1994). Enzymology of microsomal glutathione S-transferases. Adv. Pharmacol. 27: 19 35.

Anderson, N.L., Taylor, J., Scandora, A.E., Coulter, B.P. and Anderson, N.G. (1981). The TYCHO system for computerized analysis of two dimensional gel protein mapping data. Clin. Chem. 27: $1807-1820$.

Anderson, S., Davis, D.L., Dahlback, H., Jornvall, H. and Russel, D.W. (1989). Cloning, structure, and expression of the mitochondrial cytochrome P-450 sterol 26 hydroxylase, a bile acid biosynthetic enzyme. J. Biol. Chem. 264: 8222 - 8229.

Aquadro, C.F. and Avise, J.C. (1981). Genetic divergence between rodent species assessed by using 2-dimensional electrophoresis. Proc. Natl. Acad. Sci. USA. 78: $3784-3788$.

Arce, A., Aicher, L., Wahl, D., Anderson, N.L., Meheus, L., Raymackers, J., Cordier, A. and Steiner, S. (1998). Changes in the liver protein pattern of female Wistar rats treated with the hypoglycemic agent SDZ PGU 693. Life Sci. 63: 2243 - 2250.

Arlotto, M.P., Greenway, D.J. and Parkinson, A. (1989). Purification of two isoenzymes of rat liver microsomal cytochrome P-450 with testosterone $7 \alpha$ hydroxylase activity. Arch. Biochem. Biophys. 27: $441-457$. 
Armstrong, R.N. (1994). Glutathione S-transferases : structure and mechanism of an archetypical detoxication enzyme. Adv. Enzymol. Relat. Areas. Mol. Biol. 69: 1 44.

Awasthi, Y., Awasthi, S. and Zimniak, P. (1997). Multiple transport proteins involved in the detoxification of endo- and xenobiotics. Frontiers in Bioscience 2: d427 - 437 .

Aust, S.D. (1977). A biochemical approach to facial eczema. Report to New Zealand National Research Advisory Council, pp. 1 - 26.

Bammler, T.K., Smith, C.A.D. and Wolf, C.R. (1994). Isolation and characterization of two mouse Pi -class glutathione S-transferase genes. Biochem. J. 298: 385 390.

Bhasker, C.R., Adler, B.S., Dee, A., John, M.E., Kagimoto, M., Zubber, M.X., Ahlgren, R., Wang, X., Simpson, E.R. and Waterman, M.R. (1989). Structural characterisation of the bovine cyp 17 ( $17 \alpha$ - hydroxylase) gene. Arch. Biochem. Biophys. 271: $479-487$.

Beaune, P.H., Kremers, P., Dansette, P.M., Flinois, J.P. and Leroux, J.P. (1980). Monooxygenase activities of partially purified cytochrome P-450 from human liver microsomes. In : Microsomes, Drug Oxidations, and Chemical Carcinogenesis. (Coon, M.J., Conney, A.H., Estabrook, R.W., Gelboin, H.V., Gillette, J.R. and O'Brian, P.J., eds.), vol. II, pp. 413 - 418, Academic Press, New York.

Beaune, P.H., Kremers, P., Letawe-Goujon, F. and Gielen, J.E. (1985a). Monoclonal antibodies against human liver cytochrome P-450. Biochem. Pharmacol. 34: 3547 - 3552 .

Bergh, A.F. and Strobel, H.W. (1992). Reconstitution of the brain mixed-function oxidase system : purification of NADPH-cytochrome P-450 reductase and partial purification of cytochrome P-450 from whole rat brain. J. Neurochem. 59: 575 581.

Bezille, P., Brown, J.P. and Le Bars, J. (1984). Premiere identification de l'eczema facial chez les ovins in Europe, aspect epidemiologiques, cliniques et biologiques. Rec. Med. Vet. Ec. Alfort. 160: $339-347$.

Bhathal, P.S., Jordan, T.W. and Mackay, I.R. (1990). Mouse strain differences in susceptibility to sporidesmin induced biliary tract injury. Liver 10: 193 - 204.

Bhargava, M.M., Listowsky, I. and Arias, I.M. (1978). Ligation: Bilirubin binding and glutathione S-transferase activity are independent processes. J. Biol. Chem. 253: $4112-4115$.

Bhargava, M.M. (1983). Differential in vitro translation and independent in vivo regulation of mRNAs for subunits of ligandin. Biochem. Biophys. Acta 740: 190 191. 
Board, P.G. (1981). Biochemical genetics of glutathione S-transferase in man. Am. J. Genet. 33: 36 - 43.

Board, P.G., Coggan, M., Johnston, P., Ross, V., Suzuki, T. and Webb, G.C. (1990). Genetic heterogeneity of the human glutathione S-transferases: a complex of gene families. Pharmacol. Ther. 48: $357-369$.

Board, P.G., Coggan, M., Wilce, M.C.J. and Parker, M.W. (1995). Evidence for an essential serine residue in the active site of theta class glutathione transferases. Biochem. J. 311: $247-250$.

Board, P.G., Baker, R.T., Chelvanayagam, G. and Jermiin, L.S. (1997). Zeta a novel class of glutathione transferases in a range of species from plant to humans. Biochem. J. 328: 929 - 935.

Board, P.G., Coggan, M., Chelvanayagam, G., Easteal, S., Jermiin, L.S., Schulte, D.E., Danley, L.R. et. al. (2000). Identification, characterization and crystal structure of the Omega class glutathione transferases. J. Biol.Chem. 275: 24798 24806.

Bonnefoi, M., Hasim, M., Sauvagnac, P., Burgat,V. and Braun, J.P. (1989). Liver enzyme changes in a guinea-pig model of facial excema (sporidesmiotoxicosis). Enzyme 42: $39-46$.

Boobis, A.R., Duncan, J., Fawthrop, J. and Davies, D.S. (1989). Mechanisms of cell death. Trends Pharmacol. Sci. 10: $275-280$.

Boyer, T.D. (1986). Covalent labeling of the non substrate ligand-binding site of glutathione S-transferases with bilirubin - Woodward's reagent K. J. Biol. Chem. 261: $5363-5367$.

Boyland, E. and Chasseaud, L.F. (1969). The role of glutathione and glutathioneS-transferase in mercapturic acid biosynthesis. Adv. Enzymol. 23: 173-219.

Braun, J.P., Bezille, P., Galtier, P., Rico, A.G. and Ouedraogo, G. (1992). Effects of age on the distribution of some enzymes in the organs of sheep. Small Rum. Rec. 9: 149 - 156.

Bridges, J.W. and Fennell, T.R. (1980). Characteristics of the form of P-450 induced by methylene-dioxy compounds in rats and mice. In: Microsomes, Drug Oxidations, and Chemical Carcinogenesis. (Coon, M.J., Conney, A.H., Estabrook, R.W., Gelboin, H.V., Gillette, J.R. and O'Brian, P.J. eds.), pp. 993 - 996, Academic Press, New York.

Bullock, G., Eakings, M.N., Sawyer, B.C. and Slater, T.G. (1974). Studies on bile secretion with aid of the isolated perfused rat liver: 1. Inhibitory action of sporidesmin and Icterogenin. Proc. Royal. Soc. Lond. B. 186: 333 - 356.

Buening, M.K. and Franklin, M.R. (1976). SKF 525-A inhibition, induction, and $452-$ $\mathrm{nm}$ complex formation. Drug Metab. Dispose. 4: 244 - 255. 
Campbell, A.G., Meyer, H.H., Henderson, H.V. and Wesselink, C. (1981).

Breeding for facial eczema resistance a progress report. Proc. N. Z. Soc. Anim. Prod. 41: 273-278.

Campbell, A.G., Mortimer, P.H., Smith, B.L., Clark, J.H. and Ronaldson, J.W. (1975). Breeding for facial eczema resistance?. Proc. Ruakura Farmers' Conf., pp. $62-64$.

Campbell, E., Takahashi, Y., Abramovitz, M., Peretz, M. and Listowsky, I. (1990). A distinct human testis and brain $\mathrm{Mu}$-class glutathione S-transferase. Molecular cloning and characterization of a form present even in individuals lacking hepatic type Mu isoenzymes. J. Biol. Chem. 265: 9188 - 9193.

Carrillo, M.C., Carnovale, C.E. and Monti, J.A. (1990). Effect of aflatoxin B1 treatment in vivo on the in vitro activity of hepatic and extrahepatic glutathione Stransferase. Toxicol. Lett. 50: $107-116$.

Castell, J.V., Gomez-Lechen, M.J., Ponsoda, X. and Borl, R. (1997). The use of cultured hepatocytes to investigate the mechanism of drug hepatotoxicity. Cell Biol. Toxicol. 13: $331-338$.

Chasseaud, L.F., (1979). The role of glutathione and glutathione S-transferases in the metabolism of chemical carcinogens and other electrophilc agents. Adv. Cancer Res. 29: $175-274$.

Chen, W-J., Graminski, G.F. and Armstrong, R.N. (1988). Dissection of the catalytic mechanism of isoenzyme 4-4 of glutathione S-transferases with alternative substrates. Biochem. J. 27: $647-654$.

Clare, N.T. (1969). Facial excema I. The how and why of the disease. N. Z. J. Agric. 119: $17-21$.

Clark, A.G. (1982). Glutathione S-transferases and resistance to pesticides. Chemistry in New Zealand. $100-102$.

Clark, A.G. (1989). The comparative enzymology of the glutathione S-transferases from non-vertebrate organisms. Comp. Biochem. Physiol. 92: 419-446.

Clark, A.G. and Smith, J.N. (1975). Glutathione S-aryl-transferase as a model for the glutathione-S-transferases. Environmental quality and safety. Supplement III. (Coulston, F. and Korte, F. eds.), pp. 346 - 350. George Thieme, Stuttgart, Germany.

Coles, B. and Ketterer, B. (1990). The role of glutathione S-transferases in chemical carcinogenesis. CRC. Crit. Rev. Biochem. Mol. Biol. 25: 47 - 70

Comstock, K.E., Widersten, M., Hao, X-Y., Hemer, W.D. and Mannervik, B.

(1994). A comparison of the enzymatic and physiochemical properties of human glutathione S-transferase M4-4 and three other human mu class enzymes. Arch. Biochem. Biophys. 311: $487-495$ 
Conney, A.H. (1982). Induction of microsomal enzymes by foreign compounds and carcinogenesis by polycyclic aromatic hydrocarbons. Cancer Res. 42: $4875-4917$.

Coon, M.J., Vermilion, J.L., Vatsi, K.P., French, J.S., Dean, W.L. and Haugen, D.A. (1977). In: Drug Metabolism Concepts (Jenria, D.M., ed.), pp. 46 - 71, Amer. Chem. Soc. Washington D.C.

Cordiner, S.J. and Jordan, T.W. (1983). Inhibition by sporidesmin of hepatocyte bile acid transport. Biochem. J. 212: $197-204$.

Cordiner, S.J., Moore, C.M., Vintiner, S.K. and Jordan, T.W. (1983). Does sporidesmin act on membranes ? (Baxter,M., ed.), pp. $456-59$. Proceedings of the Seventh Congress of the International Society for Human and Animal Mycology, pp. 456 - 459, Massey University, New Zealand.

Cresteil,T., Beaune, P., Celier, C., Leroux, J.P. and Guengerich, F.P. Cytochrome P-450 isoenzyme content and monooxygenase activities in rat liver: effect of ontogenesis and pre-treatment by phenobarbital and 3-methylcholanthrene. J. Pharmacol. Exp. Ther. 236: $269-276$.

Dalvi, R.R., Nunn, V.A. and Jaskevich, J. (1987). Hepatic cytochrome P-450 dependent drug metabolizing enzyme activity in rats, rabbits and several food producing species. J. Vet. Pharmacol. Ther. 10: $164-168$.

Daly, A.K., Cholerton, S., Armstrong, M. and Idle, J.R. (1994). Genotyping for polymorphisms in xenobiotic metabolism as a predictor of disease susceptibility. Environ. Health Perspect. 102: $55-60$.

Danger, D.P., Baldwin, W.S. and Le Blanc, G.A. (1992). Photoaffinity labelling of steroid-hormone-binding glutathione-S-transferases with $\left[{ }^{3} \mathrm{H}\right.$ ] methyltrienolone. Inhibition of steroid-binding activity by the anti-carcinogen indole-3-carbinol. Biochem. J. 288: $361-367$.

Degen, G.H. and Neumann, H.G. (1981). Differences in aflatoxin B1 susceptibility of rat and mouse are correlated with the capacity in vitro to inactivate aflatoxin B1epoxide. Carcinogenesis 2: 299-306.

DeJong, J.L., Morgenstern, R., Jomvall, H., De Pierre, J.W. and Tu, C.P.D. (1988). Gene expression of rat and human microsomal glutathione-S-transferase. J. Biol. Chem. 263: $8430-8436$.

De Waziers, I., Cugnenc, P.H., Yang, C-S., Leroux, J.P. and Beaune, P.H.

(1990). Cytochrome P-450 isoenzymes, epoxide hydrolase and glutathione transferases in rat and human hepatic and extrahepatic tissues. J. Pharmacol. Exp. Ther. 253: $387-394$.

Dierickx, P.J. (1985). In vitro interaction of organic mercury compounds with soluble glutathione S-transferases from rat liver. Pharmac. Res. Commun. 17: 489 -500 . 
Dignam, J.D. and Strobel, H.W. (1975). Preparation of homogenous NADPHcytochrome P-450 reductase from rat liver. Biochem. Biophys. Res. Commun. 63: $845-852$.

Di llio, C., Aceto, A., Zezza, A., Ricci, G. and Federici, G. (1989). Electrophoretic and immunological analysis of glutathione transferase isoenzymes of human kidney carcinoma. Biochem. Pharmacol. 38: 1045 - 1051.

Ding, G.J.F., Ding, V.D.H., Rodkey, J.A., Bennett, C.D., Lu, A.Y.H. and Pickett, C.B. (1986). Rat liver glutathione-S-transferases. DNA sequence analysis of a $\mathrm{Yb}_{2}$ cDNA clone and regulation of the $\mathrm{Yb}_{1}$ and $\mathrm{Yb}_{2}$ mRNAs by phenobarbital. J. Biol. Chem. 261: $7952-7957$.

Ding, V.D.H. and Pickett, C.B. (1985). Transcriptional regulation of rat liver glutathione-S-transferase gene by phenobarbital and 3-methylcholanthrene. Arch. Biochem. Biophys. 240: $553-559$.

Dodd, D.C. (1960). Photosensitivity disease in N. Z. XXI The susceptibility of the rabbits to facial eczema. N. Z. J. Agr. Res. 3: $491-497$.

Done, J., Mortimer, P.H. and Taylor, A. (1960). Some observations on field cases of facial excema: Liver pathology and determinations of serum bilirubin, cholesterol, transaminase, and alkaline phosphatase. Res. Vet. Sci. 1: 76 - 83.

Dvorchik, B.H., Woodward, G, Sitar, D.S. and Tweed, W.A. (1986). Hydroxylation and glucuronidation of various xenobiotics by hepatic microsomes from the foetal lamb, pregnant ewe, and human foetus. Dev. Pharmacol. Ther. 9: $282-289$.

Enjuanes, A., Garcia-Giralt, N., Supervia, A., Nogues, X., Mellibovsky, L., Carbonell, J., Grinberg, D., Balcells, S. and Diez-Perez, A. (2003). Regulation of Cyp -19 gene expression in primary human osteoblast: effects of vitamin $D$ and other treatments. Eur. J. Endocrinol. 148: $519-526$.

Ellin, A., Jakobsson, S.B., Schenkman, J.B. and Orrenious, S. (1971). P-450k of rat kidney cortex microsomes. Its involvement in fatty acid $\mathrm{W}$. and $\mathrm{W}-1$ hydroxylation. Arch. Biochem. Biophys. 150: $64-71$.

Fairclough, R.J., Munday, R. and Campbell, A.G. (1981). Development of a biochemical test for selecting sheep for resistance or susceptibility to sporidesmin dosing. Annual report for New Zealand Ministry of Agriculture and Fisheries. Ag. Res. Div. p. 52.

Fairclough, R.J., Sissons, C.H., Holland, P.T. and Ronaldson, J.W. (1978). Studies on sporidesmin metabolism in sheep. Proc. N. Z. Soc. Anim. Prod. 38: $56-70$.

Fang, W.F.and Strobel, H.W. (1978). The drug and carcinogen metabolism system of rat colon microsomes. Arch. Biochem. Biophys. 186: $128-138$. 

Gonzalez, F.J. and Nebert, D.W. (1990). Evolution of the P-450 gene superfamily. Animal-plant 'warfare' molecular drive and human genetics differences in drug oxidation. Trends Genet. 6: $182-186$.

Gonzalez, F.J., Vilbois, F., Hardwick, N.P., McBride, O.W., Nebert, D.W., Gelboin, H.V. and Meyer, U.A. (1988). Human debrisoquine 4-hydroxylase (P-450 2D1) cDNA and deduced amino acid sequence and assignment of the cyp 2D locus to chromosome 22. Genomic 2: $174-179$.

Gottesman, M.M. and Pastan, I. (1993). Biochemistry of multidrug resistance mediated by the multidrug transporter. Ann. Rev. Biochem. 62: 385 - 427.

Goto, M., Brickwood, S., Wilson, D.I., Wood, P.J., Mason, J.I., Hanley, N.A. (2002). Steroidogenic enzyme expression within the adrenal cortex during early human gestation. Endocr. Res. 28: $641-645$.

Gourlay, G.K., Savage, J.K. and Stock, B.H. (1977). Hepatic drug metabolism in normal and vitamin E-deficient female Merino sheep. Toxicol. Appl. Pharmacol. 39: $365-375$.

Graminski, G.F., Kupo, Y. and Armstrong, R. N. (1989). Spectroscopic and kinetic evidence for the thiolate an iron of glutathione at the active site of glutathione Stransferase. Biochem. J. 28: $3562-3568$.

Grant, R. and Ironside, J.W. (1995). Glutathione S-transferases and cytochrome P-450 detoxifying enzyme distribution in human cerebral glioma. J. Neuro. Oncol. 25: $1-7$.

Guengerich, F.P. (1977a). Separation and purification of multiple forms of microsomal cytochrome P-450: activities of different forms of cytochrome P-450 toward several compounds of environmental interest. J. Biol. Chem. 252: 3970 3979.

Guengerich, F.P. (1977b). Metabolism of vinyl chloride colon destruction of the haeme of highly purified liver microsomal cytochrome P-450 by a metabolite. Mol. Pharmacol. 13: 911 - 923.

Guengerich, F.P. (1978). Separation and purification of multiple forms of microsomal cytochrome P-450. J. Biol. Chem. 253: 7931 - 7939.

Guengerich, F.P. (1987). Mammalian cytochromes P-450, Vol. 1and 2, CRC Press, Boca Raton, Florida.

Guengerich, F.P. (1992). Human cytochrome P-450 enzymes . Life Sci. 50: $1471-1478$.

Guengerich, F.P., Dannan, G.A., Wright, S.T., Martin, M.V. and Kaminsky, L.S. (1982). Purification and charactization of rat liver microsomal cytochrome P-450: electrophoretic, spectral, catalytic, and immunochemical properties and inducibility of 
eight isozymes isolated from rats treated with phenobarbital or $\beta$-naphthoflavone. Biochemistry 21: $6019-6030$.

Guengerich, F.P. and Martin, M.V. (1980). Purification of cytochrome P-450 NADPH-cytochrome P-450 reductase, and epoxide hydrates from a single preparation of rat liver microsomes. Arch. Biochem. Biophys. 250: 365 - 379.

Guengerich, F.P., Wang, P. and Davidson, N.K. (1982b). Estimation of isozymes of microsomal cytochrome P-450 in rats, rabbits and humans using immunochemical staining coupled with sodium dodecyl sulphate - polyacrylamide gel electrophoresis. Biochem. 21: $1698-1706$.

Guengerich, F.P., Wang, P., Mitchell, M.P. and Masson, P.S. (1981). Immunological comparison of rat, rabbit, and human liver NADPH-cytochrome p450 reductases. Biochemistry 20: $2379-2385$.

Guthenberg, C., Warholm, M., Rane. A. and Mannervik, B. (1986). Two distinct form of glutathione transferase from human foetal liver. Biochem. J. 235: 741 745.

Habig, W.H. (1983). Glutathione S-transferase : versatile enzymes of detoxication . In: Radioprotectors and Anticarcinogens, (Nygaard, O.F. and Simic, M.G., eds. ), pp. 169 - 190, Academic Press, San Diego.

Habig, W. H. and Jakoby. W. B. (1981). Assays for differentiation of glutathione Stransferases. Methods Enzymol. 77: 398 - 405.

Hales, B.F., Jaeger, V. and Neims, A.H. (1978). Isoelectric focusing of glutathione S-transferases from rat liver and rat kidney. Biochem. J. 135: $937-943$.

Hales, B.F. and Neims, A.H. (1977). Induction of rat hepatic glutathione Stransferase $B$ by phenobarbital and 3-methylcholanthrene. Biochem. Pharmacol. 26: $555-556$.

Hanna, P.M., Kaddiiska, M.B., Jordan, S.J. and Mason, R.P. (1993). Role of metallothionein in zinc ( II ) and chromium ( III ) mediated tolerance to carbon tetrachloride hepatotoxicity : evidence against a trichloromethyl radical-scavenging mechanism. Chem. Res. Toxicol. 6: 711 - 717.

Harada, N., Yamada, K., Saito, K., Kibe, N., Dohmae, S. and Takagi, Y. (1990). Structural characterisation of the human esterogen synthetase (aromatase) gene. Biochem. Biophys. Res. Commun. 166: 365 - 372.

Harris, J.M., Meyer, D.J., Coles, B. and Ketterer, B. (1991). A novel glutathione Stransferase (13-13) isolated from the matrix of rat liver mitochondria having structural similarity to class theta enzymes. Biochem. J. 278: $137-141$.

Haugen, D.A., Van der Hoeven, T.A. and Coon, M.J. (1975). Purified liver microsomal cytochrome P-450: Separation and characterization of multiple forms.

J. Biol. Chem. 250: $3567-3570$. 
Hayes, J.D. and Chalmers, J. (1983). Bile acid inhibition of basic and neutral glutathione S-transferases in rat liver. Biochem. J. 215: 581 - 588.

Hayes, J.D., Judah, D.J., McLellan, L.I. and Neal, G.E. (1991). Contribution of the glutathione S-transferase to the mechanism of resistance to aflatoxin B1. Pharmac. Ther. 50: $443-472$.

Hayes, J.D., Kerr, L.A. and Cronshaw, A.D. (1989). Evidence that glutathione Stransferases $B_{1} B_{1}$ and $B_{2} B_{2}$ are the products of separate genes and that their expression in human liver is subject to inter-individual variation. Molecular relationships between the $B_{1}$ and $B_{2}$ subunits and other alpha class glutathione $S$ transferases. Biochem. J. 264: $437-445$.

Hayes, J.D. and Mantle, T.J. (1986). Inhibition of hepatic and extrahepatic glutathione S-transferases by primary and secondary bile acids. Biochem. J. 233: $407-415$.

Hayes, J.D., Nguyen, T., Judah, D.J., Petersson, D.G. and Neal, G.E. (1994). Cloning of cDNAs from fetal rat liver encoding glutathione S-transferase $Y_{C}$ polypeptides. The $\mathrm{YC}_{2}$ subunit is expressed in adult rat liver resistant to the hepatocarcinogen aflatoxin B1. J. Biol. Chem. 269: 20707 - 20717.

Hayes, J.D. and Pulford, D.J. (1995). The glutathione S-transferas supergene Family : regulation of GST and the contribution of the isoenzymes to cancer chemoprotection and drug resistance. Crit. Rev. Biochem. Mol. Biol. 30: 445 600.

Hodgson, A.V., White, T.B., White, J.W. and Strobel, H.W. (1993). Expression analysis of the mixed function oxidase system in rat brain by the polymerase chain reaction. Mol. Cell. Biochem. 121: 171- 174.

Hohenboken, W.D. and Blodgett, D.J. (1997). Toxicosis response in selected mice. Growth and physiological responses to toxicosis in lines of mice selected for resistance or susceptibility to endophyte-infected Tall Fescue in the diet. J. Anim. Sci. 75: $2165-2173$.

Hohenboken, W.D., Robertson, J.L., Blodgett, D.J., Morris, C.A., Towers, N.R. (2000). Sporidesmin-induced mortality and histological lesions in mouse lines divergently selected for response to toxins in endophyte-infected fescue. J. Anim. Sci. 78: $2157-2163$.

Hong, J.Y. and Yang, C.S. (1997). Genetic polymorphism of cytochrome P-450 as biomarker of susceptibility to environmental toxicity. Enivoron. Health Perspec. 105: $759-762$.

Hostetler, K.A., Wrighton, S.A., Kremers, P. and Guzelian, P.S. (1987). Immunochemical evidence for multiple steroid-inducible hepatic cytochromes P-450 in rat. Biochem. J. 245: $27-33$. 
Hove, E.L. and Wright, D.E. (1969). Casein phosphopeptones and phosphoserine protect against the mycotoxin, sporidesmin. Life Sci. 8: 545 - 550.

Hsieh, C-H., Tsai, S-P., Yeh, H-I., Sheu, T-C. and Tam, M.F. (1997). Mass spectrometric analysis of rat ovary and testes cytosolic glutathione S-transferase (GST): Identification of noval class Alpha GST, rGSTA6 in rat testes. Biochem. J. 323: $503-510$.

Huang, M.T., West, S.B. and Lu, A.Y.H. (1976). Separation, purification and properties of multiple forms of cytochrome P-450 from the liver michrosome of phenobarbital treated mice. J. Biol. Chem. 251: $4659-4665$.

Huskey, S-E.W., Huskey, W.P., and Lu, A.Y.H. (1991). Contribution of thiolate "desolvation" to catalysis by glutathione S-transferase isoenzymes 1-1 and 2-2: evidence from kinetic solvent isotope effects. J. Am. Chem. Soc. 113: 2283 2290.

Hussey, A.J. and Hayes, J.D. (1992). Characterization of a human class Theta glutathione S-transferase with activity towards 1-menaphthyl sulphate. Biochem. J. 286: $929-935$.

Hussey, A.J. and Hayes, J.D. (1993). Human Mu - class glutathione S-transferase present in liver, skeletal muscle and testicular tissue. Biochem. Biophys. Acta 1203: $131-141$.

Hussey, A.J., Kerr, L.A., Cronshaw, A.D., Harrison, D.J. and Hayes, J.D. (1991) Variation in the expression of Mu-class glutathione S-transferase isoenzymes from human skeletal muscle. Evidence for the existence of heterodimers. Biochern. J. 273: $323-332$.

Hussey, A.J., Stockman, P.K., Beckett, J.G. and Hayes, J.D. (1986). Variations in the glutathione S-transferase subunits expressed in human livers. Biochem. Biophys. Acta 874: $1-12$.

Igarashi, T., Irokawa, N., Ono, S., Ohmori, S., Ueno, K. and Kitagawa, H. (1987). Difference in the effects of phenobarbital and 3-methylcholanthrene on subunit composition of hepatic glutathione S-transferase in male and female rats. Xenobiotica 17: $127-137$.

Inoue, M. (1985). Interorgan metabolism and membrane transport of glutathione and related compounds. In : Renal Biochem. (Kinne, R.K.H. ed.), pp. 225 - 269, Elsevier, Amsterdam.

Ishigaki, S., Abramowitz, M. and Listowsky I. (1989). Glutathione S-transferases are major cytosolic thyroid hormone binding proteins. Arch. Biochem. Biophys. 273: $265-272$.

Jagt, D.L.V., Wilson, S.P. and Heidrich, J.E. (1981). Purification and bilirubin binding properties of glutathione S-transferase from human placenta. FEBS Lett. 136: $319-321$. 
Jaiswal, A.K., Gonzalez, F.J. and Nebert, D.W. (1985). Human dioxin-inducible cytochrome P1-450 complementary DNA and amino acid sequence. Science 228: $80-83$.

Jaiswal, A.K., Nebert, D.W., McBride, O.W. and Gonzalez, F.J. (1987). Human $P(3)$ 450: cDNA and complete protein sequence, repetitive Alu sequences in the 3 nontranslated region, and localization of gene to chromosome 15. J. Exp. Pathol. 3: $1-17$.

Jakoby, W.B. (1978). The glutathione S-transferases: a group of multifunctional detoxication proteins. Adv. Enzymol. 46: $383-414$.

Jakoby, W.B. (1980) Ed. Enzymatic Basis of Detoxification, Vol. I, Academic Press, San Diego.

Jakoby, W.B. (1980) Ed. Enzymatic Basis of Detoxification, Vol. II, Academic Press, San Diego.

Jemth, P. and Mannervik, B. (1997). Kinetic characterisation of recombinant human gutathione transferase T1-1, a polymorphic detoxication enzyme. Arch. Biochem. Biophys. 348: $247-254$.

Jemth, P., Stenberg, G., Chaga, G. and Mannervik, B. (1996). Heterologous expression, purification and characterisation of rat class Theta glutathione transferase T2-2. Biochem. J. 316: $131-136$.

Ji, X.H., Zhang, P., Armstrong, R.N. and Gilliland, G.L. (1992). The three dimentional structure of the glutathione transferase from the $\mathrm{Mu}$ gene class. Structural analysis of the binary complex of isoenzyme 3-3 and glutathione at $2.2 \mathrm{~A}$ resolution. Biochemistry 31: $10169-10184$.

Johnson, E.F. and Shiverick, K.T. (1982). Differences in the regiospecific metabolism of testosterone as catalysed by varient forms of rabbit microsomal cytochrome P-450 3b. Biochem. Biophs. Res. Commun. 109: $786-791$.

Jordan, T.W. (1986). Use of indirect immunofluorescence to show changes in liver actin microfilament staining inbred mice strains exposed to the mycotoxin sporidesmin. Liver 6: $78-84$.

Jordan, T.W. and Pedersen, J.S. (1986). Sporidesmin and gliotoxin induce cell detachment and perturb microfilament structure in cultured liver cells. J. Cell Sci. 85: $33-46$.

Kaddouri, M., Brasset, N., Alvinerie, M., Eeckhoutte, C., Bonfils, C. and Derancourt, J. (1992). Ontogenic development of liver progesterone metabolism in female sheep. Contribution of cytochrome P-450 and P-450 subfamilies. J. Steroid Biochem. Mol. Biol. 42: 499 - 508. 
Kaddouri, M., Larrieu, G. Eeckhoutte, C. and Galtier, P. (1990). The development of drug-metabolising enzymes in female sheep liver. J. Vet. Pharmacol. Ther. 13: $340-349$.

Kano, T., Sakai, M. and Muramatsu, M. (1987). Structure and expression of a human class $\pi$ glutathione S-transferase messenger RNA. Cancer Res. 47: 5626 5630.

Keeran, W.S. and Lee, R.F. (1987). The purification and characterisation of glutathione S-transferase from the hepato-pancreas of the blue crab, Callinectes sapidus. Arch. Biochem. Biophys. 255: $233-243$.

Kellerman, T.S. and Coetzer, J.A.W. (1984). Hepatogenous photosensitising diseases in South Africa. Vet. Res. Inst. pp. 193, Onderstepoort, Technical Communication.

Ketley, J.N., Habig, W.H. and Jakoby, W.B. (1975). Binding of non substrate ligands to the glutathione S-transferases. J. Biol. Chem. 250: 8670-8673.

Ketterer, B., Meyer, D.J. and Clark, A.G. (1988). Soluble glutathione S-transferase isoenzymes. In: Glutathione Conjugations (Ketterer, B. and Sies, H., eds). Academic Press, London.

Ketterer, B., Ross-Mansell, P. and Whitehead, J.K. (1967). The isolation of carciogen-binding protein from livers of rats given 4-dimethylaminoazobenzene. Biochem. J. 103: 316 - 324 .

Kirsch, R., Fleischner, G., Kamisaka, K. and Arias, I.M., (1975). Structural and functional studies of ligandin, a major renal organic anion-binding protein. J. Clin. Invest. 55: $1009-1019$.

Kitahara, A., Satoh, K., Nishimura, K., Ishikawa, T., Ruike, K., Sato, K., Tsuda, H. and Ito, N. (1984). Changes in molecular forms of rat hepatic glutathione Stransferase during chemical hepatocarcinogenesis. Cancer Res. 44: $2698-2703$.

Kitteringham, N.R., Powell, H., Jenkins, R.E., Hamlett, J. et.al. (2003). Protein expression profiling of glutathione S-transferase pi null mice as a strategy to identify potential markers of resistance to paracetamol-induced toxicity in the liver. Proteomics. 3: $191-207$.

Knolle, A. P., Tieno, G., Ulrich, T., Anja, U., Edgar, S., Silke, H., Ansgar, W. L. and Guido G. (1999). Endotoxin down-regulates T cell activation by antigen-presenting liver sinusoidal endothelial cells. The journal of Immonology. 162: 1401-1417.

Krynetskii, E.Y. (1996). Polymorphism of drug-metabolising enzymes: gene structure and enzyme activity (a review). Molekulyarnaya Biologiya. 30: $33-42$.

Kunze, T. (1997). Purification and characterisation of class Alpha and $\mathrm{Mu}$ glutathione S-transferase from porcine liver. Comp. Biochem. Physiol. 116B: 397 406. 
Laemmli, U.K. (1970). Cleavage of structural proteins during the assembly of the head of bacteriophage T4. Nature 227: $680-685$.

Lenartova, V., Holovska, K., Martinez-Lara, E., Lopez-Barea., Barcena, J.A. and Rosival, I. (1996). Changes in GST isoenzyme pattern of some organs of sheep exposed to different levels of pollution. Comp. Biochem. Physiol. 114C: 153 - 158.

Li, Y.C., Wang, D.P. and Chiang, J.Y.L. (1990). Regulation of cholesterol $7 \alpha-$ hydroxylase in the liver. Cloning, sequencing, and regulation of cholesterol $7 \alpha-$ hydroxylase mRNA. J. Biol. Chem. 265: $12012-12019$.

Lim, C.W. and Jordan, T.W. (1981). Subcellular distribution of hepatic bile acidconjugating enzymes. Biochem. J. 197: $611-618$.

Listowsky, I. (1993). High capacity binding by glutathione S-transferases and glucocorticoid resistance. In: Structure and Function of Glutathione Transferases, (Tew, K.D., Pickett, C.B., Mantle, T.J., Mannervik, B. and Hayes, J.D., eds.), pp. 199 - 209, CRC Press, Boca Raton, FL.

Litwack, J., Ketterer, B. and Arias, I.M. (1971). Ligandin: a hepatic protein which binds steroid, bilirubin, carcinogens and a number of exogenous organic anions. Nature 234: $466-467$.

Liu, S., Zhang, P., Ji, X., Johnson, W.W., Gilliland, G.L. and Armstrong, R.N. (1992). Contribution of tyrosine 6 to the catalytic mechanism of isoenzyme $3-3$ of glutathione S-transferase. J. Biol. Chem. 267: 4296 - 4299.

Louerat-Oriou, B., Perret, A. and Pompon, D. (1999). Differential redox and electron-transfer properties of purified yeast, plant and human NADPH-cytochrome P-450 reductases highly modulate cytochrome P-450 activities. Eur. J. Biochem. 258: 1040 - 1049.

Lu, A.Y.H. and Coon, M. J. (1968). Role of hemoprotein P-450 in fatty acid $\gamma$ hydroxylation in a soluble enzyme system from liver microsomes. J. Biol. Chem. 243: $1331-1332$.

Lu, A.Y.H., Junk, K.W. and Coon, M.J. (1969). Resolution of the cytochrome P-450 containing $\gamma$-hydroxylation system of liver microsomes into three components. J. Biol. Chem. 244: $3714-3721$.

Lu, A.Y.H., Strobel, H.W. and Coon, M.J. (1970). Properties of a solubilized form of the cytochrome P-450 containing mixed function oxidase of liver microsomes. Mol. Pharmacol. 6: $213-220$.

Lu, Y.F., Morris, C.A., Towers, N.R. and Jordan, T.W. (1994). Hepatic protein variation among Romneys selected for their resistance or susceptibility to sporidesmin induced liver damage. A quantitative two dimensional polyacrylamide gel electrophoresis study. Proc. N. Z. Soc. Anim. Prod. 54: $19-22$. 
McLellan, L.I., Harrison, D.J. and Hayes, J.D. (1992). Modulation of glutathione Stransferase and glutathione peroxidase by the anticarcinogen butylated hydroxyanisole in murine extrahepatic organs. Carcenogenesis 13: $2255-2261$.

McLellan, L.I. and Hayes, J.D. (1987). Sex-specific constitutive expression of the pre-neoplastic marker glutathione transferase, $Y_{1}, Y_{1}$, in mouse liver. Biochem. J. 245: $399-406$.

MacKinnon, M.M. and Te Punga, W.A. (1960). Pathological effects of feeding Pithomyces chartarum to guinea-pigs. N. Z. J. Agric. Res. 4: $141-146$.

Mainwaring, G.W., Williams, S.M., Foster, J.R., Tugwood, J. and Green, T. (1996). The distribution of Theta class glutathione S-transferases in the liver and lung of mouse, rat and human. Biochem. J. 318: $297-303$.

Makary, M., Kim, H.L., Safe, S., Womack, J. and Ivie, G.W. (1988). Constitutive and Aroclor 1254-induced hepatic glutathione S-transferase, peroxidase and reductase activities in genetically inbred mice. Comp. Biochem. Physiol. 91C: 425 $-429$.

Mannervik, B. (1985). The isoenzymes of glutathione transferase. Adv. Enzymol. Relat. Areas. Mol. Bio. 57: $357-417$.

Mannervik, B., Alin, P., Guthenberg, C., Jensson, H., Tahir, M.K., Warholm, M. and Jornvall, H. (1985). Identification of three classes of cytosolic glutathione transferase common to several mammalian species: Correlation between structural data and enzymatic properties. Proc. Natl. Acad. Sci. USA. 82: 7202 - 7206.

Mannervik, B. and Danielson, U.H. (1988). Glutathione transferases. Structure and catalytic activity. CRC Crit. Rev. Biochem. 23: $283-336$.

Mannervik, B., Awasthi, Y.C., Board, P.G., Hayes, J.D., Di llio, C. et al., (1992). Nomenclature for human glutathione transferases. Biochem. J. 282: 305 - 306.

Matsuzaki, Y., Bouscarel, B., Ikegami, T., Honda, A., Doy, M., Ceryak, S., Fukushima, S., Yoshida, S., Shoda, J. and Tanaka, N. (2002). Selective inhibition of cytochrome 27A and of chenodeoxycholic acid synthesis in cholestatic hamster liver. Biochem. Biophys. Acta. 1588: $139-148$.

Meyer, D.J., Coles, B., Pemble, S.E., Gilmore, K.S., Fraser, G.M. and Ketterer, B. (1991). Theta, a new class of glutathione transferase purified from rat and man. Biochem. J. Mol. Biol. 274: $409-414$.

Meyer, D.J. and Thomas, M. (1995). Characterization of rat spleen prostaglandin -H D-isomerase as a Sigma class of glutathione transferase. Biochem. J. 311: 739 -742 .

Middleton, M.C. (1974a). Effects of mycotoxin sporidesmin on swelling and respiration of liver mitochondria. Biochem. Pharmacol. 23: $801-810$. 
Middleton, M.C. (1974b). Involvement of the disulphide group of sporidesmin in the action of the toxin on swelling and respiration of liver mitochondria. Biochem. Pharmacol. 23: $811-820$.

Miller, B.F., Armstrong, K.L., Wilson, L.A., Hohenboken, W.D. and Saacke, R.G. (1994). Variation among inbred and linecross mice in response to fescue toxicosis. J. Animal Sci. 72: 2896 - 2904.

Miller, C.M.D., Howell, M.J. and Boray, J.C. (1994). Glutathione S-transferases as markers of salicylanilide resistance in isolates of Fasciola hepatica. Internat. J. Parasitol. 24: $47-55$.

Miles, J.S., Spurr, N.K., Gough, A.C., Jowett, T., McLaren, A.W., Brook, J.D. and Wolf, C.R. (1988). A novel human cytochrome P-450 gene (P-450|IB): Chromosomal localization and evidence for alternative splicing. Nucleic Acids Res. 16: $5783-5795$.

Miles, J.S., McLaren, A.W., Forrester, L.M., Glancey, M.J., Lang, M.A. and Wolf, C.R. (1990). Identification of the human liver cytochrome P-450 responsible for coumarin 7 - hydroxylase activity. Biochem. J. 267: $365-371$.

Misra, P., Srivastava, S.K., Singhal, S.S., Awasthi, S., Awasthi, Y.C. and Boor, P.J. (1995). Glutathione S-transferase 8-8 is localised in smooth muscle cells of rat oarta and induced in an experimental model of atherosclerosis. Toxicol. Appl. Pharmacol. 133: $27-33$.

Mitchell, J.R., Jollow, D.J., Potter, W.Z., Davis, D.C., Gillette, J.R. and Brodie, B.B. (1973). Acetaminophen-induced hepatic necrosis. 1. Role of drug metabolism. J. Pharmacol.. Exp. Ther. 187: $185-194$.

Miyaura, S. and Isono, H. (1986). Purification and characterization of multiple forms of rabbit hepatic glutathione S-transferase. Chem. Pharm. Bull. 34: 194 205.

Monroe, D.H. and Eaton, D.L. (1987). Comparative effects of butylated hydroxyanisole on hepatic in vivo DNA binding and in vitro biotransformation of aflatoxin B1 in the rat and mouse. Toxicol. Appl. Pharmacol. 90: 401 - 409.

Morgenstern, R., Guthenberg, C. and De Pierre, J.W. (1982). Microsomal glutathione S-transferase : Purification, initial characterization and demonstration that it is not identical to the cytosolic glutathione S-transferase A, B and C. Eur. J. Biochem. 128: $243-248$.

Moore, C.C.D., Brentano, S.T. and Miller, W.L. (1990). Human P-450scc gene transcription is induced by cyclic AMP and repressed by 12-O-tetradecanolphorbol 13 - acetate and AZ23187 by independent cis - elements. Mol. Cell. Biol. 10: 6013 -6023 . 
Morris, C.A., Towers, N.R., Campbell, A.G., Meyer, H.H., Wesselink, C. and Wheeler, M. (1989). Responses achieved in Romney flocks selected for or against susceptibility to facial eczema, 1975-1987. N. Z. J. Agric. Res. 32: $379-388$.

Morris, C.A., Towers, N.R., Wesselink, C. and Amyes, N.C. (1994). Susceptibility of Finish Landrace, Romney and Finn $x$ Romney lambs to a sporidesmin challenge. N. Z. J. Agric. Res. 37: $547-552$.

Morris, C.A., Towers, N.R., Wheeler, M. and Wesselink, C. (1995). Selection for or against facial eczema susceptibility in Romney sheep, as monitored by serum concentrations of a liver enzyme. N. Z. J. Agric. Res. 38: 211 - 219.

Mornet, E., Dupont, J., Vitek, A. and White, P.C. (1989). Characterisation of two genes encoding human steroid $11 \beta$ - hydroxylase $\left(P_{-450} 11 \beta\right)$. J. Biol. Chem. 264: 20961 - 20967.

Morrow, C.S., Smitherman, P.K. and Townsend, A.J. Role of multidrug-resistance protein 2 in glutathione S-transferase P1-1-mediated resistance to 4-nitroquinoline 1oxide toxicities in HepG2 cells. Mol. Carcinog. 29: $170-178$.

Mortimer, P.H. (1962). The experimental intoxication of sheep with sporidesmin, a metabolic product of Pithomyces chartarum, 1. Clinical observations and findings at post-mortem examinations. Res. Vet. Sci. 3: $147-160$.

Mortimer, P.H. (1962). The experimental intoxication of sheep with sporidesmin, a metabolic product of Pithomyces chartarum. III. Some changes in cellular components and coagulation properties of the blood. Res. Vet. Sci. 3: $269-286$.

Mortimer, P.H. (1963). The experimental intoxication of sheep with sporidesmin, a metabolic product of Pithomyces chartarum. IV Histological and histochemical examination of orally dosed sheep. Res. Vet. Sci. 4: $166-185$.

Mortimer, P.H. (1967). Facial eczema in cattle. Annual Report, Anim. Res. Div. N. Z. Dept. Agric. pp. 54 - 55.

Mortimer, P.H. (1969). Facial eczema: It's effects within the animal. N. Z. J. Agric. 119: $22-25$.

Mortimer, P.H. (1970). The toxic effects of sporidesmin on mice. N. Z. J. Agric. Res. 13: 437 - 447.

Mortimer, P.H. (1971). Sporidesmin poisoning in Jersey cows. Annual Report, Anim. Res. Div. N. Z. Dept. Agric. pp. 22.

Mortimer, P.H., Manns, E. and Coe, B.D. (1978). Manipulation of liver metabolism in relation to ruminant toxicology. Proc. N. Z. Soc. Anim. Prod. 38: 59 - 64.

Mortimer, P.H. and Ronaldson, J.W. (1983). Fungal toxin induced photosensitization. In: Natural Toxins. (Keeler, R.F. and Tu, A.T., eds.), Vol. I, pp. 361 - 419, Marcel Dekker Inc., N.Y. 
Mortimer, P.H. and Smith, B.L. (1981). Facial eczema in deer. Proc. Ruakura Farmers' Conf., pp. $109-112$.

Mortimer, P.H. and Taylor, A. (1962). The experimental intoxication of sheep with sporidesmin, a metabolic product of Pithomyces chartarum. 1. Clinical examination and findings at post-mortem examination. Res. Vet. Sci. 3: $147-160$.

Mortimer, P.H., White, E.P. and di Menna, M.E. (1977). Toxicity of sporidesmin in laboratory animals. In: Mycotoxic Fungi, Mytoxin and Mycotoxicosis (Wyllie, T.D. and Morehouse, L.G., eds.), Vol. 2: pp. 478 - 484, Marcel Dekker, N.Y.

Motoyama, N. and Dauterman, W.C. (1979). Comparative studies on the molecular weight of glutathione S-transferase from mammalian liver and an insect. Comp. Biochem. Physiol. 63B: $451-454$.

Munday, R. (1982). Studies on the mechanism of toxicity of the mycotoxin, sporidesmin 1. Generation of superoxide radical by sporidesmin. Chem. Biol. Interact. 41: 361 - 374 .

Munday, R. (1984). Studies on the mechanism of toxicity of the mycotoxin, sporidesmin 2. Evidence for intracellular generation of superoxide radical from sporidesmin. J. Appl. Toxicol. 4: $176-181$.

Munday, R. (1987). Studies on the mechanism of toxicity of the mycotoxin sporidesmin, V. Generation of hydroxy radical by sporidesmin. J. Appl. Toxicol. 7: $17-22$.

Munday, R. (1989). Toxicity of thiols and disulphides: Involvement of free radical species. Free Rad. Biol. Med. 7: $659-673$.

Munday, R., Pearson, A. and Ferguson, L.R. (1993). Mouse micronuclease assays of sporidesmin, the toxin associated with facial eczema in ruminants. Mutat. Res. 302: $71-74$.

Murataliev, M.B., Arino, A., Guzov, V.M. and Feyereisen, R. (1999). Kinetic mechanism of cytochrome P-450 reductase from the house fly (Musca domestica). Insect Biochem. Mol. Biol. 29: 233 - 242.

Murray, M. (1991). Microsomal cytochrome P-450 dependent steriod metabolism in male sheep liver. Quantitative importance of $6 \beta$-hydroxylation and evidence for the involvement of a P-450 from the IIIA subfamily in the pathway. J. Steroid Biochem. Mol. Biol. 38: 611 - 619.

Nebert, D.W., Adesnik, M., Coon, M.J., Estabrook, R,W., Gonzalez, F.J., Guengerich, F.P., Gunsalus, I.C. and Johnson, E.F., Kemper, B., Levin, W., Philips, I.R., Sato, R. and Waterman, M.R. (1987). The P-450 gene superfamily: Recomended nomenclature. DNA 6: 1-11.

Nebert, D.W., Adesnik, M., Coon, M.J., Estabrook, R,W., Gonzalez, F.J., Guengerich, F.P., Gunsalus, I.C. and Johnson, E.F., Kemper, B., Levin, W., Philips, I.R., Sato, R. 
and Waterman, M.R. (1989). The P-450 superfamily: up on listing of all genes and recomended nomenclature of the chromosome loci. DNA 8: $1-13$.

Nebert, D.W. and Gonzalez, F.J. (1987). P-450 Genes : Structure, Evolution, and Regulation. Ann. Rev. Biochem. 56: 945 - 993.

Nebert, D.W., Nelson, D.R., Coon, M.J., Estabrook, R,W., Feyereisen, R., FujiiKuriyama, Y., Gonzalez, F.J., Guengerich, F.P., Gunsalus, I.C. and Johnson, E.F. (1991). The P-450 superfamily: update on new sequences, gene mapping, and recommended nomenclature. DNA Cell Biol. 10: 1 - 14.

Nelson, D.R., Kamataki, T., Waxman, D.J., Guengerich, F.P., Gunzales, I.C., Gotoh, O., Okuda, K. and Nebert, D.W. (1993). The P-450 superfamily : Update on new sequences, gene mapping, accession numbers, early trivial names and nomenclature. DNA Cell Biol. 12: $1-51$.

Nelson, D.R., Koymans, L., Kamataki, T., Stegeman, J.J., Feyereisen, R., Waxman, Waterman, M.R., Gotoh, O., Coon, M.J., Estabrook, R.W., Gunsalus, I.C. and Nebert, D.W. (1996). P-450 superfamily : up date on new sequences, gene mapping, accession numbers and nomenclature. Pharmacogenetics 6: 1-42.

Nhamburo, P.T., Gonzalez, F.J., McBridge, O.W., Gelboin, H.V. and Kimura, S. (1989). Identification of a new P-450 expressed in human lung: Complete cDNA sequence, cDNA - directed expression, and chromosome mapping. Biochemistry 28: 8060 - 8066 .

Nhamburo, P.T., Kimura, S., McBridge, O.W., Kozak, C.A., Gelboin, H.V. and Gonzalez, F.J. (1990). The human cyp2F subfamily: Identification of cDNA coding for a new cytochrome P-450 expressed in lung, cDNA - directed expression, and chromosome mapping. Biochemistry 29: $5491-5499$.

O'Farrell, P.H. (1975). High resolution 2-dimensional electrophoresis of proteins. J. Biol. Chem. 250: 4007 - 4021.

Okita, R.T., Prough, R.A. and Masters, B.S.S. (1980). Effect of inducing agents and cytochrome P-450 inhibitors on laurate hydroxylase activities in rat liver microsomes. In Microsomes, Drug Oxidations, and Chemical Carcinogenisis. (Coon, M.J., Conney, A.H., Estabrook, R.W., Gelboin, H.V., Gillette, J.R., and O'Brian, P.J., eds.), Vol II, pp. 741-44, Academic Press, New York.

Omura, T. and Sato, R. (1964). The carbon monoxide - binding pigment of liver microsomes. J. Biol. Chem. 239: $2379-2388$.

Pelkonen, O. and Raunio, H. (1997). Metabolic activation of toxins: tissue specific expression and metabolism in target organs. Environ. Health Perspect. 105: 767 774.

Pemble, S.E., Wardle, A.F. and Taylor, J.B. (1996). Glutathione transferase class Kappa. Characterisaion by the cloning of rat mitochondrial GST and identification of human homologue. Biochem. J. 319: $749-754$. 
Peters, J.A. (1963). Mechanism of early sporidesmin intoxication in sheep. Nature. 200: 286.

Peters, J.A. (1966). Effects of sporidesmin on lipid metabolism in rabbits. Nature. 210: $601-603$.

Petersen, G.L. (1977). A simplification of the protein assay method of Lowry et al. Which is more generally applicable. Analyt. Biochem. 83: $346-356$.

Phillips, M.F. and Mantle, T.J. (1993). Inactivation of mouse liver glutathione Stransferase YFYF (pi class) by ethacrynic acid and 5,5' - dithiobis-(2-nitrobenzoic acid). Biochem. J. 294: $57-62$.

Phua, S.H., Dodds, K.G., Morris, C.A., McEwan, J.C., Garmonsway, H.G., Towers, N.R., Crawford, A.M. (1999). Catalase gene is associated with facial eczema disease resistant in sheep. Anim. Genet. 30: $286-295$.

Pickett, C.B., Telakowski-Hopkins, C.A., Ding, C.J.F. and Ding, VDH. (1987). Sequence analysis and regulation of rat liver glutathione S-transferase mRNA. Xenobiotica. 17: $317-323$.

Pickett, C.B. and Lu, A.Y.H. (1988). The structure genetics and regulation of soluble glutathione S-transferase. In Glutathione Conjugation: Mechanism and Biological Significance (Sies, H. and Ketterer, B., eds.), pp 138 - 156. Academic Press London.

Pickett, C.B. and Lu, A.Y.H. (1989). Glutathione S-transferase: gene structure, regulation, and biological function. Ann. Rev. Biochem. 58: $743-764$.

Pillarisetty, V.G., Miller, G., Shah, A.B., DeMatteo, R.P. GM-CSF expands dendritic cells and their progenitors in mouse liver. Hepatology. 37: 641 - 652.

Pineau, T., Galtier, P., Bonfils, C., Derancourt, J. and Maurel, P. (1990). Purification of a sheep liver cytochrome P-450 from the P-450 IIIA gene subfamily, its contribution to the $\mathrm{N}$-dealkylation of veterinary drug. Biochem. Pharmacol. 39: 901 -909 .

Ploemen, J.H.T.M., Van Shanke, A., Van Ommen, B. and Van Bladeren, P.J. (1994). Reversible conjugation of ethacrynic acid with glutathione and human glutathione S-transferase P1-1. Cancer Res. 54: 915 - 919.

Poli, G., Albano, E. and Dianzani, M.U. (1987). The role of lipid peroxidation in liver damage. Chem. Phys. Lipids 45: $117-142$.

Porter, T.D. and Coon, M.J. (1991). Cytochrome P-450 multiplicity of isoforms, substratas and catalytic and regulatory mechanisms. J. Biol. Chem. 266: 13469 13472. 
Primiano, T. and Novak, R.F. (1993). Purification and characterization of class Mu glutathione S-transferase isozymes from rabbit hepatic tissue. Arch. Biochem. Biophys. 301: $404-410$.

Prohaska, J.R. (1980). The glutathione peroxidase activity of glutathione Stransferases. Biochem. Biophys. Acta 611: 87 - 95.

Racine, T.T. and Langley, C.H. (1980). Genetic heterozygosity in a natural population of Mus musculus assessed using 2-dimensional electrophoresis. Nature 283: 855 - 857.

Raney, K.D., Meyer, D.J., Ketterer, B., Harris, T.M. and Guengerich, F.P. (1992). Glutathione conjugation of aflatoxin B1 exo- and endo-epoxides by rat and human glutathione S-transferase. Chem. Res. Toxicol. 5: $470-478$.

Reddy, C. C., Burgess, J.R., Gong, Z-Z., Massaro, E. J. and Tu, C-P. D. (1983). Purification and characterization of individual glutathione $S$-transferases from sheep liver. Arch. Biochem. Biophs. 224: 87-101.

Reinemer, P., Dirr, H.W., Ladenstein, R., Schaffer, J., Gallay,O. and Huber, R. (1991). Three dimentional structure of class $\pi$ glutathione S-transferase in complex with glutathione sulfonate at 2.3 A resolution. EMBO. J. 10: 1997 - 2005.

Rimington, C., Slater, T.F., Spector, W.G., Strauli, U.D. and Willoughby, D.A. (1962). Sporidesmin poisoning in the rat. Nature 194: $1152-1153$.

Robertson, I.G.C., Jensson, H., Mannervik, B. and Jernstrom, B. (1986). Glutathione transferases in rat lung: the presence of transferase 7-7, highly efficient

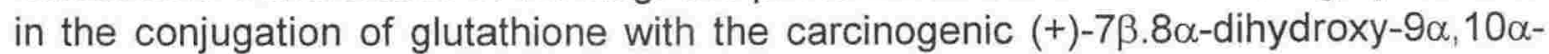
oxy-7,8,9,10-tetrahydrobenzo[ $\alpha$ ] pyrene. Carcinogenesis 7: $295-299$.

Roman-Rao, S.V. and Indera, K. (1997). Glutathione metabolism in uremic rats. Drug and Chem. Toxcol. 20: $229-237$.

Ross, D. (1989). Mechanistic toxicology: a radical perspective. J. Pharm. Pharmacol. 41: $505-511$.

Ross, V.L. and Board, P.G. (1993). Molecular cloning and heterologous expression of an alternatively spliced human Mu-class glutathione S-transferase transcript. Biochem. J. 294: $373-380$.

Ryan, R.E. and Levin, W. (1990). Purification and characterization of hepatic microsomal cytochrome P-450. Pharmacol. Ther. 45: 153-239.

Ryan, D.E., Lu, A.Y.H., Kawalek, J., West, S.B. and Levin, W. (1975). Highly purified cytochrome $\mathrm{p}-442$ and P-450 from rat liver microsomes. Biochem. Biophys. Res. Comm. 64: 1134. 
Ryan, D.E., Lu, A.Y.H., West, S.B. and Levin, W. (1975). Multiple forms of cytochrome $\mathrm{P}-450$ in phenobarbital and 3-methylchloranthrene treated rats : separation of spectral properties. J. Biol. Chem. 250: 2157 - 2163.

Sancar, A. and Sancar, G. B. (1988). DNA repair enzymes. Ann. Rev. Biochem. 57: $29-67$.

Satoh, K., Kitahara, A., Soma, V., Inaba,Y., Hatayama, I. and Sato, K. (1985). Purification, induction, and distrbution of placental glutathione transferase : a new marker enzyme for preneoplastic cells in rat chemical hepatocarcinogenesis. Proc. Natl. Acad. Sci. USA. 82: 3964 - 3968.

Satoh, M., Kondo, Y., Mita, M., Nakagawa, I., Naganura, A. and Imura, N. (1993). Prevention of carcinogenicity of anti-cancer drugs by metallothionein induction. Cancer Res. 53: 4767 - 4768.

Seidegard, J., Pero, R.W. (1985). The hereditary transmission of high glutathione S-transferase activity towards trans-stilbene oxide in human mononuclear leukocytes. Hum. Genet. 69: 66 - 72.

Seidegard, J., Pero, R.W., Miller, D.G. and Beattie, E.J. (1986). A glutathione Stransferase in human leukocytes as a marker for the susceptibility to lung cancer. Carcinogenesis 7: $751-753$.

Seidegard, J., Vorachek, W.R., Pero, R.W. and Pearson, W.R. (1988). Hereditary differences in the expression of the human glutathione S-transferase active on transstilbene oxide are due to a gene deletion. Proc. Natl. Acad. Sci. U.S.A. 85: 7293 7297.

Shephard, E.A., Philips, I.R., Santisteban, I., Palmer, C.N.A. and Povey, S. (1989). Cloning, expression, and chromosomal localization of a member of the human cytochrome P-450 IIC gene subfamily. Ann. Hum. Genet. 53: 23 - 31.

Sherratt, P.J., Pulford, D.J., Harrison, D.J., Green, T. and Hayes, J.D.

(1997). Evidence that human class Theta glutathione S-transferase T1-1 can catalyse the activation of dichloromethane, a liver and lung carcinogen in the mouse. Comparison of the tissue distribution of GST T1-1 with that of classes Alpha, Mu, and Pi GST in humans. Biochem. J. 326: 837 - 846.

Shet, Ms. Fisher, C.W., Holman, P.L., Estabrook, R.W. (1996). The Omega hydroxylation of lauric acid: Oxidation of 12 - hydroxlauric acid to dodecanedioic acid by a purified recombinant fusion protein containg P-450 4A1 and NADPH P-450 reductase. Arch. Biochem. Biophys. 330: $199-208$.

Shetty, S.N., Himes, J.A. and Edds, G.T. (1972). Enzyme induction in sheep. Effects of phenobarbital on in vivo and in vitro drug metabolism. Amer. J. Vet. Res. 33: $935-942$.

Shimada, T., Yamazaki, H., Mimura, M., Inni, Y. and Guengerich, F.P. (1994). Interindividual variations in human liver cytochrome P-450 enzymes involved in the 
oxidation of the drugs, carcinogens and toxic chemicals: studies with liver microsomes of 30 Japanese and 30 Caucasians. J. Pharmacol. Exper. Ther. 270: $414-423$.

Shoaf, S.E., Schwark, N.S., Guard, C.L. and Babsin, J.G. (1987). The development of hepatic drug metabolising enzyme activities in the neonatal calf and its effects on drug disposition. Drug Metab. Dispos. 15: 676 - 681 .

Short, C.R. and Stith, R.D. (1973). Perinatal development of hepatic mixed function oxidase activity in swine. Biochem. Pharmacol. 22: $1309-1319$.

Short, C.R., Flory, W., Hsieh, L.C., Aranas, T., Ou, S.P. and Weissinger, J. (1988). Comparison of hepatic drug metabolizing enzyme activities in several agricultural species. Comp. Biochem. Physiol. 91C: $419-24$.

Siekevitz, P. (1973). The differentiation of rat liver endoplasmic reticulum membranes: apo-cytochrome P-450 as a membrane protein. J. Supramolec. Struct. 1: $471-489$.

Singh, S.V., Kurosky, A. and Awasthi, Y.C. (1987). Human liver glutathione transferase. Chemical characterization and secondary structure comparison with other mammalian glutathione S-transferases. Biochem. J. 243: 61-67.

Singh, S.V., Saunders, M.O., Moller, P.C., Haber, B. and Awasthi Y.C.

(1987). Comparative studies on the isoenzymes of glutathione S-transferases of rat brain and other tissues. Comp. Biochem. Physiol. 86B: $73-81$.

Singhal, S.S., Saxena, M., Ahmad, H. and Awasthi,Y.C. (1992). Glutathione Stransferases of mouse livers: sex-related differences in the expression of various isoenzymes. Biochem. Biophys. Acta 116: $137-146$.

Singhal, S.S., Zimniak, P., Sharma, R., Srivastava, S.K., Awasthi, S. and Awasthi, Y.C. (1994). A novel glutathione S-transferase isoenzyme similar to GST 8-8 of rat and mGST A4-4 of mouse is selectively expressed in human tissues. Biochem. Biophys Acta 1204: $279-286$.

Sinning, I., Kleywegt, G.J., Cowan, S.W., Reinemer, P., Dirr, H.W., Huber, R., Gilliland, G.L., Armstrong, R.N., Ji, X., Board, P.G., Olin, B., Mannervik, B. and Jones, T.A. (1993). Structure determination and refinement of human Alpha class glutathione S-transferase $\mathrm{A} 1-1$, and a comparison with the $\mathrm{Mu}$ and $\mathrm{Pi}$ class enzymes. J. Mol. Biol. 232: $192-212$.

Sissons, C.H. (1981). Protection against facial eczema and ryegrass staggers by controlling toxin metabolism. A study in the Biochemical, Pharmacology and Genetics of Resistance to Facial Eczema and Ryegrass Staggers. Report to National Research Advisory Council, pp. i - v.

Sissons, C.H., Clark, A.G. and Ronaldson, J.R. (1980). Sporidesmin reaction with cellular thiols. Abstract: N. Z. Inst. Of Chemistry Conference, pp. 1 - 2. 
Sissons, C.H. and Fairclough, R.J. (1978). Biochemical genetics of facial eczema and ryegrass staggers. In Agricultural Research in the New Zealand Ministry of Agriculture and Fisheries, 1977 - 1978. New Zealand Government Printer, Wellington.

Slater, T.F. (1981). Free radicals as reactive intermediates in tissue injury. Adv. Exp. Med. Biol. 136: 575 - 589.

Slater, T.F., Strauli, U.D. and Sawyer, B. (1964). Sporidesmin poisoning in rats. 1-Chemical changes. Res. Vet. Sci. 5: $450-472$.

Smith, B.L. and Embling, P.P. (1991). Facial eczema in goats: the toxicity of sporidesmin in goats and its pathology. N. Z. Vet. J. 39: $18-22$.

Smith, B.L. and Payne, E. (1991). Adrenal-associated changes in experimental sporidesmin poisoning of sheep. N. Z. Vet. J. 39: $46-49$.

Smith, G.S., Watkins, J.B. (1984). Biotransformations of xenobiotics in tissues of cattle and sheep. Can. J. Anim. Sci. 64: 278.

Smith, G.S., Watkins, J.B., Thomson, T.N., Rozman, K. and Klaassen, C.D. (1984). Oxidative and conjugative metabolism of xenobiotics by livers of cattle, sheep, swine and rats. J. Anim. Sci. 58: $386-395$.

Song, B.J., Gelboin, H.V., Park, S.S., Yang, C.S. and Gonzalez, F.J. (1986). Complementary DNA and protein sequences of ellianol-inducible rat and human cytochrome P-450. Transcriptional and post-transcriptional regulation of the rat enzyme. J. Biol. Chem. 261: $16689-16697$.

Srinivasan, U., Jordan, T.W., Jao, S.C. and Mieyal, J.J. (1997). Selective inactivation of thioltransferase (glutaredoxin). Abstract, FASEB. J. 11: 2612.

Stockman, P.K., Bekett, G.J. and Hayes, J.D. (1985). Identification of basic hybrid glutathione S-transferase from human liver. Glutathione S-transferase $\delta$ is composed of two distinct subunits $\left(B_{1}\right.$ and $\left.B_{2}\right)$. Biochem. J. 227: $457-465$.

Stockman, P.K., McLellan, L. and Hayes, J.D. (1987). Characterization of the basic glutathione S-transferase $B_{1}$ and $B_{2}$ subunits from human liver. Biochem. J. 244: $55-61$.

Stohs, S.J., Grafstrom, R.C., Burke, M.D., Moldeus, P.W. and Orrenius, S. (1976). The isolation of rat intestinal microsomes with stable cytochrome P-450 and their metabolism of benzo(a)pyrene. Arch. Biochem. Biophys. 177: $105-116$.

Strange, R.C., Davis, D.A. and Hume, R. (1985). The human glutathione Stransferases: developmental aspects of the GST1, GST2, and GST3 loci. Biochem. Genet. 23: $1011-1028$. 
Strobel, H.W., Lu, A.T.H., Heidema, J. and Coon, M.J. Phosphatidylcholine requirement in the enzymatic reduction of hemoprotein P-450 and in fatty acid, hydrocarbon and drug hydroxylation. J. Biol. Chem. 245: 4851 4854.

Suzuki, T., Johnston, P.N. and Board, P.G. (1993). Structure and organization of the human Alpha class glutathione S-transferase gene and related pseudogenes. Genomics 18: $680-686$.

Swick, R.A. (1984). Hepatic metabolism and bioactivation of myotoxins and plant toxins. J. Anim. Sci. 58: $1017-1028$.

Takahashi, Y., Campbell, E.A., Hirata, Y., Takayama, T. and Listowsky, I. (1993). $\mathrm{A}$ basic for differentiating among the multiple human $\mathrm{Mu}$-glutathione S-transferases and molecular cloning of brain GSTM5. J. Biol. Chem. 268: 8893 - 8898 .

Tanaka, K. and Wood, R.D. (1994). Xeroderma pigmentosum and nucleotide excision repair of DNA. Trends Biol. Sci. 19: 83 - 86 .

Thomas, P.E., Lu, A.Y.H., Ryan, D., West, S.B., Kawalek, J. and Levin, W. (1976). Multiple forms of rat liver cytochrome P-450: Immunochemical evidence with antibody against cytochrome p-448. J. Biol. Chem. 251: $1385-1391$.

Thompson, K.G., Jones, D.H., Sutherland, R.J., Camp, B.J. and Bowers, D.E. (1983). Sporidesmin toxicity in rabbits: biochemical and morphological changes. J. Comp. Path. 93: $319-29$.

Towbin, H., Staehelin, T. and Gordon, L. (1979). Electrophoretic transfer of proteins from polyacrylamide gels to nitrocellulose sheets. Procedure and some applications. Proc. Natl. Acad. Sci. USA. 76: 4350 - 4354.

Towers, N.R. (1970a). Tissue distribution and excretion of ${ }^{35}$ sulphur after adminstration of ${ }^{35} \mathrm{~S}$-sporidesmin to guinea pigs. N. Z. J. Agric. Res. 13: 182 191.

Towers, N.R. (1970b). Tissue distribution and excretion of radioactivity in rats dosed with ${ }^{35}$ S-sporidesmin. N. Z. J. Agric. Res. 13: $428-436$.

Towers, N.R. (1972). Absorption and excretion of ${ }^{35}$ sulphur by biliary fistulated rats and guinea pigs following adminstration of ${ }^{35}$ S-sporidesmin. Life Sci. 11: 691 - 698.

Turner, J.C. and Green, R.S. (1974). Effect of hexachlorobenzene on microsomal enzyme systems. Biochem. Pharmacol. 23: $2387-2390$.

Turner, J.C. and Green, R.S. (1976). The use of liver biopsy technique for investigating the effect of hexachlorobenzene on some drug metabolising enzymes in sheep. Res. Vet. Sci. 20: 155- 157. 
Van Ommen, B., Bogaards, J.J.P., Peters, W.H.M., Blaauboer, B. and Van Bladeren, P.J. (1990). Quantification of human hepatic glutathione Stransferases. Biochem. J. 269: $609-613$.

Van T' Klooster, G.A.E., Blaauboer, B.J., Noordhoek, J. and Van Miert, A.S.J.P.A.M. (1993). Cytochrome P-450 induction and metabolism of alkoxyresorufins, ethylmorphine and testosterone in cultured hepatocytes from goats, sheep and cattle. Biochem. Pharmacol. 46: $1781-1790$.

Van T' Klooster, G.A.E., Woutersen - Van Nijnanten, F.M.A., Blaauboer, B. J., Noordhoek, J. and Van Miert, A. S. J. P.A.M. (1994). Applicability of cultured hepatocytes derived from goat, sheep and cattle in comparative drug metabolism studies. Xenobiotica 24: $417-428$.

Vlasuk, G.P., Ghrayeb, J., Ryan, D.E., Reik, L.M., Thomas, P.E., Levin, W. and Walz, F.G. Jr. (1982). Multiplicity, strain differences, and topology of phenobarbital-induced cytochromes P-450 in rat liver microsomes. Biochemistry 21: 789 - 798 .

Wang, L.H., Zakim, D., Rudolph, A.M. and Benet, L.Z. (1986). Developmental alterations in hepatic UDP glucuronosyltransferase. A comparison of the kinetic properties of enzyme from adult sheep and foetal lambs. Biochem. Pharmacol. 35: $3065-3070$.

Warholm, M., Guthenberg, C., Mannervik, B.M., Pacifici, G.M. and Rane, A. (1981). Glutathione S-transferases in human foetal liver. Acta. Chem. Scan. Ser. P. B35: $225-227$.

Welton, A.F., O'Neal, F., Chaney, L.C. and Aust, S.D. (1975). Multiplicity of cytochrome P-450 hemoproteins in rat liver microsomes. Preparation and specificity of an antibody to the hemoprotein induced by phenobarbital. J. Biol. Chem. 250: $5631-5639$.

White, R.E. (1991). The involvement of free radicals in the mechanisms of monooxygenases. Pharmac. Ther. 49: $21-42$.

White, T.J., Arnheim, N. and Erlich, H.A. (1989). The polymerase chain reaction. Trends. Genet. 5: $185-189$.

Wigg, P.A., Jensen, O.N., Holmes, S., Soues, S., Mann, M. and Kilmartin, J.V. (1998). Analysis of the saccharomyces spindle pole by matrix-assisted laser desorption / ionization (MALDI) mass spectrometry. J. Cell Biol. 141: 967 - 977.

Wilce, M.C.J., Board, P.G., Feil, S.C. and Parker, M.W. (1995). Crystal structure of a Theta-class glutathione tranferase. EMBO J. 14: $2133-2143$.

Williams, N.T., Carrington, H. and Herrera, A. (1986). Stimulation of mouse liver glutathione S-transferase activity in propylthiouracil-treated mice in vivo by triiodothyronine. Biochem. J. 233: 595 - 598. 
Wisniewski, J.A., Moody, D.E., Hammock, B.D. and Shull, L.R. (1987). Interlobular distribution of hepatic xenobiotic metabolizing enzyme activities in cattle, goats and sheep. J. Anim. Sci. 64: $210-215$.

Worker, N.A. and Dodd, D.C. (1960). Photosensitivity diseases in New Zealand XXII. Studies in the effect on the rabbit of injection of extracts containing facial eczema toxin. N. Z. J. Agric. Res. 3: 712 -724.

Wright, D.E. and Forrester, I.T. (1965). Some biochemical effects of sporidesmin. Can. J. Biochem. 43: $881-888$.

Zhang, W. and Chait, BT. (2000). ProFound: an expert system for protein indentification using mass spectrometric peptide mapping information. Anal. Chem. 72: $2482-2489$.

Zimmerman, H.J. and Ishak, K.G. (1995). General aspects of drug-induced liver disease. Gastroenterol. Clin. North Am. 24: 739 - 758. 